\title{
Studies on nonlinear mechanical wave behavior to characterize cement based materials and its durability
}

"Estudio del comportamiento no lineal de ondas mecánicas para la caracterización de materiales basados en cemento y
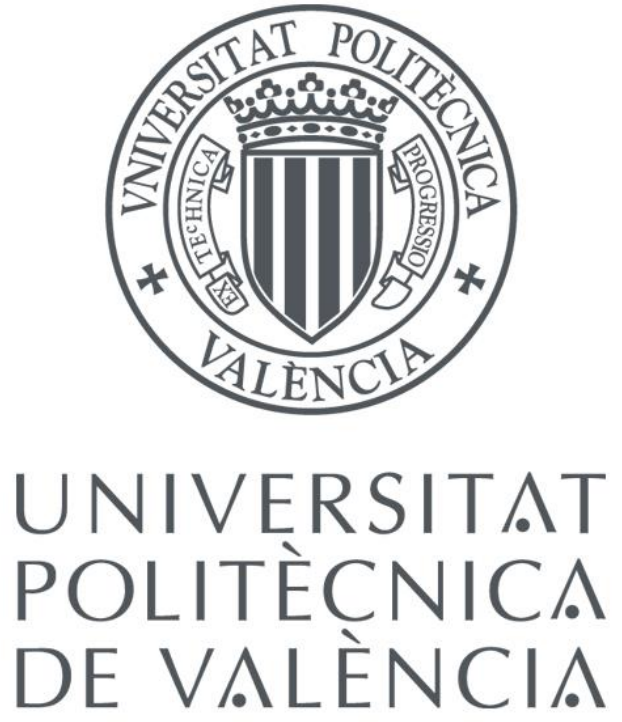

July 2016

Autor:

Jesús Nuño Eiras Fernández

Directores:

Jordi Payá Bernabeu John S. Popovics 
Quiero expresar mi agradecimiento a mi tutor Jordi Payá por sus acertadas directrices durante la elaboración de esta tesis, por haberme dado la oportunidad de trabajar en este proyecto e iniciarme en la carrera investigadora. Extiendo este agradecimiento al resto del equipo: Mercedes Bonilla, Victoria Borrachero, José Monzó, Ana Mellado y Lourdes Soriano, que con su buen hacer han contribuido a la construcción de un grupo de reconocido prestigio. A mis compañeros con los que he compartido horas en las aulas, laboratorio, y en discusiones de diferente índole: Mauro Tashima (el chino de Guadasuar), Lourdes Soriano, Noelia Bouzón, Erich Rodríguez, Walter Roldán, Esther Fernández, Diego Martínez, Luis Felipe Lalinde, Juan Carlos Ochoa, Tarek Sloma, Alfonso Gimeno, Tomás Serrano, Lucía Reig, Rosana Méndez, David Ariño, Gonzalo Mármol, Marian Mas, Clara Calvo, Alba Font, Pablo Lorca, Vicente Genovés, David Ganado, Fernando Gaona, Covadonga Riestra, Edwin Gudiel, Amin Názer, Yasna Segura, Juan Cosa, José Moreno, y Ariel Rey. En especial, quiero agradecer a Lourdes Soriano (la jefa) quien ha sabido velar por la armonía del grupo, y con quien también he podido compartir mis mejores experiencias en la universidad. También, a Consuelo Martínez por suministrar paella un lunes cualquiera. A Ester Giménez por avisarme algún miércoles para acudir a clases de yoga. A los técnicos de laboratorio Pascual Hernández, Juan Monzó, Juan Franqueza por eventualmente asistir en la preparación de probetas, y a Inmaculada López por ayudar en la preparación de muestras. También estas líneas de agradecimiento van dirigidas a aquellos que dejaron su impronta en el grupo durante sus estadías de investigación, como Jorge Akasaki, Jose Luis Melges, Karel Pérez, Nelson Díaz, Jorge Ivan Tobón, Antonio Beraldo, Javier Quiñónez, Holmer Savastano, Fei Zhang, Michelle Rodrigues, Gladis Camarini, Camila Pereira, y Joao de Moraes. También quiero agradecer a Carlos Hidalgo y Angel Morilla por provechosas discusiones y ayudarme en la realización de ensayos y pruebas experimentales. No quiero olvidar a Antonio Romero, quien me instigó en todo momento para que continuara estudiando.

Special thanks are given to Tribikram Kundu who actively collaborated during the course of this project, and for advice and helpful discussions during the analysis of experimental results. Also, for hosting me during a short stay at University of Arizona. Also thanks are given to Umar Amjad, Ehsan Mahmoudabadi, Ajoy Kumar Das, and Abdullah Al-Hussein for good friendship and helpful discussions during my stay at UA.

Special thanks are also given to John S. Popovics, for helpful advice and guidance, and for thoughtful discussions during the course of the PhD. Also, for hosting me and supervising my work at University of Illinois at Urbana-Champaign. I want to extend these thanks to those with whom I shared time in the laboratory at UIUC, preparing samples, 
conducting experiments or discussing and interpreting experimental results: Agustin Spalvier, Jeevaka Somaratna, Suyun Ham, James Bittner, Hajin Choi, and Homin Song.

Je remercie Vincent Garnier et Cédric Payan pour m'avoir accueilli à I'IUT d'Aix-enProvence de l'Université Aix-Marseille, pour leurs discussions utiles lors de mes recherches. Je veux étendre mes remerciements à Jean-François Chaix et Sandrine Rakotonaviro. Ainsi qu'aux restes des professeurs, techniciens, doctorants et stagiaires que j'ai rencontré pendant mon étape à l'Université d'Aix-Marseille. Mais aussi à Yoann Bonnefond pour son aide lors des manips. Pour finir, un remerciement spécial pour Quang Anh Vu et Martin Lott avec qui j'ai partagé beaucoup de mon temps, ils m'ont offert une aide inestimable pour la réalisation des manips et pour l'interprétation des résultats. "C'est pas physique, c'est electrique».

Quiero agradecer al Ministerio de Economía y Competitividad por proveer soporte económico para la realización del doctorado - beca de Formación de Personal Investigador BES-2011-044624-, y por las becas destinadas a realizar estancias breves de investigación en otros centros de investigación EEBB I-13-06609, EEBB-I-1408993, y EEBB I-15- 10178.

No voy a olvidar en estas últimas líneas a mi familia. A mis hermanos Juan y Bárbara, y mis sobrinos Bárbara y Xosé. A Sandra quien ha sido mi apoyo en las buenas y en las malas. Por último, voy a dedicar la tesis a mi madre quien me ha apoyado de forma incondicional y se ha esforzado para ofrecerme siempre lo mejor, y a mi padre, a quien siempre está presente en mi corazón y sé que está conmigo en todo momento.

[...] Ring the bells that still can ring,

Forget your perfect offering

There is a crack in everything

That's how the light gets in. from Anthem, Leonard Cohen. 


\section{Resumen}

Las construcciones de hormigón deben ser diseñadas para perdurar en el tiempo manteniendo su integridad mecánica y sus condiciones de servicio durante la vida útil para la que han sido proyectadas. A este respecto, la evaluación del hormigón y sus constituyentes tanto en laboratorio como en ensayos in situ es, por tanto, esencial para garantizar las condiciones de servicio requeridas al hormigón. El ensayo de determinación de las frecuencias de resonancia ha sido tradicionalmente empleado para determinar la integridad mecánica de testigos de hormigón, en la evaluación de la conformidad de mezclas de hormigón en diversos ensayos de durabilidad, y en la terminación de propiedades constitutivas como son el módulo elástico y el factor de amortiguamiento. Las condiciones del ensayo de determinación de las frecuencias de resonancia en probetas de hormigón, están actualmente normalizadas por organizaciones como ASTM American Society for Testing Materials - o recomendadas por RILEM —International union of laboratories and experts in construction materials, systems and structures-. Su uso es referido en estándares para la evaluación de la durabilidad del hormigón frente a ciclos hielo-deshielo y a ataque por sulfatos. Sin embargo, esta técnica no destructiva no solo ha sido aplicada bajo estas normativas si no que ha sido ampliamente apelada para la evaluación de las propiedades mecánicas en todo tipo de ensayos de durabilidad. La evolución del daño es comúnmente evaluada a partir de la reducción del módulo dinámico, producido como resultado de cualquier proceso de fisuración.

El comportamiento mecánico del hormigón es intrínsecamente no lineal y presenta histéresis. Como resultado de un comportamiento tensión-deformación con histéresis, el módulo elástico depende de la deformación. En ensayos dinámicos, la no linealidad del material se manifiesta por una disminución de las frecuencias de resonancia, la cual es inversamente proporcional a la amplitud de excitación. Este fenómeno es normalmente denominado como dinámica rápida. Una vez la excitación cesa, el material experimenta un proceso de relajación por el cual, el módulo elástico es restaurado a aquel en situación de reposo. Este fenómeno es denominado como dinámica lenta. Estos fenómenos — dinámicas rápida y lenta- encuentran su origen en la fricción interna del material. Por tanto, en materiales basados en cemento, la presencia de microfisuras y las interfaces entre sus constituyentes juegan un rol importante en la no linealidad mecánica del material. En el contexto de evaluación de la durabilidad del hormigón, la evolución del daño está basada en el incremento de histéresis, como resultado de cualquier proceso de fisuración.

En esta tesis se investigan tres técnicas diferentes las cuales utilizan el impacto como medio de excitación de las frecuencias de resonancia. La primera técnica consiste en determinar las frecuencias de resonancia a diferentes energías de impacto. La técnica es denominada en inglés: Nonlinear Impact Resonant Acoustic Spectroscopy (NIRAS). Ésta consiste en relacionar el 
detrimento que el material experimenta en sus frecuencias de resonancia, con el aumento de la amplitud de la excitación. La relación entre la frecuencia de resonancia y la amplitud de excitación es utilizada para evaluar el comportamiento no lineal. En esta tesis, la técnica NIRAS es empleada en morteros de cemento Portland de $40 \times 40 \times 160 \mathrm{~mm}^{3}$, producidos con diferentes relaciones agua/cemento y árido/cemento. Los morteros son sometidos a diferentes procesos de degradación. En particular, el programa experimental incluye la evaluación de las propiedades dinámicas de los morteros cuando son sometidos a ciclos hielo-deshielo, y a niveles incrementales de carga a compresión. Los resultados demuestran que los parámetros derivados del comportamiento mecánico no lineal varían en mayor medida que las variaciones de los parámetros estándar (lineales) como son la frecuencia de resonancia o la atenuación. También, el programa experimental incluye la investigación del efecto de la humedad interna y la microfisuración por secado. Los resultados demuestran que el secado puede inducir microfisuras y tanto más, en aquellas relaciones agua/cemento bajas y con menor proporción de árido. La generación de microfisurado es detectada mediante la técnica NIRAS. Además, los resultados señalan que la humedad interna es capaz de aliviar los mecanismos que dan lugar al comportamiento no lineal. Por otra parte, la configuración NIRAS adoptada en este estudio permite la observación de los modos fundamentales de resonancia a flexión y longitudinal de forma simultánea. Durante la cuantificación del comportamiento no lineal, se observa que diferentes familias de modos de vibración exhiben un comportamiento diferente. Las causas precisas de este comportamiento son aún desconocidas, pero es plausible atribuirlas a diferencias de comportamiento no lineal en acciones a compresión y cortante.

La técnica NIRAS es empleada en esta tesis también para evaluar la durabilidad de materiales compuestos de cemento reforzados con fibras. La incorporación de fibras al hormigón mejora sus propiedades mecánicas de tenacidad y resistencia a la tracción, y ayuda a controlar los procesos de fisuración. Las fibras constituyen un defecto en sí mismo y contribuyen a la no linealidad del material, la cual depende además de las características de la interfaz entre la fibra y la matriz cementante. Sin embargo, en muchos casos la durabilidad de las fibras se ve comprometida en la matriz de cemento, lo que causa un menoscabo de las propiedades mecánicas. En este sentido, el hormigón reforzado con fibra de vidrio es un caso de especial interés. El proceso de degradación de las fibras de vidrio consiste en un caso especial de corrosión bajo tensión, por el cual la fibra acaba combinándose químicamente con los productos de hidratación, lo cual debilita la fibra y endurece la interfase. Por tanto, a medida que las fibras de vidrio se deterioran, el material reduce su comportamiento no lineal. Los resultados demuestran que la técnica NIRAS es sensible a las modificaciones microestructurales que se producen durante la degradación de las fibras de vidrio en el hormigón. Estas medidas pueden ser extrapoladas a la evaluación de la durabilidad de otros materiales reforzados con fibras.

La segunda técnica consiste en investigar el comportamiento no lineal mediante el análisis de la señal correspondiente a un solo impacto. Ésta consiste en determinar las propiedades 
instantáneas de frecuencia, atenuación y amplitud. Esta técnica se denomina, en inglés, Nonlinear Single Impact Resonant Acoustic Spectroscopy (NSIRAS). Se proponen dos técnicas de extracción del comportamiento no lineal mediante el análisis de las variaciones instantáneas de frecuencia y atenuación. La primera técnica consiste en la discretización de la variación de la frecuencia con el tiempo, mediante un análisis basado en Short-Time Fourier Transform (STFT). La segunda técnica consiste en un ajuste por mínimos cuadrados de las señales de vibración a un modelo que considera las variaciones de frecuencia y atenuación con el tiempo. La técnica de ajuste por mínimos cuadrados provee estimaciones de la amplitud de la señal, más precisas que aquellas obtenidas con la técnica de extracción basada en STFT. Sin embargo, el uso de la técnica basada en STFT puede ser recomendado en aquellas señales que contengan múltiples modos de vibración. En este último caso, el método de ajuste por mínimos cuadrados puede ser excesivamente complicado. Además, se comparan las técnicas NIRAS y NSIRAS. La dependencia entre frecuencia y amplitud difieren entre los ensayos NIRAS y NSIRAS. La dependencia entre frecuencia de resonancia y amplitud exhibe una dependencia de orden superior cuando es investigada en un solo impacto, mientras que la dependencia es lineal - frecuencia de resonancia es inversamente proporcional a la amplitud de excitación-. Este efecto es atribuido al fenómeno de dinámica lenta. Se propone entonces en descomponer la variación de frecuencia de resonancia como aquella estrictamente proporcional a la amplitud de la señal, y aquella que desvía la relación entre frecuencia y amplitud de la proporcionalidad. Al realizar esta descomposición se observa que NIRAS y NSIRAS determinan valores similares de la constante de proporcionalidad. Este procedimiento permite cuantificar el comportamiento no lineal. La aplicación de las técnicas de extracción NSIRAS se demuestra en morteros y hormigones sometidos a ciclos de hielo-deshielo, choque térmico y carbonatación.

NIRAS y NSIRAS están especialmente indicados para ensayos de durabilidad en condiciones de laboratorio, o en todo caso, en aquellas aplicaciones en los que el ensayo estándar de resonancia puede ser empleado. Sin embargo, su uso queda excluido para aplicaciones de evaluación de estructuras de hormigón. De hecho, aún son pocos los estudios que han conseguido extrapolar las posibilidades de la evaluación no lineal a las condiciones reales de estructuras de hormigón. La tercera técnica empleada en esta tesis puede ser empleada para la evaluación de estructuras in situ. La técnica se trata de un ensayo acusto-elástico en régimen dinámico. En inglés Dynamic Acousto-Elastic Test (DAET). Las variaciones del módulo elástico obtenidas mediante los métodos NIRAS y NSIRAS proporcionan un comportamiento "promedio" y no permiten derivar las variaciones del módulo elástico en un solo ciclo de vibración. Actualmente, la técnica DAET es la única que permite investigar todo el rango de fenómenos no lineales en el material. Por otra parte, a diferencia de otras técnicas DAET, en este estudio se emplea como "contraste" una onda continua. El uso de una onda continua permite investigar las variaciones relativas del módulo elástico, para una señal transitoria como la que es obtenida mediante un impacto. Además, permite 
la inspección de elementos mediante el acceso por una sola cara. Esto, es especialmente importante para aplicaciones in situ. 


\section{Abstract}

Concrete constructions must be designed to last over time while maintaining their mechanical integrity and conditions of service during the service life they have been projected. In this regard, the evaluation of concrete and its constituents in laboratory and field tests is therefore essential to ensure the service conditions required to the concrete. The test for determining the resonance frequencies has traditionally been used to investigate the mechanical integrity of concrete cores, to assess the conformity of concrete constituents in different accelerated durability tests, and to ascertain constitutive properties such as the elastic modulus and the damping factor. The test conditions for determining the resonance frequencies in concrete samples are currently standardized by organizations such as ASTM - American Society for Testing Materials - or recommended by RILEM - International union of laboratories and experts in construction materials, systems and structures-. Its use is referred in standards for assessing the durability of concrete against freeze-thaw cycles and sulfate attack. However, this nondestructive technique has not only been applied under these standards, but it has been quite appealed for evaluation of mechanical properties in all kinds of durability tests. The damage evolution is commonly assessed from the reduction of dynamic modulus which is produced as a result of any cracking process.

The mechanical behavior of concrete is intrinsically nonlinear and hysteretic. As a result of a hysteretic stress-strain behavior, the elastic modulus is a function of the strain. In dynamic tests, the nonlinearity of the material is manifested by a decrease of the resonance frequencies, which is inversely proportional to the excitation amplitude. This phenomenon is commonly referred as fast dynamic effect. Once the dynamic excitation ceases, the material undergoes a relaxation process whereby the elastic modulus is restored to that at rest. This phenomenon is termed as slow dynamics. These phenomena - fast and slow dynamics - find their origin in the internal friction of the material. Therefore, in cement-based materials, the presence of microcracks and interfaces between its constituents plays an important role in the material nonlinearity. In the context of the assessment of concrete durability, the damage evolution is based on the increase of hysteresis, as a result of any cracking process.

In this thesis three different nondestructive techniques are investigated, which use impacts for exciting the resonant frequencies. The first technique consists in determining the resonance frequencies over a range of impact forces. The technique is termed Nonlinear Impact Resonant Acoustic Spectroscopy (NIRAS). It consists in ascertaining the downward resonant frequency shift that the material undergoes upon increasing excitation amplitude. The relationship between the resonance frequency and amplitude of excitation is used to evaluate the nonlinear behavior. In this thesis, the NIRAS technique is used in Portland cement mortars $40 \times 40 \times 160 \mathrm{~mm}^{3}$ produced with different water-cement and aggregate-cement ratios. The mortar samples are subjected to various 
degradation processes. In particular, the experimental program includes the evaluation of the dynamic properties of the mortars when subjected to increasing number of freeze-thaw cycles, and increasing levels of compressive load. The results show that the parameters derived from the nonlinear mechanical behavior exhibit larger variations than those obtained for the standard parameters (linear) such as resonance frequency or attenuation. Also, the experimental research program includes the effect of internal humidity and drying shrinkage cracking. The results show that drying can induce microcracks. This is especially true in low water-cement ratio and less aggregate content. The microcracking damage generation is detected by NIRAS technique. Moreover, the results indicate that the internal moisture is able to alleviate the mechanisms that lead to nonlinear behavior. Moreover, the NIRAS configuration adopted in this study allows observation of the fundamental flexural and longitudinal modes of vibration simultaneously. It is observed that different vibration mode families exhibit different nonlinear behavior. The precise causes of this behavior are still unknown, but it is plausible to attribute the differences to different hysteretic behavior under compression and shear motions.

The NIRAS technique is also used in this thesis to assess the durability of fiber reinforced concrete. The incorporation of fibers to concrete improves mechanical properties, such as toughness and tensile strength, and helps to control cracking processes. The fibers contribute to increase the material nonlinearity which in turn depends on the characteristics of the interface between fibers and the cementitious matrix. However, in many cases the durability of the fiber is compromised in the cementitious matrix, which causes an impairment of the mechanical properties. In this sense, the concrete reinforced with glass fibers is a case of particular interest. The degradation process of the glass fibers is a special case of corrosion under stress, whereby the fiber chemically combines with the hydration products of the matrix, which in turn weakens the fiber and hardens the interface. Therefore, as the glass fibers deteriorate the material reduces its nonlinear behavior. The results show that the NIRAS technique is sensitive to the microstructural changes occurring during the degradation of the glass fibers in concrete. These results can be extrapolated to evaluate the durability of other fiber reinforced materials.

The second technique consists in investigating the nonlinear behavior by analyzing the signal corresponding to a single impact. This is, to determine the instantaneous frequency, amplitude and attenuation variations corresponding to a single impact event. This technique is termed as Nonlinear Resonant Acoustic Single Impact Spectroscopy (NSIRAS). Two techniques are proposed to extract the nonlinear behavior by analyzing the instantaneous frequency variations and attenuation over the signal ring down. The first technique consists in discretizing the frequency variation with time through a Short-Time Fourier Transform (STFT) based analysis. The second technique consists of a least-squares fit of the vibration signals to a model that considers the frequency and attenuation variations over time. The technique of least-squares fit provides more accurate estimates of the signal amplitude, than those obtained through STFT based approach. However, the STFT based approach may be preferred in those signals containing multiple modes 
of vibration, wherein the least-squares minimization may result costly. Furthermore, NSIRAS and NIRAS techniques are compared. The dependence between frequency and amplitude differ between NIRAS and NSIRAS tests. The dependence between resonance frequency and amplitude exhibits a higher order dependence (nonlinear) when it is investigated in a single impact, and linear-frequency is inversely proportional to the excitation amplitude - when it is investigated from multiple impact events. This effect is attributed to the slow dynamic effect. It is then proposed to decompose the resonance frequency variation as, one strictly proportional to the amplitude of the signal, and one that directs away from proportionality the relationship between frequency and amplitude. After decomposing both contributions, it is observed that NIRAS and NSIRAS ascertain similar values of the proportionality constant. This procedure allows quantification of the nonlinear behavior from a single impact event. The application of NSIRAS techniques is demonstrated in mortar and concrete samples subjected to freeze-thaw cycles, thermal shock and carbonation.

NSIRAS NIRAS techniques are particularly suitable for durability tests under laboratory conditions, or in any case, in applications where the standard resonance test may be employed. However, its use is excluded for the assessment of concrete structures. In fact, there are still few studies that have managed to extrapolate the possibilities of nonlinear evaluation to on-site measurements of concrete structures. The third technique used in this thesis can be used for onsite evaluation of structures. The technique is based on the Dynamic Acousto- Elastic Test (DAET). The variations of elastic modulus as derived through NIRAS and NSIRAS techniques provide an "average" behavior and do not allow derivation of the elastic modulus variations over one vibration cycle. Currently, DAET technique is the only one capable to investigate the entire range of nonlinear phenomena in the material. Moreover, unlike other DAET approaches, this study uses a continuous wave source as "probe". The use of a continuous wave allows investigation of the relative variations of the elastic modulus, as produced by an impact. Moreover, the experimental configuration allows one-sided inspection. This is especially important for on-site measurements. 


\section{Resum}

Les construccions de formigó han de ser dissenyades per a perdurar en el temps mantenint la seua integritat mecànica i les seues condicions de servici durant la vida útil per a la que han sigut projectades. A este respecte, l'avaluació del formigó i els seus constituents tant en laboratori com en assajos in situ és, per tant, essencial per a garantir les condicions de servici requerides al formigó. L'assaig de determinació de les freqüències de ressonància ha sigut tradicionalment empleat per a determinar la integritat mecànica de testimonis de formigó, en l'avaluació de la conformitat de mescles de formigó en diversos assajos de durabilitat, i en la terminació de propietats constitutives com són el mòdul elàstic i el factor d'amortiment. Les condicions de l'assaig de determinació de les freqüències de ressonància en provetes de formigó, estan actualment normalitzades per organitzacions com ASTM -American Society for Testing Materials - 0 recomanades per RILEM - International union of laboratories and experts in construction materials, systems and structures- El seu ús és referit en estàndards per a l'avaluació de la durabilitat del formigó enfront de cicles gel-desgel i a atac per sulfats. No obstant això, esta tècnica no destructiva no sols ha sigut aplicada davall estes normatives si no que ha sigut àmpliament apel·lada per a l'avaluació de les propietats mecàniques en tot tipus d'assajos de durabilitat. L'evolució del dany és comunament avaluada a partir de la reducció del mòdul dinàmic, produït com resultat de qualsevol procés de fissuració.

El comportament mecànic del formigó és intrínsecament no lineal i presenta histèresi. Com resultat d'un comportament tensió-deformació amb histèresi, el mòdul elàstic depén de la deformació. En assajos dinàmics, la no linealitat del material es manifesta per una disminució de les freqüències de ressonància, la qual és inversament proporcional a l'amplitud d'excitació. Este fenomen és normalment denominat com a dinàmica ràpida Una vegada l'excitació cessa, el material experimenta un procés de relaxació pel qual, el mòdul elàstic és restaurat a aquell en situació de repòs. Este fenomen és denominat com a dinàmica lenta. Estos fenòmens --dinàmiques ràpida i lenta troben el seu origen en la fricció interna del material. Per tant, en materials basats en ciment, la presència de micro-fissures i les interfícies entre els seus constituents juguen un rol important en la no linealitat mecànica del material. En el context d'avaluació de la durabilitat del formigó, l'evolució del dany està basada en l'increment d'histèresi, com resultat de qualsevol procés de fissuració. En esta tesi s'investiguen tres tècniques diferents les quals utilitzen l'impacte com a mitjà d'excitació de les freqüències de ressonància. La primera tècnica consistix a determinar les freqüències de ressonància a diferents energies d'impacte. La tècnica és denominada en anglés: Nonlinear Impact Resonant Acoustic Spectroscopy (NIRAS). Esta consistix a relacionar el detriment que el material experimenta en les seues freqüències de ressonància, amb l'augment de l'amplitud de l'excitació. La relació entre la freqüència de ressonància i l'amplitud d'excitació és utilitzada per a avaluar el comportament no lineal. En esta tesi, la tècnica NIRAS és 
empleada en morters de ciment Pòrtland de $40 \times 40 \times 160 \mathrm{~mm}^{3}$, produïts amb diferents relacions agua/cemento i àrid/ciment. Els morters són sotmesos a diferents processos de degradació. En particular, el programa experimental inclou l'avaluació de les propietats dinàmiques dels morters quan són sotmesos a cicles gel-desgel, i a nivells incrementals de càrrega a compressió. Els resultats demostren que els paràmetres derivats del comportament mecànic no lineal varien en major grau que les variacions dels paràmetres estàndard (lineals) com són la freqüència de ressonància o l'atenuació. També, el programa experimental inclou la investigació de l'efecte de la humitat interna i la micro-fissuració per assecat. Els resultats demostren que l'assecat pot induir micro-fissures i tant més, en aquelles relacions agua/cemento baixes i amb menor proporció d'àrid. La generació de micro-fissures és detectada per mitjà de la tècnica NIRAS. A més, els resultats assenyalen que la humitat interna és capaç d'alleujar els mecanismes que donen lloc al comportament no lineal. D'altra banda, la configuració NIRAS adoptada en este estudi permet l'observació dels modes fonamentals de ressonància a flexió i longitudinal de forma simultània. Durant la quantificació del comportament no lineal, s'observa que diferents famílies de modes de vibració exhibixen un comportament diferent. Les causes precises d'este comportament són encara desconegudes, però és plausible atribuir-les a diferències de comportament no lineal en accions a compressió i tallant.

La tècnica NIRAS és empleada en esta tesi també per a avaluar la durabilitat de materials compostos de ciment reforçats amb fibres. La incorporació de fibres al formigó millora les seues propietats mecàniques de tenacitat i resistència a la tracció, i ajuda a controlar els processos de fissuració. Les fibres constituïxen un defecte en si mateix i contribuïxen a la no linealitat del material, la qual depén a més de les característiques de la interfície entre la fibra i la matriu cementant. No obstant això, en molts casos la durabilitat de les fibres es veu compromesa en la matriu de ciment, la qual cosa causa un menyscabament de les propietats mecàniques. En este sentit, el formigó reforçat amb fibra de vidre és un cas d'especial interés. El procés de degradació de les fibres de vidre consistix en un cas especial de corrosió baix tensió, pel qual la fibra acaba combinant-se químicament amb els productes d'hidratació, la qual cosa debilita la fibra i endurix la interfase. Per tant, a mesura que les fibres de vidre es deterioren, el material reduïx el seu comportament no lineal. Els resultats demostren que la tècnica NIRAS és sensible a les modificacions micro-estructurals que es produïxen durant la degradació de les fibres de vidre en el formigó. Estes mesures poden ser extrapolades a l'avaluació de la durabilitat d'altres materials reforçats amb fibres.

La segona tècnica consistix a investigar el comportament no lineal per mitjà de l'anàlisi del senyal corresponent a un sol impacte. Esta consistix a determinar les propietats instantànies de freqüència, atenuació i amplitud. Esta tècnica es denomina, en anglés, Nonlinear Single Impact Resonant Acoustic Spectroscopy (NSIRAS). Es proposen dos tècniques d'extracció del comportament no lineal per mitjà de l'anàlisi de les variacions instantànies de freqüència i atenuació. La primera tècnica consistix en la discretització de la variació de la freqüència amb el 
temps, per mitjà d'un anal basat en short-Time Fourier Transform (STFT) . La segona tècnica consistix en un ajust per mínims quadrats dels senyals de vibració a un model que considera les variacions de freqüència i atenuació amb el temps. La tècnica d'ajust per mínims quadrats proveïx estimacions de l'amplitud del senyal, més precises que aquelles obtingudes amb la tècnica d'extracció basada en STFT. No obstant això, l'ús de la tècnica basada en STFT pot ser recomanat en aquells senyals que continguen múltiples modes de vibració. En este últim cas, el mètode d'ajust per mínims quadrats pot ser excessivament complicat. A més, es comparen les tècniques NIRAS i NSIRAS. La dependència entre freqüència i amplitud diferixen entre els assajos NIRAS i NSIRAS. "La dependència entre freqüència de ressonància i amplitud exhibix una dependència d'orde superior quan és investigada en un sol impacte, mentres que la dependència és lineal -freqüència de ressonància és inversament proporcional a l'amplitud d'excitació-. Este efecte és atribuït al fenomen de dinàmica lenta. Es proposa llavors a descompondre la variació de freqüència de ressonància com aquella estrictament proporcional a l'amplitud del senyal, i aquella que desvia la relació entre freqüència i amplitud de la proporcionalitat. Al realitzar esta descomposició s'observa que NIRAS i NSIRAS determinen valors semblants de la constant de proporcionalitat. Este procediment permet quantificar el comportament no lineal. L'aplicació de les tècniques d'extracció NSIRAS es demostra en morters i formigons sotmesos a cicles de gel-desgel, xoc tèrmic $i$ carbonatació.

NIRAS i NSIRAS estan especialment indicats per a assajos de durabilitat en condicions de laboratori, o en tot cas, en aquelles aplicacions en què l'assaig estàndard de ressonància pot ser empleat. No obstant això, el seu ús queda exclòs per a aplicacions d'avaluació d'estructures de formigó. De fet, inclús són pocs els estudis que han aconseguit extrapolar les possibilitats de l'avaluació no lineal a les condicions reals d'estructures de formigó. La tercera tècnica empleada en esta tesi pot ser empleada per a l'avaluació d'estructures in situ. La tècnica es tracta d'un assaig acusto-elàstic en règim dinàmic. En anglés Dynamic Acousto-Elastic Test (DAET) . Les variacions del mòdul elàstic obtingudes per mitjà dels mètodes NIRAS i NSIRAS proporcionen un comportament "promedio" i no permeten derivar les variacions del mòdul elàstic en un sol cicle de vibració. Actualment, la tècnica DAET és l'única que permet investigar tot el rang de fenòmens no lineals en el material. D'altra banda, a diferència d'altres tècniques DAET, en este estudi s'empra com "contraste" una ona contínua. L'ús d'una ona contínua permet investigar les variacions relatives del mòdul elàstic, per a un senyal transitori com la que és obtinguda per mitjà d'un impacte. A més, permet la inspecció d'elements per mitjà de l'accés per una sola cara. Açò, és especialment important per a aplicacions in situ. 


\section{Index}

\section{Chapter 1. Introduction}

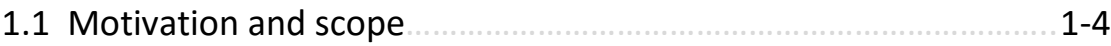

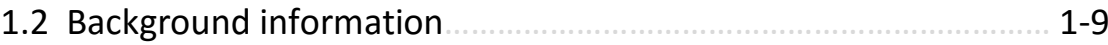

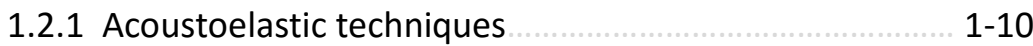

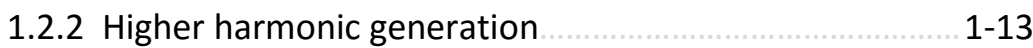

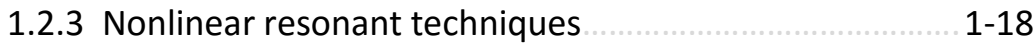

1.2.4 Pump and probe wave interaction based techniques .... 1-24

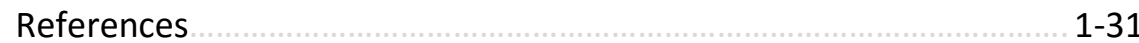

Chapter 2. Materials and methods

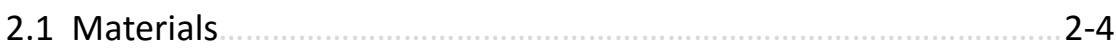

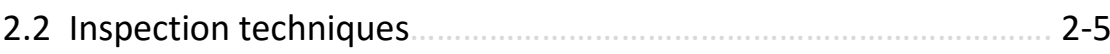

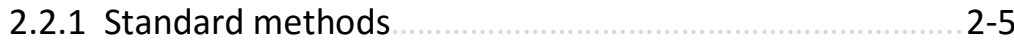

2.2.2 Nonlinear Impact Resonance Acoustic Spectroscopy …. 2-6

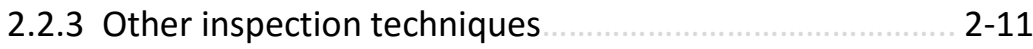

References

Chapter 3. Effect of drying and internal moisture content (I)

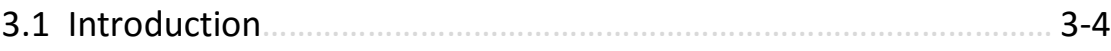

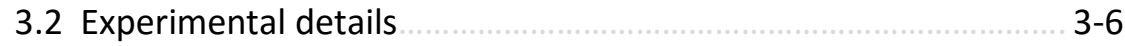

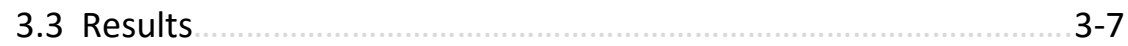

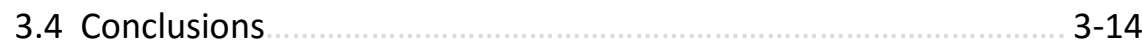

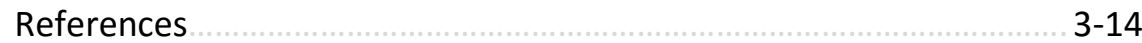


Chapter 4. Effect of drying and internal moisture content (II)

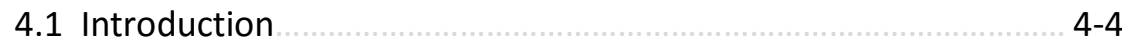

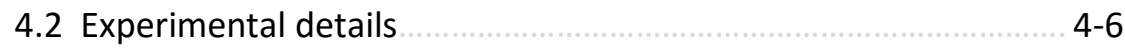

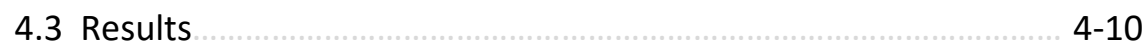

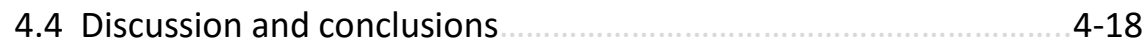

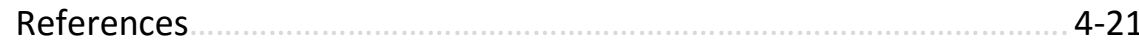

Chapter 5. Mechanical damage

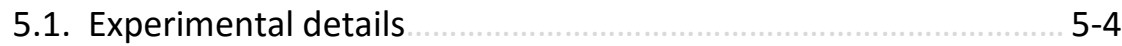

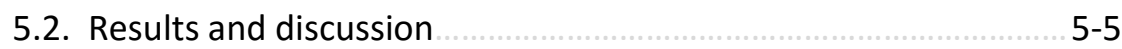

5.2.1. Standard resonant frequency method .......................5-5

5.2.2. Nonlinear Impact Resonant Acoustic Spectroscopy …...5-12

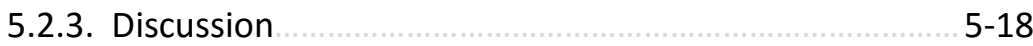

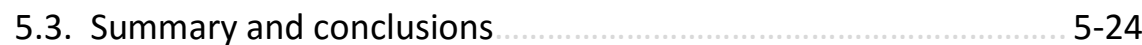

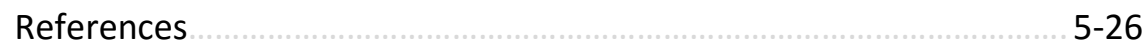

Chapter 6. Freezing-thawing damage

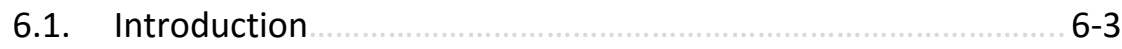

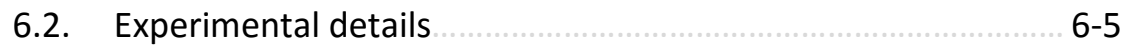

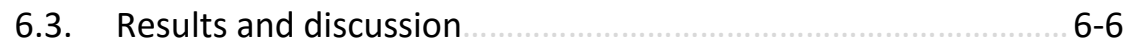

6.4. Conclusions

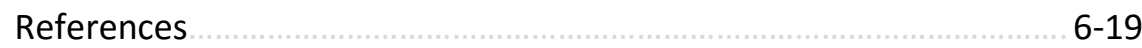

Chapter 7. Reinforced cement composites: case of glass reinforced concrete (GRC)

7.1. Introduction $7-4$

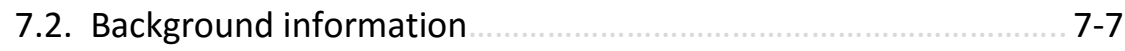

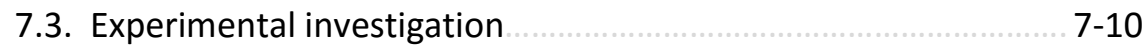


7.3.1. Specimen fabrication

7.3.2. Nonlinear Impact Resonance Acoustic Spectroscopy … 7-11

7.4. Results and discussion

7.4.1. Nonlinear Impact Resonance Acoustic Spectroscopy … 7-15

7.5. Conclusions

References $\ldots$

Chapter 8 Nonlinear Single Impact Resonance Acoustic Spectroscopy (NSIRAS): Frequency domain analysis

8.1. Introduction $\quad 8-3$

8.1.1. Effect of window type and window length $\quad 8-5$

8.2. Assessment of freezing-thawing damage $\ldots$

8.2.1. Experimental details $\ldots \ldots \ldots \ldots \ldots$

8.2.2. Results

8.3. Summary and conclusions

8.4. References

Chapter 9. Nonlinear Single Impact Resonance Spectroscopy

(NSIRAS). Time domain analysis

9.1. Introduction $\ldots$

9.2. Signal processing in the time domain $\ldots$

9.3. Experimental details $\ldots$

9.3.1. Materials

9.3.2. Damage protocol $\ldots$

9.3.3. Inspection techniques and signal processing …...... 9-10

9.4. Algorithm $9-11$

9.5. Comparison between NIRAS and NSIRAS approaches …....... 9-21

9.6. Summary and conclusions 
Chapter 10. Assessment of carbonation of Portland cement mortar

10.1. Background on carbonation $\ldots . . . . . . . .10-4$

10.2. Experimental details $\ldots$

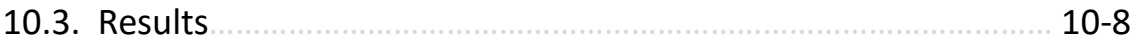

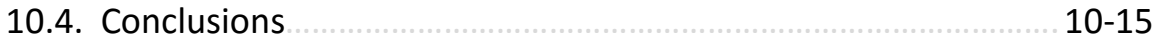

References $\ldots \ldots \ldots \ldots$

Chapter 11. Dynamic acousto-elastic test using continuous probe wave and hammer blow

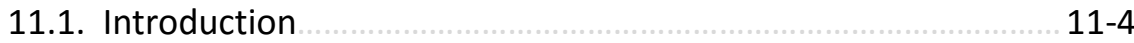

11.2. Experimental details $\ldots$

11.2.1. Materials $11-8$

11.2.2. Experimental configuration ………….................... 11-9

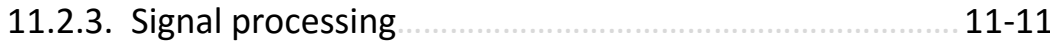

11.2.4. Estimation of strain from acceleration response …..... 11-14

11.3. Results and discussion $\ldots$

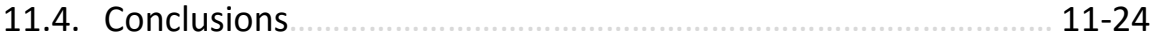

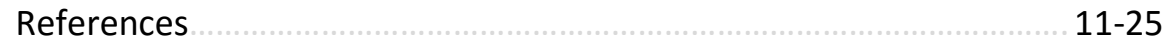

Chapter 12. Further discussion, conclusions, disparate tests and future work 


\section{Chapter 1. Introduction}

" [...] Strike a bell, and the bell rings at its resonance modes. Strike it harder and the bell rings at the same tone, only louder. Now imagine a small crack in the bell, perhaps invisible to the eye. We strike the bell gently and it rings normally. Striking it harder we find, to our surprise, that the tone drops in frequency ever so slightly. Striking it even harder, the tone drops even further down in frequency. This frequency shift is a manifestation of nonlinearity due to the presence of the crack."

(Paul A Johnson, 1999) 



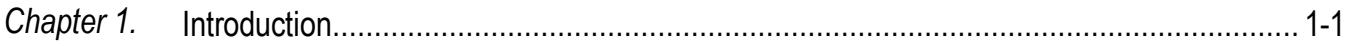

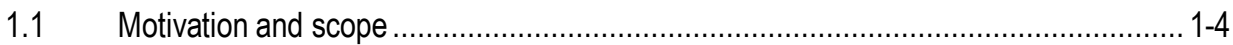

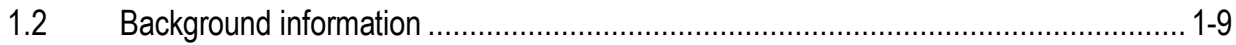

1.2.1 Acoustoelastic techniques............................................................ 1-10

1.2.2 Higher harmonic generation ......................................................... 1-13

1.2.3 Nonlinear resonant techniques ............................................................ 1-18

1.2.4 Pump and probe wave interaction based techniques................................ 1-23

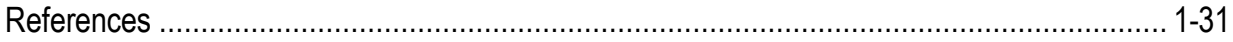




\subsection{Motivation and scope}

The durability of infrastructure materials such as concrete has direct impacts on economy, not only because of maintenance and repair costs of the infrastructure, but also on the productivity of industries that directly or indirectly depend on infrastructure conditions (American Society of Civil Engineers, 2013). The enhancement of concrete durability is therefore a major concern in many countries. Along with proper on-site workmanship, the assessment of concrete quality in the laboratory, are the mainstays to ensure the performance of the infrastructure during its working life (Neville, 1987). The resonant frequency method (Malhotra \& Sivasundaram, 2004) has been traditionally used in the laboratory, to assess and deem the performance of concrete batches subjected to different accelerated aging distresses. It was the first nondestructive test standardized by American Society for Testing and Materials (Carino 1994). Since pioneer work conducted by Powers (Powers, 1938) for determining the dynamic modulus of elasticity on concrete samples, it was used to monitor freezing-thawing damage (Hornibrook, 1939) and later adopted by the ASTM as an alternative method to check material conformity of concrete against frost damage (ASTM-C666, 2012). However, its use has not only been limited to freezing-thawing damage, rather it has been broadly used to assess alkali-silica reaction (Swamy \& Al-Asali, 1988), sulfate attack (Rozière, Loukili, El Hachem, \& Grondin, 2009), fire damage (Reis \& Dilek, 2012) or mechanical damage (Subramaniam, Goldstein, Popovics, \& Shah, 1999). The conformity of the material is normally deemed through the relative variations of dynamic modulus.

Most of the usual threats to concrete durability: alkali-silica reaction, delayed ettringite formation, freezing and thawing damage, crystallization of salts and thermal induced stresses, result in distributed microcracking damage which favors a hysteretic behavior in the stress-strain relationship (Chrisp, Waldron, \& Wood, 1993). In resonant frequency measurements, the hysteretic behavior manifests as a downward shift of the resonant frequency with increasing excitation amplitude. Along with the frequency-amplitude dependence, the damping properties also become amplitude dependent (Ostrovsky \& 
Johnson, 2001a). The origin of such behavior appears to be on the relative rubbing between the interfaces of internal defects produced upon mechanical wave propagation (J. A. TenCate, Shankland, \& Johnson, 2006). Figure 1-1 illustrates the evolution of the amplitude dependent dynamic features (frequency and attenuation) observed in nonlinear resonant experiments. These effects are disregarded on standard (linear based) measurements. However, the investigation of nonlinear phenomena has demonstrated enhanced sensitivity to detect damage features such as microcracks. Therefore, considerable effort has been conducted to develop nondestructive techniques aiming at investigating nonlinear acoustic phenomena. These effects are the underlying physical phenomena for nonlinear resonant spectroscopies based techniques, which have been collectively termed as nonlinear elastic wave spectroscopies (NEWS) (K. E. Van Den Abeele, Sutin, Carmeliet, \& Johnson, 2001). Some of these techniques are described within subsection 1.2.

The frequency-amplitude dependence can be probed, by repeating the resonant frequency test at increasing levels of impact energy - henceforth, this is termed Nonlinear Impact Resonant Acoustic Spectroscopy (NIRAS) - The resonant frequency shift $(\Delta f)$ obtained with increasing strain amplitude $(\Delta \varepsilon)$ exhibits in many materials ( $P$. Johnson \& Sutin, 2005) a linear relation as

$$
\frac{\Delta f}{f_{o}}=\alpha_{f} \cdot \Delta \varepsilon
$$

and analogously, the shift of the attenuation properties as

$$
\frac{1}{Q}-\frac{1}{Q_{o}}=\alpha_{Q} \cdot \Delta \varepsilon
$$

where $f_{0}$ and $Q_{0}$ are the resonant frequency and quality factor obtained in the linear strain regime. The magnitudes of the parameters $\alpha_{f}$ and $\alpha_{Q}$ are related to the extent of mechanical hysteresis (K. E. Van Den Abeele, Sutin, et al., 2001), and hence to the presence of damage features, and constitute the basis of the nonlinear resonance based techniques. Both 
hysteretic parameters $\left(\alpha_{f}\right.$ and $\left.\alpha_{Q}\right)$ have demonstrated improved sensitivity to detect subtle microcracking, especially at early stages of damage, where the sole measurement of the resonant frequency failed to discern it (J. Chen, Jayapalan, Kim, Kurtis, \& Jacobs, 2010; Jesús N Eiras, Popovics, Borrachero, Monzó, \& Payá, 2012; C. Payan, Garnier, Moysan, \& Johnson, 2007). Alternatively, the frequency variation with varying amplitude can be investigated using a single-impact acquisition —henceforth, this is termed Nonlinear Single Impact Resonant Acoustic Spectroscopy (NSIRAS)—. NSIRAS requires the determination of the instantaneous signal parameters (phase and attenuation) during the ring down of the signal associated with the single impact resonance event (Dahlén, Ryden, \& Jakobsson, 2015; J. N. Eiras, Monzó, Payá, Kundu, \& Popovics, 2014; Neild, Williams, \& McFadden, 2003; Koen Van Den Abeele \& De Visscher, 2000).
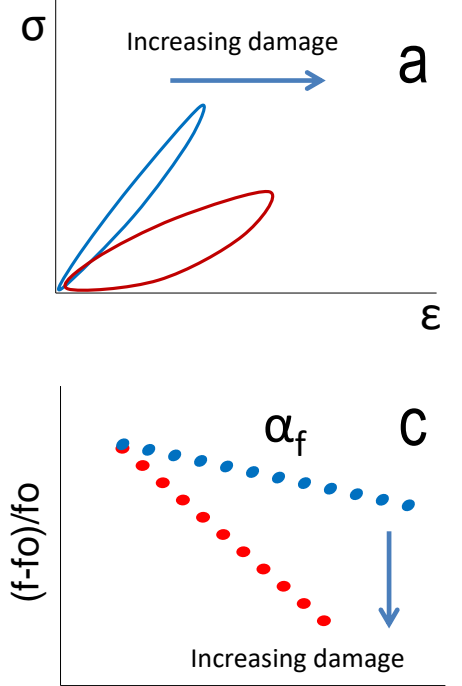

$\Delta \varepsilon$

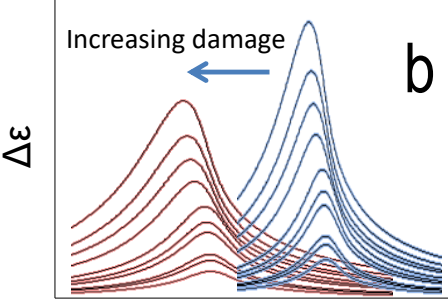

Frequency

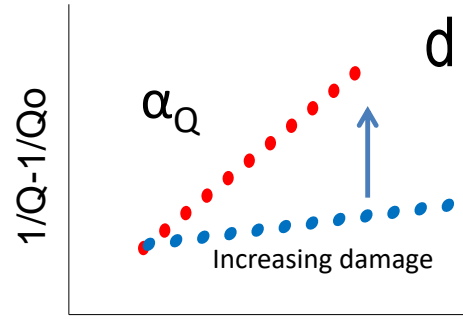

$\Delta \varepsilon$
Figure 1-1 a) Stress-strain behavior under quasi-static conditions, b) evolution of the resonant spectra with increasing damage, and extraction of the hysteretic parameters c) $\alpha_{f}$ and, d) $\alpha_{Q}$

In this thesis, different vibration based nondestructive techniques are investigated. On one hand, NIRAS and NSIRAS approaches are further investigated. The main advantage of NIRAS and NSIRAS techniques is the ease of use, since no need of cumbersome equipment, but that instructed in ASTM C215-14 (ASTM C215-14, 2014) is required. This nondestructive test is based on a well vetted technique that has been broadly used to 
characterize concrete (Malhotra \& Sivasundaram, 2004; Swamy \& Al-Asali, 1988), and other construction materials (Ryden, 2011). Other nonlinear based techniques still remain difficult to perform, especially in concrete like materials, and usually cumbersome equipment is required. The application of other techniques is debatable when the scope of application requires timely assessment in laboratory, or quality control inspection of materials. On the other hand, a nondestructive technique is investigated. Most of the nonlinear based techniques have been applied for laboratory inspection purposes. Dynamic Acoustoelastic Test (DAET). Unlike NIRAS and NSIRAS techniques, DAET allows accounting the whole range of nonlinear phenomena (fast and slow dynamics).

The thesis is organized as follows,

- In the present Chapter 1 is introduced the research significance and the scope of this thesis. Furthermore, in subsection 1.2 Background information different techniques to evaluate the material nonlinearity are presented.

- In Chapter 2, the equipment, test configuration and test specimens used to investigate the dynamic properties of cement based materials are described. These descriptions concern the specimens and test configuration used in the chapters 3 to 6 . In particular, the NIRAS test configuration allows monitoring simultaneously, the first bending and longitudinal modes of vibration. Then, the hysteretic parameter for both family modes can be investigated.

- Chapter 3 and Chapter 4 investigate the effect of oven-drying and moisture content on the dynamic properties of mortar samples. Moisture is known to affect the mechanical properties of cement based materials. In these chapters, linear and nonlinear resonant tests were applied to investigate the effect of moisture on the dynamic properties of cement based materials. These results call attention on the effect of moisture on the interpretation of the dynamic responses, and especially, when damage wants to be discerned.

- Chapter 5 and Chapter 6 investigate the effects of microcracking damage on the material nonlinearity. In Chapter 5 , the specimens are subjected to increasing compressive load steps. In Chapter 6, the specimens are subjected to increasing number of freezing-thawing cycles. The evolution of damage is followed up in both cases through NIRAS technique, as described in Chapter 2. The relative variation of the nonlinear hysteretic parameters demonstrated enhanced sensitivity to detect 
damage, especially, at early stages of damage. Different damage parameters are proposed, which underlie on the relative variations of the dynamic properties with regard those obtained in pristine state.

- Chapter 7 investigates the durability of Glass Reinforced Cement (GRC) through linear and nonlinear dynamic properties. The incorporation of fibers within a cementitious matrix represents a defect itself, so that it is expected that the incorporation of fibers exacerbates the nonlinear hysteretic behavior. The special ageing mechanism of glass fibers within the cement matrix makes the interfacial zones harder so that, the nonlinear behavior decreases with ageing. These results may also have relevance for the evaluation fiber reinforced concretes, in which the durability of the fibers is compromised at usual levels of $\mathrm{pH}$ in concrete $(\mathrm{pH}>12)$.

- In Chapter 8 the NSIRAS technique is introduced. Herein, the basic test configuration for the standard resonant frequency test (ASTM C215-14, 2014) is applied and demonstrated in mortar samples subjected to increasing number of freezing-thawing damage. The analysis of the signal consists of a sliding window that extracts the frequency variation over the ring down of the signal. The signal analysis presented in this chapter allows quantification of the nonlinear behavior from standard resonant frequency data.

- In Chapter 9 an alternative approach to investigate the signal parameters from a single impact is presented. Unlike previous chapter, the signal analysis is conducted in the time domain. This approach allows a more precise estimation of the signal amplitude when compared with that presented in Chapter 8 . Both, frequency and time domain analysis are compared, and the advantages and disadvantages of both approaches are also discussed.

- In Chapter 10 the NSIRAS technique (in frequency domain) is applied to monitor the evolution of the mechanical properties of a standard Portland cement mortar exposed to accelerated carbonation conditions.

- In Chapter 11 presents a Dynamic Acoustoelastic Test (DAET). Unlike NIRAS and NSIRAS techniques, DAET allows accounting the whole range of nonlinear phenomena (fast and slow dynamics). The approach is demonstrated in a prismatic concrete sample. Unlike other DAET configurations (see subsection 1.2.4.2) this particular test configuration allows one-sided measurement which entails interesting applications for on-site evaluation of concrete structures. This possibility is also discussed. 
- Finally, Chapter 12 summarizes the conclusions drawn in this thesis. Moreover, a critical review of the nonlinear resonant acoustic techniques presented in this thesis is conducted. The advantages and disadvantages of the nonlinear resonant techniques investigated in this thesis are also discussed.

\subsection{Background information}

Linear acoustic based techniques study the effects of properties such a transmission, scattering, reflection and absorption on the phase and amplitude of the driven signal (Kundu, 2007). The techniques based on linear acoustics can detect macroscale defects, such as open cracks, and in general macroscopic-sized flaws. Conversely, nonlinear based techniques are showing promise for sensitive early damage detection, in a wide range of materials and damage mechanisms. Investigation of the nonlinear dynamic properties of materials and structures is attracting keen interest among several scientific communities such as geosciences (P. a Johnson \& Jia, 2005), medicine (Muller et al., 2005), and materials science (V. Gusev, Tournat, \& Castagnède, 2010), thanks to their improved detection of microstructural features within materials. The link between the concerned materials in the different research areas is the presence of defects in a wide range of scales (from nano- to macro-scale), which enhances the nonlinear acoustic phenomena. In general, materials whose mechanical properties are dependent on the quality of the bond between their constituents fall in the nonlinear mesoscopic elasticity (NME) class (Robert A. Guyer \& Johnson, 2009). Examples of such materials are concrete, soil, rocks, granular media or damaged materials. The particular behavior of these materials is characterized by hysteresis and discrete memory in their quasi-static strain-stress relationships. A nonlinear modulus $(M)$ including mechanical hysteresis can be written as (P. Johnson \& Sutin, 2005)

$$
M=M_{o}\left\lfloor 1+\beta \varepsilon+\delta \varepsilon^{2}+\ldots\right\rfloor+U(\Delta \varepsilon, \dot{\varepsilon}),
$$

where the linear elastic modulus $\left(M_{0}\right)$ is extended to include classical elastic higher order terms of strain, and a function that takes account of mechanical hysteresis; usually written as (McCall \& Guyer, 1996) 
$U(\Delta \varepsilon, \dot{\varepsilon})=M_{o} \cdot \alpha \cdot(\Delta \varepsilon+\varepsilon \cdot \operatorname{sign}(\dot{\varepsilon}))$,

Eq. 1-4

where $\alpha$ is a parameter that controls the magnitude of the hysteretic behavior, $\Delta \varepsilon$ is the strain amplitude, $\varepsilon$ is strain, and $\dot{\varepsilon}$ is the strain rate. Under moderate dynamic strain amplitudes, $\sim 10^{-7}$ and above (Pasqualini et al., 2007), the hysteretic behavior is manifested as an apparent softening of the material: the velocity of propagation and attenuation of the material depend on the strain amplitude (fast dynamic effect), which in turn is accompanied by a long period of relaxation after dynamic excitation (slow dynamic effect). The two mechanisms are thought to coexist during dynamic excitation (material conditioning), and dominate the nonlinear behavior of highly heterogeneous media such as those in concrete-like materials (P. Johnson \& Sutin, 2005). The equation of state as presented in Eq. 1-4 falls short of describing the slow dynamic effect, and only the fast dynamic effect can be considered therein. Despite of the wealth of experimental results there is still a gap on modelling the nonlinear phenomena, and most likely because the underlying origins are still not well understood (Ja TenCate, Smith, \& Guyer, 2000). In the following, some of the techniques that are based on extract and quantify the nonlinear behavior of the material are described.

\subsubsection{Acoustoelastic techniques}

The nonlinear mechanical behavior of materials has been traditionally tested by applying a stress or confining pressure onto the material under inspection, while the variations of modulus produced in the solid are ascertained through phase velocity measurements (Hughes \& Kelly, 1953). The effect whereby the phase velocity of a wave changes with applied stress is referred as acoustoelastic effect. The speed of sound in a material stressed beyond the linear elastic regime can be expressed as a polynomial expansion of the applied strain —or alternatively stress—as (Adler \& Nagy, 1991)

$$
c(\varepsilon)=c_{0}+c_{1} \cdot \varepsilon+c_{2} \cdot \varepsilon^{2}+\ldots
$$

where $c_{0}$ is the velocity in the unstressed material, and $c_{n}$ is the $n$th order acoustoelastic coefficient. The relative velocity variations may thus be related, to either higher-order 
Murnaghan's (Murnaghan, 1951) or Landau's (Landau \& Lifshitz, 1970) elastic coefficients. This method has been applied to characterize the nonlinear mechanical properties of steel (Bergman \& Shahbender, 1958), rock (P A Johnson \& Rasolofosaon, 1996), wood (Bucur \& Rasolofosaon, 1998), and concrete (C. Payan, Garnier, Moysan, \& Johnson, 2009). The ultrasonic attenuation is also affected by the applied stress, as the material is pressed or released upon compression or tension loading (Morris, Buck, \& Inman, 1979). Analogously to the strain dependent speed of sound (Eq. 1-5), the acoustoelastic effect on the attenuation properties can be expressed as (Nagy, 1998)

$$
\xi(\varepsilon)=\xi_{0}+\xi_{1} \cdot \varepsilon+\xi_{2} \cdot \varepsilon^{2}+\ldots
$$

where $\xi_{0}$ is the attenuation in the unstressed material, and $\xi_{n}$ is the $n$th order acoustoelastic attenuation coefficient. A modified version of the acoustoelastic technique investigates the acoustoelastic effects under low-cycle dynamic loading conditions - frequency up to $10 \mathrm{~Hz}$, and strain amplitude $\sim 10^{-4}$ to $10^{-3}$ - (Nagy, McGowan, \& Adler, 1990; Nagy, 1998). The dynamic loading conditions allowed reducing creep effects in the material, and improved the accuracy on the measured acoustoelastic coefficients when compared with static measurements (Nagy et al., 1990). Such a test configuration was used to assess the fatigue strength of polymeric materials and aluminum alloys (Nagy, 1998). The results shown therein demonstrated that second-order acoustoelastic coefficients ( $c_{2}$ and $\xi_{2}$ ) show enhanced sensitivity to fatigue damage when compared to the zero-order coefficients ( $c_{0}$ and $\left.\xi_{0}\right)-$ those corresponding to the unstressed material一.

Besides fatigue strength, and higher-order constant characterization, the acoustoelastic tests have been adapted to monitor damage and stress condition of infrastructure materials, by using test configurations that comply with one-sided measurements. This condition is sought by many researchers, since very often, the inspection of in-service structural components does not allow accessing two facing sides. Shokouhi and coworkers (Shokouhi, Zoëga, Wiggenhauser, \& Fischer, 2013) used Rayleigh waves to monitor the stressdependent velocity in concrete samples subjected to uniaxial compressive stress. On other 
hand, Fröjd and Ulriksen (Fröjd \& Ulriksen, 2016) used a continuous sine wave excitation on the bottom side of a reinforced concrete slab subjected to static three-point bending loading conditions. The variations in phase and amplitude of the received continuous wave signal exhibited similar variations as pulse transmission measurements upon increasing load. The authors discussed that continuous wave excitation shows promise for structural health monitoring applications, since the continuous excitation can propagate with higher energy than ultrasonic pulses, and hence allowing inspection of large structures. The acoustoelastic experimental configurations are summarized in Figure 1-2.

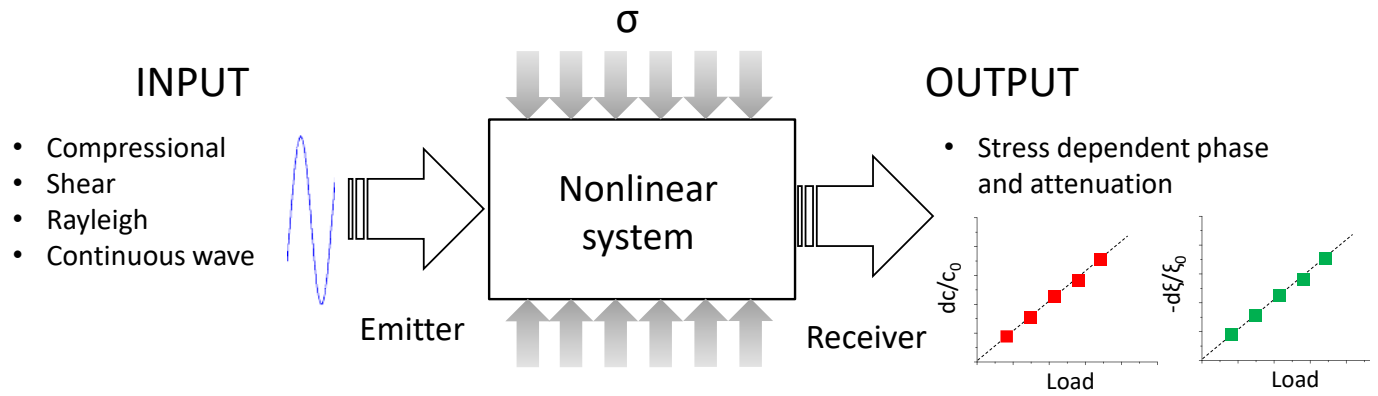

Figure 1-2 Schematic representation of acoustoelastic tests. The ultrasonic pulses are generated under a static load.

Testing the acoustoelastic effects in heterogeneous materials such as concrete is indeed more challenging because of scattering and dissipation effects (C. Payan et al., 2009). Recently, different studies leveraged the enhanced sensitivity of the multiple scattered waves in heterogeneous media to investigate the relative variations of wave velocity upon compressive loading. This technique is referred as Coda Wave Interferometry (Snieder, Grêt, Douma, \& Scales, 2002). The test employs high frequency ultrasonic pulses wherein multiple scattering effects are expected. At such frequencies, the received wave exhibits long lasting waves (coda wave) that have been scattered multiple times by the different heterogeneities within the material. Figure 1-3 shows typical recorded signals. Different signals are recorded at different load steps. The variations of wave velocity are obtained by cross-correlating the coda wave portions of the received signal with regard the 
unstressed coda wave. Larose and Hall (Larose \& Hall, 2009) used high frequency ultrasonic pulses at $500 \mathrm{kHz}$ in concrete. The acoustoelastic effect was investigated under compressive load, from the time shift produced in the coda wave with regard the reference signal. The authors argued that the test configuration might be used for in situ determination of the firstorder acoustoelastic coefficient in concrete structures. Using similar experimental configuration and signal analysis, Payan and coworkers (C. Payan et al., 2009) derived the Murnaghan's constants in concrete. This procedure has been also used for assessing distributed-like damaged materials, as it is produced by a thermal shock in concrete (Schurr, Kim, Sabra, \& Jacobs, 2011).

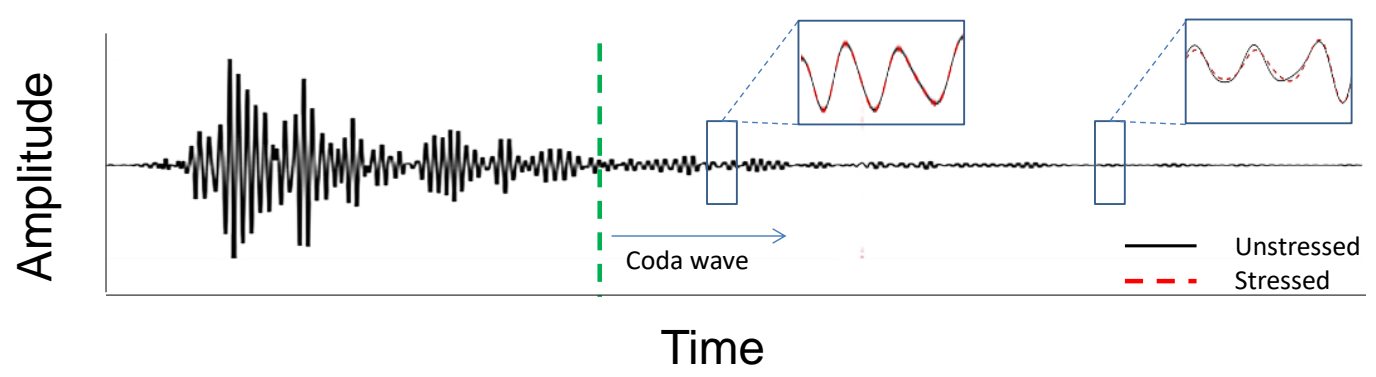

Figure 1-3 Typical recorded signals in coda wave interferometry experiments. Insets show the time shift produced in the coda after loading the concrete samples.

\subsubsection{Higher harmonic generation}

The sound wave velocity of a propagating monochromatic acoustic wave -with frequency $\omega$ and amplitude $A_{1}-$ is constant during its propagation in a linear medium, although its amplitude is reduced, owing to dissipation and diffraction. Conversely, in the case of a nonlinear medium, the propagating wave is distorted resulting in higher harmonic generation. The amplitudes of such harmonics give insight on the nonlinear mechanism. Figure 1-4a-c illustrates the process of wave distortion for three representative cases: linear elastic, classical nonlinear elastic, and nonlinear hysteretic (non-classical) cases. The process of higher harmonic generation can be explained after considering a nonlinear stressstrain relationship in the wave equation. As a result, the relationship between the displacement amplitudes of the harmonics corresponding the provides insight on the 
nonlinear mechanisms contributing to the wave distortion (Koen E-A Van Den Abeele, Johnson, Guyer, \& McCall, 1997).
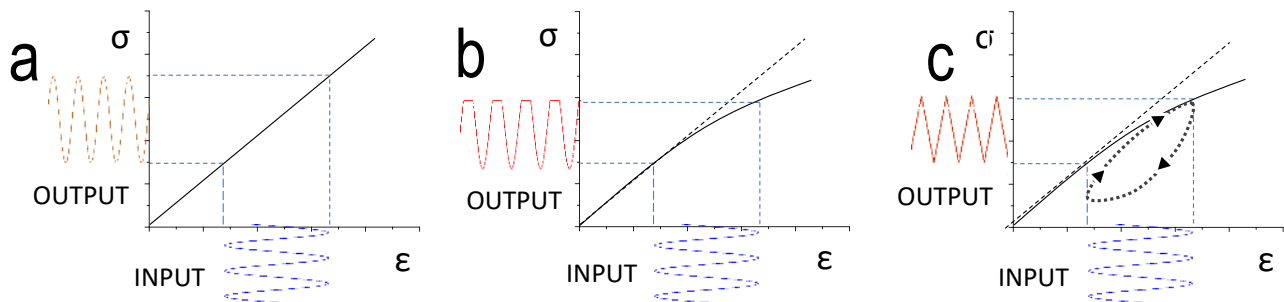

Figure 1-4 Relationship between input and output signals as a result of propagation through a) a linear system, b) a nonlinear system, and c) a nonlinear and hysteretic system.

The nonlinear stress-strain (classical) can be described as a polynomial expansion in terms of strain as (Landau \& Lifshitz, 1970)

$$
\sigma=K_{0} \cdot\left(\varepsilon+\beta \varepsilon^{2}+\delta \varepsilon^{3}+\ldots\right)
$$

where $K_{0}$ is the linear elastic modulus, and $\beta$ and $\delta$ are higher-order elastic coefficients. Onedimensional wave propagation along coordinate $x-\rho \cdot \partial^{2} u / \partial t^{2}=\partial \sigma / \partial x$, where $\rho$ is material density - through a rod whose stress-strain relationship obeys Eq. 1-7 leads to a nonlinear equation of motion. The solution of the displacement $u$ is normally obtained through the perturbation theory, whereby the zero-order solution assumes a single frequency wave $-u_{0}=A_{1} \cdot \cos (k \cdot x-\omega \cdot t)$ - The first- and second-order perturbation solutions predict an enrichment of the spectral frequency content at twice $(2 \cdot \omega)$ and thrice $(3 \cdot \omega)$ the frequency of the initial monochromatic wave. The displacement amplitudes corresponding to the second $\left(A_{2}\right)$ and third $\left(A_{3}\right)$ harmonic are thus related to the higher-order parameters $(\beta$ and $\delta)$. Experimentally, the higher-order elastic constants can be obtained (without attenuation corrections) as

$$
\beta=-\frac{8 \cdot A_{2} \cdot c_{0}^{2}}{A_{1}^{2} \cdot \omega^{2} \cdot x}
$$


wherein $x$ is the propagation distance, and $c_{0}$ is the phase velocity. An example of attenuation corrections can be found in (Hikata \& Elbaum, 1966). In any event, the second and third harmonic amplitudes are proportional to $A_{1}{ }^{2}$ and $A_{1}{ }^{3}$ respectively. The relation between third harmonic amplitude and $\beta$ is approximately obtained as (K. E. Van Den Abeele, 1996)

$$
A_{3} \approx \frac{\beta^{2} \cdot A_{1}^{3} \cdot \omega^{4} \cdot x^{2}}{32 \cdot c_{0}^{4}}
$$

The deviation from such scaling relation in the harmonic response of a material may indicate that higher-order elastic terms must be considered, or that hysteresis is contributing to the material nonlinearity (K. E. Van Den Abeele, 1996). A hysteretic equation of state can be considered as

$$
\sigma=K_{0} \cdot \varepsilon+U(\varepsilon, \dot{\varepsilon})
$$

wherein $U(\varepsilon, \dot{\varepsilon})$ is a function that adds a hysteretic departure from the linear behavior. The behavior of the hysteretic behavior was considered to be reversible ("butterfly" shape) (Veniamin E. Nazarov, Ostrovsky, Soustova, \& Sutin, 1988; Ostrovsky \& Johnson, 2001b), and anelastic (Koen E-A Van Den Abeele et al., 1997) in the wave equation. In both hysteretic cases, the second harmonic is not generated and the $A_{3}$ is proportional to $A_{1}{ }^{2}$. These conclusions also apply for higher harmonic generation in nonlinear acoustic resonance experiments — see section 1.2.3 Nonlinear resonant techniques-.

In other instances, the material nonlinearity stems from an unbounded interface within the material, perhaps, being a clapping crack the most representative case. This is the phenomena of contact acoustics nonlinearity (CAN). The generation of harmonics arises from the relative opening and closing of an unbounded interface (kissing bonds, delamination, cracks, etc.). Even a perfect isotropic material can generate higher harmonics because of a structural inhomogeneity (Zheng, Maev, \& Solodov, 1999). The material nonlinearity can be modelled from the nonlinear characteristics of the interface contact (Pecorari \& Solodov, 2006). This is generally achieved considering a nonlinear spring model 
to describe the nonlinear stiffness of the contacting interface. Figure 1-5 illustrates different nonlinear spring models used to describe the contact acoustic nonlinearity —adapted from (Klepka, 2013)—. The propagation of a monochromatic wave through the contacting interface yields to considerable wave distortion which manifests as an enrichment of the frequency spectra with higher harmonics. These type of models have been applied and validated to specific damage processes involving contact acoustics nonlinearity in steel and polymeric materials (Biwa, Nakajima, \& Ohno, 2004; Kim, Baltazar, Hu, \& Rokhlin, 2006; Yan, Drinkwater, \& Neild, 2009).
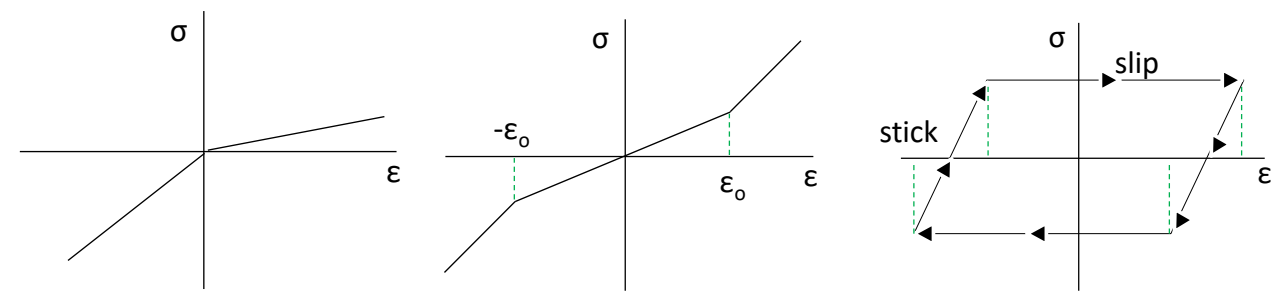

Figure 1-5 Three different nonlinear springs models.

The higher harmonic method have been used to characterize the material nonlinearity of metallic substances (Hikata \& Elbaum, 1966; Matlack, Kim, Jacobs, \& Qu, 2015), rock (Meegan, Johnson, Guyer, \& McCall, 1993), and concrete (Shah, Ribakov, \& Hirose, 2009; Stauffer, Woodward, \& White, 2005). In addition, the determination of the second, and third harmonic has been used as sensitive parameter in fatigue experiments of different materials (Amura, Meo, \& Amerini, 2011; Buck, Morris, \& Richardson, 1978; Cantrell \& Yost, 2001; K.Y. Jhang \& Kim, 1999). The test configurations are commonly configured for longitudinal wave transmission, but Rayleigh wave (Shui, Kim, Qu, Wang, \& Jacobs, 2008; Thiele, Kim, Qu, \& Jacobs, 2014), and Lamb waves (Bermes, Kim, Qu, \& Jacobs, 2007) have been also used. Elastic waves can be also used in reflection mode (Romer, Kim, Qu, \& Jacobs, 2016). An extensive review of test configurations has been given in (Zheng et al., 1999). Figure 1-4a illustrates a schematic representation of the test configuration. It shows generation of a single frequency burst with preset number of cycles. Figure 1-4b shows typical transmitted and received signals. 
INPUT $\quad$ OUTPUT

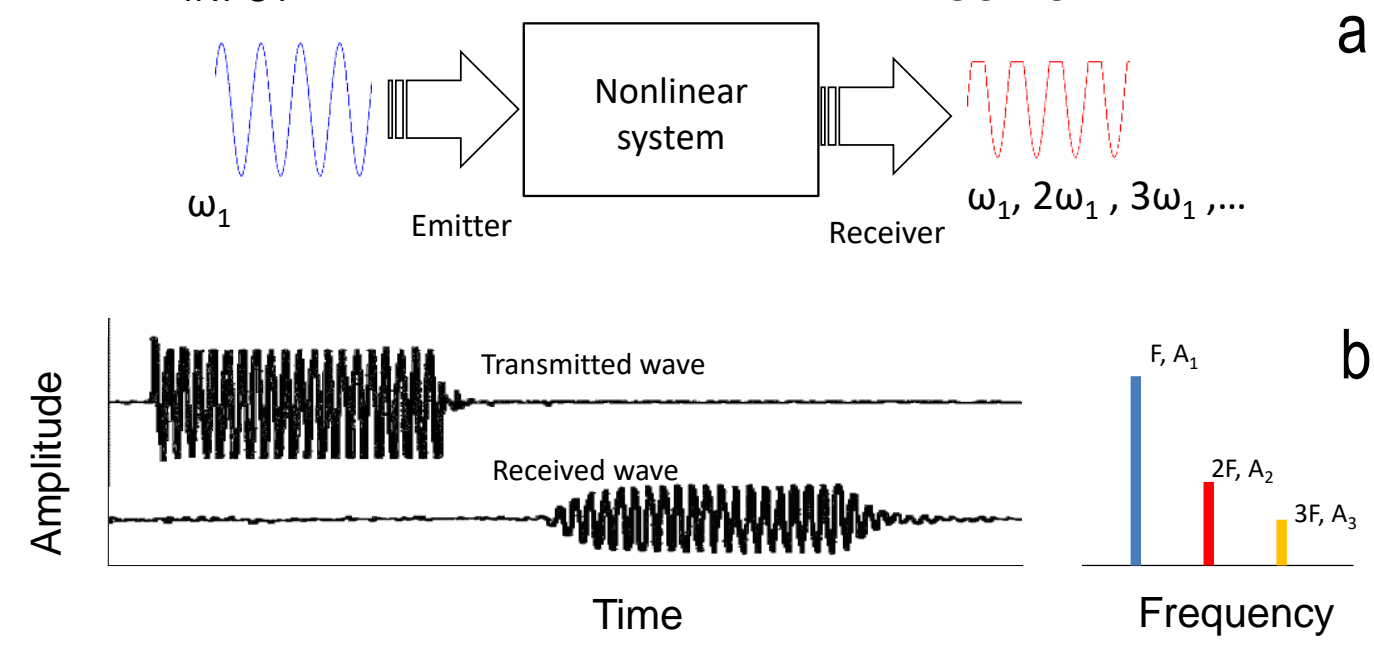

a

Figure 1-6 a) Schematic test configuration for higher harmonic generation. The transmission of a pure tone signal through a nonlinear system results in higher harmonic distortion; b) representative transmitted and received signal and analysis of the received signal in frequency domain. Adapted from (K. Y. Jhang, 2000)

On the other hand, the signal processing is normally conducted in the frequency domain through the Fast Fourier Transform (FFT), or through bispectral analysis (Hillis, Neild, Drinkwater, \& Wilcox, 2006; K. Y. Jhang, 2000). These analyses allow a quantification of the amplitudes of the higher harmonics while other nonlinear mechanisms such as nonlinear attenuation or amplitude dependent effects are overlooked. In addition, the results may be affected by the signal processing parameters: windowing, zero-padding, band-pass filtering, etc. Bruno and coworkers (Bruno, Gliozzi, Scalerandi, \& Antonaci, 2009) pointed out these disadvantages, and proposed a time domain feature extraction method termed scaling subtraction method (SSM). It requires subtracting a linear reference signal which is scaled to the amplitude of the received (nonlinear) signal. The resulted residuals contain the nonlinear contributions of the signal, which in turn can reveal the dominant mechanisms in the material nonlinearity: phase shift, nonlinear attenuation and higher harmonic generation (Bruno et al., 2009). The SSM has been satisfactorily applied in the assessment of different damage mechanisms in concrete (Antonaci, Bruno, Gliozzi, \& Scalerandi, 2010; Scalerandi, 
Griffa, Antonaci, Wyrzykowski, \& Lura, 2013), clay bricks (Antonaci, Formia, Gliozzi, Scalerandi, \& Tulliani, 2013), and steel (Scalerandi, Gliozzi, \& Olivero, 2014).

\subsubsection{Nonlinear resonant techniques}

Nonlinear resonant tests are based on the investigation of the resonant frequency shift and attenuation variations with increasing amplitude excitation. For every excitation level, the resonant frequency and attenuation are determined. The nonlinear behavior is investigated by increasing the excitation amplitude. The material nonlinearity manifests as a downward resonant peak shift, and as a decrease of quality factor $(Q)$-inverse attenuation - with increasing excitation amplitude. Figure 1-7a schematically describes a nonlinear resonant experiment. The test configuration consists in sweeping over a frequency range to match the resonant frequency of interest. Alternatively, the resonant frequencies can be determined through an impactor. The resonant spectra are collected by increasing the excitation amplitude in consecutive experiments. These techniques are referred as Nonlinear Resonant Spectroscopies (K. E.-A. Van Den Abeele, Carmeliet, Ten Cate, \& Johnson, 2000). Figure 1-7b shows representative frequency spectra obtained in a nonlinear resonant experiment and the evaluation of the amplitude dependent frequency and quality factor $(Q)$. The magnitudes of both shifts are related with damage features.

The consideration of higher order terms in the equation of state leads to the generation of higher harmonics. From the acceleration corresponding to the fundamental resonant peak $\left(A_{1}\right)$ and the harmonic amplitudes at twice and thrice the fundamental resonant frequency peaks ( $A_{2}$ and $A_{3}$ ), the quadratic and cubic elastic terms can be obtained as (Paul A. Johnson \& Rasolofosaon, 1996)

$$
\beta=-\frac{A_{2} \cdot \omega_{0}^{2} \cdot L}{A_{1}^{2}} .
$$




$$
\delta=-\frac{A_{3} \cdot \omega_{0}^{4} \cdot L^{2}}{A_{1}^{3}}
$$

Usually, the average strain over one strain cycle is zero, thus the quadratic term $\beta$ is eliminated (Paul A. Johnson \& Rasolofosaon, 1996). Therefore, from the downward resonant frequency shift, the third order elastic nonlinear term can be obtained as

$$
\frac{f-f_{o}}{f_{o}} \approx \frac{\delta}{2} \cdot \varepsilon^{2}
$$

where $f_{0}$ is the resonant frequency in the linear strain regime. In practice, $f_{0}$ is set for the lowest excitation level. The determination of the third-order elastic nonlinearity has been the objective of many researchers, as it provides insight on the ultimate stress in brittle materials such as concrete, and the yield stress in ductile materials (Zarembo, Krasil'nikox, \& Shkol'nik, 1989). However, experimental evidences in polycrystalline solids and rocks revealed a linear dependence of the resonant frequency and attenuation shifts with strain amplitude, along with third harmonic amplitudes unexpectedly high (Robert A. Guyer \& Johnson, 1999; Robert Alan Guyer, McCall, \& Boitnott, 1995; Paul A. Johnson \& Rasolofosaon, 1996; Read, 1940). These observations do not comply with the classical nonlinear behavior (Eq. 1-7), and were associated with hysteresis in the stress-strain relationship. Such behavior was found to be characteristic of material with defects at the mesoscale level: rocks, concrete, soil, cracked materials, etc., which are collectively termed nonlinear mesoscopic elastic materials, NMEM (Robert A. Guyer \& Johnson, 1999). By including hysteresis in modelling resonant experiments (Campos-Pozuelo, Vanhille, \& Gallego-Juárez, 2006; R. a. Guyer, McCall, \& Van Den Abeele, 1998; V. E. Nazarov, Radostin, Ostrovsky, \& Soustova, 2003), it was demonstrated that the resonant frequency shift is proportional to the strain amplitude $(\Delta \varepsilon)$, so that

$$
\frac{\Delta f}{f_{o}}=\alpha_{f} \cdot \Delta \varepsilon
$$


along with a linear decrease of attenuation as

$\frac{1}{Q}-\frac{1}{Q_{o}}=\alpha_{Q} \cdot \Delta \varepsilon$

wherein $Q$ is the quality factor (inverse attenuation) and $Q_{0}$ is the quality factor obtained in linear strain regime. These dependences (Eq. 1-14 and Eq. 1-15) may exhibit even higher order dependences depending on the characteristics of the hysteretic function (Pecorari \& Mendelsohn, 2014). The parameters $\alpha_{\mathrm{f}}$ and $\alpha_{Q}$ quantify the extent of hysteresis, and are presumed to underlie on the same physical origins (P. Johnson \& Sutin, 2005; K. E. Van Den Abeele, Sutin, et al., 2001). Such behavior was demonstrated to ensue from the bond and relative contact between grains (Darling, Tencate, Brown, Clausen, \& Vogel, 2004). These effects are referred as fast dynamic effects (P. Johnson \& Sutin, 2005) or amplitude dependent internal friction effects (Nazarov \& Radostin, 2015).

Along with hysteresis, NMEM exhibit a "creep-like" behavior upon dynamic excitation. It manifests in dynamic experiments as a progressive softening of the material towards a new equilibrium state while the material is under dynamic excitation (material conditioning). Once the excitation ceases, the material experiences a relaxation process whereby the material temporarily memorized the attained strain amplitude, and progressively recovers the resonant frequency obtained at linear strain regime. Such a relaxation process may take hours and is referred as slow dynamics (Robert A. Guyer \& Johnson, 1999). Up to date, slow dynamic has been modeled in a phenomenological way by using rheological models (Bentahar, El Aqra, El Guerjouma, Griffa, \& Scalerandi, 2006; Favrie \& Lombard, 2014; Nazarov \& Radostin, 2015). However, although the nonlinear hysteresis and relaxation can be fairly well represented by rheological models, the underlying mechanisms may be different in different materials (Nazarov \& Radostin, 2015). Indeed, the physical origins of slow dynamics are still not very well understood (TenCate, 2011). On other hand, there seems to exist a strain amplitude threshold, from which fast and slow dynamic effects are triggered (Pasqualini et al., 2007). Figure 1-7b illustrates the nonlinear regimes observed in resonant experiments on NMEM. At low strain amplitudes — say below $\sim 10^{-7}$ —, the material 
exhibits nonlinear classical (reversible) behavior. Beyond this threshold amplitude, hysteresis is activated which is accompanied by a long time recovery (slow dynamic effect); that is non-equilibrium or non-classical regime. The recovery process is illustrated in Figure 1-7c. After a resonant experiment driven at excitation amplitudes within the non-equilibrium regime, the recovery can be probed by monitoring the resonant frequency with time at low strain amplitude (linear regime). The strain threshold value is not a characteristic property of the material but it seems to depend on the stress rate (Pecorari, 2015). Indeed, the size of the hysteresis loop depends on the strain rate excitation as revealed through dynamic acousto-elastic tests (Rivière, Renaud, Guyer, \& Johnson, 2013) —see section 1.2.4.2 Dynamic acoustoelastic tests-. Therefore, the strain amplitude value above which nonequilibrium effects are triggered depends on frequency.

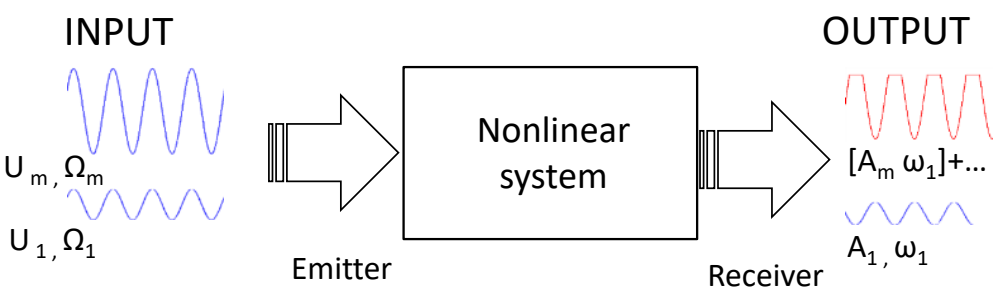

a

$$
U_{1}, \Omega_{1}
$$

Emitter Receiver

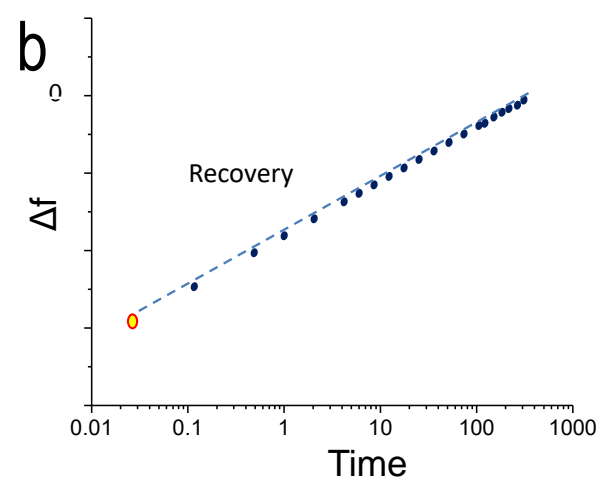

C

Figure 1-7 a) Schematic test configuration for nonlinear resonant spectroscopies, b) resonant frequency shift regimes, and c) resonant frequency relaxation with time produced after a excitation within the nonequilibrium regime. 
Since the fast and slow dynamic effects appear to be related to the damage features such as microcracks, different resonant techniques have been developed to assess the mechanical integrity of different materials (K. E. Van Den Abeele, Sutin, et al., 2001). The fast dynamic effect has been used to discern damage in polymer composites (K. E. Van Den Abeele, Van de Velde, \& Carmeliet, 2001), fatigued steel (Campos-Pozuelo et al., 2006), and concrete (C. Payan et al., 2007). The less sophisticated nonlinear resonant test based on an impactor was used to qualitatively asses alkali-silica reaction (Chen et al., 2010), fire damage (Park, Park, Yim, \& Kwak, 2015) and freezing-thawing damage (Eiras et al., 2014) in concrete-like materials. Fast and slow dynamic effects are thought to coexist during dynamic excitation (Johnson \& Sutin, 2005), so that the measurement of the hysteretic parameters may be affected by slow dynamic effect. Such an effect can be minimized by increasing the time lapse between consecutive acquisitions.

Other resonant test configurations do not differ in the basic test configuration equipment, but they do, in the signal processing and testing protocol. Novak and colleagues (Novak, Bentahar, Tournat, El Guerjouma, \& Simon, 2012) used a nonlinear convolution signal processing for identifying higher harmonics in damaged polymer composites. Interestingly, it was found that higher harmonics exhibited larger shifts than those corresponding to the fundamental mode of vibration. These observations suggest a dispersive behavior of the nonlinear parameters, as postulated by Gusev and coworkers (Gusev, Lauriks, \& Thoen, 1998). On other hand, Van Den Abeele et al. (K. Van Den Abeele, Le Bas, Van Damme, \& Katkowski, 2009) used a pure tone burst excitation close to the resonant frequency of plate-like samples. The resonant frequency tests were performed in a fully non-contact manner by using a loudspeaker as emitter and a laser vibrometer sensing the dynamic excitation. The pure tone burst was generated at different amplitudes and the signal was analyzed during the ring down once the monochromatic excitation was switched off. The analysis of the signal consisted in extracting the instantaneous frequency and attenuation variations produced during the ring down of the signal. It was found that both frequency shift and amplitude dependences investigated during the ringdown differed from the observation of the amplitude dependent frequency and attenuation from consecutive 
experiments. Such a discrepancy is most likely owed to the slow dynamic effect, which is also present during the signal ring down (Van Damme \& Van Den Abeele, 2014). Van Damme and Van Den Abeele (Van Damme \& Van Den Abeele, 2014) discussed that Nonlinear Reverberation Spectroscopy tests are difficult to apply in on-site applications, since it requires free boundary conditions - this condition, is fulfilled by hanging the samples in fishing wires-. Also, it was argued that it performs better for low attenuation materials. However, Gudmarsson and colleagues (Gudmarsson, Ryden, \& Birgisson, 2015), successfully performed nonlinear resonant tests using non-contact excitation on PVC, asphalt and concrete disk samples. In other cases, the testing protocol was designed to isolate the slow dynamic effect from fast hysteresis motion. Haller and Hedberg (Haller \& Hedberg, 2008) used a constant strain frequency sweep measurement, and compared the results with the constant force frequency sweep, although the method allows disentangling the material conditioning effect. In a second study, Haller and Hedberg (Haller \& Hedberg, 2012) applied a high strain amplitude input at the resonant frequency during 30 minutes in order to induce a material conditioning; thereafter the material nonlinearity was probed at low strain levels for short periods of time at a discrete time 0.2 into the resonator, alternated with 5 seconds of high strain conditioning and so on, in order to determine the resonant frequency. The process was repeated by setting the discrete time point at a higher value. Overall, the investigation of careful slow dynamic experiments are time consuming (Haller \& Hedberg, 2012; Haller \& Hedberg, 2008). Besides, the repeatability of experiments require long rests between tests and controlled temperature and moisture environments (Ten Cate, Duran, \& Shankland, 2002).

\subsubsection{Pump and probe wave interaction based techniques}

\subsubsection{Vibro-acoustic modulation}

The techniques that underlie on the modulation phenomena consist of a continuous high-frequency probe wave (at frequency $f_{\text {probe}}$ ), and a low-frequency vibration or pump wave (at frequency $f_{\text {pump }}$ ), normally, at a given resonance mode of the tested sample. The pump vibration aims to induce stresses within the sample, while the probe wave senses the 
variation of modulus produced by pump vibration. If the material under inspection behaves linearly, the phase and amplitude of the probe wave does not depend on the stresses induced by the pump wave excitation. However, in a nonlinear material the phase and amplitude of the probe wave are modulated by pump wave excitation. The interaction of both waves - with frequencies $f_{\text {probe }}$ and $f_{\text {pump }}$ - manifests as sideband components in the frequency spectra of the received signal. This process is commonly illustrated through the nonlinear behavior ensued by the existence of a crack in a sample (Sutin \& Nazarov, 1995): the probe wave propagates through the crack surfaces, while the pump vibration makes the contact area between the crack surfaces to increase in compression, and decrease in tension. By this process, amplitude and phase of the received wave are modulated, according to the frequency of the pump vibration. The frequency domain of the received signal exhibit higher harmonics, and modulated frequencies. This process is schematically shown in Figure 1-8. Indeed, vibro-acoustic modulation techniques were formerly conceived to detect localized defects such as cracks in structural parts (Korotkov, Slavinskii, \& Sutin, 1994; V.Y. Zaitsev, Sutin, Belyaeva, \& Nazarov, 1995).

As in nonlinear resonant and finite-amplitude techniques, the scaling relations between strain amplitude corresponding to every harmonic, are affected by the type of nonlinearity: classical or non-classical hysteretic (K. E.-A. Van Den Abeele, Johnson, \& Sutin, 2000). In the case of quadratic nonlinearity, first-order sidebands $f_{\text {probe }} \pm f_{\text {pump }}$ are produced, with amplitude proportional to $\beta \cdot A_{\text {pump }} \cdot A_{\text {probe. }}$ In the case of cubic nonlinearity, second-order sidebands $f_{\text {probe }} \pm 2 \cdot f_{\text {pump }}$ are produced, with amplitude proportional to $C_{\beta \delta} \cdot\left(A_{\text {probe }}\right)^{2}$-with $C_{\beta \delta}$ being a constant combination of $\beta$ and $\delta$ - In case of non-classical hysteretic behavior, second-order sidebands $f_{\text {probe }} \pm 2 \cdot f_{\text {pump }}$ arise with amplitude proportional to $\alpha \cdot A_{\text {probe }} \cdot A_{\text {pump }}-$ with $\alpha$ being the hysteretic parameter-. In case of localized defects such as cracks, the modulation arises from the nonlinear stiffness that ensues from the interfacial contact. In this case, considerable enrichment of the frequency spectra may be produced, which in turn, depends on the physical properties of the contact wherein the behavior can be even chaotic (Solodov \& Korshak, 2002). 

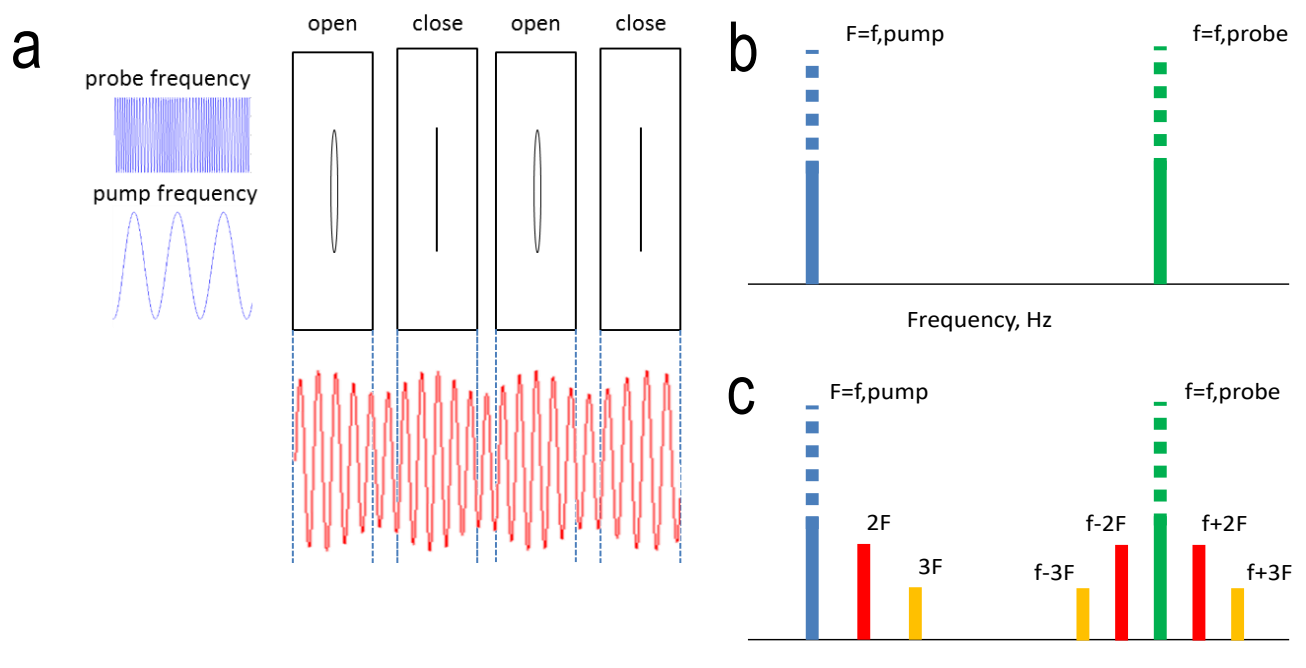

Frequency, $\mathrm{Hz}$

Figure 1-8 a) Schematic representation of the acoustic modulation process, and resulted spectra for $b$ ) a undamaged sample and c) a cracked sample. Adapted from (Klepka, 2013).

In contrast with finite-amplitude techniques (higher harmonic generation) -see subsection 1.2.2 Higher harmonic generation-, the modulation technique offers some advantages (D. M. Donskoy \& Sutin, 1998). First, higher harmonic generation requires a travelling path, thus this is difficult to fulfill in the presence of reflecting boundaries and other structural inhomogeneities. Second, high voltages are needed which frequently add some nonlinear background signal, which may affect the sensitivity of the technique. There exist two basic test configurations which are referred in the literature as vibro-acoustic modulation and impact modulation techniques. The former, consists of a continuous harmonic excitation with a weak probing frequency while the resonant vibration is produced by an electromagnetic shaker. The technique requires careful coupling between the shaker rig and the sample, otherwise additional contact nonlinearities may arise (Duffour, Morbidini, \& Cawley, 2006). On other hand, impact modulation techniques use a shock vibration to excite the resonant modes. The advantage of the impact modulation technique resides in the absence of nonlinear contacts in the source of excitation. The drawback is related to the impossibility to sustain the same shock force all runs of the experiment (Duffour et al., 2006; 
Ekimov, Didenkulov, \& Kazakov, 1999). Nevertheless, the impact modulation shows improved sensitivity when compared to the vibro-acoustic technique (V Yu Zaitsev, Matveev, \& Matveyev, 2009; V. Yu Zaitsev, Matveev, \& Matveyev, 2011).
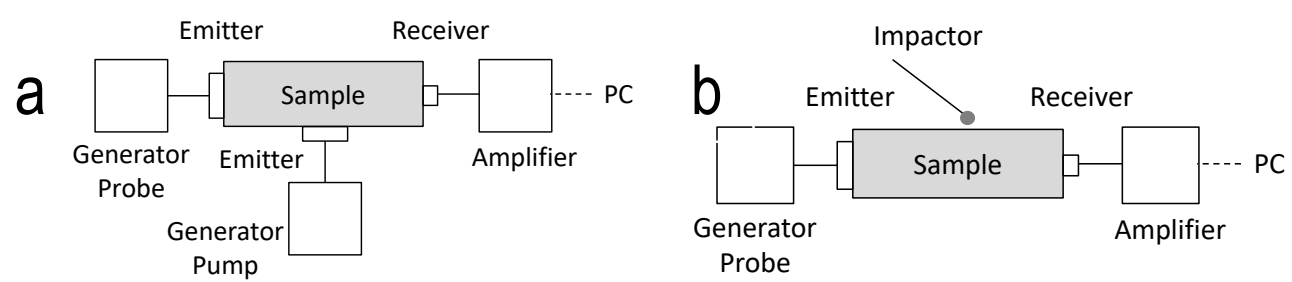

Figure 1-9 Nonlinear wave modulation spectroscopy based techniques: a) Vibro-acoustic modulation, and b) Impact modulation.

The damage severity is normally evaluated through damage parameters that relate the intensity of the spectral sideband amplitudes with regard the amplitude of the probing wave. A modulation index $(M I)$, is normally used to assess the damage severity. It is defined as (Donskoy, Sutin, \& Ekimov, 2001)

$$
M I=\sum_{m=1}^{M} \frac{A_{m \pm n}}{A_{m} \cdot A_{n}}
$$

wherein $A_{m \pm n}$ is the spectral magnitude at the frequency $f_{m \pm n} F_{n}, A_{m}$ the spectral magnitude at the frequency $f_{m}$ and $A_{n}$ the spectral magnitude at the frequency $F_{n}$. The analysis of distributed like damage does not produce always a clear sideband generation but the energy of the sideband was successfully used to screen mechanical damage in concrete, alkali silica reaction, or moisture content. The latter evidences the effect of moisture conditions on the measurement of the nonlinear properties, through nonlinear based techniques. Alternatively from the relative of the sideband energy with regard the energy of the ultrasonic probe as (K. E.-A. Van Den Abeele, Johnson, et al., 2000)

$$
M I=\frac{E_{m \pm n}}{E_{m} E_{n}}
$$


In some cases, the modulation signal has not been clearly screened, even at considerable extents of damage. The energy of the sidebands with regard the energy of the main probe is a relative measurement of material nonlinearity (X. J. Chen et al., 2008; Cédric Payan, Garnier, \& Moysan, 2010). The sideband generation is sometimes accompanied by scattered, and multiple reflection from the boundaries as the energy is scattered by the presence of nonlinear scatters. Alternatively, the sideband generation may be quantified by a quantification of the relative minor peaks. The modulation index cannot be reliable however (Hu, Staszewski, Hu, Jenal, \& Qin, 2010), and it can lead to false positive

\subsubsection{Dynamic acoustoelastic test (DAET)}

The dynamic acoustoelastic test (DAET) consists in monitoring the variations of modulus while the inspected sample is subjected to dynamic loading conditions. Nagy and coworkers (Nagy et al., 1990) used DAET to evaluate the adhesive joints in composite materials under superimposed dynamic shear stress loading. The test configuration and signal analysis conducted therein allowed relating the averaged variations of wave velocity to the attained shear stress produced upon dynamic loading. Therefore, the analysis was based on the "classical" higher-order expansion of wave velocity as function of the stress analogously to the static acoustoelastic tests described in subsection 1.2.1 Acoustoelastic techniques-. Unlike the approach presented by Nagy and coworkers (Nagy et al., 1990), Renaud and coworkers (Renaud, Callé, Remenieras, \& Defontaine, 2008) presented a test configuration that allowed extracting the variations of modulus across different stress levels imparted during dynamic loading. In this case, the test allowed not only description of higherorder terms, but also hysteresis and relaxation of elastic and dissipative properties (Renaud, Callé, \& Defontaine, 2009).

Figure 1-10 shows a schematic representation of a basic DAET configuration. Normally, the test consists of a long low frequency burst that matches a fundamental resonant mode (pump wave), while repeated ultrasonic pulses (probe wave) sense the variation of modulus across different strain values of the pump excitation. The received ultrasonic pulses are modulated in phase and amplitude, as in vibro-acoustic modulation based techniques — see 
subsection 1.2.4.1 Vibro-acoustic modulation techniques-. However, the analysis is focused on the instantaneous variations of modulus and attenuation properties, rather than on sideband spectral components, which may arise from the same physical effect. Figure 1-10 shows typical recorded signals in a DAET experiment.

Considering that the variations of the speed of sound $(\Delta c)$ with respect to the speed of sound in the linear elastic regime $\left(c_{0}\right)$ are so small that $c \approx c_{0}$-and hence, $c^{2}-c_{0}^{2} \approx 2 \cdot\left(c-c_{0}\right)$-, the corresponding relative variations of time of flight $\left(\Delta t / t_{0}\right)$ can be approximately related to the material nonlinearity as

$$
\frac{\Delta M}{M_{o}}-2 \cdot \frac{\Delta t}{t_{o}} \approx C_{E}(\Delta \varepsilon)+\beta \varepsilon+\delta \varepsilon^{2}+\ldots+H_{E}(\varepsilon, \dot{\varepsilon})
$$

where, in addition to the quadratic and cubic nonlinear classical parameters ( $\beta$ and $\delta$ ), the ad hoc function $C_{E}(\Delta \varepsilon)$ is introduced ad hoc to describe the material conditioning effect: the offset between strain and the relative variation of modulus. In addition, the variations of material attenuation $(\Delta \bar{\alpha})$ produced during low frequency burst excitation, are also derived from the amplitude $(A)$ of the ultrasonic pulses as

$$
\Delta \bar{\alpha} \approx-\ln \left(1+\frac{\Delta A}{A_{o}}\right) / d \approx C_{D}(\Delta \varepsilon)+\beta_{D} \varepsilon+\delta_{D} \varepsilon^{2}+\ldots+H_{D}(\varepsilon, \dot{\varepsilon})
$$

Analogously, the same terms can be defined for the variation of the attenuation properties, which are denoted herein with subscript $D$. These tests allowed revealing also dispersive behavior of the nonlinear mechanisms. 


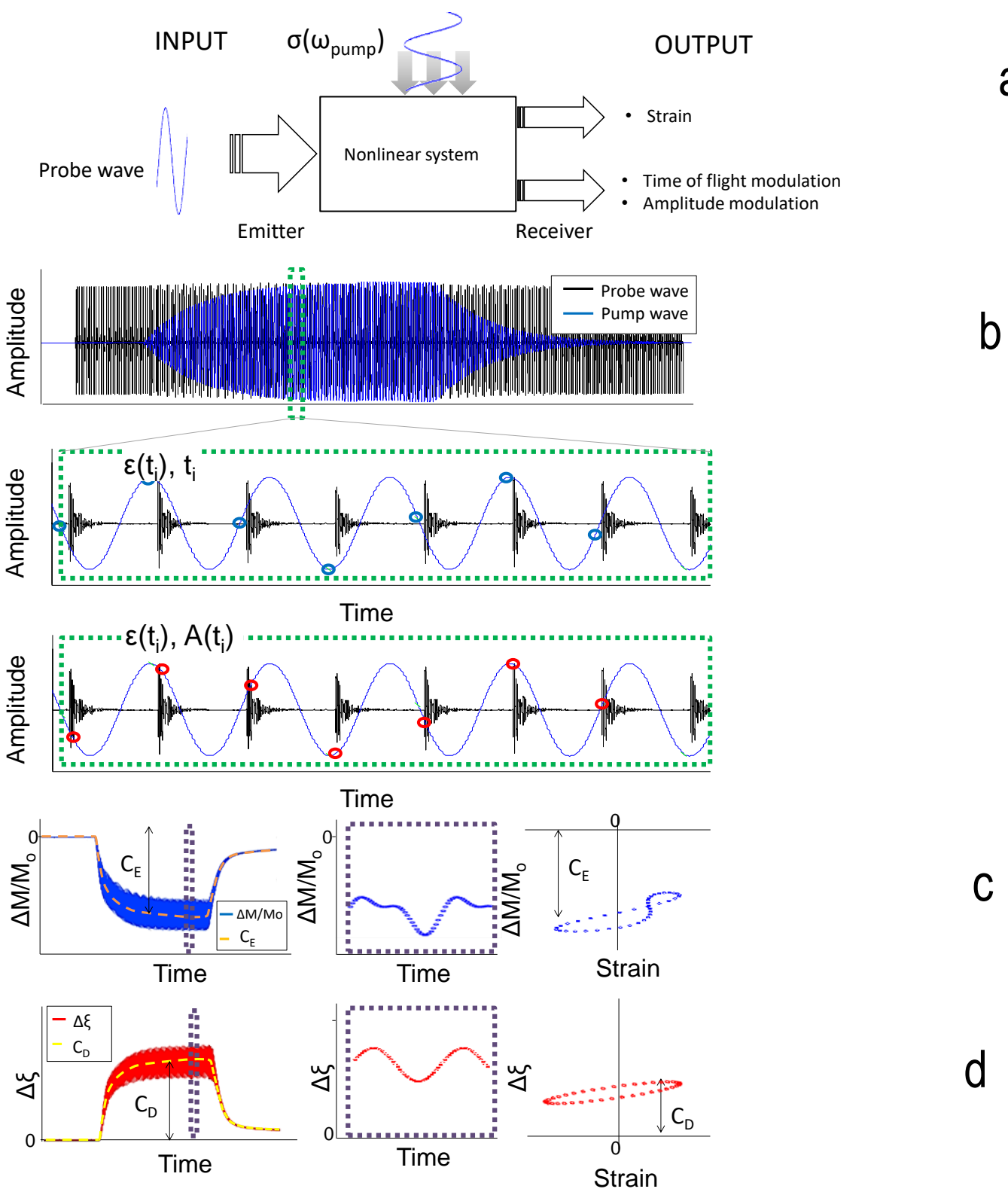

Figure 1-10 a) Schematic diagram representing a dynamic acoustoelastic test, b) typical recorded signals in a $D A E T$ experiment, c) resulted variation of modulus and d) attenuation properties, after processing the received signals. 
Dynamic acoustoelastic experiments have been successfully used on the assessment of trabecular bone (Renaud et al., 2008), rocks (Renaud, Talmant, Callel, Defontaine, \& Laugier, 2011) and fatigued metallic samples (Haupert et al., 2014), under controlled laboratory conditions. The test configurations for such studies are not convenient for field applications. Yet some attempts have been made. Renaud and coworkers (Renaud et al., 2014) performed in-situ DAET to measure the elastic properties of soil. The tests were performed by using a thumper truck as pump wave source, and a buried system consisting of a high frequency generation and sensing. In other instances, the ultrasonic pulses were modulated by using a shock load. Such an approach aims on-field monitoring of concrete structures by using a hammer blow (Bui, Kodjo, Rivard, \& Fournier, 2013), or passive structural health monitoring applications, for instance, by using traffic loads in bridges (Moradi-Marani, Kodjo, Rivard, \& Lamarche, 2014, 2012). The technique is referred in these studies as Time Shift technique. The signal analysis conducted in such studies, is based on the simultaneous comparison between a number of time segments of the received ultrasonic pulses, before, and after shock wave perturbation, through the cross-correlation function. The summation of the time shifts obtained in every time segment was used as a quantification of the material nonlinearity. The approaches proposed in (Bui et al., 2013; Moradi-Marani et al., 2014) do not allow description of the strain dependent nonlinear elastic and dissipative characteristics, but a quantification of the material nonlinearity in a sole parameter. Moreover, such studies pointed out that the major contribution to the cumulative time shift mainly comes from the late coda wave segments (Bui et al., 2013; Moradi-Marani et al., 2014). These results further confirm the sensitivity of the coda wave to detect subtle microstructural modifications (Snieder et al., 2002). Indeed, the analyses of the coda wave have been leveraged to diagnose the material nonlinearity after a pump wave excitation. 


\section{References}

Adler, L., \& Nagy, P. B. (1991). Second order nonlinearities and their application in NDE. In D. O. Thompson \& D. E. Chimenti (Eds.), Review of Progress in Quantitative Nondestructive Evaluation (pp. 1813-1820). New York.

American Society of Civil Engineers. (2013). Failure to Act: The Impact of Current Infrastructure Investment on America's Economic Future.

Amura, M., Meo, M., \& Amerini, F. (2011). Baseline-free estimation of residual fatigue life using a third order acoustic nonlinear parameter. The Journal of the Acoustical Society of America, 130(4), 1829-37.

Antonaci, P., Bruno, C. L. E., Gliozzi, A. S., \& Scalerandi, M. (2010). Monitoring evolution of compressive damage in concrete with linear and nonlinear ultrasonic methods. Cement and Concrete Research, 40(7), 1106-1113.

Antonaci, P., Formia, A., Gliozzi, A. S., Scalerandi, M., \& Tulliani, J. M. (2013). Diagnostic application of nonlinear ultrasonics to characterize degradation by expansive salts in masonry systems. NDT \& E International, 55, 57-63.

ASTM C215-14. (2014). Standard Test Method for Fundamental Transverse , Longitudinal and Torsional Resonant Frequencies of Concrete.

ASTM-C666. (2012). Standard Test Method for Resistance of Concrete to Rapid Freezing and Thawing.

Bentahar, M., El Aqra, H., El Guerjouma, R., Griffa, M., \& Scalerandi, M. (2006). Hysteretic elasticity in damaged concrete: Quantitative analysis of slow and fast dynamics. Physical Review B, 73(1), 014116.

Bergman, R. H., \& Shahbender, R. A. (1958). Effect of statically applied stresses on the velocity of propagation of ultrasonic waves. Journal of Applied Physics, 29(12), 17361738.

Bermes, C., Kim, J. Y., Qu, J., \& Jacobs, L. J. (2007). Experimental characterization of material nonlinearity using Lamb waves. Applied Physics Letters, 90(2), 1-4.

Biwa, S., Nakajima, S., \& Ohno, N. (2004). On the Acoustic Nonlinearity of Solid-Solid Contact With Pressure-Dependent Interface Stiffness. Journal of Applied Mechanics, 
71(4), 508.

Bruno, C., Gliozzi, a., Scalerandi, M., \& Antonaci, P. (2009). Analysis of elastic nonlinearity using the scaling subtraction method. Physical Review B, 79(6), 064108.

Buck, O., Morris, W. L., \& Richardson, J. M. (1978). Acoustic harmonic generation at unbonded interfaces and fatigue cracks. Applied Physics Letters, 33(5), 371.

Bucur, V., \& Rasolofosaon, P. N. J. (1998). Dynamic elastic anisotropy and nonlinearity in wood and rock. Ultrasonics, 36(7), 813-824.

Bui, D., Kodjo, S. a., Rivard, P., \& Fournier, B. (2013). Evaluation of Concrete Distributed Cracks by Ultrasonic Travel Time Shift Under an External Mechanical Perturbation: Study of Indirect and Semi-direct Transmission Configurations. Journal of Nondestructive Evaluation, 32(1), 25-36.

Campos-Pozuelo, C., Vanhille, C., \& Gallego-Juárez, J. A. (2006). Comparative Study of the Nonlinear Behavior of Fatigued and Intact Samples of Metallic Alloys. IEEE Transactions on Ultrasonics, Ferroelectrics, and Frequency Control, 53(1), 175-184.

Cantrell, J. H., \& Yost, W. T. (2001). Nonlinear Ultrasonic Characterization of Fatigue Microstructures. International Journal of Fatigue, 23, S487-S490.

Carino N. J. (1994). Nondestructive Testing of Concrete: History and Challenges. In Concrete Technology - Past, Present and Future.

Chen, J., Jayapalan, A. R., Kim, J. Y., Kurtis, K. E., \& Jacobs, L. J. (2010). Rapid evaluation of alkali-silica reactivity of aggregates using a nonlinear resonance spectroscopy technique. Cement and Concrete Research, 40(6), 914-923.

Chen, X. J., Kim, J.-Y., Kurtis, K. E., Qu, J., Shen, C. W., \& Jacobs, L. J. (2008). Characterization of progressive microcracking in Portland cement mortar using nonlinear ultrasonics. NDT \& E International, 41(2), 112-118.

Chrisp, T. M., Waldron, P., \& Wood, J. G. M. (1993). Development of a non-destructive test to quantify damage in deteriorated concrete. Magazine of Concrete Research, 45(165), 247-256.

Dahlén, U., Ryden, N., \& Jakobsson, A. (2015). Damage identification in concrete using impact non-linear reverberation spectroscopy. NDT and $E$ International, 75, 15-25. 
Darling, T. W., Tencate, J. A., Brown, D. W., Clausen, B., \& Vogel, S. C. (2004). Neutron diffraction study of the contribution of grain contacts to nonlinear stress-strain behavior. Geophysical Research Letters, 31(16), 31-34.

Donskoy, D. M., \& Sutin, A. M. (1998). Vibro-Acoustic Modulation Nondestructive Evaluation Technique. Journal of Intelligent Material Systems and Structures, 9, 765-771.

Donskoy, D., Sutin, A., \& Ekimov, A. (2001). Nonlinear acoustic interaction on contact interfaces and its use for nondestructive testing. NDT \& E International, 34(4), 231238.

Duffour, P., Morbidini, M., \& Cawley, P. (2006). A study of the vibro-acoustic modulation technique for the detection of cracks in metals. The Journal of the Acoustical Society of America, 119(3), 1463.

Eiras, J. N., Kundu, T., Popovics, J. S., Monzó, J., Soriano, L., Payá, J., ... València, U. P. De. (2014). Evaluation of frost damage in cement-based materials by a nonlinear elastic wave technique. Proceedings of SPIE Conference, 9064, 1-8.

Eiras, J. N., Monzó, J., Payá, J., Kundu, T., \& Popovics, J. S. (2014). Non-classical nonlinear feature extraction from standard resonance vibration data for damage detection. The Journal of the Acoustical Society of America, 135(2), EL82-EL87.

Eiras, J. N., Popovics, J. S., Borrachero, M. V., Monzó, J., \& Payá, J. (2012). Nonlinear impact resonant acoustic spectroscopy to discern mechanical damage in cement based materials. 15th International Conference on Experimental Mechanics, Porto (Portugal), 1-6.

Ekimov, A. E., Didenkulov, I. N., \& Kazakov, V. V. (1999). Modulation of torsional waves in a rod with a crack. The Journal of the Acoustical Society of America, 106(3), 1289.

Favrie, N., \& Lombard, B. (2014). Fast and slow dynamics in a nonlinear elastic bar excited by longitudinal vibrations.

Fröjd, P., \& Ulriksen, P. (2016). Amplitude and phase measurements of continuous diffuse fields for structural health monitoring of concrete structures. NDT \& E International, 77, $35-41$.

Gudmarsson, A., Ryden, N., \& Birgisson, B. (2015). Non-contact excitation of fundamental resonance frequencies of an asphalt concrete specimen. In AIP Conference 
Proceedings (Vol. 1650, pp. 1401-1408).

Gusev, V. E., Lauriks, W., \& Thoen, J. (1998). Dispersion of nonlinearity, nonlinear dispersion, and absorption of sound in micro-inhomogeneous materials. Journal of Acoustic Society of America, 103(6), 3216-3226.

Gusev, V., Tournat, V., \& Castagnède, B. (2010). Nonlinear Acoustic Phenomena in Microinhomogeneous Media. In M. Bruneau \& C. Potel (Eds.), Materials and Acoustics Handbook (pp. 433-471). Wiley.

Guyer, R. A., \& Johnson, P. A. (1999). Nonlinear Mesoscopic Elasticity: Evidence for a New Class of Materials. Physics Today, 52(4), 30-36.

Guyer, R. A., \& Johnson, P. A. (2009). Nonlinear Mesoscopic Elasticity. Wiley-VCH.

Guyer, R. A., McCall, K. R., \& Boitnott, G. N. (1995). Hysteresis, Discrete Memory, and Nonlinear Wave Propagation in Rock. Physical Review Letters, 74(17), 3491-3494.

Guyer, R. a., McCall, K. R., \& Van Den Abeele, K. (1998). Slow elastic dynamics in a resonant bar of rock. Geophysical Research Letters, 25(10), 1585-1588.

Haller, K. C. E., \& Hedberg, C. M. (2012). Method for monitoring slow dynamics recovery. Acoustical Physics, 58(6), 713-717.

Haller, K., \& Hedberg, C. (2008). Constant Strain Frequency Sweep Measurements on Granite Rock. Physical Review Letters, 100(6), 068501.

Haupert, S., Rivière, J., Anderson, B., Ohara, Y., Ulrich, T. J., \& Johnson, P. (2014) Optimized Dynamic Acousto-elasticity Applied to Fatigue Damage and Stress Corrosion Cracking. Journal of Nondestructive Evaluation, 33(2), 226-238.

Hikata, A., \& Elbaum, C. (1966). Generation of ultrasonic second and third harmonics due to dislocations. Physical Review, 144(2), 469-477.

Hillis, a J., Neild, S. a, Drinkwater, B. W., \& Wilcox, P. D. (2006). Global crack detection using bispectral analysis, (August 2005), 1515-1530.

Hornibrook, F. B. (1939). Application of sonic method to freezing and thawing studies of concrete. ASTM Bulletin, 101.

Hu, H. F., Staszewski, W. J., Hu, N. Q., Jenal, R. B., \& Qin, G. J. (2010). Crack detection 
using nonlinear acoustics and piezoceramic transducers-instantaneous amplitude and frequency analysis. Smart Materials and Structures, 19(6), 065017.

Hughes, D. S., \& Kelly, J. L. (1953). Second-Order Elastic Deformation of Solids. Physical Review, 92(5), 1145-1149.

Jhang, K. Y. (2000). Applications of nonlinear ultrasonics to the NDE of material degradation. IEEE Transactions on Ultrasonics, Ferroelectrics, and Frequency Control, 47(3), 5408.

Jhang, K.-Y., \& Kim, K.-C. (1999). Evaluation of material degradation using nonlinear acoustic effect. Ultrasonics, 37(1), 39-44.

Johnson, P. a, \& Jia, X. (2005). Nonlinear dynamics, granular media and dynamic earthquake triggering. Nature, 437(7060), 871-4.

Johnson, P. A. (1999). The new wave in acoustic testing. Materials World, 7(9), 544-546.

Johnson, P. A., \& Rasolofosaon, P. N. J. (1996). Nonlinear elasticity and stress-induced anisotropy in rock. Journal of Geophysical Research, 101, 3113-3124.

Johnson, P. A., \& Rasolofosaon, P. N. J. (1996). Resonance and elastic nonlinear phenomena in rock. Journal of Geophysical Research, 101(B5), 553-564.

Johnson, P., \& Sutin, A. (2005). Slow dynamics and anomalous nonlinear fast dynamics in diverse solids. The Journal of the Acoustical Society of America, 117(1), 124.

Kim, J.-Y., Baltazar, A., Hu, J. W., \& Rokhlin, S. I. (2006). Hysteretic linear and nonlinear acoustic responses from pressed interfaces. International Journal of Solids and Structures, 43(21), 6436-6452.

Klepka, A. (2013). Nonlinear acoustics. In T. Stepinski, T. Uhl, \& W. Staszewski (Eds.), Advanced Structural Damage Detection: From Theory to Engineering Applications (pp. 73-107). Wiley.

Korotkov, A. S., Slavinskii, M. M., \& Sutin, A. M. (1994). Variations of Acoustic Nonlinear Parameters with the concentration of the defects in Steel. Acoustical Physics, 40(1), 71-74.

Kundu, T. (2007). Advanced Ultrasonic Methods for Material and Structure Inspection. 
Landau, L. D., \& Lifshitz, E. M. (1970). Theory of Elasticity. Physics Today (Vol. 7).

Larose, E., \& Hall, S. (2009). Monitoring stress related velocity variation in concrete with a $2 \times 10(-5)$ relative resolution using diffuse ultrasound. The Journal of the Acoustical Society of America, 125(4), 2641.

Malhotra, V. M., \& Sivasundaram, V. (2004). Resonant Frequency Methods. In Handbook on Nondestructive Testing of Concrete (pp. 167-188).

Matlack, K. H., Kim, J.-Y., Jacobs, L. J., \& Qu, J. (2015). Review of Second Harmonic Generation Measurement Techniques for Material State Determination in Metals. Journal of Nondestructive Evaluation, 34(1), 273.

McCall, K. R., \& Guyer, R. A. (1996). A new theoretical paradigm to describe hysteresis, discrete memory and nonlinear elastic wave propagation in rock. Nonlinear Processes in Geophysics, 3(2), 89-101.

Meegan, G. D., Johnson, P. A., Guyer, R. A., \& McCall, K. R. (1993). Observations of nonlinear elastic wave behavior in sandstone. Journal of Acoustic Society of America, 94(6), 3387-3391.

Moradi-Marani, F., Kodjo, S. A., Rivard, P., \& Lamarche, C. (2014). Nonlinear Acoustic Technique of Time Shift for Evaluation of Alkali-Silica Reaction Damage in Concrete Structures. ACI Materials, 111(January-December 2014), 1-12.

Moradi-Marani, F., Kodjo, S. a., Rivard, P., \& Lamarche, C. P. (2012). Application of the mechanical perturbation produced by traffic as a new approach of nonlinear acoustic technique for detecting microcracks in the concrete: A laboratory simulation. In AIP Conference Proceedings (Vol. 1430, pp. 1493-1499).

Morris, W. L., Buck, O., \& Inman, R. V. (1979). Acoustic harmonic generation due to fatigue damage in high-strength aluminum. Journal of Applied Physics, 50(11), 6737-6741.

Muller, M., Sutin, A., Guyer, R., Talmant, M., Laugier, P., \& Johnson, P. a. (2005). Nonlinear resonant ultrasound spectroscopy (NRUS) applied to damage assessment in bone. The Journal of the Acoustical Society of America, 118(6), 3946.

Murnaghan, F. D. (1951). Finite Deformation of an Elastic Solid. John Wiley \& Sons, Ltd.

Nagy, P. B. (1998). Fatigue damage assesstment by nonlinear ultrasonic materials 
characterization. Ultrasonics, 36, 375-381.

Nagy, P. B., McGowan, P., \& Adler, L. (1990). Acoustic nonlinearities in adhesive joints. In Review of Progress in Quantitative Nondestructive Evaluation (Vol. 9, pp. 1685-1692).

Nazarov, V. E., Ostrovsky, L. A., Soustova, I. A., \& Sutin, A. M. (1988). Nonlinear acoustics of micro-inhomogeneous media. Physics of the Earth and Planetary Interiors, 50(1), 65-73.

Nazarov, V. E., Radostin, a. V., Ostrovsky, L. a., \& Soustova, I. a. (2003). Wave processes in media with hysteretic nonlinearity: Part 2. Acoustical Physics, 49(4), 444-448.

Nazarov, V. E., \& Radostin, A. V. (2015). Nonlinear Acoustic Waves in Microinhomogeneous Solids. Wiley.

Neild, S. a., Williams, M. S., \& McFadden, P. D. (2003). Nonlinear Vibration Characteristics of Damaged Concrete Beams. Journal of Structural Engineering, 129(2), 260-268.

Neville, A. (1987). Why We Have Concrete Durability Problems. In American Concrete Institute (Ed.), Katharine and Bryant Mather International Conference (Vol. Special Pu, pp. 21-30). Farmington Hills, Mich: American Concrete Institute.

Novak, A., Bentahar, M., Tournat, V., El Guerjouma, R., \& Simon, L. (2012). Nonlinear acoustic characterization of micro-damaged materials through higher harmonic resonance analysis. NDT \& E International, 45(1), 1-8.

Ostrovsky, L. A., \& Johnson, P. A. (2001a). Dynamic nonlinear elasticity in geomaterials. Rivista Del Nuovo Cimento, 24(7), 1-46.

Ostrovsky, L. A., \& Johnson, P. A. (2001b). Nonlinear dynamics of rock: Hysteretic behavior. Radiophysics and Quantum Electronics, 44(5-6), 487-501.

Park, S.-J., Park, G., Yim, H. J., \& Kwak, H.-G. (2015). Evaluation of residual tensile strength of fire-damaged concrete using a non-linear resonance vibration method. Magazine of Concrete Research, 67(5), 235-246.

Pasqualini, D., Heitmann, K., TenCate, J. a., Habib, S., Higdon, D., \& Johnson, P. a. (2007). Nonequilibrium and nonlinear dynamics in Berea and Fontainebleau sandstones: Lowstrain regime. Journal of Geophysical Research, 112(B1), B01204.

Payan, C., Garnier, V., \& Moysan, J. (2010). Effect of water saturation and porosity on the 
nonlinear elastic response of concrete. Cement and Concrete Research, 40(3), 473476.

Payan, C., Garnier, V., Moysan, J., \& Johnson, P. a. (2007). Applying nonlinear resonant ultrasound spectroscopy to improving thermal damage assessment in concrete. The Journal of the Acoustical Society of America, 121(4), EL125-L130.

Payan, C., Garnier, V., Moysan, J., \& Johnson, P. A. (2009). Determination of third order elastic constants in a complex solid applying coda wave interferometry. Applied Physics Letters, 94(1), 011904.

Pecorari, C. (2015). A constitutive relationship for mechanical hysteresis of sandstone materials. Proceedings of the Royal Society of London A: Mathematical, Physical and Engineering Sciences, 471(2184).

Pecorari, C., \& Mendelsohn, D. A. (2014). Forced Nonlinear Vibrations of a One-Dimensional Bar with Arbitrary Distributions of Hysteretic Damage. Journal of Nondestructive Evaluation, 33(2), 239-251.

Pecorari, C., \& Solodov, I. (2006). Nonclassical Nonlinear Dynamics of Solid Surfaces in Partial Contact for NDE Applications. In P. P. Delsanto (Ed.), Universality of Nonclassical Nonlinearity (pp. 309-326). Springer.

Powers, T. C. (1938). Measuring Young's Modulus of elasticity by means of sonic vibrations. In Proceedings ASTM (Vol. 38, p. 460).

Read, T. A. (1940). The Internal Friction of Single Metal Crystals. Physical Review, 58, $371-$ 380.

Reis, E. M., \& Dilek, U. (2012). Non-Destructive Evaluation and Laboratory Testing of a Concrete Structure Damaged by Fire. In Forensic Engineering 2012 (pp. 1159-1166). Reston, VA: American Society of Civil Engineers.

Renaud, G., Callé, S., \& Defontaine, M. (2009). Remote dynamic acoustoelastic testing: Elastic and dissipative acoustic nonlinearities measured under hydrostatic tension and compression. Applied Physics Letters, 94(011905), 1-4.

Renaud, G., Callé, S., Remenieras, J.-P., \& Defontaine, M. (2008). Exploration of trabecular bone nonlinear elasticity using time of flight modulation. IEEE Transactions on Ultrasonics, Ferroelectrics, and Frequency Control, 55(7), 1-10. 
Renaud, G., Rivière, J., Larmat, C., Rutledge, J. T., Lee, R. C., Guyer, R. A., ... Johnson, P. A. (2014). In situ characterization of shallow elastic nonlinear parameters with Dynamic Acousto-Elastic Testing. Journal of Geophysical Research: Solid Earth, 1-17.

Renaud, G., Talmant, M., Callé, S., Defontaine, M., \& Laugier, P. (2011). Nonlinear elastodynamics in micro-inhomogeneous solids observed by head-wave based dynamic acoustoelastic testing. The Journal of the Acoustical Society of America, 130(6), 3583.

Rivière, J., Renaud, G., Guyer, R. A., \& Johnson, P. A. (2013). Pump and probe waves in dynamic acousto-elasticity: Comprehensive description and comparison with nonlinear elastic theories. Journal of Applied Physics, 114(5), 054905.

Romer, A., Kim, J.-Y., Qu, J., \& Jacobs, L. J. (2016). The Second Harmonic Generation in Reflection Mode: An Analytical, Numerical and Experimental Study. Journal of Nondestructive Evaluation, 35(1), 6.

Rozière, E., Loukili, A., El Hachem, R., \& Grondin, F. (2009). Durability of concrete exposed to leaching and external sulphate attacks. Cement and Concrete Research, 39(12), 1188-1198.

Ryden, N. (2011). Resonant frequency testing of cylindrical asphalt samples. European Journal of Environmental and Civil Engineering, 15(4), 587-600.

Scalerandi, M., Gliozzi, A. S., \& Olivero, D. (2014). Discrimination Between Cracks and Recrystallization in Steel Using Nonlinear Techniques. Journal of Nondestructive Evaluation.

Scalerandi, M., Griffa, M., Antonaci, P., Wyrzykowski, M., \& Lura, P. (2013). Nonlinear elastic response of thermally damaged consolidated granular media. Journal of Applied Physics, 113(15), 154902.

Schurr, D. P., Kim, J.-Y., Sabra, K. G., \& Jacobs, L. J. (2011). Damage detection in concrete using coda wave interferometry. NDT \& E International, 44(8), 728-735.

Shah, A. A., Ribakov, Y., \& Hirose, S. (2009). Nondestructive evaluation of damaged concrete using nonlinear ultrasonics. Materials \& Design (Vol. 30).

Shokouhi, P., Zoëga, A., Wiggenhauser, H., \& Fischer, G. (2013). Surface Wave VelocityStress Relationship in Uniaxially Loaded Concrete. ACI Materials Journal, (109), 141- 
148.

Shui, G., Kim, J. Y., Qu, J., Wang, Y. S., \& Jacobs, L. J. (2008). A new technique for measuring the acoustic nonlinearity of materials using Rayleigh waves. NDT and $E$ International, 41(5), 326-329.

Snieder, R., Grêt, A., Douma, H., \& Scales, J. (2002). Coda wave interferometry for estimating nonlinear behavior in seismic velocity. Science (New York, N.Y.), 295(5563), 2253-2255.

Solodov, I. Y., \& Korshak, B. a. (2002). Instability, chaos, and "memory" in acoustic-wavecrack interaction. Physical Review Letters, 88(1), 014303.

Stauffer, J. D., Woodward, C. B., \& White, K. R. (2005). Nonlinear Ultrasonic Testing with Resonant and Pulse Velocity Parameters for Early Damage in Concrete. ACI Materials Journal, 102(2), 4-7.

Subramaniam, K. V, Goldstein, G., Popovics, J. S., \& Shah, S. P. (1999). Monitoring Crack Length in Concrete Beams using Resonance Measurements, 3586(March), 129-136.

Sutin, A. M., \& Nazarov, V. E. (1995). Nonlinear acoustic methods of crack diagnostics. Radiophysics and Quantum Electronics, 38(3), 109-120.

Swamy, N. R., \& Al-Asali, M. M. (1988). Engineering Properties of Concrete Affected by Alkali-silica Reaction. ACI Material Journal, 85(5), 367-374.

Ten Cate, J. a., Duran, J., \& Shankland, T. J. (2002). Nonlinearity and Slow Dynamics in Rocks : Response to Changes of Temperature and Humidity. In O. V. Rudenko \& 0. A. Sapozhnikov (Eds.), Nonlinear Acoustics at the Beginning of the 21st Century (Vol. 2, pp. 767-770). Moscow.

TenCate, J. A. (2011). Slow Dynamics of Earth Materials: An Experimental Overview. Pure and Applied Geophysics, 168(12), 2211-2219.

TenCate, J. A., Shankland, T. J., \& Johnson, P. A. (2006). Nonlinear Elastic Wave Experiments: Learning About the Behavior of Rocks and Geomaterials. In P. P. Delsanto (Ed.), Universality of Nonclassical Nonlinearity (p. 557). New York: Springer

TenCate, J., Smith, E., \& Guyer, R. (2000). Universal slow dynamics in granular solids. Physical Review Letters, 85(5), 1020-3. 
Thiele, S., Kim, J.-Y. Y., Qu, J., \& Jacobs, L. J. (2014). Air-coupled detection of nonlinear Rayleigh surface waves to assess material nonlinearity. Ultrasonics, 54, 1470-1475.

Van Damme, B., \& Van Den Abeele, K. (2014). The application of nonlinear reverberation spectroscopy for the detection of localized fatigue damage. Journal of Nondestructive Evaluation, 33(2), 263-268.

Van Den Abeele, K., \& De Visscher, J. (2000). Damage assessment in reinforced concrete using spectral and temporal nonlinear vibration techniques. Cement and Concrete Research, 30(9), 1453-1464.

Van Den Abeele, K. E. (1996). Elastic pulsed wave propagation in media with second- or higher-order nonlinearity. Part I. Theoretical framework Koen. Journal of the Acoustical Society of America, 99(May 1995), 3334-3345.

Van Den Abeele, K. E., Sutin, A., Carmeliet, J., \& Johnson, P. a. (2001). Micro-damage diagnostics using nonlinear elastic wave spectroscopy (NEWS). NDT \& E International, 34(4), 239-248.

Van Den Abeele, K. E., Van de Velde, K., \& Carmeliet, J. (2001). Inferring the Degradation of Pultruded Composites From Dynamic Nonlinear Resonance Measurements. Polymer Composites, 22(4), 555-567.

Van Den Abeele, K. E.-A., Carmeliet, J., Ten Cate, J. A., \& Johnson, P. A. (2000). Nonlinear Elastic Wave Spectroscopy (NEWS) Techniques to Discern Material Damage, Part II: Single-Mode Nonlinear Resonance Acoustic Spectroscopy. Research in Nondestructive Evaluation, 12(1), 31-42.

Van Den Abeele, K. E.-A., Johnson, P. A., Guyer, R. A., \& McCall, K. R. (1997). On the quasi-analytic treatment of hysteretic nonlinear response in elastic wave propagation. The Journal of the Acoustical Society of America.

Van Den Abeele, K. E.-A., Johnson, P. A., \& Sutin, A. (2000). Nonlinear Elastic Wave Spectroscopy (NEWS) Techniques to Discern Material Damage, Part I: Nonlinear Wave Modulation Spectroscopy (NWMS). Research in Nondestructive Evaluation, 12(1), 17-30.

Van Den Abeele, K., Le Bas, P.-Y., Van Damme, B., \& Katkowski, T. (2009). Quantification of material nonlinearity in relation to microdamage density using nonlinear reverberation spectroscopy: Experimental and theoretical study. The Journal of the 
Acoustical Society of America, 126(3), 963-72.

Yan, D., Drinkwater, B. W., \& Neild, S. a. (2009). Measurement of the ultrasonic nonlinearity of kissing bonds in adhesive joints. NDT and E International, 42(5), 459-466.

Zaitsev, V. Y., Matveev, L. a., \& Matveyev, a. L. (2011). Elastic-wave modulation approach to crack detection: Comparison of conventional modulation and higher-order interactions. NDT and E International, 44(1), 21-31.

Zaitsev, V. Y., Matveev, L. A., \& Matveyev, A. L. (2009). On the ultimate sensitivity of nonlinear-modulation method of crack detection. NDT and E International, 42(7), 622629.

Zaitsev, V. Y., Sutin, A., Belyaeva, I. Y., \& Nazarov, V. (1995). Nonlinear interaction of acoustical waves due to cracks and its possible usage for cracks detection. Journal of Vibration and Control, 1(3), 335-344.

Zarembo, L. K., Krasil'nikox, V. A., \& Shkol'nik, I. E. (1989). Nonlinear acoustics in a problem of diagnosing the strength of solids. Problemy Prochnosti, 11, 86-92.

Zheng, Y., Maev, R. G., \& Solodov, I. Y. (1999). Nonlinear acoustic applications for material characterization : A review. Canadian Journal of Physics, 77, 927-967. 


\section{Chapter 2. Materials and methods}



Unless that specifically stated within every chapter, the experimental details described herein concern the specimens and vibration techniques used in the chapters 3 to 6 . More detailed description on the experimental details is provided in every chapter.

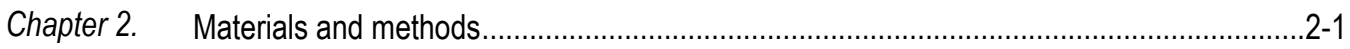

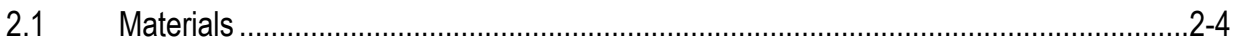

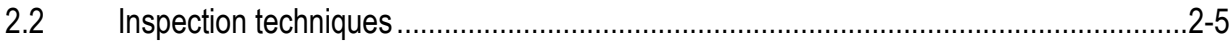

2.2.1 Standard methods ................................................................................... 2-5

2.2.2 Nonlinear Impact Resonance Acoustic Spectroscopy ....................................2-7

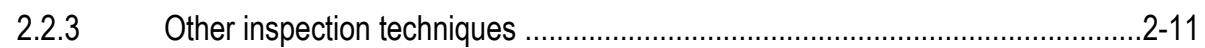

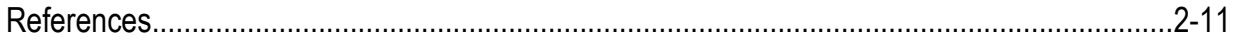




\subsection{Materials}

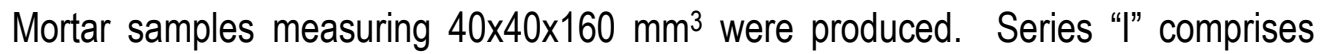
samples with aggregate to cement ratio $(a / c)$ of 3 with water to cement ratio $(w / c)$ varying from 0.40 to 0.65 . Series "II" comprises samples with $a / c$ of 1 with $w / c$ varying from 0.25 to 0.45. The Portland cement used was type CEM II 42.5R/A-L. A siliceous aggregate was used with sieve size distribution following the recommendation in the standard EN 196-1 (EN 196$1,2005)$. The lowest $w / c$ samples (I-0.40 and II- 0.25$)$ were prepared with a $1 \%$ by weight of a sulphonated melamine-based superplasticizer to obtain a workable consistency. Dry bulk density and open porosity were determined from saturated, immersed and dried weights. Three samples per type of mortar were produced to determine bending and compressive strengths at the age of 28 days after mixing, according to EN 196-1 (EN 196-1, 2005). Table 0-1 lists mortar designations, mix proportions and physical properties such as slump (EN 1015-3, 2000), open porosity, dry bulk density and compressive strength at 28 days.

Table 2-1 Mortar designation, mixture proportions (cement:water:sand, C:W:S) and physical properties in fresh and hardened states.

\begin{tabular}{|c|c|c|c|c|c|c|}
\hline & C:W:S & Slump, mm & $\begin{array}{l}\text { Dry bulk } \\
\text { density, } \\
\mathrm{g} / \mathrm{cm}^{3}\end{array}$ & $\begin{array}{l}\text { Open } \\
\text { porosity, \% }\end{array}$ & $\begin{array}{l}\text { Flexural } \\
\text { strength, } \\
\mathrm{MPa}\end{array}$ & $\begin{array}{l}\text { Compressive } \\
\text { strength, } \\
\mathrm{MPa}\end{array}$ \\
\hline I-040 & $1: 0.40: 3$ & $131 \pm 5$ & $2.14 \pm 0.01$ & $11.4 \pm 0.5$ & $6.2 \pm 1.2$ & $65.41 \pm 1.84$ \\
\hline I-045 & $1: 0.45: 3$ & $120 \pm 5$ & $2.12 \pm 0.01$ & $12.9 \pm 0.6$ & $5.6 \pm 0.5$ & $54.86 \pm 2.98$ \\
\hline I-050 & $1: 0.50: 3$ & $155 \pm 9$ & $2.06 \pm 0.01$ & $15.0 \pm 0.4$ & $4.4 \pm 0.2$ & $53.85 \pm 1.36$ \\
\hline 1-055 & $1: 0.55: 3$ & $190 \pm 11$ & $2.05 \pm 0.01$ & $17.2 \pm 0.3$ & $5.9 \pm 1.2$ & $52.65 \pm 1.84$ \\
\hline I-060 & 1:0.60:3 & $222 \pm 11$ & $2.05 \pm 0.01$ & $18.0 \pm 0.5$ & $5.3 \pm 0.7$ & $49.97 \pm 2.35$ \\
\hline I-065 & 1:0.65:3 & $245 \pm 6$ & $2.03 \pm 0.02$ & $19.3 \pm 0.8$ & $7.3 \pm 0.7$ & $40.30 \pm 2.96$ \\
\hline II-025 & $1: 0.25: 1$ & $150 \pm 6$ & $2.21 \pm 0.01$ & $8.7 \pm 0.8$ & $15.3 \pm 0.4$ & $83.04 \pm 3.55$ \\
\hline$\| 1-030$ & 1:0.30:1 & $146 \pm 6$ & $2.17 \pm 0.01$ & $10.3 \pm 1.3$ & $11.9 \pm 1.3$ & $74.93 \pm 3.48$ \\
\hline II-035 & 1:0.35:1 & $187 \pm 6$ & $2.05 \pm 0.01$ & $17.4 \pm 1.0$ & $13.5 \pm 0.3$ & $68.14 \pm 2.00$ \\
\hline II-040 & $1: 0.40: 1$ & $225 \pm 8$ & $2.03 \pm 0.01$ & $18.3 \pm 0.4$ & $10.5 \pm 0.2$ & $62.25 \pm 2.28$ \\
\hline II-045 & 1:0.45:1 & $246 \pm 8$ & $1.96 \pm 0.01$ & $21.9 \pm 1.3$ & $9.4 \pm 0.9$ & $57.31 \pm 2.52$ \\
\hline
\end{tabular}




\subsection{Inspection techniques}

\subsubsection{Standard methods}

\subsubsection{Resonant frequency method}

The resonant frequency test was conducted according to the standard ASTM C215 (ASTM C215-14). The test was configured to promote the first bending mode of vibration. To this end, the sample was supported at its nodal points -as shown in Figure 2-1a-. An alumina ball (diameter $15 \mathrm{~mm}$ ) was dropped onto the sample from a height of $12 \mathrm{~cm}$. An accelerometer (PCB model 352A21 with a sensitivity of $0.956 \mathrm{mV} /\left(\mathrm{m} . \mathrm{s}^{-2}\right)$ ) attached to the sample sensed the vibration. The signals were acquired with an USB-oscilloscope tool Easysync with 12-bits of vertical resolution. The signals were acquired with 8192 samples and a sample frequency of $50 \mathrm{kHz}$. Figure 2-1b shows typical recorded signals on mortar samples $\left(40 \times 40 \times 160 \mathrm{~mm}^{3}\right)$.
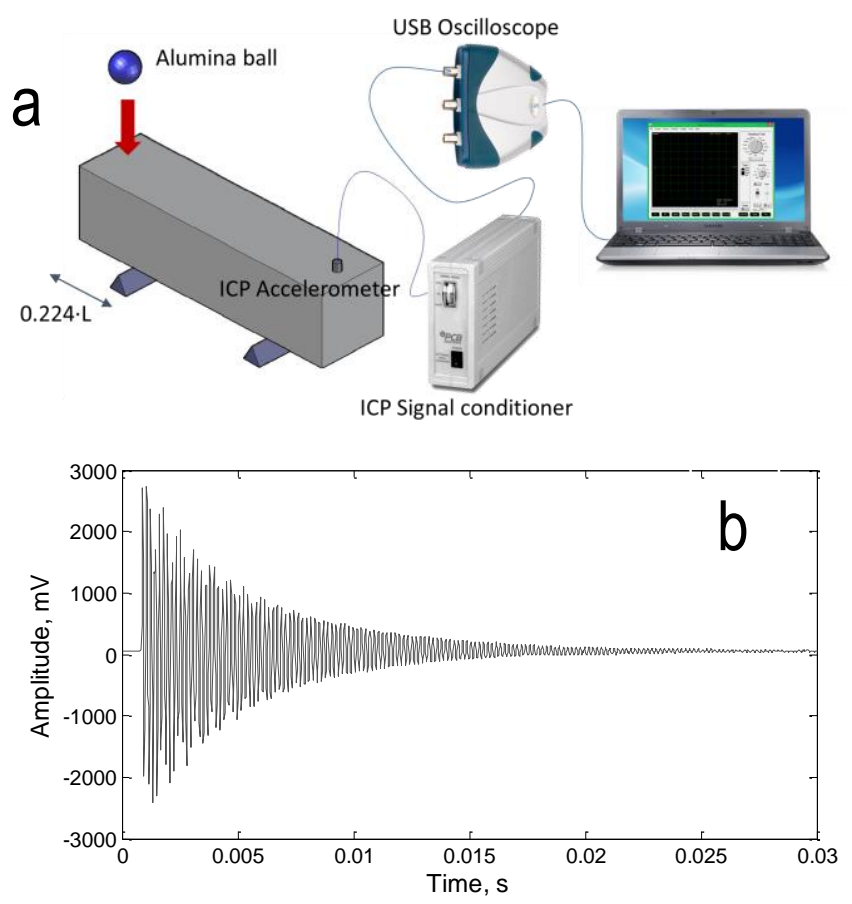

Figure 2-1 a) Schematic representation of the resonant frequency test, and b) typical recorded signals on prismatic $\left(40 \times 40 \times 160 \mathrm{~mm}^{3}\right)$ mortar samples 


\subsubsection{Measurement of dynamic modulus}

From standard resonance vibration test the dynamic bending modulus of elasticity $\left(E_{d}\right)$ can be ascertained. From the transverse frequency $\left(f_{f}\right)$, density $(\rho)$, length $(L)$ and radius of gyration $(t)$ the $E_{d}$ can be obtained as (ASTM E1876, 2009)

$$
E_{d}=\frac{4 \pi^{2} \cdot L^{4} \cdot f_{f}^{2} \cdot \rho \cdot C}{4.73^{4} \cdot t^{2}}
$$

wherein $C$ is a correction factor that depends on sample dimensions and Poisson's ratio $(v)$. The theory relating the resonant frequencies to the dynamic modulus of prismatic samples is approximate and errors of the order of $1 \%$ are inherently present in the equations (Etcheverry \& Sánchez, 2009). In addition, the values of dynamic modulus also depend on the accuracy of the measured density, sample dimensions and Poisson's ratio (v). For our given sample dimensions $\left(40 \times 40 \times 160 \mathrm{~mm}^{3}\right)$, the correction factor $C$ varies between 1.40 and 1.42 , for $v$ between 0.20 and 0.30 .

\subsubsection{Measurement of damping}

The mechanical energy losses were determined through the quality factor $(Q)$, which is defined as the ratio between the resonance frequency peak $\left(f_{i}\right)$, and the bandwidth frequencies $\left(f_{i, b}\right.$ and $\left.f_{i, a}\right)$ corresponding to a $50 \%$ reduction of vibration energy in the power frequency spectrum (Malhotra \& Sivasundaram, 2004). The value of $Q$ is obtained from the shape of resonant frequency spectrum as

$$
Q=\frac{f_{i}}{f_{i, b}-f_{i, a}} .
$$




\subsubsection{Nonlinear Impact Resonance Acoustic Spectroscopy}

\subsubsection{Test configuration}

The Nonlinear Impact Resonant Acoustic Spectroscopy (NIRAS) test consists in to investigate the dynamic response of samples at increasing levels of impact energy. For the NIRAS tests, an instrumented hammer (model Brüel \& Kjær 8206, $22.7 \mathrm{mV} / \mathrm{N}$ ) was used to strike the samples at ten different energy levels. To this end, an instrumented hammer mounted in a frame acts as a pendulum under the force of gravity and strikes the sample. Ten impacts of incremental increasing energy were registered at each test. The relative position between impact and accelerometer allows investigation of the first bending and longitudinal resonant modes of vibration. Longitudinal and flexural modes are normally used to evaluate concrete samples with the standard methods, so the response of both is of interest. The impact excitation was sensed with an accelerometer (PCB model 352A21 and

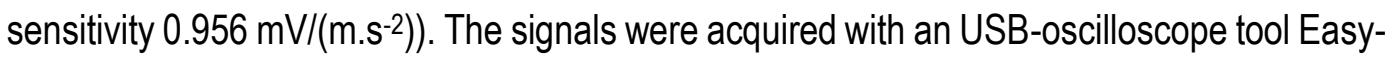
sync. The signals were acquired with 8192 points and a sampling frequency of $50 \mathrm{kHz}$. Figure 2-2 shows three photos a general overview, a schematic representation of the test configuration, typical hammer load step, and the resulting frequency spectra showing two fundamental resonant peaks: first bending and longitudinal modes of vibration 

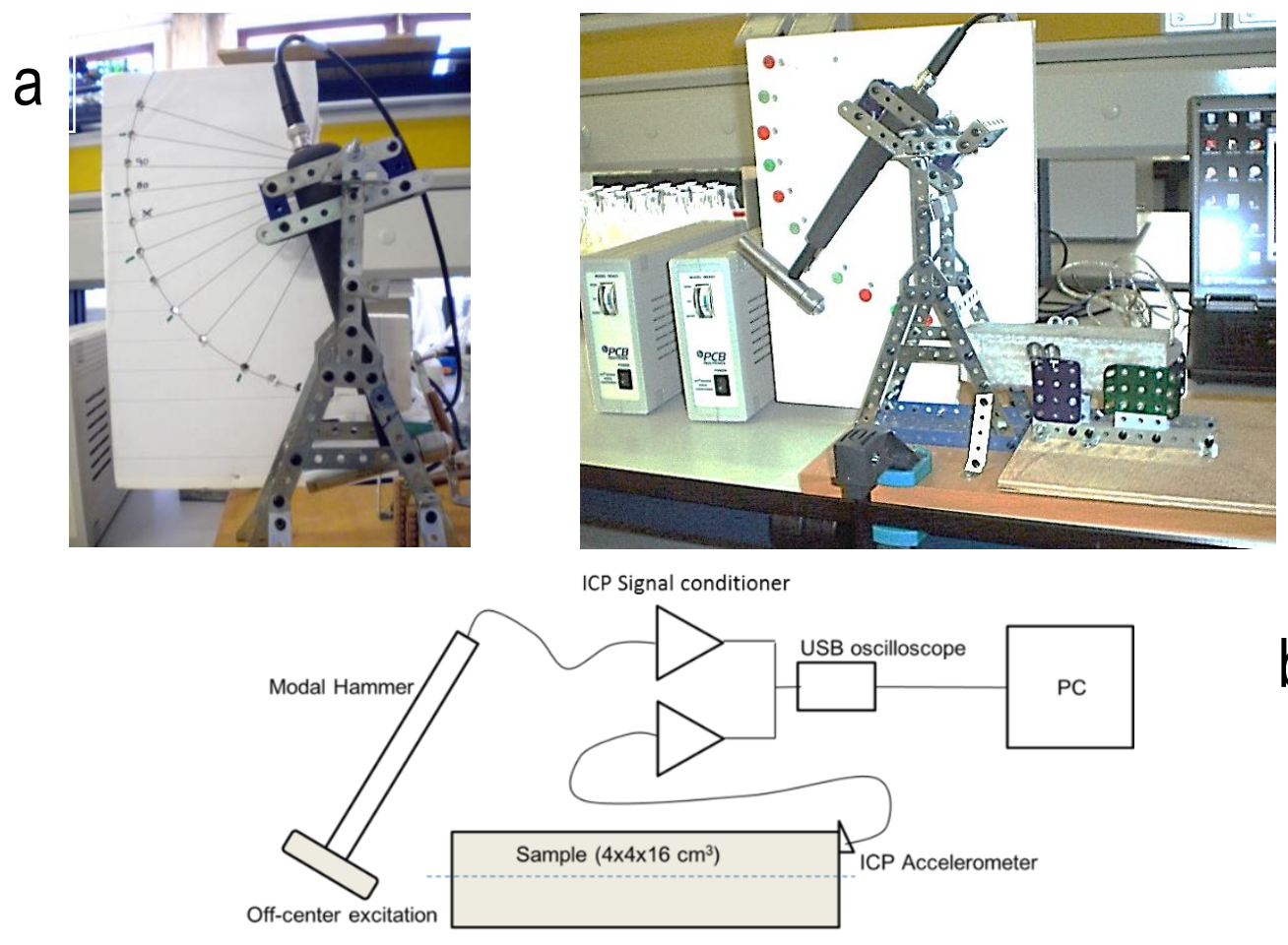

b
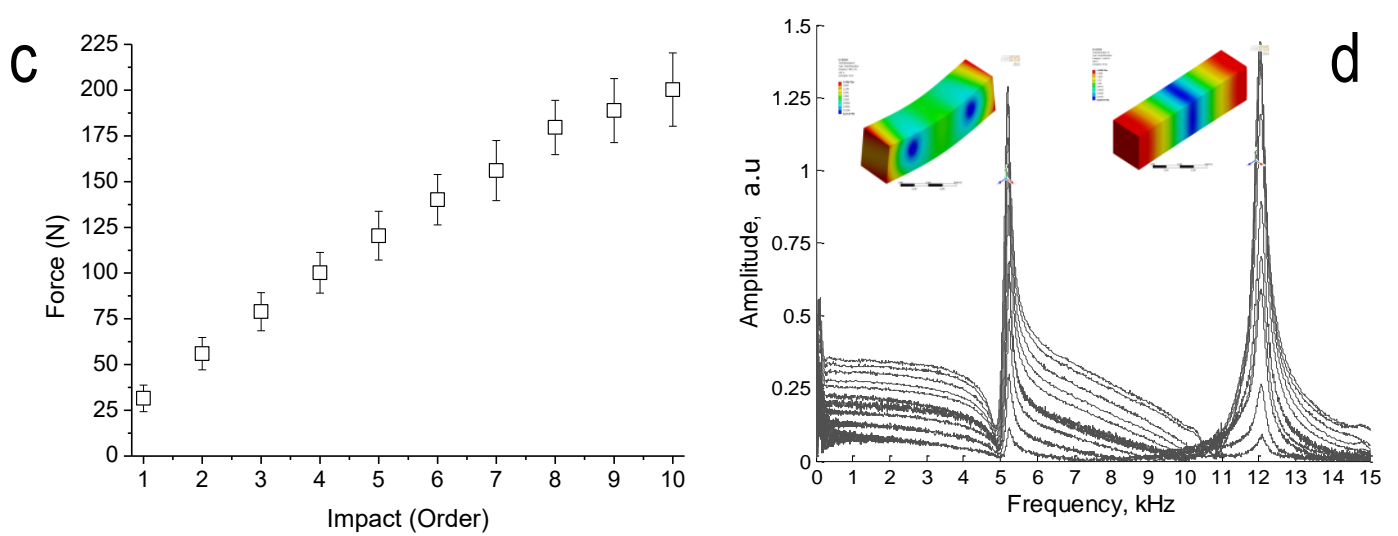

Figure 2-2.a) General overview of the test configuration and sample disposition, and b) schematic setup for NIRAS. Note off-center impact location and sensing in the sample, c) typical incrementally increasing hammer load values applied to samples, and d) typical received frequency spectra showing flexural $(5-6 \mathrm{kHz})$ and longitudinal (11-13 kHz) resonance modes; inset images illustrate respective modal vibration shapes of each mode obtained by eigen-frequency analysis. 
The presence of defects within the complex microstructure of cement based materials across a range of length scales (microcracks, porosity, interfacial transition zones, etc.) gives rise to so called non-classical nonlinear phenomena (Guyer \& Johnson, 1999). With such behavior, a nonlinear constitutive parameter should be used to describe hysteresis in the stress-strain relationship. In resonance vibration tests, the nonlinear hysteretic behavior typical of concrete and mortar manifests as a down shift of resonance frequency value with an increase in vibration energy (normally represented as dynamic strain) amplitude; this is also referred to as the "fast dynamics" effect. The normalized down shift of the resonance frequency $\left(\Delta f / f_{0}\right)$ is proportional to the strain amplitude $(\Delta \varepsilon)$ within a given dynamic range (Johnson \& Sutin, 2005). The proportionality constant is referred as the hysteretic parameter $\alpha$-see Chapter 1 Introduction, subsections 1.1 Motivation and scope, and 1.3.3 Nonlinear resonant techniques-. The strain amplitude can be estimated from the measured acceleration using a numerical eigen-frequency solution of the prismatic sample (Payan, Ulrich, Le Bas, Saleh, \& Guimaraes, 2014). However, the amplitude and frequency values obtained from the Fast Fourier Transform algorithm are weighted averaged values of the actual acceleration amplitude. In NIRAS experiments, the hysteretic behavior is investigated using a relationship that relates the normalized frequency shift to the spectral amplitude $(A)$ as

$$
\frac{\Delta f}{f_{o}}=\eta \cdot A
$$

where $f_{0}$ is a low amplitude linear resonance frequency value that is used as a comparative standard, and is normally set to that frequency obtained for the lowest excitation level. The parameter $\eta$ is a relative hysteretic parameter measured in arbitrary units (a.u.), and is proportional to the dimensionless parameter $\alpha$. Regrettably, the relative characteristic of the parameter $\eta$ impedes the comparison of the hysteretic behavior among the yet reported studies -this issue is further discussed in the Chapters 8, 9, and 12-. Likewise, the amplitude-dependent attenuation because of the mechanical hysteretic behavior can be investigated as 
$\frac{1}{Q_{o}}-\frac{1}{Q_{i}}=\eta_{Q} \cdot A$

where $Q$ is the quality factor obtained at increasing impact energy levels, and $Q_{0}$ is the quality factor obtained for the lowest impact energy event.

\subsubsection{Comparison between NIRAS and standard ASTM C215 methods}

The particular boundary conditions, and the relative position between impact and sensing used in the NIRAS test differ from those instructed in the standard method (ASTM C215-14, 2014) - see Figure 2-2-. To determine if the resonant frequency and $Q$ data are affected by the test configuration an Analysis of Variance (ANOVA) was conducted. The resonant frequency and $Q$ data corresponding to a three mortar samples with $w / c$ of 0.50 were selected. Three signals per method were registered for every mortar sample. From NIRAS tests, only the lowest impact energy values were selected. Figure 2-3a and 2-3b show the mean value and the 95\% Tukey's HSD (honest significant difference) intervals. The results show that the values of flexural frequency (F1FLEX) are similar to those obtained using the standard method. Conversely, the values of $Q$ are affected by the test configuration.
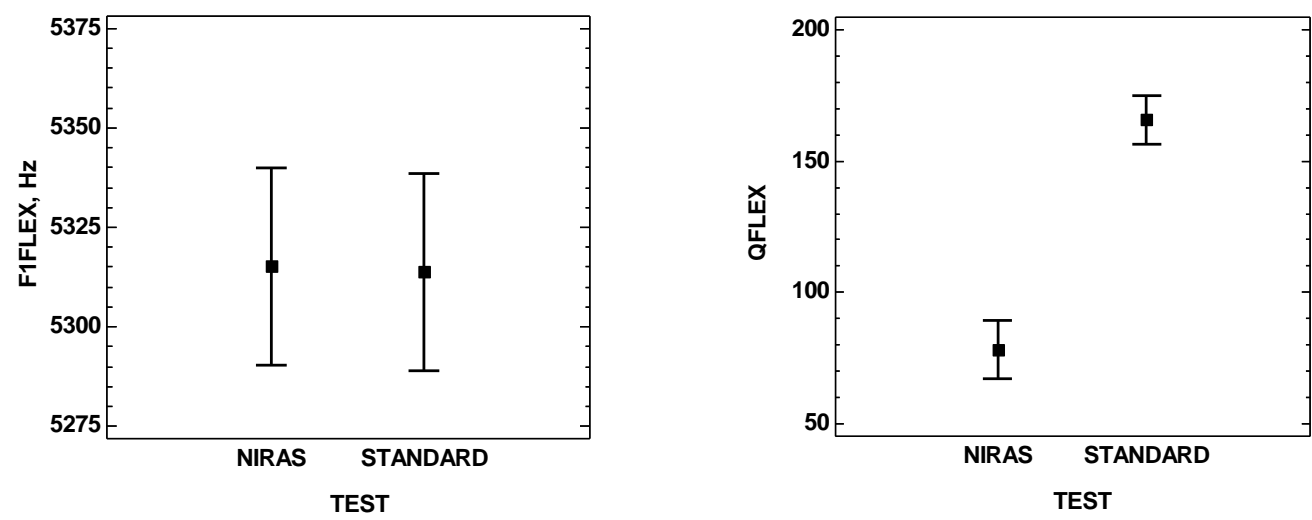

Figure 2-3. Mean and HSD intervals obtained for a) resonant frequency values (F1FLEX), and b) quality factor (Q), in NIRAS and standard methods. 


\subsubsection{Other inspection techniques}

\subsubsection{Scanning electron microscopy (SEM)}

Morphological examination of the samples was conducted with a JEOL JSM-6300 scanning electron microscope.

\subsubsection{Compressive strength}

The flexural and compressive strength of the mortars was ascertained according to EN 196-1 (EN 196-1, 2005).

\section{References}

ASTM C215-14. (2014). Standard Test Method for Fundamental Transverse , Longitudinal , and Torsional Resonant Frequencies of Concrete.

ASTM E1876. (2009). Standard Test Method for Dynamic Young's Modulus, Shear Modulus , and Poisson's Ratio by Impulse Excitation of Vibration.

EN 1015-3. (2000). Methods of test for mortar for masonry. Part 3: determination of consistence of fresh mortar (by flow table). Madrid (Spain): AENOR.

EN 196-1. (2005). Methods of testing cement. Part 1: determination of strength. Madrid (Spain): AENOR.

Etcheverry, J. I., \& Sánchez, G. A. (2009). Resonance frequencies of parallelepipeds for determination of elastic moduli: An accurate numerical treatment. Journal of Sound and Vibration, 321(3-5), 631-646.

Guyer, R. A., \& Johnson, P. A. (1999). Nonlinear Mesoscopic Elasticity: Evidence for a New Class of Materials. Physics Today, 52(4), 30-36.

Johnson, P., \& Sutin, A. (2005). Slow dynamics and anomalous nonlinear fast dynamics in diverse solids. The Journal of the Acoustical Society of America, 117(1), 124.

Malhotra, V. M., \& Sivasundaram, V. (2004). Resonant Frequency Methods. In Handbook 
on Nondestructive Testing of Concrete (pp. 167-188).

Payan, C., Ulrich, T. J., Le Bas, P. Y., Saleh, T., \& Guimaraes, M. (2014). Quantitative linear and nonlinear resonance inspection techniques and analysis for material characterization: Application to concrete thermal damage. The Journal of the Acoustical Society of America, 136, 537. 


\section{Chapter 3. Effect of drying and internal moisture content (I)}




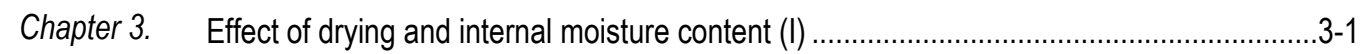

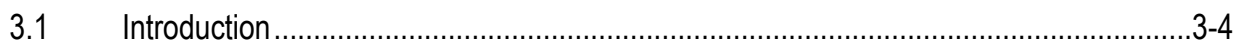

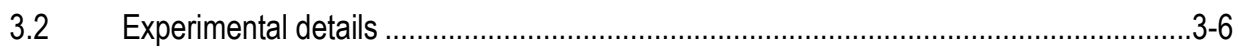

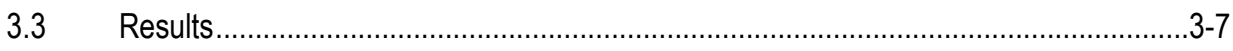

Conclusions …............................................................................................

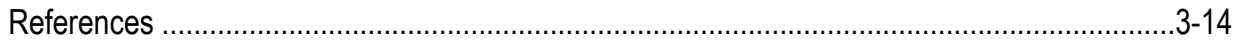




\subsection{Introduction}

Porous solids, such as cement-based materials, swell and shrink upon varying internal moisture content, resulting in dimensional changes and tensile stresses that can promote internal cracking (Chatterji, 2008). Two principal mechanisms cause internal moisture changes. The first is that caused by autogenous shrinkage that occurs during cement hydration, what especially occurs in low water to binder ratio mixtures (e.g. $<0.40)$ (Jensen $\&$ Hansen, 2001). The second is that caused by the removal of water from the cement matrix pore structure driven by external evaporation what causes significant volumetric shrinkage of the material, and whose main mechanisms are disjoining pressure, capillary pressure and changes in surface free energy (Scherer, 1990). Both mechanisms cause a reduction of internal moisture and significant volumetric shrinkage of the material, which can promote internal cracking that depends on the external geometrical restraint conditions of the sample (Hossain \& Weiss, 2006), the exposure conditions (Jiang, Yang, Wang, Zhou, \& Ma, 2014), and the aggregate content and properties (Alrifai, Aggoun, Kadri, Kenai, \& Kadri, 2013; Bisschop \& van Mier, 2002; Pickett, 1956; Zhang, Zakaria, \& Hama, 2013). Moreover, because outer surfaces dry faster, moisture gradients that lead into tensile cracking can be produced, which in turn will be enhanced in those materials with lower diffusion rates. As a result of the internal pressure and volume changes produced upon varying moisture content, the constitutive properties of the material are affected. In concrete-like materials, the compressive and tensile strength decreases, whereas static and dynamic modulus and Poisson's ratio increases with water saturation (Burlion, Bourgeois, \& Shao, 2005; Rossi, Mier, Boulay, \& Maou, 1992; Skoczylas, Burlion, \& Yurtdas, 2007; Yaman, Hearn, Aktan, \& Yaman, 2002).

External evaporation can also promote microstructural modification within cement based materials. For example, some hydrated phases such as ettringite begin to degrade at drying temperatures of $60^{\circ} \mathrm{C}$ (Galan, Beltagui, García-Maté, Glasser, \& Imbabi, 2016). In 
addition, drying is known to increase the surface energy that results in increased bonding between particles of C-S-H, even in the absence of shrinkage cracking, under moderate oven drying temperatures (at and below $105^{\circ} \mathrm{C}$ ) (Kanna, Olson, \& Jennings, 1998). Moreover, Moukwa and Aitcin (1988) demonstrated that cement paste samples oven dried at $105^{\circ} \mathrm{C}$ showed an increase in capillary-sized porosity (mainly in the range from 0.01 to 0.1 $\mu \mathrm{m})$, but no obvious signs of microcracking, where this effect became more prevalent with decreasing w/c. Gallé (2001) confirmed the findings of Moukwa and Aitcin for oven dried cement pastes, and further observed similar behavior in concrete samples, but at lower oven drying temperatures $\left(60^{\circ} \mathrm{C}\right)$.

The cracking potential of cement-based materials owing to drying is commonly assessed by dilatometry based techniques, such as the ring test (Gao, Zhang, \& Han, 2013; Zou \& Weiss, 2014). Acoustic emission-based monitoring has also been successfully applied to monitor microstructural changes in cement-based materials owing to cement hydration and setting (Lura, Couch, Jensen, \& Weiss, 2009; K. Van Den Abeele, Desadeleer, De Schutter, \& Wevers, 2006), and drying (Nadeau, Bennett, \& Mindess, 1980). Although acoustic emission can be used to monitor active transient events related to hydration, setting and drying, the method cannot be applied to assess a sample after the specific processes have occurred; thus the method is unable to characterize the existing damage level in a sample in situ, or to derive constitutive properties of the material. Mechanical wave methods, such as ultrasonic pulse velocity or vibration resonance, are sensitive to internal damage and constitutive properties in cement-based materials (Naik \& Popovics, 2004). However, conventional methods based on linear mechanical wave propagation have rarely been used to monitor the microstructural changes owing to desiccation, most likely because of the high degree of sensitivity needed to detect such subtle characteristics in the materials.

In this chapter, it is further investigated the utility of nonlinear mechanical vibration based nondestructive tests to detect the global material effects, including both subtle shrinkage microcracking and microstructural modification, produced in cement-based 
materials upon drying. For more comprehensive analysis, linear and nonlinear vibration results are considered. Because of the bulk shrinkage of the material upon drying, linear and nonlinear constitutive parameters are expected to be sensitive to the aforementioned material modifications. Mortar samples with varying aggregate to cement ratio and water to cement ratio were subjected to an oven drying process at $60^{\circ} \mathrm{C}$. An oven drying temperature of $60^{\circ} \mathrm{C}$ is commonly used to determine moisture content, dry bulk density, or as pretreatment to other test procedures, despite the fact that this process is suspected to cause some degradation of hydrated phases, increased amounts of capillary porosity, and subtle microcracking (Collier, Sharp, Milestone, Hill, \& Godfrey, 2008; Galle, 2001; Kanna et al., 1998; Moukwa \& Aitcin, 1988; Snoeck et al., 2014). The samples with very low water to binder ratio are expected to exhibit exacerbated cracking, either because of enhanced autogenous shrinkage or non-uniform drying because of their lower diffusion rate. Furthermore, these processes concerning microcracking shrinkage are expected to be further enhanced in low aggregate to cement mortar samples (Pickett, 1956).

\subsection{Experimental details}

Mortar samples of dimension $40 \times 40 \times 160 \mathrm{~mm}^{3}$ and with varying composition were produced. Series "l" comprises samples with aggregate to cement ratio $(a / c)$ of 3 with water to cement ratio $(w / C)$ varying from 0.40 to 0.65 . Series "Il" comprises samples with a/c of 1 with w/c varying from 0.25 to 0.45 -see Chapter 2 Materials and methods-. The samples were tested at two moisture conditions: fully saturated and oven dried. All samples were immersed in $20^{\circ} \mathrm{C}$ water for more than 28 days after mixing. Under these conditions, the pore structure of the mature mortar is expected to be fully saturated with water. The samples were removed from the water bath and subjected to linear vibration (ASTM C215-14, 2014) and NIRAS tests - see Chapter 2 for detailed description on the NIRAS test-, while maintaining saturated material conditions. Then the samples were oven-dried at $60^{\circ} \mathrm{C}$ until stable mass 
$( \pm 1 \mathrm{~g})$, removed from the oven, allowed to cool naturally over 24 hours at room temperature and ambient relative humidity, and then subjected to linear vibration and NIRAS tests again.

\subsection{Results}

Figure 3-1a shows the values of $E_{d}$ as a function of $w / c$ at the saturated and dried states. It can be seen that $E_{d}$ decreases with increasing $w / c$ regardless of internal moisture condition and mixture composition, confirming expected behavior (Malhotra \& Sivasundaram, 2004). The change of $E_{d}$ with respect to moisture removal with drying was found to be dependent on both $w / c$ and $a / c$. To better understand this behavior, the relative reduction of $E_{d}(R E)$ after oven drying can be expressed as

$$
R E=\left(1-\frac{E_{d_{(s=0)}}}{E_{d_{(s=1)}}}\right)
$$

where $E_{d(s=1)}$ is the dynamic modulus in the pristine saturated state, and $E_{d(s=0)}$ that after oven drying. Figure 3-1b shows values of the relative reduction of $E_{d}(R E)$ after drying. Except for the $w / c=0.25$ sample, the results demonstrate that higher $w / c$ mortars experience more reduction in $E_{d}$ after drying for a given a/c value. Similar behavior has been reported for static modulus of elasticity measured on mortars with different $w / c$ content after drying (Yurtdas, Peng, Burlion, \& Skoczylas, 2006), and most plausibly is a result of the increased capillary porosity content obtained with increasing w/c. The work of Yaman et al. (Yaman et al., 2002) observed that the reduction of both static and dynamic moduli upon drying of concrete samples is chiefly dominated by capillary porosity, referred as active porosity therein.

The moisture inside of a pore network affects the measured global stiffness of the material. This pore water-induced stiffening effect appears to be dependent on pore size distribution, where capillary-sized pore networks demonstrate a strong influence on such 
behavior (K. E.-A. Van Den Abeele, Carmeliet, Johnson, \& Zinszner, 2002; Yaman et al., 2002; Yurtdas et al., 2006). The results shown in Figure 3-1b demonstrate that the reduction of dynamic modulus upon drying is also dependent on a/c. In particular, the values of $R E$ obtained on mortars with $a / c$ of 3 are greater than those obtained on mortars with $a / c$ of 1 , and for a given a/c pairwise mean comparison (computations not shown here for brevity) shows statistical distinction between relatively low $\mathrm{w} / \mathrm{c}$ and higher ones at significance level of $95 \%$. For instance, mortars I-060 and II-040 have similar open porosity of about $18 \%$, though the $R E$ values are $15 \%$ and $7.5 \%$, respectively. The presence of aggregates endows a more open pore structure at the interfacial transition zone (ITZ), compared with the bulk cement paste (Winslow, Liu, \& Lafayette, 1990), such that the volume of capillary-sized pore networks increases with increasing aggregate content (Winslow, Cohen, Bentz, Snyder, \& Garboczi, 1994). Therefore, greater values of $R E$ for mortars with $a / c=3$ as compared with those with $a / c=1$ can be attributed to the expected increased capillary and ITZ pore volume that is expected from increased aggregate volume.
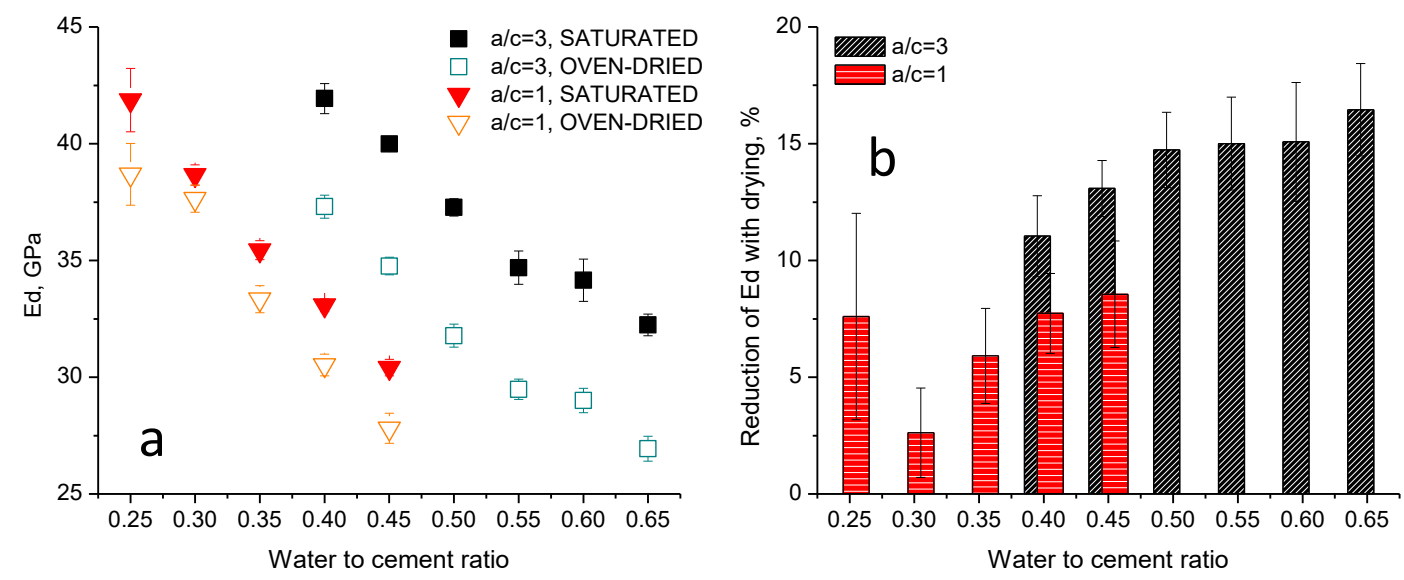

Figure 3-1 a) Variation of $E_{d}$ (measured using flexural resonance according to ASTM C215) with w/c of pristine saturated samples, and again after oven drying, b) RE\% for varying w/c. Error bars indicate standard deviation. 
The Figure 3-2a and Figure 3-2b show $Q$ data (inverse attenuation) for mortar as function of $w / c$ and $a / c$, for saturated and oven-dried conditions, respectively. The relative reduction of $Q(R Q)$ after oven drying is expressed as

$$
R Q=\left(1-\frac{1 / Q_{(s=0)}}{1 / Q_{(s=1)}}\right)
$$

where $Q_{s=1}$ is the $Q$ in the pristine saturated state, and $Q_{s=0}$ that after oven drying. At saturated conditions (Figure 3-2a) mortars exhibited a slight inverse relation between $w / c$ and $Q$, for both $a / c$ values. Studies have proposed that the magnitude of damping is directly related to the volume of water filled pores (Swamy \& Rigby, 1971). However, this phenomenon appears to be quite minor, as the change in $Q$ value across $w / c$ values is relatively small, and nearly insignificant. When the samples are oven-dried and all free water is removed, the dependence of $Q$ with $w / c$ reverses sense (Figure 3-2b). Amick and Monteiro (Amick \& Monteiro, 2006) found that damping in concrete increases (that is, $Q$ decreases) with $w / c$ for relatively early age (4-week old) concrete, but then decreases with $w / c$ for relatively mature (18-week old) concrete. Amick and Monteiro attributed this behavior to the lower internal moisture content in the mature samples owing to the completion of hydration (self-desiccation), and the resulting switch of dominating damping mechanism type from viscous to Coloumb. The results presented in Figure 3-2b suggest that lower w/c mortars developed more microcracks upon drying, and hence display an inverse relation between $Q$ and $w / c$. 

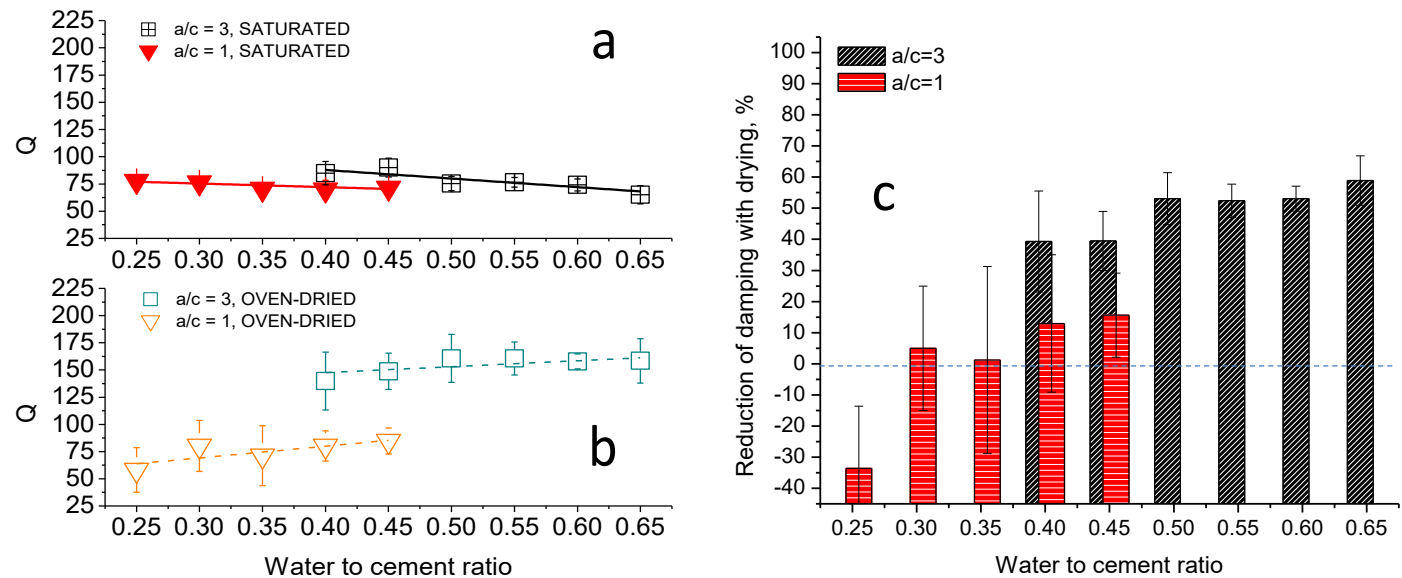

Figure 3-2 Damping properties (measured using flexural resonance according to ASTM C215) versus w/c for a) saturated, and b) oven dried samples; continuous and dashed lines illustrate the shift from inverse towards direct proportionality after drying, c) $R Q$ for varying w/c. Error bars indicate standard deviation.

Although the $Q$ data exhibited higher amounts of variability, a linear regression analysis demonstrates a statistically relevant relation between $w / c$ and $Q$, although the relations are not strong enough for predictive purposes $\left(R^{2<0.5}\right)$. Table 3-1 summarizes the linear regression results. In general, $Q$ values of mortars at saturated state are lower than those after oven drying. However, the samples with w/c $=0.25$ show lower $Q$ values upon drying; this behavior is discussed further in the Discussion section below. With the exception of the $w / c=0.25$ samples, the relative increase of $Q$ after oven drying depends, slightly, on $w / c$ and, more significantly, on $a / c$ as seen in Figure 3-2c. The increase in $Q$ with drying is proportional to the $w / c$ for both values of $a / c$. For $a / c=3$ samples, the increase in $Q$ with drying is significant, while for $a / c=1$ samples the increase in $Q$ with drying is modest, and nearly insignificant. The relatively modest increase in $Q$ for dried mortars with $a / c=1$ can be attributed to increased microcracking shrinkage, which is especially expected in these mortars after the heat treatment. which offsets the damping reduction (that is $Q$ increase) expected from the reduction of internal moisture content. 
3- Effect of drying and internal moisture content (I)

Table 3-1 Linear regression results for the relation $Q=$ Intercept + Slope $(w / c)$.

\begin{tabular}{|llrrrr|}
\hline Mortar & Treatment & \multicolumn{1}{c}{ Intercept } & Slope & $\mathbf{R}^{2}$ & \multicolumn{2}{c|}{$\mathbf{p}$-value } \\
\hline $\mathbf{a} / \mathbf{c}=\mathbf{3}$ & SATURATED & 118.6 & -78.6 & 0.47 & 0.00 \\
& DRY & 109.5 & 88.05 & 0.16 & 0.02 \\
a/c=1 & SATURATED & 84.6 & -31.1 & 0.26 & 0.01 \\
& DRY & 37.6 & 106.6 & 0.13 & 0.05 \\
\hline
\end{tabular}

Figure 3-3a and Figure 3-3b show the behavior of relative nonlinear parameter $\eta$ for mortar samples in the saturated state and after oven drying. Results for both the fundamental bending and longitudinal modes are presented. At saturated conditions, $\eta$ maintains a consistently low value, and no clear relation between $\eta$ and $w / c$ is seen for any of the samples. However, the oven-dried samples exhibit different behavior: $\eta$ is constant with respect to $w / c$ and at low value for $a / c=3$ samples, but increases dramatically with decreasing $w / c$ for $a / c=1$ samples. The flexural and longitudinal modes exhibit different behavior in $\eta$ with decreasing $w / c$. The precise cause of this difference is not clear at this time, but is likely to be in part caused by distinct strain fields within the sample associated with each mode (vibration mode shape), and how that strain field coincides with the accrued microcracking and microstructural changes. More study on this issue is needed. Nevertheless, the sources of non-classical hysteretic effects that are captured by $\eta$ are mainly attributed to contact interactions between rough interfaces, such as those along cracks (Guyer \& Johnson, 1999). The increase in $\eta$ after oven drying suggests a notable increase of nonlinear sources, such as microcracks, throughout the low $w / c$ and low a/c samples, which is plausibly attributed to the restraining effect of the aggregates on microcracking shrinkage and the overall volume of neat paste. After drying, the relative hysteretic parameter $\eta$ increases approximately exponentially as the $w / c$ decreases below $w / c=0.45$, but remains constant with respect to $w / c$ above 0.45 . Similar observations from dried concrete samples were reported by Payan et al. (Payan, Garnier, \& Moysan, 2010), where dry concrete with w/c of 0.8 exhibited significantly lower hysteretic nonlinear behavior than those with $w / c$ of 0.3 . 

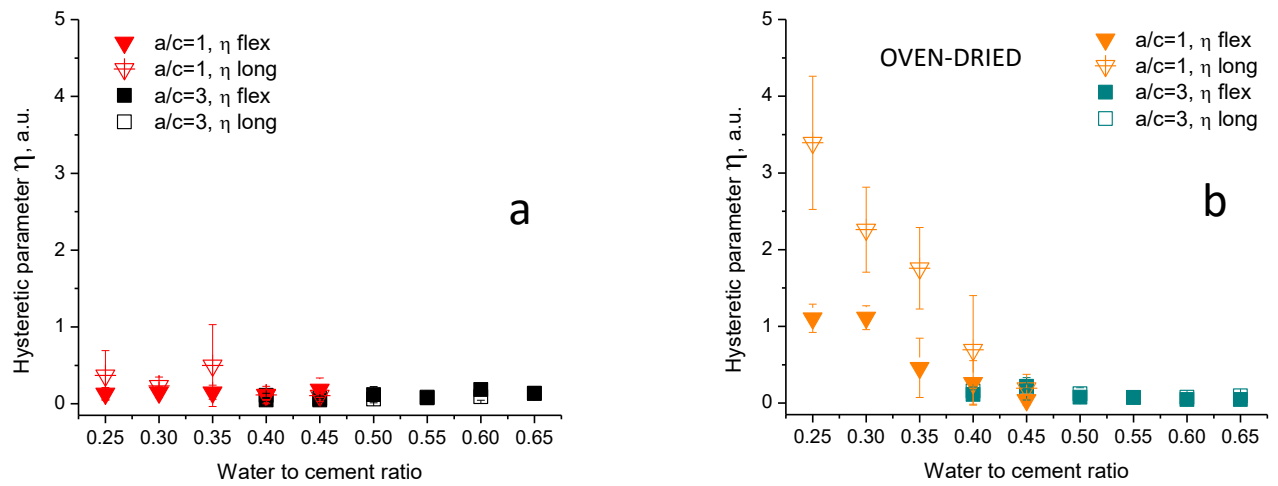

Figure 3-3 Hysteretic parameter $\eta$ from flexural and longitudinal resonance modes for: a) saturated pristine samples, and b) oven-dried samples. Error bars represent standard deviation.

Linear $\left(E_{d}\right.$ and $Q$ ) and nonlinear $(\eta)$ dynamic parameters are affected by both moisture content reduction and microstructural changes that are induced by drying. $E_{d}$ consistently and significantly decreases with drying, and the extent of this decrease apparently depends on capillary porosity content. After water removal with drying, the hydrostatic stiffening effect on the pore structure system is alleviated, which leads to an apparent reduction in material modulus. But furthermore, material microcracking induced by drying further contributes to the reduction of $E_{d}$. It is difficult to distinguish the contributions to the reduction of $E_{d}$ owing to the coupled microcracking shrinkage and pore moisture loss effects, although it can be argued from the presented data that pore moisture effects likely dominate the value of $E_{d}$ unless the extent of microcracking is significantly large. Consider the anomalous behavior of the mortar II-025 samples, where an unexpectedly large reduction in $E_{d}$ with drying was observed. This phenomenon is likely due to significantly enhanced drying and autogenous shrinkage microcracking that contributes in a more equitable way to the reduction of $E_{d}$ after drying. In general, autogenous shrinkage effects are more prominent in low water to binder cement-based materials, and their effects extend over time. Drying at $60^{\circ} \mathrm{C}$ can promote further hydration and autogenous shrinkage, especially in very low w/c mortars, even after 
28 days of wet curing; this damage is additive to that caused by normal drying shrinkage. The $Q$ and $\eta$ parameter data for the Mortar II-025 samples also indicate greater than expected levels of damage after drying. All together, these results indicate the likelihood that the very low $w / c$ samples $(w / c=0.25)$ experienced notably higher microcracking damage upon drying because of enhanced autogenous shrinkage effects and, further, that pore moisture effects dominate $E_{d}$ values unless the extent of microcracking is large.

$Q$ values and the nonlinear hysteretic parameter $\eta$ are also affected by coupled pore moisture and microcracking phenomena. However, it appears that both parameters, but especially $\eta$, are more influenced by increased cracking damage than by pore water removal that are caused by drying. Assuming a constant level of material microcracking damage, $Q$ values are expected to be lower under dry conditions than saturated because of the damping effect of the pore water. However, only the mortars with $a / c=3$ exhibited notable increases in $Q$ with drying, and consistent increases in $R Q$ with higher porosity (higher w/c). Mortars with $a / c=1$ displayed negligible increase in $R Q$ with drying. These materials are expected to exhibit more microcracking with drying because of lower levels of internal restrain exerted by aggregates to resist drying shrinkage stresses than those mortars with $a / c=3$. In fact the samples with $w / c=0.25$ exhibited a notable decrease in $Q$ with drying, which as before is attributed to the extensive amounts of drying and autogenous shrinkage cracking experienced by the very low w/c materials. Similar to, but perhaps even more so than, the behavior of $Q$, and $\eta$ values appear to be largely unaffected by varying $w / c$ and $a / c$ at saturated conditions. This insensitivity to capillary pore variation under saturated conditions suggests that the pore moisture effect on $\eta$ is negligible, and further that microcracking effects dominate the response of cement-based materials. This contention is supported by the notable increase in $\eta$ with drying in cases of lower $w / c$ and $a / c$, where enhanced microcracking is expected. 


\subsection{Conclusions}

Linear and nonlinear vibration nondestructive tests were conducted on mature mortar bar samples with varying $w / c$ and $a / c$ at pristine saturated moisture condition, and again after oven drying to stable mass at $60^{\circ} \mathrm{C}$. The obtained results demonstrate that the linear $\left(E_{d}\right.$ and $Q$ ) and nonlinear $(\eta)$ constitutive properties of cement-based materials are affected by the oven drying treatment. However, the reduction in $E_{d}$ appears to be mostly dependent on internal moisture content, and less so on the accrued damage and microstructural changes; $E_{d}$ is also affected by the aggregate cement ratio of the mixture. $Q$ and $\eta$ appear to be mostly sensitive to the accrued microstructural modifications and cracking, and less to the changing internal moisture content. The $\eta$ parameter appears to show particular sensitivity to accrued damage owing to external drying without being masked by the effects of changing pore moisture content.

\section{References}

Alrifai, A., Aggoun, S., Kadri, A., Kenai, S., \& Kadri, E. (2013). Paste and mortar studies on the influence of mix design parameters on autogenous shrinkage of self-compacting concrete. Construction and Building Materials, 47, 969-976.

Amick, H., \& Monteiro, P. J. M. (2006). Experimental Determination of Modal Damping in Concrete Beams. ACl Material Journal, 103(3), 153-160.

ASTM C215-14. (2014). Standard Test Method for Fundamental Transverse , Longitudinal , and Torsional Resonant Frequencies of Concrete.

Bisschop, J., \& van Mier, J. G. M. (2002). Effect of aggregates on drying shrinkage microcracking in cement-based composites. Materials and Structures, 35(October), 453-461.

Burlion, N., Bourgeois, F., \& Shao, J.-F. (2005). Effects of desiccation on mechanical behaviour of concrete. Cement and Concrete Composites, 27(3), 367-379. 
Chatterji, S. (2008). Intrinsic Instability of Hardened Portland Cement Pastes and its Significance. The Open Construction and Building Technology Journal, 2, 170-175.

Collier, N. C., Sharp, J. H., Milestone, N. B., Hill, J., \& Godfrey, I. H. (2008). The influence of water removal techniques on the composition and microstructure of hardened cement pastes. Cement and Concrete Research, 38(6), 737-744.

Galan, I., Beltagui, H., García-Maté, M., Glasser, F. P., \& Imbabi, M. S. (2016). Impact of drying on pore structures in ettringite-rich cements. Cement and Concrete Research, $84,85-94$.

Galle, C. (2001). Effect of drying on cement-based materials pore structure as identified by mercury intrusion porosimetry A comparative study between oven-, vacuum- , and freeze-drying. Cement and Concrete Research, 31(10), 1467-1477.

Gao, Y., Zhang, J., \& Han, P. (2013). Determination of stress relaxation parameters of concrete in tension at early-age by ring test. Construction and Building Materials, 41, 152-164.

Guyer, R. A., \& Johnson, P. A. (1999). Nonlinear Mesoscopic Elasticity: Evidence for a New Class of Materials. Physics Today, 52(4), 30-36.

Hossain, A. B., \& Weiss, J. (2006). The role of specimen geometry and boundary conditions on stress development and cracking in the restrained ring test. Cement and Concrete Research, 36(1), 189-199.

Jensen, O. M., \& Hansen, P. F. (2001). Autogenous deformation and RH-change in perspective. Cement and Concrete Research, 31(12), 1859-1865.

Jiang, C., Yang, Y., Wang, Y., Zhou, Y., \& Ma, C. (2014). Autogenous shrinkage of high performance concrete containing mineral admixtures under different curing temperatures. Construction and Building Materials, 61, 260-269.

Kanna, V., Olson, R. A., \& Jennings, H. M. (1998). Effect of shrinkage and moisture content on the physical characteristics of blended cement mortars. Cement and Concrete Research, 28(10), 1467-1477.

Lura, P., Couch, J., Jensen, O. M., \& Weiss, J. (2009). Early-age acoustic emission 
measurements in hydrating cement paste: Evidence for cavitation during solidification due to self-desiccation. Cement and Concrete Research, 39(10), 861-867.

Malhotra, V. M., \& Sivasundaram, V. (2004). Resonant Frequency Methods. In Handbook on Nondestructive Testing of Concrete (pp. 167-188).

Moukwa, M., \& Aittcin, P.-C. (1988). The effect of drying on cement pastes pore structure as determined by mercury porosimetry. Cement and Concrete Research, 18(5), 745-752.

Nadeau, J. S., Bennett, R., \& Mindess, S. (1980). Acoustic Emission in the Drying of Hardened Cement Paste and Mortar, 64(7), 410-415.

Naik, T. R., \& Popovics, J. S. (2004). The Ultrasonic Pulse Velocity Method. In V. M. Malhotra \& N. J. Carino (Eds.), Handbook on Nondestructive Testing of Concrete (2nd ed.). Boca Raton: CRC Press.

Payan, C., Garnier, V., \& Moysan, J. (2010). Effect of water saturation and porosity on the nonlinear elastic response of concrete. Cement and Concrete Research, 40(3), 473476.

Pickett, G. (1956). Effect of aggregate on shrinkage of concrete and a hypothesis concerning shrinkage. Journal of the American Concrete Institute, 27(52), 581-590.

Rossi, P., Mier, J. G. M. van, Boulay, C., \& Maou, F. Le. (1992). The dynamic behaviour of concrete: influence of free water. Materials and Structures, 25(9), 509-514.

Scherer, G. W. (1990). Theory of Drying. Journal of the American Ceramic Society, 14(1), 3-14.

Skoczylas, F., Burlion, N., \& Yurtdas, I. (2007). About drying effects and poro-mechanical behaviour of mortars. Cement and Concrete Composites, 29(5), 383-390.

Snoeck, D., Velasco, L. F., Mignon, a., Van Vlierberghe, S., Dubruel, P., Lodewyckx, P., \& De Belie, N. (2014). The influence of different drying techniques on the water sorption properties of cement-based materials. Cement and Concrete Research, 64, 54-62.

Swamy, N., \& Rigby, G. (1971). Dynamic properties of hardened paste, mortar and concrete. Matériaux et Constructions, 4(1), 13-40. 
Van Den Abeele, K., Desadeleer, W., De Schutter, G., \& Wevers, M. (2006). Acoustic Emission (AE) and Nonlinear Elastic Wave Spectroscopy (NEWS) for Online Monitoring of Concrete Curing. Advanced Materials Research, 13-14, 213-220.

Van Den Abeele, K. E.-A., Carmeliet, J., Johnson, P. A., \& Zinszner, B. (2002). Influence of water saturation on the nonlinear elastic mesoscopic response in Earth materials and the implications to the mechanism of nonlinearity. Journal of Geophysical Research, 107, 1-11.

Winslow, D. N., Cohen, M. D., Bentz, D. P., Snyder, K. A., \& Garboczi, E. J. (1994). Percolation and pore structure in mortars and concrete. Cement and Concrete Research, 24, 25-37.

Winslow, D. N., Liu, D., \& Lafayette, W. (1990). The pore structure of paste in concrete. Cement and Concrete Research, 20(2), 227-235.

Yaman, L. O., Hearn, N., Aktan, H. M. I., \& Yaman, I. O. (2002). Active and non-active porosity in concrete Part I: Experimental evidence. Materials and Structures, 35(2), 102-109.

Yurtdas, I., Peng, H., Burlion, N., \& Skoczylas, F. (2006). Influences of water by cement ratio on mechanical properties of mortars submitted to drying. Cement and Concrete Research, 36(7), 1286-1293.

Zhang, W., Zakaria, M., \& Hama, Y. (2013). Influence of aggregate materials characteristics on the drying shrinkage properties of mortar and concrete. Construction and Building Materials, 49, 500-510.

Zou, D., \& Weiss, J. (2014). Early age cracking behavior of internally cured mortar restrained by dual rings with different thickness. Construction and Building Materials, 66, 146153. 


\section{Chapter 4. Effect of drying and internal moisture content (II)}


Chapter 4. Effect of drying and internal moisture content (II) ...........................................................

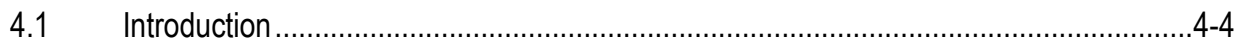

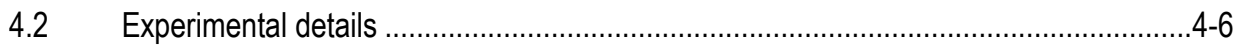

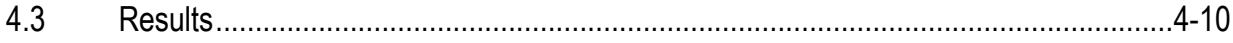

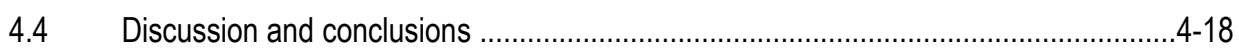

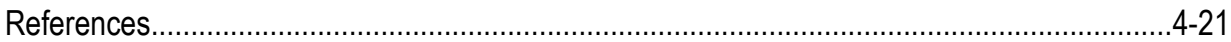




\subsection{Introduction}

Results from previous chapter demonstrated that internal moisture variations within the pore structure can alter the dynamic properties of cement based materials. In particular, moisture results in a build-up of capillary pressure which manifests as an apparent increase of material stiffness and enhances energy losses because of viscous damping. In addition, upon removal of water, microcracking shrinkage and microstructure modification can be produced, and whose origins can be attributed to different causes. First, drying can produce moisture gradients that can lead into tensile cracking. Low water-cement mortars are prone to such a damage generation because of their intrinsically lower diffusion rates, which in turn, this feature can be further aggravated by using superplasticizer (Hall \& Tse, 1986). Second, a drying treatment can further promote autogenous shrinkage, which is additive to that produced upon drying; this is also especially true in low water-cement mortars. Third, degradation of hydrate phases such as calcium silicate hydrate (C-S-H) or ettringite can take place even at drying temperatures of $60^{\circ} \mathrm{C}$ (Galan, Beltagui, García-Maté, Glasser, \& Imbabi, 2016; Snoeck et al., 2014). The degradation of C-S-H phases can also contribute to the pore coarsening (increase of capillary porosity) observed upon drying of cement pastes at and below $105^{\circ} \mathrm{C}$ (Galle, 2001; Moukwa \& Aitcin, 1988; Snoeck et al., 2014). These effects impart changes on the dynamic properties of cement based materials.

Results from previous chapter shown that dynamic modulus $\left(E_{d}\right)$ decreases as internal pore moisture content decreases. Thus, higher water-cement mortars exhibit greater reductions of $E_{d}$ upon loss of moisture. On other hand, it seemed that $E_{d}$ was not as sensitive as $Q$ and $\eta$ to the accrued microcracking produced after completing the drying treatment at $60^{\circ} \mathrm{C}$. This may be owed because of $Q$ and $\eta$ strongly depend on the internal friction characteristics. Studies have demonstrated that moisture within the pore structure can either enhance or alleviate the mechanisms of internal friction (Carmeliet \& Van Den Abeele, 2004). Figure 4-1 compares the hysteretic nonlinear parameter monitored from almost fully saturated to dry state for three different materials included concrete (Cédric Payan, Garnier, 
\& Moysan, 2010), and two rocks types (Johnson, Zinszner, Rasolofosaon, Cohen-Tenoudji, $\&$ Van Den Abeele, 2004). Although the testing procedures differ across the different studies, the techniques used therein are thought to be sensitive to the same features within the materials (e.g. microcracks and contacting between rough interfaces). The obtained hysteretic nonlinear parameters are normalized by the value obtained in dry state $\left(\alpha_{(S=0)}\right)$ in their respective experiments. From results shown in Figure 4-1, it can be observed that the hysteretic parameter behaves in a different fashion for the three materials being considered, and whose behaviors most plausibly respond to differences in the pore network characteristics (Van Den Abeele, Carmeliet, Johnson, \& Zinszner, 2002). None of the studies, however, accounted for the damage that can be produced upon loss of moisture, but they assumed that the features that give rise to the hysteretic behavior were already present within the material. In this chapter, the effects of drying and internal pore moisture on the dynamic properties of cement based materials are further investigated. To this end, a set of mortar samples, with varying water to cement ratio, were subjected to successive drying treatments. The severity of the damage imparted during drying depends on temperature. Thus, every drying treatment was conducted at increasing temperature, for increasingly impart microcracking damage and progressively enhance the degradation of hydrated phases. First drying treatment was conducted at $40^{\circ} \mathrm{C}$. Previous studies identified an oven-drying at $40^{\circ} \mathrm{C}$ as a gentle drying process that results in low damage, and relatively low. Once the samples reached stable mass, the samples were then rewetted and subjected to a drying treatment at $60^{\circ} \mathrm{C}$. This second drying is expected to enhance microcracking shrinkage and microstructural modification (Eiras, Popovics, Borrachero, Monzó, \& Payá, 2015). Then, the samples were rewetted and subjected to a third drying treatment at $80^{\circ} \mathrm{C}$. The linear and nonlinear dynamic properties were followed up through resonant frequency tests. 


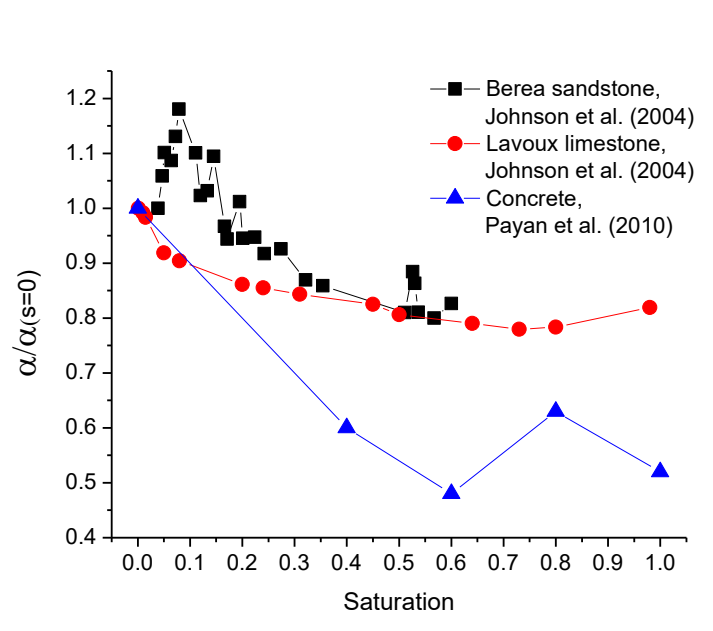

Figure 4-1 Nonlinear hysteretic parameter normalized by the hysteretic parameter obtained in dry state $\left(\alpha_{(S=0)}\right)$ as a function of saturation, for Berea sandstone (Johnson et al., 2004), Lavoux limestone (Johnson et al., 2004), and concrete (Cédric Payan et al., 2010).

\subsection{Experimental details}

Three prismatic samples $\left(40 \times 40 \times 160 \mathrm{~mm}^{3}\right)$ per type of "series I" mortars - see Chapter 2 Materials and methods - were produced. The samples were cured in water at $20^{\circ} \mathrm{C}$ for 28 days after casting. The linear and nonlinear dynamic properties were monitored upon loss of internal moisture, through the standard resonant frequency method (ASTM C215-14, 2014) and NIRAS technique - see Chapter 2 Materials and methods - . Initially, the samples were tested in fully saturated conditions, then upon loss of moisture during ovendrying at $40^{\circ} \mathrm{C}$. The variation of the dynamic properties upon loss of moisture was followed up until the stable mass was reached. The same protocol was repeated after rewetting the samples in water during 24 hours and then drying them at $60^{\circ} \mathrm{C}$. The entire process was repeated a third time after rewetting the samples in water during 48 hours, and then drying them at $80^{\circ} \mathrm{C}$. Figure $4-2$ shows a schematic diagram of the testing protocol. 


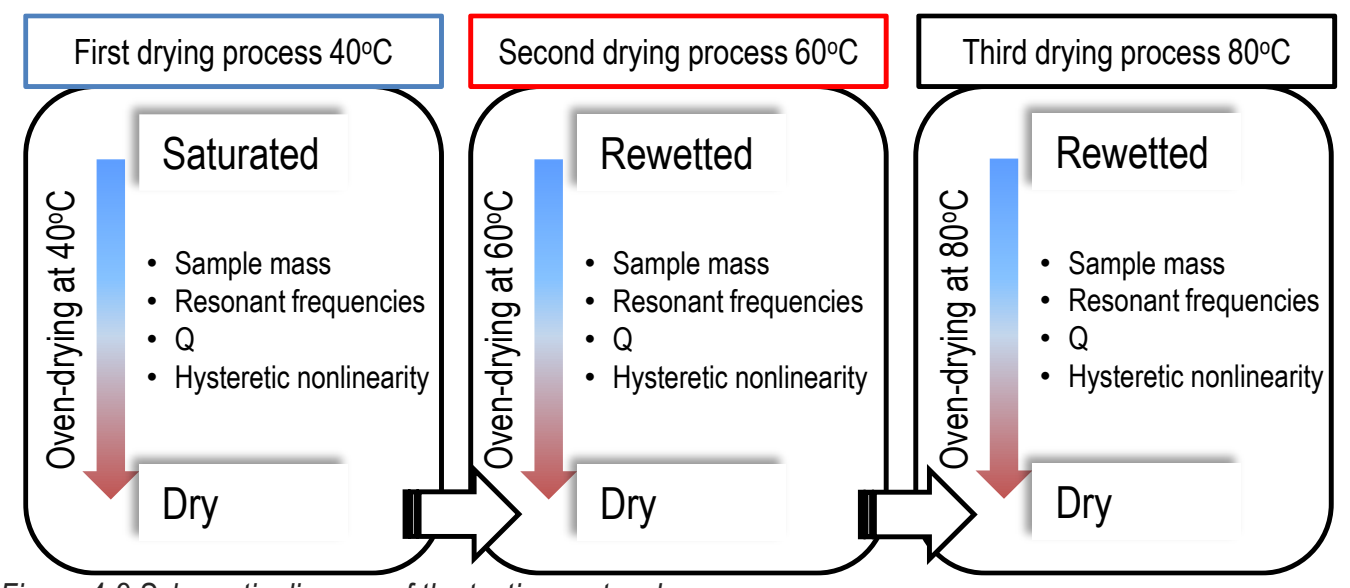

Figure 4-2 Schematic diagram of the testing protocol.

Each time the samples were removed from the oven, they were allowed to cool at room temperature during more than one hour to prevent that the measured dynamic properties were affected by the sample temperature. For reference, the resonant frequencies of a separate sample set of completely dried samples at $60^{\circ} \mathrm{C}$ were monitored during cooling at room temperature. The temperature was read directly from the sample surface with an infrared thermometer (PCE Instruments ${ }^{\circledR}$, PCE-MF $1, \pm 2^{\circ} \mathrm{C}$ ). Four standard resonant frequency tests (10 acquisitions per test) were conducted since the samples were removed from the oven. Figure 4-3a shows the modulus variation during cooling at room temperature $\left(T_{a} \sim 25^{\circ} \mathrm{C}\right)$. The results show that the modulus varied with temperature following a Wachtman-like law (Watchman, Tefet, Lam, \& Apstein, 1961). Analogously, herein the relative variations of modulus with regard that at room temperature $\left(\Delta E / E_{a}\right)$ were described as

$\frac{\Delta E}{E_{a}}=p-q \cdot \exp (-r \cdot T)$

wherein $T$ is the sample temperature, and $p, q$ and $r$ are fitting coefficients. Figure 4-3b shows the temperature variations during cooling. After $3600 \mathrm{~s}$ the variations of temperature reached 
almost a stable value. This additional verification demonstrates that the elapsed time since the samples were removed from the oven up to the dynamic tests were performed is enough to prevent that the sample temperature affect the measurements.
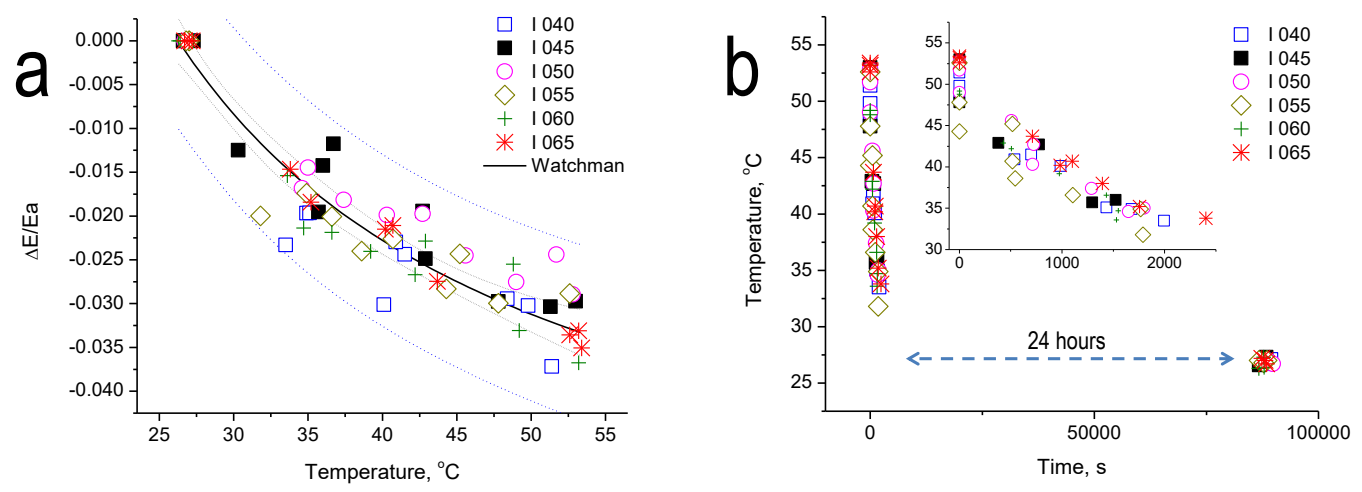

Figure 4-3 a) Resonant frequency as a function of surface temperature, and b) surface temperature evolution with time.

The extent of water saturation $(S)$ was ascertained from the mass of the sample at the moment the test was performed $\left(m_{i}\right)$ as,

$$
S=\frac{m_{i}-m_{d r y}}{m_{s a t}-m_{d r y}}
$$

wherein $m_{d r y}$ is the dried mass after completing every drying treatment, and $m_{\text {sat }}$ is the saturated mass obtained at initial fully saturated conditions and before any drying treatment. Henceforth, the linear and nonlinear dynamic properties of every mortar sample are related to $S$. The extent of water saturation $S$ varies between 0 (completely dried) and 1 (fully saturated). However, it should be noted that higher water-cement ratios are expected to bear greater amounts of water. In Figure 4-4a to 4-4c are shown the evolution of the mass of every mortar during all three oven-drying treatments (mean values of three samples). The 
values of total water content can be deducted from Figure 4-4. These results also show that the drying rate is also noticeably faster in higher water-cement mortars.

Table 4-1. Initial saturated mass of prismatic samples $\left(40 \times 40 \times 160 \mathrm{~mm}^{3}\right)$, and dried mass after completion of oven drying at different temperatures.

\begin{tabular}{|lrrrr|}
\hline w/C & $\begin{array}{l}\text { Saturated mass } \\
(\mathbf{g})\end{array}$ & Dry mass $(\mathbf{g}), \mathbf{4 0 ^ { \circ } \mathbf { C }}$ & Dry mass $(\mathbf{g}), \mathbf{6 0 ^ { \circ } \mathbf { C }}$ & Dry mass $(\mathbf{g}), \mathbf{8 0 ^ { \circ }} \mathbf{C}$ \\
\hline $\mathbf{0 . 4 0}$ & $586.8 \pm 5.1$ & $558.1 \pm 4.1$ & $558.4 \pm 4.1$ & $559.3 \pm 4.1$ \\
$\mathbf{0 . 4 5}$ & $581.3 \pm 2.0$ & $547.6 \pm 1.5$ & $547.4 \pm 1.3$ & $548.0 \pm 1.2$ \\
$\mathbf{0 . 5 0}$ & $577.7 \pm 1.1$ & $539.9 \pm 1.2$ & $539.3 \pm 1.0$ & $540.8 \pm 0.7$ \\
$\mathbf{0 . 5 5}$ & $575.0 \pm 1.7$ & $531.6 \pm 1.3$ & $530.9 \pm 1.5$ & $532.2 \pm 1.7$ \\
$\mathbf{0 . 6 0}$ & $570.8 \pm 2.3$ & $526.1 \pm 1.4$ & $525.3 \pm 1.5$ & $525.9 \pm 1.3$ \\
$\mathbf{0 . 6 5}$ & $572.0 \pm 0.3$ & $524.7 \pm 0.3$ & $523.7 \pm 0.5$ & $524.3 \pm 0.2$ \\
\hline
\end{tabular}
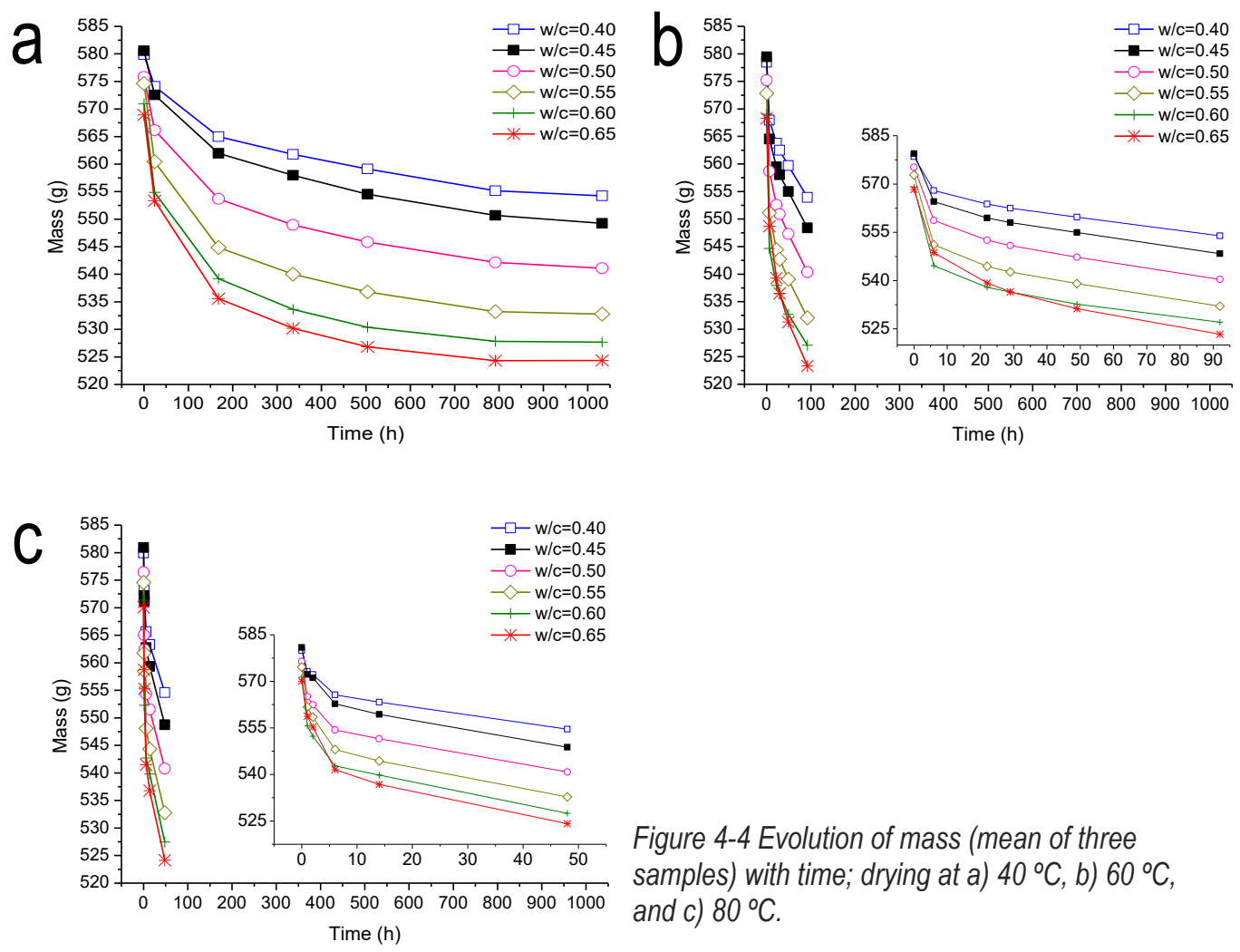

Figure 4-4 Evolution of mass (mean of three samples) with time; drying at a) $40^{\circ} \mathrm{C}$, b) $60^{\circ} \mathrm{C}$, and c) $80^{\circ} \mathrm{C}$. 


\subsection{Results}

Figure $4-5 a$ and $4-5 b$ show the values of $E_{d}$ at saturated states ( $S>0.90$ ), and after completing the drying treatments. The values of $E_{d}$ were consistently higher in saturated than in dry states $(S \sim 0.00)$, thus confirming the stiffening effect because of internal pore moisture. However, for a given condition (saturated or dry) the values of $E_{d}$ exhibited slightly variations. For instance, the $E_{d}$ values after rewetting the samples during 24 hours were consistently lower than those obtained at pristine state, so that the rewetting process seemed not to recover the initial values of $E_{d}$ (see Figure 4-6a). In contrast, the second rewetting process conducted during 48 hours after the second drying at $60^{\circ} \mathrm{C}$ attained values of $E_{d}$ similar to those obtained in pristine state. These results may indicate that the rewetting processes were not able to restore the pristine saturated conditions. Figure 4-5c-e show the values of $E_{d}$ as a function of water saturation $(S)$. $E_{d}$ exhibited a fairly linear dependence with decreasing moisture content $(S)$ for all the set of mortars being investigated herein. Thus, an empirical relation between $E_{d}$ and unitary moisture content $(S)$ can be established as

$$
E_{d}(S)=E_{d(S=0)}+k \cdot S
$$

where $E_{d(S=0)}$ is the intercept and $k$ is the averaged change of $E_{d}$ from saturated $(S=1)$ to dry state $(S=0)$. The model parameters were determined for every mortar and for every ovendrying treatment, through a least-squares estimation. In Table 4-2 the resulted values of $E_{d(S=0)}$ and $k$ are listed. The values of $k$ did not render any difference between different $w / c$. Conversely, $k$ differed across different oven-drying temperatures. After first drying at $40^{\circ} \mathrm{C}$, an average reduction of dynamic modulus ( $k$ ) of $\sim 5.7 \mathrm{GPa}$ was obtained, while further drying processes (at $60^{\circ} \mathrm{C}$ and $80^{\circ} \mathrm{C}$ ) resulted in a lower reduction $\sim 3.8 \mathrm{GPa}$. 
a

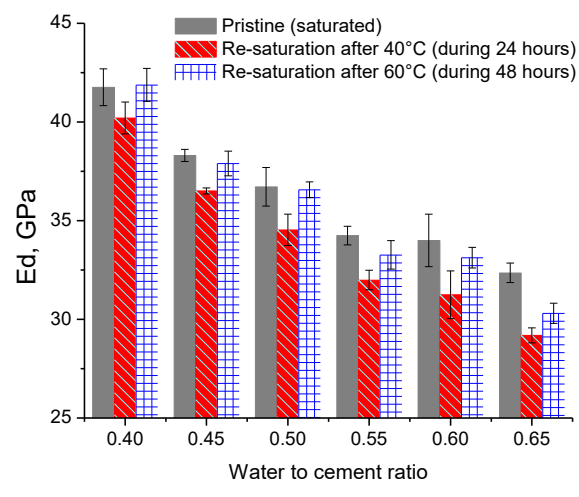

C
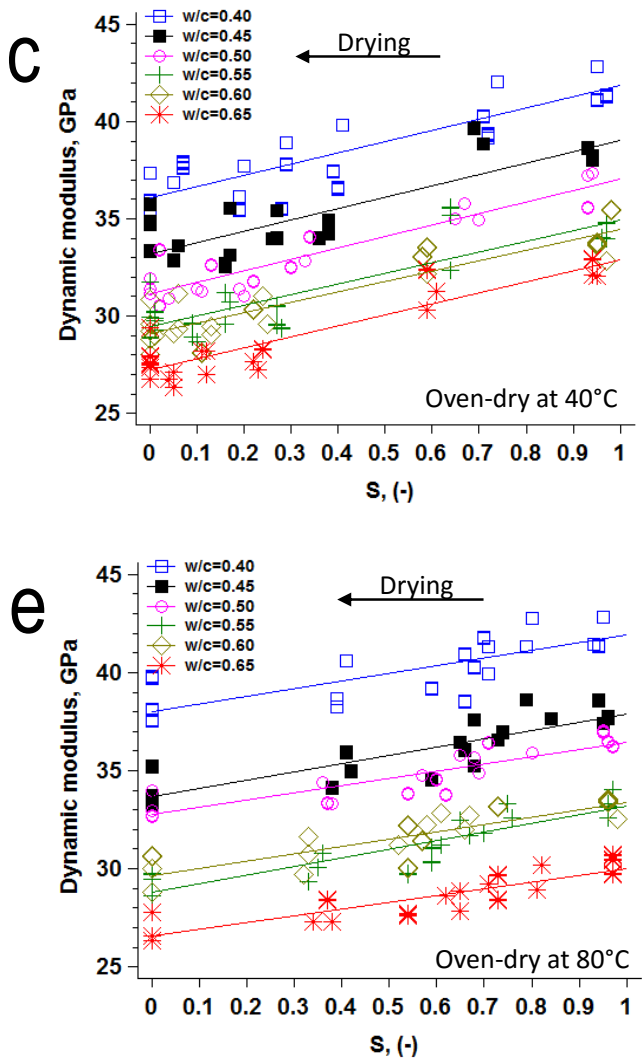
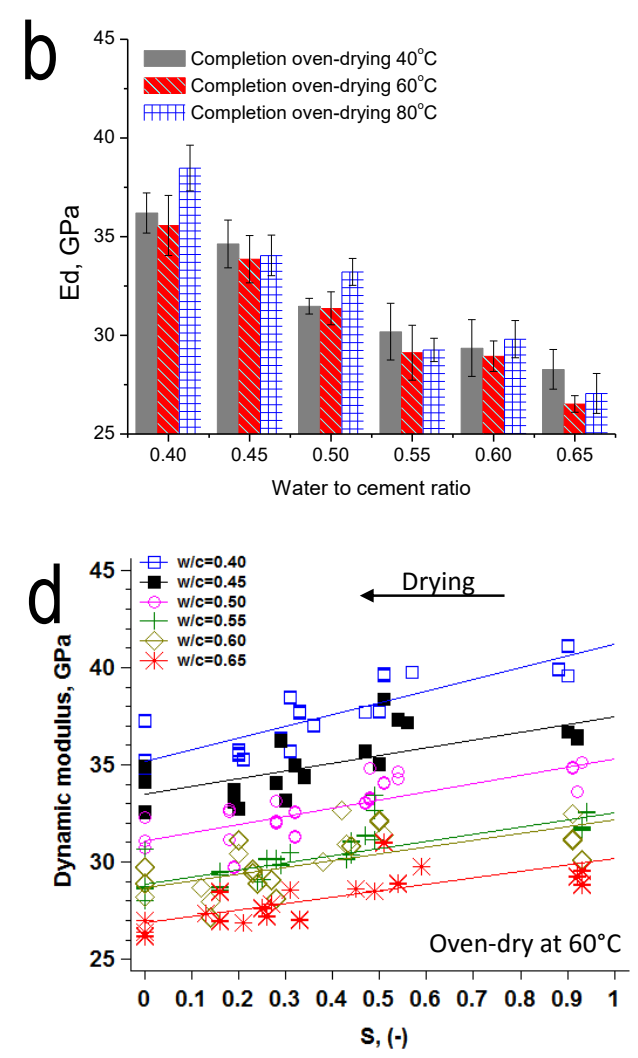

Figure 4-5 a) Mean values of $E_{d}$ obtained at saturated states $(S>0.90)$, and b)after completing the oven-drying treatments; c) relationship between saturation (S)and $E_{d}$ for during oven-drying at $40^{\circ} \mathrm{C}$, d) during oven-drying at $60^{\circ} \mathrm{C}$, and e) during oven-drying at $80^{\circ} \mathrm{C}$. 
Table 4-2

\begin{tabular}{|c|c|c|c|c|c|c|c|c|c|}
\hline & \multicolumn{3}{|c|}{ Oven-dry at $40^{\circ} \mathrm{C}$} & \multicolumn{3}{|c|}{ Oven-dry at $60^{\circ} \mathrm{C}$} & \multicolumn{3}{|c|}{ Oven-dry at $80^{\circ} \mathrm{C}$} \\
\hline$w / c$ & $E_{d,(S=0)}$ & $k$ & $\mathrm{R}^{2}$ & $E_{d,(S=0)}$ & $k$ & $2^{2}$ & $E_{d,(S=0)}$ & $k$ & $\mathrm{R}^{2}$ \\
\hline 0.40 & 36.07 & 5.79 & 0.73 & 36.21 & 6.03 & 0.58 & 37.99 & 3.94 & 0.56 \\
\hline 0.45 & & 5.8 & & & & & & & 0.72 \\
\hline 0.50 & 31.12 & 5.93 & 0.8 & 31.08 & 4.22 & 0.76 & 32.76 & 3.68 & 0.68 \\
\hline 0.55 & 29.45 & 5.52 & 0.84 & 28.92 & 3.63 & 0.8 & 28.8 & 4.41 & 0.77 \\
\hline 0.60 & 29.13 & 5.34 & 0.7 & & 3.46 & 0.6 & & 3.76 & 0.65 \\
\hline 0.65 & 27.21 & 5.68 & 0.83 & 26.86 & 3.35 & 0.57 & 26.60 & 3.38 & 0.55 \\
\hline
\end{tabular}

Figures 4-7a and 4-7b show the mean values of $Q$ obtained at saturated and after completing every drying treatment. After completing the drying at $40^{\circ} \mathrm{C}$, the values of $Q$ were found to be greater than those obtained at saturated state $(S>0.9)$. Such an effect can be explained since water into the pore structure enhances viscous damping of mechanical waves. However, oven-drying at $60^{\circ} \mathrm{C}$ caused a decrease on the values of $Q$, especially in low water-cement mortars - herein, w/c of 0.50 and below-. These results are suggesting that the oven-drying treatment at $60^{\circ} \mathrm{C}$ induced damage on the mortar samples, especially in low water-cement mortars. Further drying at $80^{\circ} \mathrm{C}$ produced similar values of $Q$ for all mortars and regardless moisture condition. These results indicate that the energy losses obtained in dry state (after $80^{\circ} \mathrm{C}$ treatment) arise from friction like mechanism. Figures 4-7c and 4-7d show the evolution of $Q$ as a function of the moisture content, during the ovendrying processes. It can be noticed a progressive increase of $Q$ upon loss of moisture. Similar trends of damping properties with increasing moisture content were found for different rock types (Johnston, Toksoz, \& Timur, 1979; Van Den Abeele et al., 2002). In general, Q decreased exponentially as function of the saturation extent was found in the form of

$Q=a+b \cdot \exp (-c \cdot S)$

Eq. 4-4

where the coefficients $a, b$, and $c$ are fitting coefficients. The evolution of $Q$ during first drying treatment (shown in Figure 4-7c) revealed no clear relation between different water-cement mortars, so that the whole data was fitted to the model in Eq. 4-5. The oven-drying treatment at $60^{\circ} \mathrm{C}$ produced greater variability on the $Q$ data when compared to the $40^{\circ} \mathrm{C}$ treatment. 
Especially, the lowest water-cement mortar remained almost constant $(Q \sim 75)$ upon loss of moisture at $60^{\circ} \mathrm{C}$. Such effect was also observed for the rest of mortars during the third drying treatment at $80^{\circ} \mathrm{C}$, whereby the values of $Q$ remained almost constant during the drying treatment.
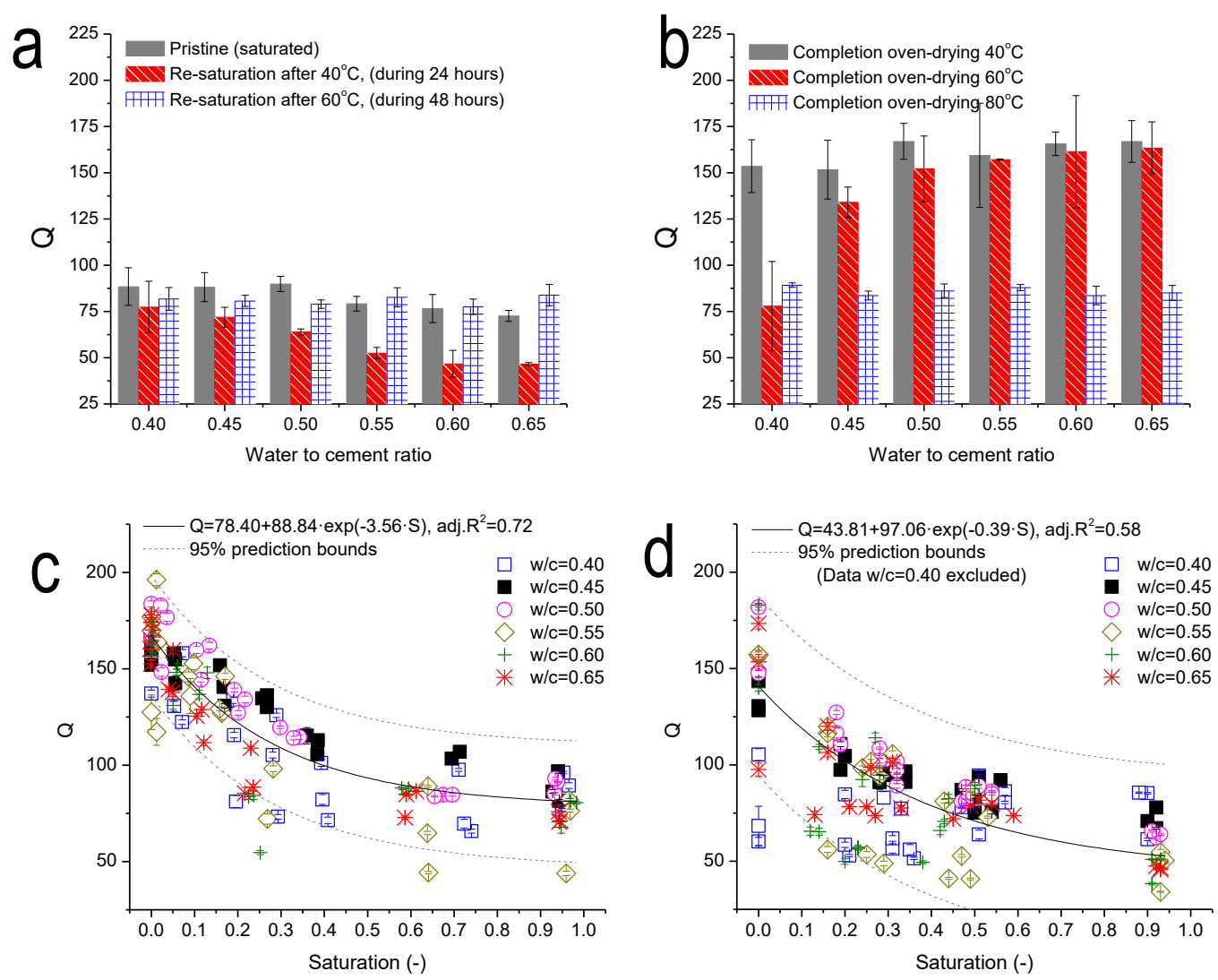

Figure 4-6 a) Mean values of $Q$ obtained at saturated states ( $S>0.90)$, and b)after completing the ovendrying treatments; c) Relationship between saturation (S) and quality factor (Q) for mortar samples during oven-drying at $40^{\circ} \mathrm{C}$ and d) during oven-drying at $60^{\circ} \mathrm{C}$. 
Figure 4-8 shows representative frequency spectra, as obtained through NIRAS technique for three mortar samples ( $w / c$ of $0.45,0.50$, and 0.65 ) at pristine saturated state (upper row), and after completing the oven-drying treatment at $60^{\circ} \mathrm{C}$ (bottom row). Congruently, NIRAS tests reproduced the effects observed through linear resonant tests: resonant frequency and attenuation decreased with drying. In addition, the resonant frequency exhibited noticeable downward shifts at dry state, and such shifts were larger in low water-cement mortars. The hysteretic parameter has been obtained for flexural $\left(\eta_{\text {flex }}\right)$ and longitudinal ( $\eta_{\text {long }}$ ) modes of vibration. Figures $4-9 \mathrm{a}$ and $4-9 \mathrm{~b}$ show the values of $\eta_{\text {flex }}$ for saturated and dry conditions. In all cases, the values of $\eta_{\text {flex }}$ were found to be higher than those obtained for $\eta_{\text {long. }}$. Moreover, the material nonlinearity were found to be lower in saturated (Figures 4-9a and 4-9c) than in dry state (Figures 4-9b and 4-9d). However, the same behavior was not reproduced at all oven-drying treatments. Initially, the hysteretic parameter $\eta$ remained almost constant during oven-drying at $40^{\circ} \mathrm{C}$, and across different water-cement mortars. Conversely, the drying treatments conducted at $60^{\circ} \mathrm{C}$ and $80^{\circ} \mathrm{C}$ increased the material nonlinearity in all cases, and low water-cement mortars exhibited greater change in the hysteretic parameter than higher ones.
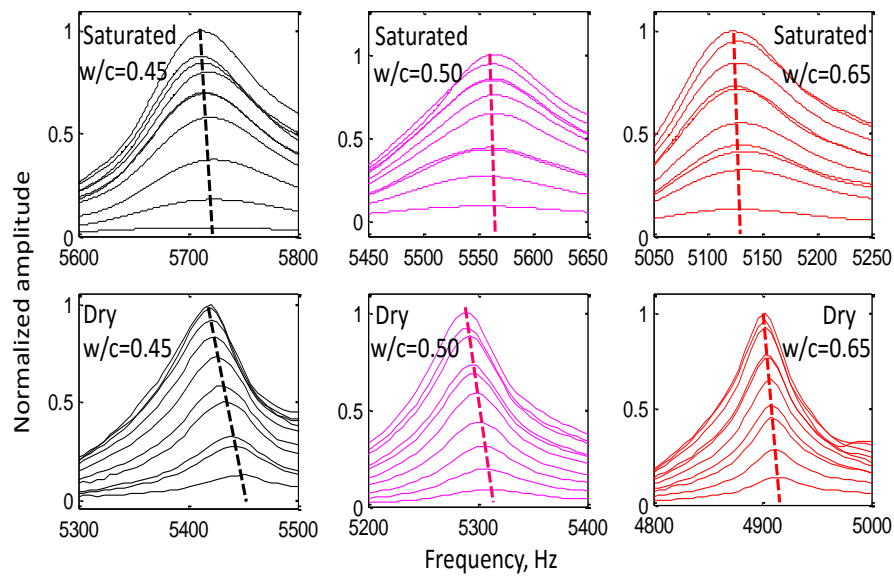

Figure 4-7 Frequency spectra obtained for representative mortars at saturated (upper row) and dry state (bottom row). 

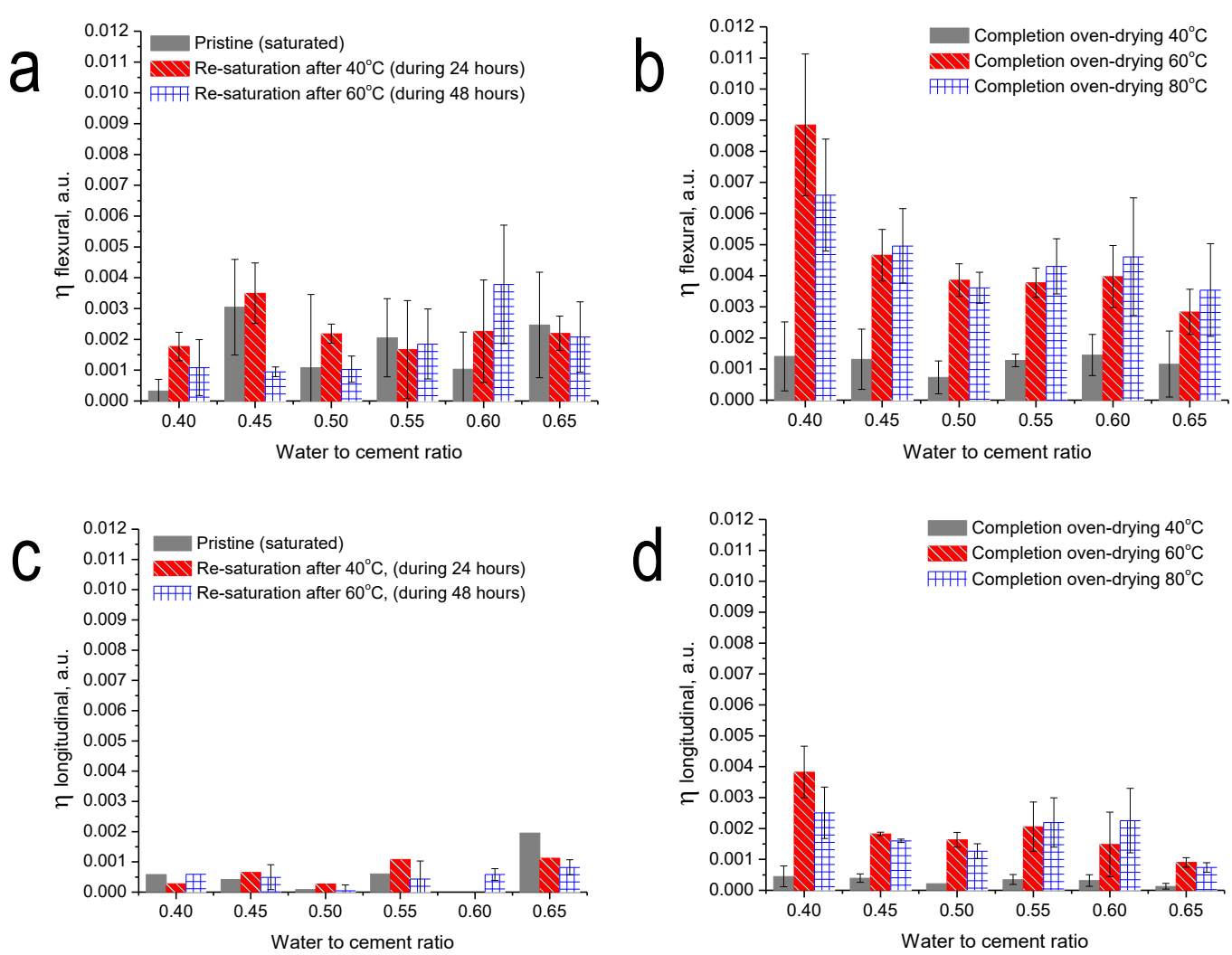

Figure 4-8 Hysteretic parameter corresponding to flexural mode $\left(\eta_{f l e x}\right)$ at a) saturated and b) dry states; and hysteretic parameter corresponding to longitudinal mode( $\eta_{\text {long }}$ ) at c) saturated and d) dry states.

Figure 4-10 shows the evolution of the hysteretic parameter $\eta_{\text {flex }}$ upon varying moisture content $(S)$ during the drying treatments at $60^{\circ} \mathrm{C}$ and $80^{\circ} \mathrm{C}$. In general, the material nonlinearity increased progressively as the internal moisture content is reduced upon drying. Then, subsequent rewetting during 48 hours restored the values of $\eta_{\text {flex }}$ to those obtained at pristine saturated state. The values of $\eta$ exhibited an exponential decrease as function of the internal moisture content increase as

$\eta(S)=p+q \cdot \exp (-r \cdot S)$

Eq. 4-5

\section{4-15}


wherein $p, q$, and $r$ are fitting coefficients. The model in Eq. 4-6 was fitted to the $\eta(S)$ data for every mortar (Figures 4-10a-f). These results are in good agreement with previous results reported by Payan et al. (Cédric Payan et al., 2010) for concrete. Likewise, in such study, an exponential law was used to describe the changes of hysteretic parameter with increasing moisture content. However, the results shown herein demonstrate that low water-cement mortars are affected by the drying treatment, and that the hysteretic behavior that arises from the internal friction is alleviated with increasing internal moisture content. 

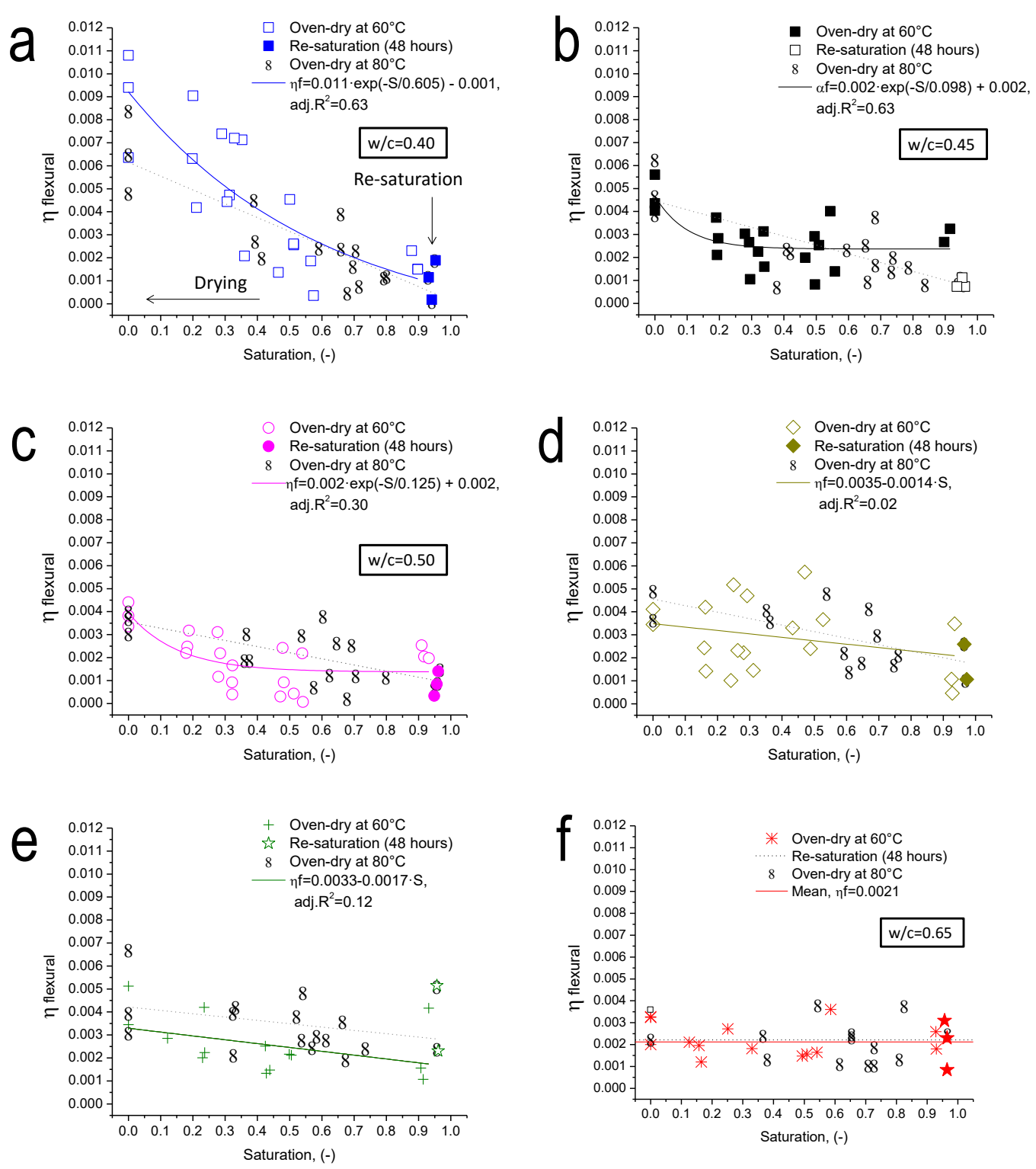

Figure 4-9 Hysteretic parameter $\eta_{\text {flex }}$ monitored on drying at $60^{\circ} \mathrm{C}$ a) .040 b) I.045 c) I.050 d) I.055, e) I. 060, f) 1065. 


\subsection{Discussion and conclusions}

Linear and nonlinear dynamic properties were affected by moisture content and ovendrying temperature. The $E_{d}$ values obtained in saturated states were found to be consistently higher than those at dry states and regardless water-cement ratio. At saturated state, water acts confining the pore structure resulting in an increase of elastic modulus, and hence, subsequent removal of water yields to a decrease of $E_{d}$. However, the variations of $E_{d}$ were not reproduced across different temperature treatments. First drying at $40^{\circ} \mathrm{C}$ produced a variation of $E_{d}$ between $10 \%$ and $15 \%$, and such reduction did not render any difference between different water-cement ratios. This effect may indicate that all moisture was not completely removed after first drying, as some remnant moisture is expected to remain physically bounded within the pore structure, even, if stable mass was reached (Snoeck et al., 2014). By increasing the temperature of the drying treatment, further moisture losses can be attained, but also microcracking shrinkage and pore coarsening can be enhanced. In fact, the relative reductions of $E_{d}$ produced after subsequent drying treatments (at $60^{\circ} \mathrm{C}$ and $80^{\circ} \mathrm{C}$ ) were significantly greater than those produced on first drying, and rendered a nontrivial relation between $w / c$ and $E_{d}$. In particular, the reduction of $E_{d}$ attained for the mortar I-065 was significantly greater than those obtained for the mortar I-040 and I-045. These results further enforce the conclusion that the reduction of modulus upon loss of moisture is dominated by capillary porosity (Eiras et al., 2015; Yaman, Hearn, Aktan, \& Yaman, 2002). On other hand, after rewetting the mortar samples during 24 hours, $E_{d}$ values were consistently lower than those obtained in pristine state. The restoration of internal moisture in concrete was pointed out as an irreversible process. Chatterji (Chatterji, 2004) observed internal concrete cores were observed to remain unsaturated, even after two years soaked in water. Rewetting during 48 hours seemed to further increase the dynamic modulus values. The $E_{d}$ data point out a tradeoff between pore moisture content, microcracking shrinkage, pore coarsening and even further hydration and carbonation (Snoeck et al., 2014). From $E_{d}$ data is virtually not possible to distinguish between all these effects. Although, the variations of dynamic modulus appeared mostly dominated by pore moisture content rather than by the 
possible subtle microstructure modifications induced during the drying treatments. For the set of mortar being investigated herein, the dependence of $E_{d}$ on moisture content seems to be well described through a linear relation (Eq. 4-4). However, higher order dependences in terms of $S$ may be also be relevant —thus, $E_{d}=E_{d,(S=0)}+k_{1}{ }^{*} S+k_{2}{ }^{*} S+\ldots-$ Moreover, in this chapter, the $E_{d}$ values were followed up upon loss of moisture. Results reported by Somaratna (Somaratna, 2014) demonstrated that the reverse process (mass gain because of rewetting) can produce a recovery of the $E_{d}$ that not necessarily follows the same path obtained upon loss of moisture; thus exhibiting a hysteretic $E_{d}(S)$. These results point out that not only moisture content but moisture distribution, and how the moisture interacts with the pore structure strongly affect the dynamic properties. All these effects deserve to be further investigated.

Internal friction effects and energy losses were also affected by moisture content and drying treatments. In general, in saturated conditions the internal moisture enhances the energy losses because of viscous damping mechanism. Then, upon moisture removal, the dominating damping mechanism turns into friction-like dissipation, and more so, if the drying treatment involved microcracking generation. First drying at $40^{\circ} \mathrm{C}$ produced higher values of $Q$ than those obtained in saturated pristine state for all mortars, and the hysteretic parameters remained stable. The values of $Q$ exhibited an exponential increase upon drying at $40^{\circ} \mathrm{C}$, while the hysteretic parameters remained stable. In this sense, the hysteretic parameters seem to be insensitive to internal pore moisture variations, so that their variations are not meaningful unless microcracking is involved. Attending to the dynamic properties, drying treatment at $40^{\circ} \mathrm{C}$ did not produce perceptible damage within the mortar samples. Rewetting during 24 hours was able to lower again the values of $Q$, which indicate that viscous damping was again enhanced. Then, subsequent drying at $60^{\circ} \mathrm{C}$ adversely affected the mortar samples, especially, in low w/c mortars. In particular, the $Q$ values did not increase upon loss of moisture but they remained stable. Finally, subsequent rewetting and drying at $80^{\circ} \mathrm{C}$ was not able to further increase the values of $Q$, so that the values of $Q$ were similar for all mortars $Q \sim 90$. Thus, microcracking damage appeared to be also extended to the rest 
of mortars. In this stage, the differences on $Q$ values between saturated and dry states diminished drastically, though the mechanisms of damping can be attributed to different mechanisms; viscous damping the former, and Coloumb damping the latter, yet providing almost similar values of $Q$. There are, however, noticeably differences in the shape of the resonance curve -see Figure 4-8, wherein visible sharper resonant curves were obtained at dry states-, but perhaps, such differences are not well stressed through standard halfpower bandwidth measurements - this is $Q-$. These effects were also reflected on the hysteretic parameter, as the drying treatment at $60^{\circ} \mathrm{C}$ escalated the values of $\eta$ in dry states. However, the rewetting periods were able to progressively alleviate the internal friction, and hence, to lower the values of $\eta$ following an exponential-like dependence on moisture content. These trends were somewhat reproduced during drying at $80^{\circ} \mathrm{C}$. Similar results were reported by Payan et al. (Cédric Payan et al., 2010) for concrete with varying w/c. More recently, Legland et al. (Legland, Abraham, Villain, Durand, \& Tournat, 2016) also observed how the mechanisms of material nonlinearity progressively were alleviated as the moisture content increased in concrete samples. Interestingly, the results shown herein demonstrated that not all w/c mortars exhibited similar behavior, but higher ones exhibited lower values of hysteretic parameter. The lowest mortar exhibited considerable higher values of $\eta$ than higher ones. This observation can also be derived from the results reported by Payan et al. (Cédric Payan et al., 2010) in concrete batches with w/c varying from 0.3 to 0.8 , and by Chen and Zhang (Chen \& Zhang, 2015) in mortars with w/c varying from 0.45 to 0.60 . In both studies, the hysteretic parameters decreased as the $w / c$ increased. The precise cause of this relation it is still not clear, since the origin of the microcracking across the different studies can be attributed to different causes. Herein, the enhanced nonlinear behavior in low $w / c$ may be owed to the susceptibility of low $w / c$ to drying shrinkage. However, this may not be the case for the results reported by Payan et al. (Cédric Payan et al., 2010). On other hand, the microstructure of the low w/c mortars is denser and more compact, which in turn may favor rubbing phenomena between microcracks. Conversely, even if microcracks are present, the rubbing phenomena may be prevented in more open microstructures. For 
reference, in Figure 4-11 are shown micrographs corresponding to mortars with w/c of 0.40 and 0.60 , which further support these contentions. Also different binder and aggregate content in cement-based materials can lead to different values of hysteretic behavior ( $C$ Payan, Ulrich, Le Bas, Saleh, \& Guimaraes, 2014). Still, all these aspects deserve further research.
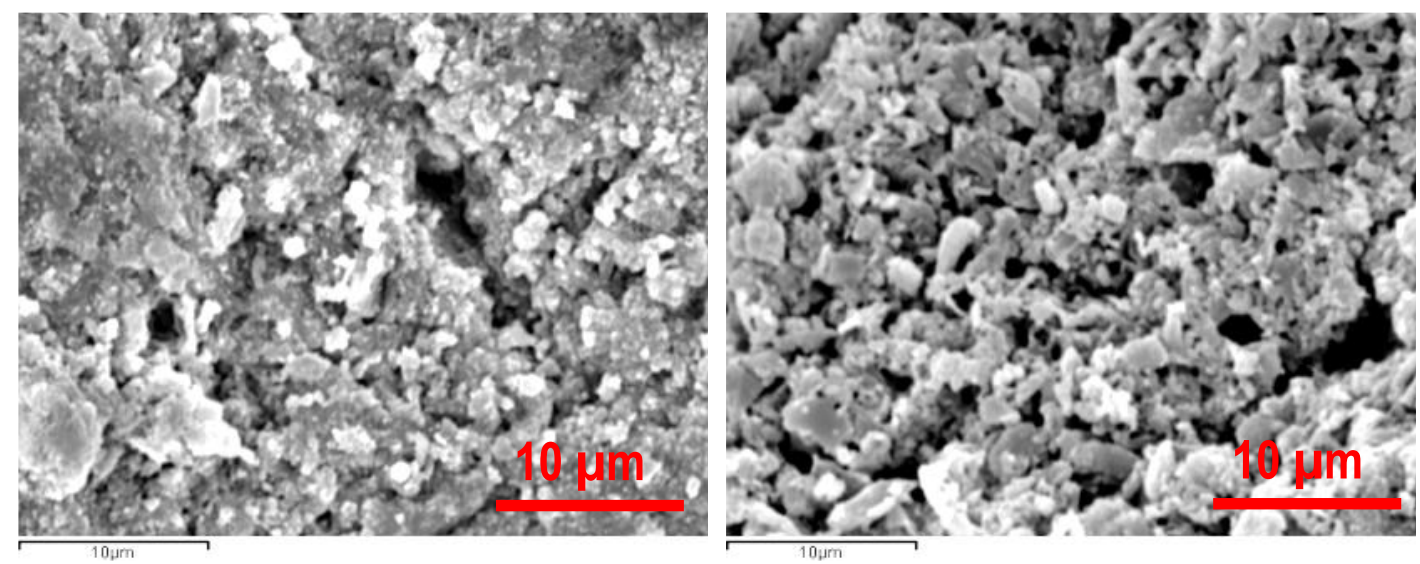

Figure 4-10 SEM micrographs for mortars with $w / c=0.40$ (left), and $w / c=0.60$ (right)

\section{References}

ASTM C215-14. (2014). Standard Test Method for Fundamental Transverse , Longitudinal , and Torsional Resonant Frequencies of Concrete.

Carmeliet, J., \& Van Den Abeele, K. (2004). Poromechanical approach describing the moisture influence on the non-linear quasi-static and dynamic behaviour of porous building materials. Materials and Structures, 37(4), 271-280.

Chatterji, S. (2004). An explanation for the unsaturated state of water stored concrete. Cement and Concrete Composites, 26(1), 75-79.

Chen, J., \& Zhang, L. (2015). Experimental study of effects of water-cement ratio and curing time on nonlinear resonance of concrete. Materials and Structures, 48(1-2), 423-433. 
Eiras, J. N., Popovics, J. S., Borrachero, M. V., Monzó, J., \& Payá, J. (2015). The effects of moisture and micro-structural modifications in drying mortars on vibration-based NDT methods. Construction and Building Materials, 94, 565-571.

Galan, I., Beltagui, H., García-Maté, M., Glasser, F. P., \& Imbabi, M. S. (2016). Impact of drying on pore structures in ettringite-rich cements. Cement and Concrete Research, $84,85-94$.

Galle, C. (2001). Effect of drying on cement-based materials pore structure as identified by mercury intrusion porosimetry A comparative study between oven- , vacuum- , and freeze-drying. Cement and Concrete Research, 31(10), 1467-1477.

Hall, C., \& Tse, T. K. M. (1986). Water movement in porous building materials-VII. The sorptivity of mortars. Building and Environment, 21(2), 113-118.

Johnson, P. A., Zinszner, B., Rasolofosaon, P. N. J., Cohen-Tenoudji, F., \& Van Den Abeele, K. (2004). Dynamic measurements of the nonlinear elastic parameter a in rock under varying conditions. Journal of Geophysical Research, 109(B2), B02202.

Johnston, D. H., Toksoz, M. N., \& Timur, A. (1979). Attenuation of seismic waves in dry and saturated rocks II. Mechanisms. Geophysics, 44(4), 691-711.

Legland, J.-B., Abraham, O., Villain, G., Durand, O., \& Tournat, V. (2016). Suivi du gradient de teneur en eau dans les betons par modulation non lineaire de la coda ultrasonore. In CFA / VISHNO (pp. 1271-1277).

Moukwa, M., \& Aitcin, P.-C. (1988). The effect of drying on cement pastes pore structure as determined by mercury porosimetry. Cement and Concrete Research, 18(5), 745-752.

Payan, C., Garnier, V., \& Moysan, J. (2010). Effect of water saturation and porosity on the nonlinear elastic response of concrete. Cement and Concrete Research, 40(3), 473476.

Payan, C., Ulrich, T. J., Le Bas, P. Y., Saleh, T., \& Guimaraes, M. (2014). Quantitative linear and nonlinear resonance inspection techniques and analysis for material characterization: Application to concrete thermal damage. The Journal of the Acoustical Society of America, 136, 537. 
Snoeck, D., Velasco, L. F., Mignon, a., Van Vlierberghe, S., Dubruel, P., Lodewyckx, P., \& De Belie, N. (2014). The influence of different drying techniques on the water sorption properties of cement-based materials. Cement and Concrete Research, 64, 54-62.

Somaratna, J. (2014, September 16). Evaluation of linear and nonlinear vibration methods to characterize induced microstructural damage in portland cement-based materials. University of Illinois at Urbana-Champaign. Retrieved from https://www.ideals.illinois.edu/handle/2142/50670

Van Den Abeele, K. E.-A., Carmeliet, J., Johnson, P. A., \& Zinszner, B. (2002). Influence of water saturation on the nonlinear elastic mesoscopic response in Earth materials and the implications to the mechanism of nonlinearity. Journal of Geophysical Research, $107,1-11$.

Watchman, J. B., Tefet, W. E., Lam, D. G., \& Apstein, C. S. (1961). Exponential Temperature Dependance of Young's Modulus for Several Oxides. Physical Review, 122(6), 1754.

Yaman, L. O., Hearn, N., Aktan, H. M. I., \& Yaman, I. O. (2002). Active and non-active porosity in concrete Part I: Experimental evidence. Materials and Structures, 35(2), 102-109. 
Chapter 5. Mechanical damage 


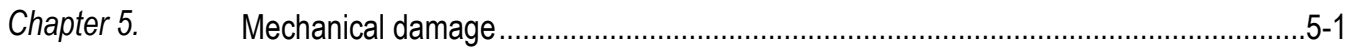

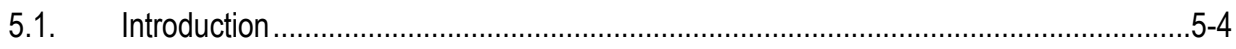

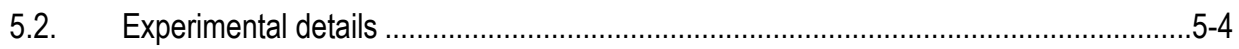

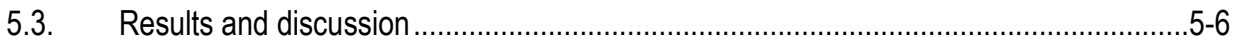

5.3.1. Standard resonant frequency method .....................................................

5.3.2. Nonlinear Impact Resonant Acoustic Spectroscopy .....................................5-13

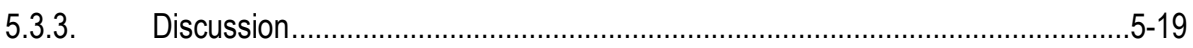

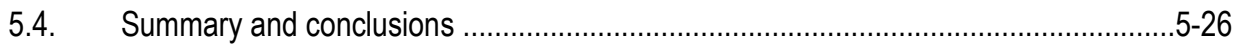

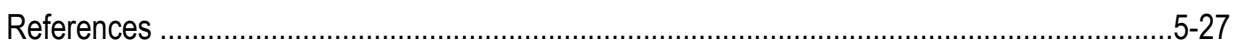




\subsection{Introduction}

In this chapter, the relative sensitivity to detect damage features through nonlinear vibration based techniques is demonstrated on a range of mortar samples produced with varying water-cement ratio. The samples were dried at $60^{\circ} \mathrm{C}$ up to stable mass, so that it moisture effects do not obscure the measurements - see Chapter 4 Effect of drying and internal moisture content (II)- . The samples were loaded at increasing compressive load steps to produce different damage states. The evolution of damage was monitored through the Nonlinear Impact Resonant Acoustic Spectroscopy technique. Also, linear resonant frequency and energy losses were determined on the same set of mortar samples through the resonant frequency method (ASTM C215-14, 2014) as a comparative standard. The relative sensitivity of the linear and nonlinear dynamic properties to detect damage is then compared. Moreover, the results demonstrate that the variability of the dynamic properties also increases with damage. Some of the sources that contribute to increase the variability on the dynamic measurements with damage are identified and discussed.

\subsection{Experimental details}

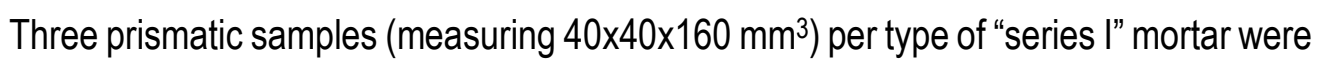
dried at $60^{\circ} \mathrm{C}$ until the weight between consecutive measurements differed in $\pm 1 \mathrm{~g}$. The sample mass was determined every 24 hours. The drying pretreatment was conducted in order to avoid that the dynamic measurements be affected by internal moisture content variations (Eiras, Popovics, Borrachero, Monzó, \& Payá, 2015) —see also Chapter 3 and 4-. A compressive load was applied onto an area of $40 \times 40 \mathrm{~mm}^{2}$ at the center of the long axis of the samples. The compressive load was gradually increased in eight consecutive load steps, starting at $5 \mathrm{kN}$ and up to $40 \mathrm{kN}$. To this end, a universal testing machine INSTRON model 3382 was configured for applying the compressive load. Figure 5-1 shows representative data as recorded by the load cell in the universal testing machine, 
corresponding to the first and the eighth load steps. The load velocity was set to $1 \mathrm{~mm} / \mathrm{min}$ and sustained once the target load is reached. Every loading cycle lasted for 120 seconds.

As a measure that the target load increases, an increase of the extent of microcracking is expected. After every load step, the damage evolution was assessed through two nondestructive techniques: i) the standard resonant frequency method (ASTM C215-14, 2014), and ii) Nonlinear Impact Resonant Acoustic Spectroscopy (NIRAS). The vibration responses were compared with those values obtained at pristine state. The resonant tests were performed so that the relative position of the axial load with regard the sensing and excitation points were consistently maintained across different load steps (see Figure 5-1a). Finally, the samples were loaded up to failure stress, Table 5-1 lists the 28-days strength obtained in sample replicates and the residual compressive strength. The values of the residual compressive strength were consistently lower than the 28-days compressive strength obtained on sample replicates. The reduction of compressive strength varied across the different mortars between $8 \%$ and $19 \%$.

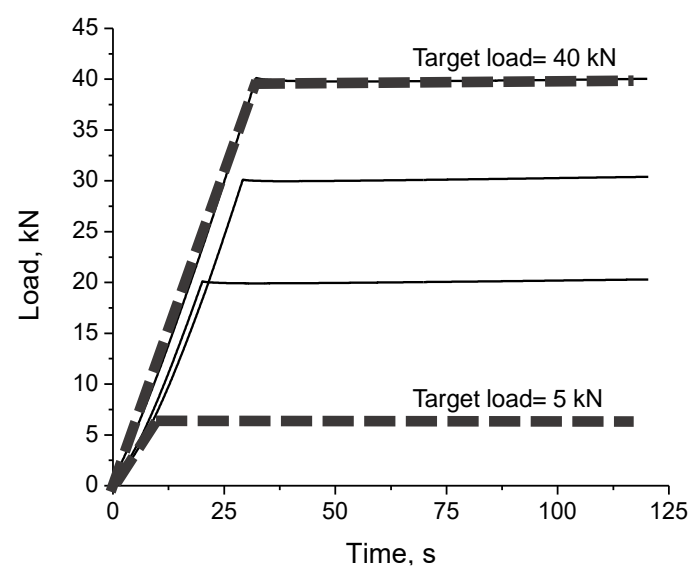

Figure 5-1 Representative compressive load steps (first and eighth). 
Table 5-1 Mortar designation, 28-days compressive strength and residual compressive strength obtained after the damage protocol.

\begin{tabular}{|lccc|}
\hline Designation & $\begin{array}{c}\text { 28-days compressive } \\
\text { strength (MPa) }\end{array}$ & $\begin{array}{c}\text { Residual compressive } \\
\text { strength (MPa) }\end{array}$ & Reduction (\%) \\
\hline I-040 & $65.41 \pm 1.84$ & $55.90 \pm 6.09$ & 15 \\
I-045 & $54.86 \pm 2.98$ & $50.69 \pm 2.13$ & 8 \\
I-050 & $53.85 \pm 1.36$ & $45.27 \pm 0.58$ & 16 \\
I-055 & $52.65 \pm 1.84$ & $42.77 \pm 1.20$ & 19 \\
I-060 & $49.97 \pm 2.35$ & $42.66 \pm 1.28$ & 15 \\
I-065 & $40.30 \pm 2.96$ & $36.23 \pm 1.92$ & 10 \\
\hline
\end{tabular}

\subsection{Results and discussion}

\subsubsection{Standard resonant frequency method}

Figure 5-2 shows representative frequency spectra corresponding to one pristine sample, and after $30 \mathrm{kN}$ and $40 \mathrm{kN}$ load steps; ten repetitions are shown. The mechanical damage led to i) a decrease of the resonant frequency value, ii) an increase of material attenuation -that is $Q$ decreased-, and iii) the resonant peak became asymmetric for severe cases of damage, especially after the $40 \mathrm{kN}$ load step. The latter effect was previously noted in resonance experiments conducted in rocks (P. A. Johnson \& Rasolofosaon, 1996), and was pointed out as a typical signature of those materials that exhibit mechanical hysteresis in their stress-strain relationships. Experimental evidences have demonstrated that a frequency-time variation within the signal produces an asymmetric resonant peak as analyzed through the FFT. This assertion is further supported in Chapter 8: Nonlinear Single Impact Resonance Acoustic Spectroscopy. (NSIRAS): Frequency domain analysis. In this chapter however, the hysteretic behavior is investigated through NIRAS technique. 


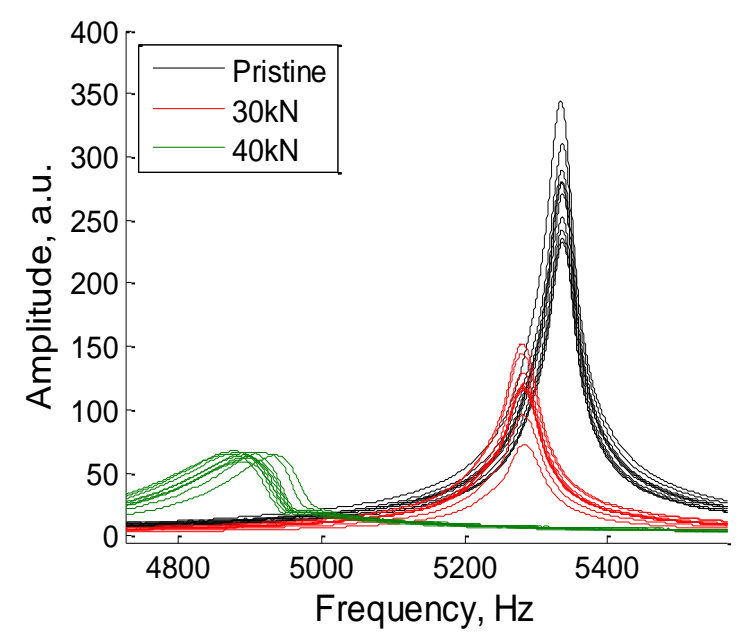

Figure 5-2 Representative frequency spectra, as obtained by the standard ASTM C215 method on a sample 1-050 at pristine state, and after applying $30 \mathrm{kN}$ and $40 \mathrm{kN}$ load steps. Ten impacts of relatively same energy are shown.

Figure 5-3a and Figure 5-3b show the evolution of the resonant frequency and $Q$, obtained for every mortar and after every load step. The mean value of ten impacts of relatively same energy is shown. The microcracking damage originated upon increasing compressive loading, caused a reduction of the stiffness, and enhanced the internal friction so that the material attenuation increased. However, the succeeding load steps did not cause a monotonic reduction of resonant frequency and $Q$, but they were almost constant showing only test-to-test variations during the firsts load steps (loads lower than $25 \mathrm{kN}$ ). Once a critical load step was reached, the dynamic properties were significantly altered, so that they significantly differed from those obtained in pristine state. For the range of mortars being studied herein, there existed no strong relationship between $Q$ and water-cement ratio, as they exhibited for resonant frequency. Still, the values of $Q$ slightly decreased with watercement, and most likely because of the drying pretreatment favored microcracking damage (Eiras et al., 2015). This effect might be exacerbated for the lowest water-cement mortar, since it exhibited noticeable lower values of $Q$ than the rest of mortars. These conclusions further support the idea that oven-dried mortar samples (say at $60^{\circ} \mathrm{C}$ and above) leads to subtle microcracking damage (Yurtdas, Peng, Burlion, \& Skoczylas, 2006). On other hand the mechanical damage also caused an increase on the variability of the dynamic properties, so that the reduction of stiffness and increase of attenuation within the material was 
accompanied by an increase of the variability of the dynamic properties. Figure $5-3 c$ and Figure 5-3d show the evolution of the standard deviation obtained on the measurement of the dynamic properties in every mortar sample.
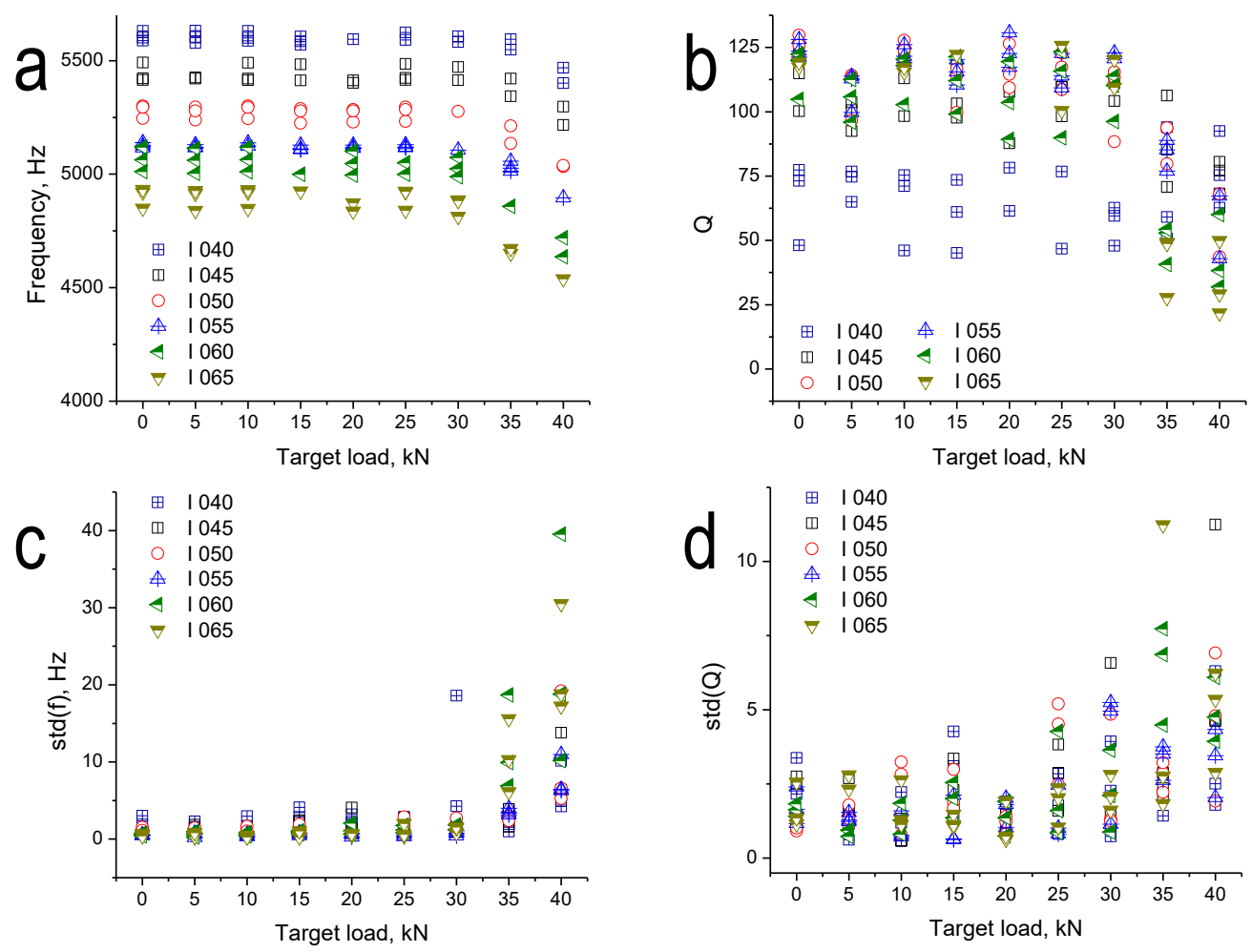

Figure 5-3 Evolution of mean and standard deviation values of the dynamic parameters with increasing compressive load: a) mean resonant frequency, b) mean quality factor, c) standard deviation of the resonant frequency, and d) standard deviation of the quality factor. Three samples per type of mortar and ten data per value.

Along with an increase of the attenuation of the mechanical vibration energy, the mechanical damage enhances the hysteretic behavior. The latter causes resonant frequency and attenuation depend on the excitation amplitude (K. E. Van Den Abeele, Sutin, Carmeliet, \& Johnson, 2001). Such effects may affect the measurements of the dynamic properties, as measured through the standard test ASTM C215-14. Figure 5-4a and Figure 5-4b show the 
frequency-amplitude and Q-amplitude dependences, corresponding to the representative spectra shown in Figure 5-2 -one sample I-050 at pristine state and after 30kN and 40kN load steps-; three insets show magnified plots of the relationship between spectral amplitude and resonant frequency, for every damage case. In pristine state and after $30 \mathrm{kN}$ load step, the resonant frequency data correlated with the spectral amplitude. In some extent, the increase of variability can be explained through the variations of spectral amplitude in every test. This can be quantified with the magnitude of the slope of the amplitude-frequency relationship, shown within the inset plots in Figure 5-4. These variations were in some extent explained by the variations of spectral amplitude, since the resonant frequency values correlated with the variation of spectral amplitude. This is indeed, a manifestation of the fast dynamic effect.

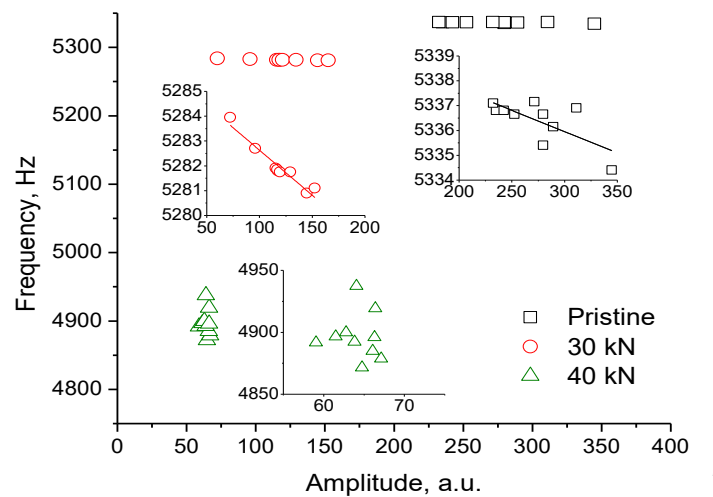

After $40 \mathrm{kN}$ load step, the spectral amplitude was significantly reduced meaning that the same range of mechanical energy input did not produce similar variation of signal amplitude. In addition, the resonant frequency did not correlate with the spectral amplitude, and hence, the resonant frequency variability seemed not to be explained as a function of the spectral amplitude. However, it did so with the order whereby the data was collected. Figure 5-5a to Figure $5-5 \mathrm{c}$ show the relation between the impact order and the spectral amplitude, the resonant frequency and $Q$. To determine the impact of such effect, a multiple regression 
analysis was performed, so that the resonant frequency data $(f)$ is related to the spectral amplitude $(A)$, and to the order in which the data was collected (ORDER) as

$$
f=p_{0}+p_{1} \cdot A+p_{2} \cdot \text { ORDER }
$$

where $p_{0}, p_{1}$, and $p_{2}$, are the intercept, and the regression coefficients related to the effects $A$ and ORDER on the resonant frequency data. Figure 5-5a shows the variables ORDER and $A$ were not correlated; the absolute value of the Pearson's correlation coefficient $(R)$ was in all cases lower than 0.5 , and hence multicollinearity did not disturb the analysis. Likewise, it was investigated whether the variability of the $Q$ data, could be explained through the variables $A$ and ORDER as

$$
Q=q_{0}+q_{1} \cdot A+q_{2} \cdot \text { ORDER }
$$

where $q_{0}, q_{1}$ and $q_{2}$ are the intercept and the regression coefficients related to the effects $A$ and ORDER on the $Q$ data. Table 5-2 lists the results of the multiple regression analysis obtained in different damage states for one sample I-050. The variability of the resonant frequency values seemed to be well explained by the spectral amplitude and the order in which the data was collected, even in the undamaged state. The analogous analysis performed on the $Q$ data resulted in lower percentages of explained variance, yet the effects of $A$ and ORDER were meaningful at severe damaged states (after $30 \mathrm{kN}$ and $40 \mathrm{kN}$ load steps). 

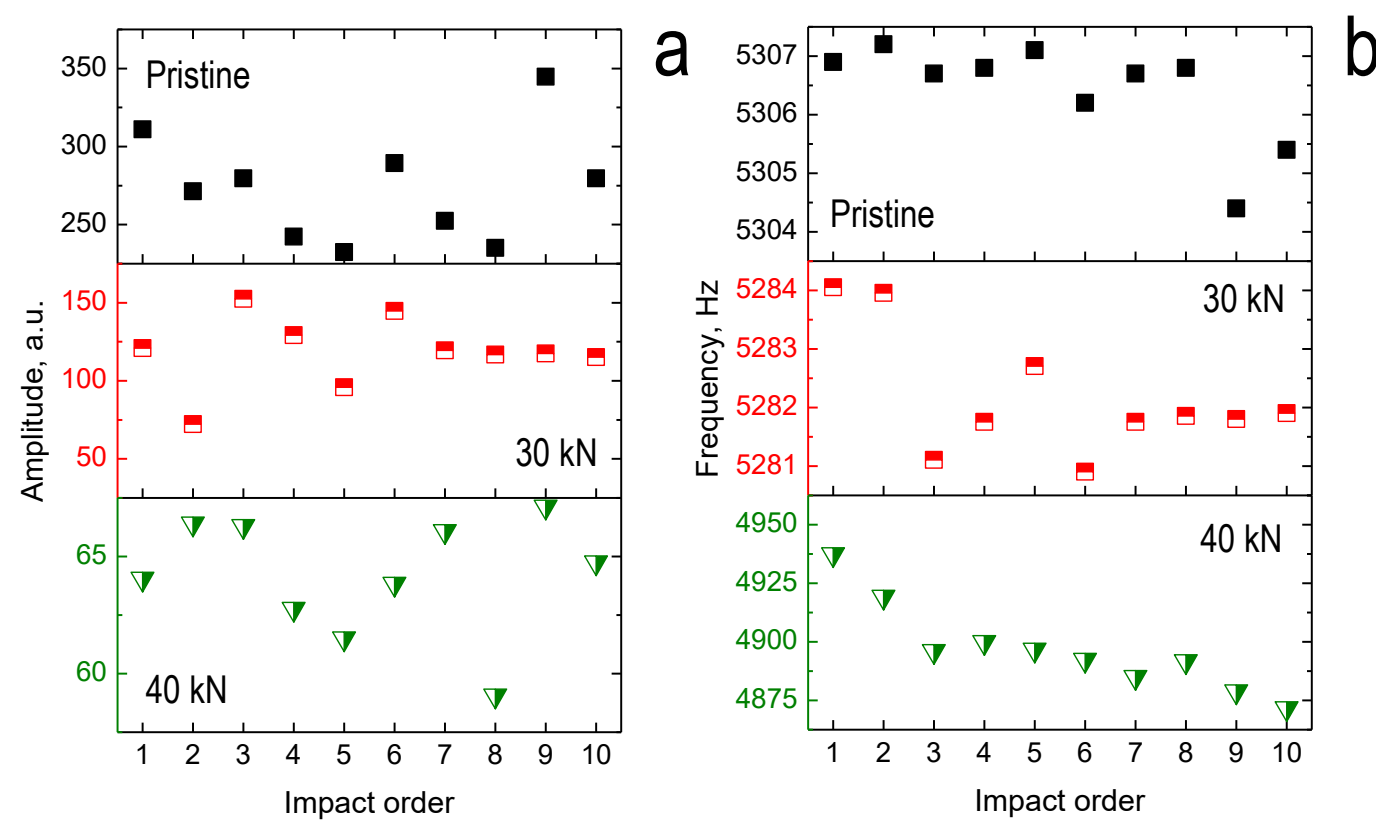

Figure 5-5 a) Spectral amplitude as a function of the

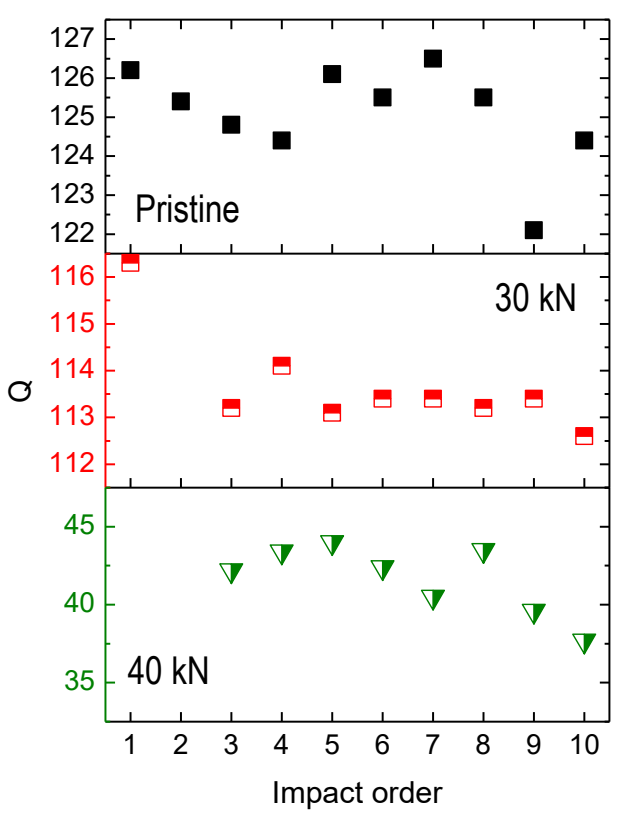

C order in which the signals were collected, across

C three damage states: in pristine state (top plot), after $30 \mathrm{kN}$ (middle plot), and after $40 \mathrm{kN}$ (bottom plot).

Same conventions for b) flexural frequency, and c) quality factor (Q). 
Table 5-2 Multiple regression results conducted on the variables $f$ and $Q$ as function of the spectral amplitude. Results for one representative sample I-050; p-values are shown in parentheses.

\begin{tabular}{|c|c|c|c|c|c|c|c|c|}
\hline \multirow[t]{2}{*}{ Load } & \multicolumn{4}{|c|}{$\begin{array}{c}\text { Resonant frequency } \\
f=p_{0}+p_{1} \cdot A+p_{2} \cdot \text { ORDER }\end{array}$} & \multicolumn{4}{|c|}{$\begin{array}{c}\text { Quality factor } \\
Q=p_{0}+p_{1} \cdot A+p_{2} \cdot \text { ORDER }\end{array}$} \\
\hline & constant & $A$ & ORDER & $R^{2}$ & constant & $A$ & ORDER & $R^{2}$ \\
\hline Pristine & 5311.97 & $\begin{array}{l}-0.02 \\
(0.00)\end{array}$ & $\begin{array}{c}-0.20 \\
(0.00)\end{array}$ & 0.94 & 131.52 & $\begin{array}{c}-0.02 \\
(0.07)\end{array}$ & $\begin{array}{l}-0.17 \\
(0.17)\end{array}$ & 0.50 \\
\hline $5 \mathrm{kN}$ & 5299.32 & $\begin{array}{l}-0.02 \\
(0.00)\end{array}$ & $\begin{array}{l}-0.10 \\
(0.00)\end{array}$ & 0.99 & 113.59 & $\begin{array}{c}0.01 \\
(0.43)\end{array}$ & $\begin{array}{l}-0.19 \\
(0.02)\end{array}$ & 0.59 \\
\hline $10 \mathrm{kN}$ & 5293.16 & $\begin{array}{c}0.04 \\
(0.00)\end{array}$ & $\begin{array}{l}-0.28 \\
(0.00)\end{array}$ & 0.90 & 123.06 & $\begin{array}{c}0.03 \\
(0.04)\end{array}$ & $\begin{array}{l}-0.11 \\
(0.34)\end{array}$ & 0.51 \\
\hline $15 \mathrm{kN}$ & 5292.31 & $\begin{array}{l}-0.09 \\
(0.00)\end{array}$ & $\begin{array}{l}-0.10 \\
(0.00)\end{array}$ & 0.97 & 107.31 & $\begin{array}{c}0.05 \\
(0.01)\end{array}$ & $\begin{array}{c}0.02 \\
(0.87)\end{array}$ & 0.62 \\
\hline $20 \mathrm{kN}$ & 5289.51 & $\begin{array}{l}-0.02 \\
(0.00)\end{array}$ & $\begin{array}{l}-0.13 \\
(0.00)\end{array}$ & 0.97 & 132.57 & $\begin{array}{l}-0.02 \\
(0.10)\end{array}$ & $\begin{array}{c}0.08 \\
(0.28)\end{array}$ & 0.48 \\
\hline $25 \mathrm{kN}$ & 5298.66 & $\begin{array}{l}-0.02 \\
(0.00)\end{array}$ & $\begin{array}{l}-0.11 \\
(0.00)\end{array}$ & 0.91 & 100.46 & $\begin{array}{c}0.08 \\
(0.01)\end{array}$ & $\begin{array}{l}-0.27 \\
(0.16)\end{array}$ & 0.63 \\
\hline $30 \mathrm{kN}$ & 5287.14 & $\begin{array}{l}-0.03 \\
(0.01)\end{array}$ & $\begin{array}{l}-0.18 \\
(0.02)\end{array}$ & 0.79 & 116.99 & $\begin{array}{l}-0.01 \\
(0.49)\end{array}$ & $\begin{array}{l}-0.29 \\
(0.03)\end{array}$ & 0.57 \\
\hline $35 \mathrm{kN}$ & 5226.45 & $\begin{array}{l}-0.10 \\
(0.00)\end{array}$ & $\begin{array}{l}-0.57 \\
(0.00)\end{array}$ & 0.92 & 105.67 & $\begin{array}{l}-0.09 \\
(0.00)\end{array}$ & $\begin{array}{l}-0.54 \\
(0.00)\end{array}$ & 0.93 \\
\hline $40 \mathrm{kN}$ & 4996.41 & $\begin{array}{l}-1.05 \\
(0.39)\end{array}$ & $\begin{array}{l}-5.81 \\
(0.00)\end{array}$ & 0.84 & 75.56 & $\begin{array}{l}-0.47 \\
(0.00)\end{array}$ & $\begin{array}{l}-0.64 \\
(0.00)\end{array}$ & 0.91 \\
\hline
\end{tabular}

The foregoing results (shown in Table 5-2) were not an isolated case, but they were consistently reproduced in all mortar samples. Besides the fast dynamic effect -that is frequency-amplitude and Q-amplitude dependences-, every impact excitation seemed to drive the material away from the elastic modulus at rest. Such an effect is most likely owed to the slow dynamic effect. The transient vibrations, as those produced in resonant frequency tests, cause an apparent softening of the material, so that the resonant frequency decreases. However, once the dynamic excitation energy is completely damped —this is after $\sim 3 \cdot 10^{-2}$ seconds herein (see Figure 2.1b, in Chapter 2: Materials and methods)-, the resonant frequency may not be completely recovered. The time that the material takes to recover its original resonant frequency value at rest, can range from $\sim 10^{3}$ to $\sim 10^{5}$ seconds according to other studies (P. Johnson \& Sutin, 2005). The rate of recovery largely depends on the extent of damage, so that the more damage features, the more time the material takes to recover. 
Such an effect leads to increase the variability on the measurement of the resonant frequency. In pristine samples, an average downward shift of $\sim 0.5 \mathrm{~Hz}$ between consecutive impacts was found. This value increased with damage. The average downward shift between consecutive impacts escalated up to $\sim 10 \mathrm{~Hz}$, for severely damaged samples. Regrettably, the actual impact of the slow dynamics effect onto the dynamic responses cannot be precisely determined with the test data reported here, since the time lapse between consecutive impacts was not controlled. For reference, it normally varied between 3 and 10 seconds. Still, in all cases, it was identified a negative correlation of the resonant frequency value with the order in which the data were collected. This effect motivated additional experiments described in Chapter 12, which consisted on performing a constant rate and energy input excitation in damaged concrete samples. These results call attention to the effect of slow dynamic on the robustness on the measurement of the dynamic properties as investigated through vibration-based nondestructive methods. Therefore, for ten repeated impacts of relatively same energy, the natural variation of the spectral amplitude produces a downward shift of the resonant frequency, as the damage features increase within the samples. This condition is not considered in the standards, and it contributes to increase the variability on the measurement of the resonant frequency. The latter, also concerns the robustness of the NIRAS test results.

\subsubsection{Nonlinear Impact Resonant Acoustic Spectroscopy}

NIRAS tests were conducted for investigating the dependence between resonant frequency and spectral amplitude across different damage states. The NIRAS test consists in determining the resonant frequency at increasing impact energy levels. The particular test configuration conducted herein allowed simultaneous comparison of first bending and longitudinal modes of vibration - see Chapter 2 for detailed description of the NIRAS test. Figure 5-6a and Figure 5-6b show representative frequency spectra for ten impact events, obtained in one pristine mortar sample, and after $30 \mathrm{kN}$ and $40 \mathrm{kN}$ compressive load steps; first bending $\left(f_{\text {flex }}\right)$ and longitudinal $\left(f_{\text {long }}\right)$ modes are shown. Congruently with the results 
obtained through the standard resonant frequency method, the resonant frequency values ( $f_{\text {flex }}$ and $f_{\text {long }}$ ) decreased, and the vibration responses progressively became more attenuated with damage.

Figure 5-6b shows magnified spectra corresponding to the first bending mode of vibration for every damage condition. With increasing mechanical damage, the downward resonant frequency shift frequency was more noticeable. This apparent softening of the material is a manifestation of mechanical hysteresis (K. E. Van Den Abeele et al., 2001), and it is normally quantified through the slope $(\eta)$ of the relation between the normalized frequency shift and the spectral amplitude $-\Delta f / f_{0}=\eta \cdot A$, wherein $f_{o}$ is the resonant frequency obtained for the lowest impact energy event-. Figure 5-6c and Figure 5-6d show the relationship between the normalized resonant frequency shift and the spectral amplitude for flexural and longitudinal modes of vibration, and the computation of the hysteretic parameter for the representative cases shown in Figure 5-6a and Figure 5-6b. The growth of microcracking damage almost obliterated the longitudinal mode of vibration. For this reason, the longitudinal mode of vibration produced considerably scattered results in severe damage conditions (after $40 \mathrm{kN}$ herein), and hence, the computation of the hysteretic parameter was not reliable. Figure 5-6e and Figure 5-6f show the hysteretic parameters for flexural ( $\left.\eta_{\text {flex }}\right)$ and longitudinal $\left(\eta_{\text {long }}\right)$ modes for all mortars and across all loading steps. The values $\eta_{\text {flex }}$ and $\eta_{\text {long }}$ increased in all mortar samples as a measure that mechanical damage increased, and following similar trends, to those exhibited by the resonant frequency and $\mathrm{Q}$.

Interestingly, the values of $\eta_{\text {long }}$ were consistently lower than $\eta_{\text {flex }}$ regardless of the water-cement ratio and across all load steps. A fair comparison of the hysteretic parameter must consider the attained strain amplitude, meaning that the acceleration to strain conversion factors corresponding to each family mode ( $k_{\text {flex }}$ and $k_{\text {long }}$ ) have to be determined. However, a hard conversion from acceleration to strain is not straightforward, and the yet conducted conversions underlie on an Euler beam model, assuming linear elastic behavior (Gaberson, 2012; Hunt, 1960). On other hand, the hysteretic behavior appears to be strain- 
rate dependent, and also, the relative position of the microcracks with regard the dynamic motion of every family of vibration modes, can contribute in different extent to the downward frequency shift. In this respect, experimental evidences suggest that the nonlinear response in shear is larger than in bulk mode resonance (P. A. Johnson, 2006). However, still a threedimensional formulae is not yet established (K. E.-A. Van Den Abeele, 2007). In any event, both hysteretic parameters progressively increased as the mechanical damage progressed, and allowed identifying an increase of material nonlinearity. 

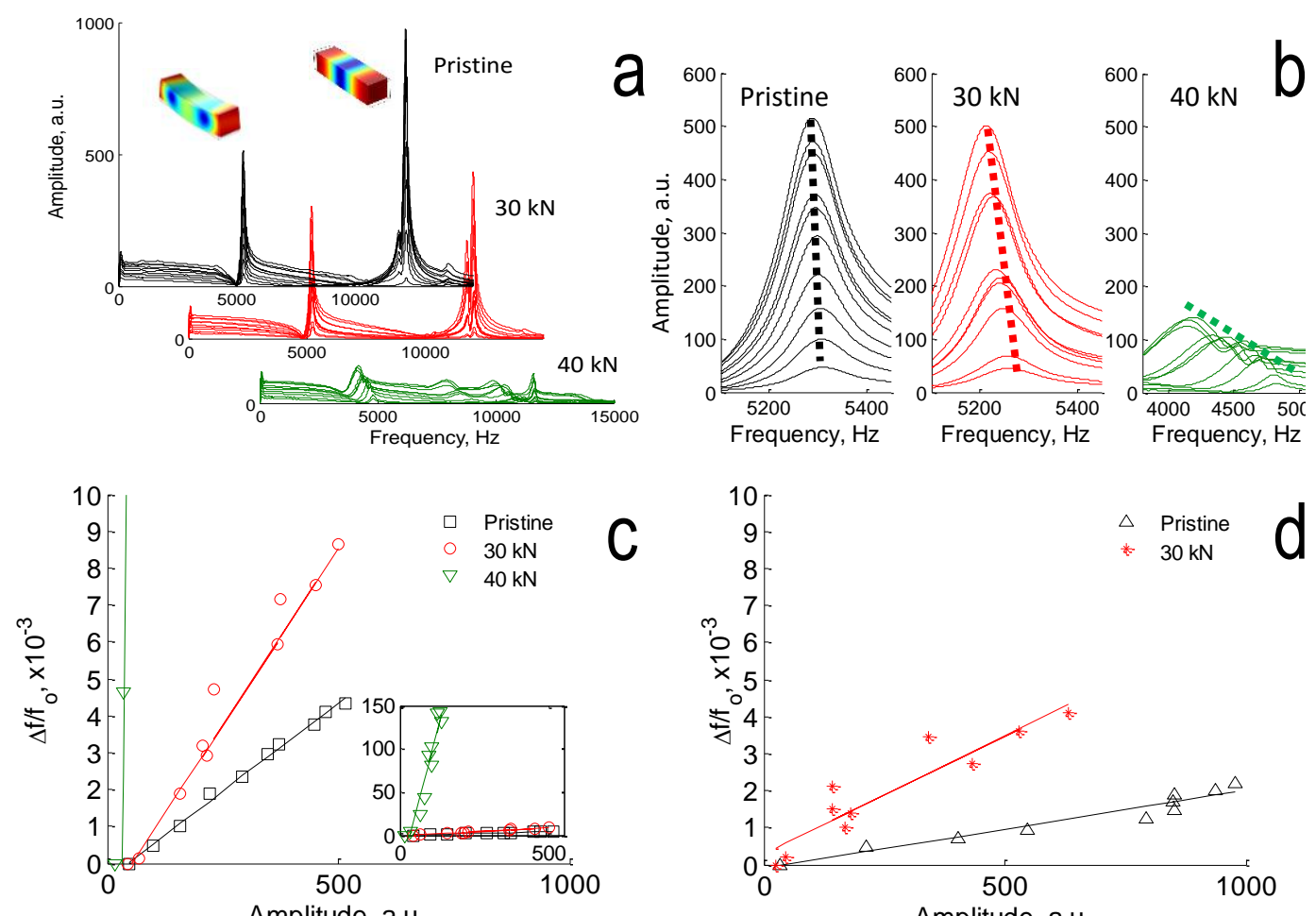

10
9
8
7
7
06
$\times \quad 5$
04
4
3
3
2
1
0
0

Frequency, $\mathrm{Hz}$

Amplitude, a.u.
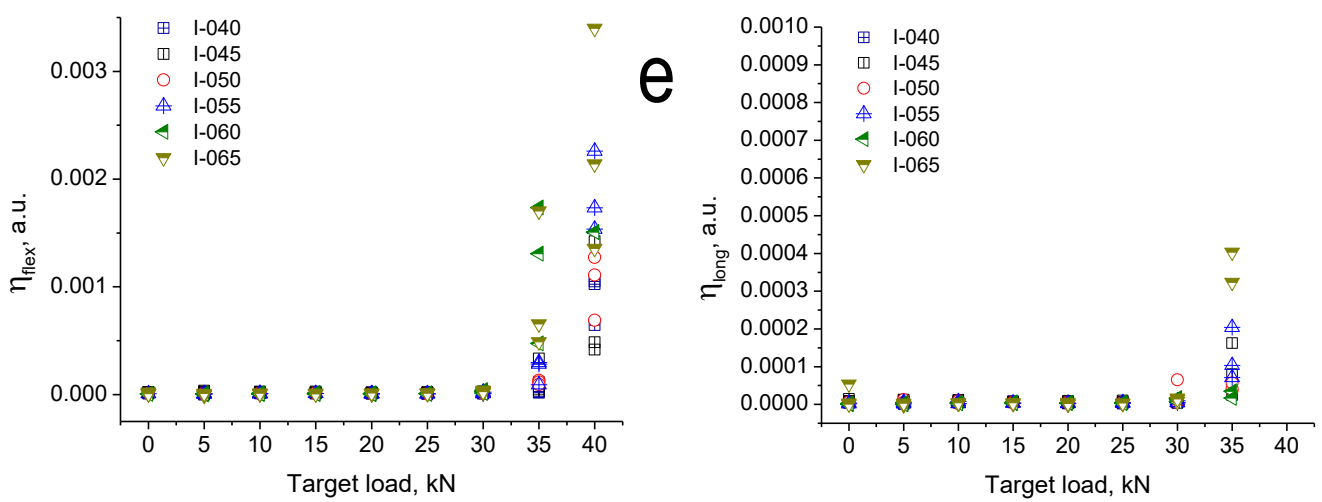

Figure 5-6 Representative spectra obtained in a mortar sample 1-050 through NIRAS test. The spectra showthe occurrence of two vibration modes (flexural and longitudinal) obtained in pristine state and after $30 \mathrm{kN}$ and $40 \mathrm{kN}$ load steps, and b) magnified plots of the flexural mode of vibration; c) normalized frequency shift as a function of the attained spectral amplitude for flexural mode, and for d) Iongitudinal mode. e) and f) show the hysteretic parameter corresponding to the flexural and longitudinal vibration modes. 
On other hand, the relative position of the longitudinal peak respect to the flexural peak increased with damage. The Figure 5-7a illustrates such an effect, wherein the spectra of one sample I-050 at pristine state and after the $30 \mathrm{kN}$ load step are shown. The spectra are normed with respect to their respective $f_{\text {flex }}$ values. At pristine state the $f_{\text {long }}$ lied at $\sim 2.30$ times the $f_{\text {flex}}$, whereas the ratio increased up to $\sim 2.32$ after the $30 \mathrm{kN}$ load step. Figure $5-7 \mathrm{~b}$ shows the evolution of the $f_{\text {long }} / f_{\text {flex }}$ with increasing compressive load, obtained for the lowest impact energy level (impact force $\sim 35 \mathrm{~N}$ ). Although the results were somewhat scattered, the override trend was consistently reproduced for all mortar samples, showing an increase of the $f_{\text {long }} / f_{\text {flex }}$ especially in the last load step. The values of $f_{\text {long }} / f_{\text {flex }}$ at pristine state ranged from 2.29 to 2.34 and escalated by $\sim 0.5 \%$ to $\sim 4 \%$ those obtained in pristine state. Equating the equations for obtaining the dynamic modulus of elasticity from longitudinal and flexural modes - for instance, those provided in (Jones, 1962) - it can be drawn that for a given prismatic sample geometry, the ratio $f_{\text {long }} / f_{\text {flex }}$ is a function of the shape-correction factors given by Pickett's for flexural vibrations ( $\left.T_{\text {flex }}\right)$ (Pickett, 1945), and by Spinner and Tefft's (Spinner \& Tefft, 1961) for longitudinal vibrations ( $\left.T_{\text {long }}\right)$; the relevant equation is

$$
\frac{f_{\text {long }}}{f_{\text {flex }}}=\frac{\sqrt{12} \cdot \pi \cdot l}{4.73^{2} \cdot h} \sqrt{T_{\text {long }}(v, h, l) \cdot T_{\text {flex }}(v, h, l)} .
$$

The shape-correction factors $T_{\text {long }}$ and $T_{\text {flex }}$ are functions of $v$, and of the sample dimensions: thickness $(h)$ and length $(l)$. It follows from Eq. 5-3 that for given sample dimensions the values of $f_{\text {long }} / f_{\text {flex }}$ only depend on $v$. For reference, the $f_{\text {long }} / f_{\text {flex }}$ varies between 2.298 and 2.318 for $v$ varying from 0.15 to 0.40 for our particular sample geometry $(l / h=4)$, according to Eq. 5-3. Etcheverry and Sánchez (Etcheverry \& Sánchez, 2009) pointed out that the traditional formulae (Pickett, 1945; Spinner \& Tefft, 1961) for obtaining the dynamic modulus from resonant frequency measurements fall into errors which magnitudes depend on sample dimensions and material properties. The authors quantified the magnitudes of the errors by comparing the traditional formulae solutions with those provided by an eigen-frequency solution of prismatic samples, with varying sample dimensions and material properties 
(modulus, density and Poisson's ratio). The results demonstrated, that the errors become important, especially when the $l / h$ is relatively small: $l / h<6$. For our particular sample geometry, a three-dimensional numerical eigen-frequency analysis, and considering linear elastic isotropic behavior, led to $f_{\text {long }} / f_{\text {flex }}$ values varying from 2.300 to 2.303 with $v$ ranging from 0.15 to 0.40 . Therefore, it follows from the observation of the $f_{\text {long }} / f_{\text {flex }}$ values that the mechanical damage causes an apparent increase of $v$ (see Figure 5-7b).

Figure $5-7 \mathrm{c}$ shows the experimental $f_{\text {long }} / f_{\text {flex }}$ values obtained across the damage protocol for one I-050 sample. The same plot shows the $f_{\text {long }} / f_{\text {flex }}$ variation in a $4 \times 4 \times 16 \mathrm{~cm}^{3}$ sample as a function of the Poisson's ratio (top axis). For reference, the analogous analysis performed on a $3.95 \times 3.95 \times 16 \mathrm{~cm}^{3}(h / l=0.246875)$ led to values of $f_{\text {long }} / f_{\text {flex }}$ of $\sim 2.32$. Therefore, the $f_{\text {long }} / f_{\text {flex }}$ value is far more sensitive to sample geometry variations. However, the $f_{\text {long }} / f_{\text {flex }}$ values obtained across the damage protocol cannot only be explained through sample dimension and $v$ variations, and thus an important deviation from the linear elastic behavior can be devised. Elaqra and coworkers (Elaqra, Godin, Peix, R'Mili, \& Fantozzi, 2007) observed similar behavior on concrete samples investigated upon increasing compressive mechanical loading. The results showed therein elucidated an apparent increase of the Poisson's ratio as compressive damage progressed. This is rather not a true Poisson's ratio because such increase ensues from the cracking damage within the samples, and sample dimensions variations produced upon compressive loading (Neville, 1995). Moreover, from the observation of the downward resonant frequency shift produced upon increasing impact hammer force, it can be drawn that $f_{\text {long }} / f_{\text {flex }}$ varies on a single test, as a function of the impact hammer force. However, this effect did not mask the override trend shown in Figure 5-7b. 

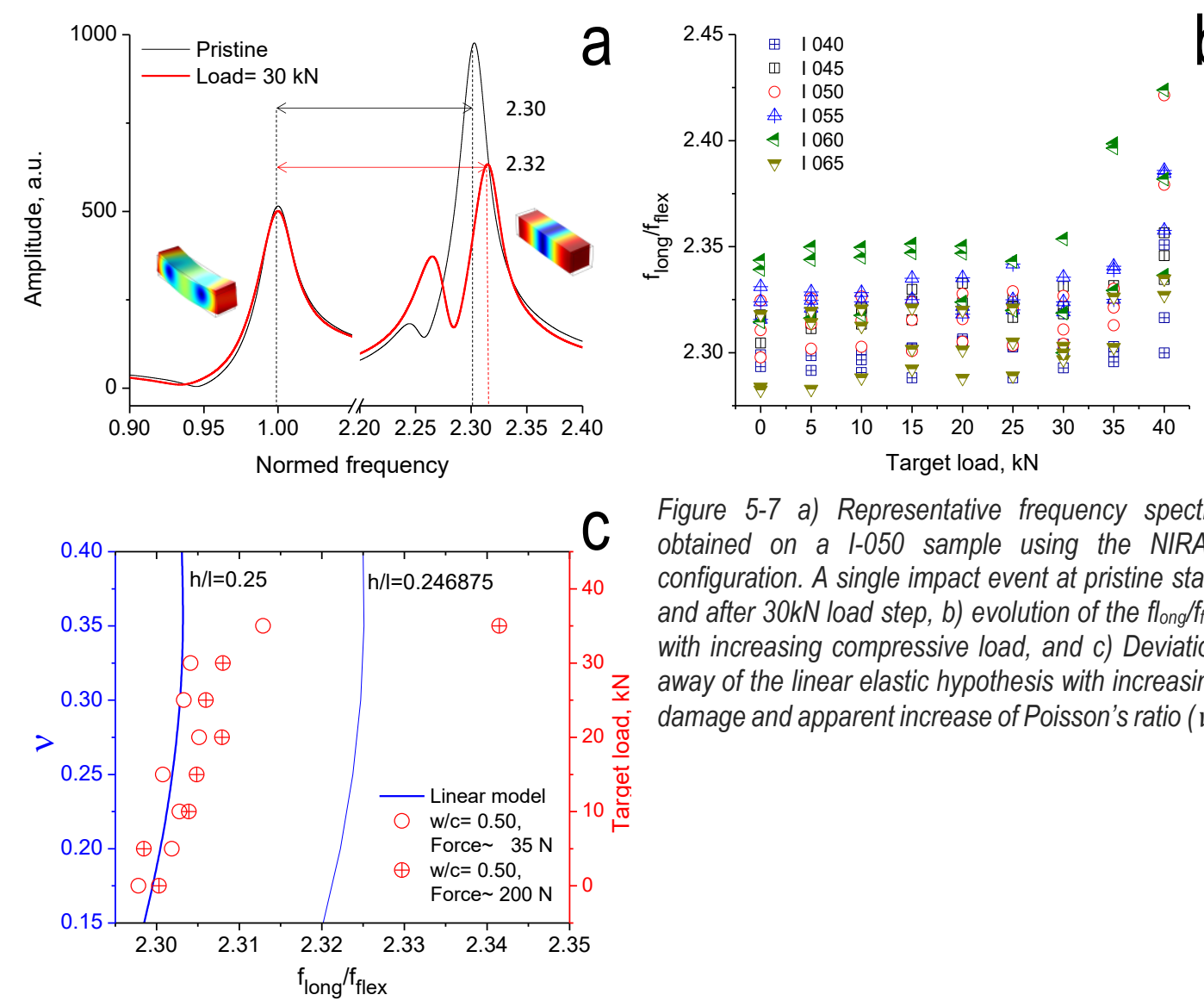

Figure 5-7 a) Representative frequency spectra obtained on a 1-050 sample using the NIRAS configuration. A single impact event at pristine state and after $30 \mathrm{kN}$ load step, b) evolution of the flong/fflex with increasing compressive load, and c) Deviation away of the linear elastic hypothesis with increasing damage and apparent increase of Poisson's ratio ( $v)$.

\subsubsection{Discussion}

Overall, linear and nonlinear dynamic properties were altered during the damage protocol for all mortars. Usually, the effective reduction of material stiffness because of microcracking damage is considered as (Lemaitre \& Chaboche, 1994)

$$
E_{o, n}=\left(1-D_{o}\right) \cdot E_{o, r},
$$


wherein the linear modulus after every load step $\left(E_{o, n}\right)$ decreases with regard that obtained at pristine state $\left(E_{0, r}\right)$ by a factor $\left(1-D_{0}\right)$; subscripts $r$ and $n$ stand for pristine and damaged states. Ignoring Poisson's ratio, mass and volume variations across different damage states, the damage parameter $D_{0}$ can be expressed as a function of the linear resonant frequency $\left(f_{0}\right)$ as

$$
D_{o} \approx 1-\frac{f_{o, n}^{2}}{f_{o, r}^{2}}
$$

where $f_{o, r}$ is the linear resonant frequency obtained at pristine state, and $f_{o, n}$ that obtained for increasing damage. The damage parameter in Eq. 5-5 is used on the assessment of freezing-thawing damage, and commonly appealed in accelerated ageing tests in cement based materials. Analogously, the damage parameter can be considered by including the relative variations of material nonlinearity. If a one-dimensional nonlinear modulus $(E)$ wherein the hysteresis is the main source of nonlinearity is considered as (K. E. Van Den Abeele et al., 2001)

$$
E=E_{o}(1-\alpha \cdot(\Delta \varepsilon+\varepsilon \cdot \operatorname{sign}(\dot{\varepsilon})))
$$

the damage parameter $(D)$ including the relative variations of the nonlinear modulus is

$$
D \approx 1-\frac{f_{o, n}^{2} \cdot\left(1-2 \cdot \alpha_{n} \cdot \Delta \varepsilon\right)}{f_{o, r}^{2} \cdot\left(1-2 \cdot \alpha_{r} \cdot \Delta \varepsilon\right)},
$$

where $\alpha_{r}$ and $\alpha_{n}$ are the hysteretic parameters obtained at pristine and damaged states. Note, $D$ is evaluated for the maximum strain value $\left(\varepsilon_{\max }\right)$, and it is convened that $\operatorname{sign}\left(\varepsilon_{\max }\right)=1$ and $\varepsilon_{\max }=-\varepsilon_{\min }$; thus, $\varepsilon_{\max } \operatorname{sign}\left(\varepsilon_{\max }\right)=\Delta \varepsilon$. Thereby, the damage parameter $D$ lumps the relative decrease of linear elastic modulus and the relative increase of nonlinear hysteretic behavior because of accrued microcracking damage, in a sole parameter. It follows from Eq. 5-7 that the value of $D$ depends on the attained strain amplitude $(\Delta \varepsilon)$. Thus, the more strain 
amplitude is attained, the more the material softs, which in turn results in greater values of $D$. Therefore, by including the nonlinear behavior within the damage parameter, the detection of damage is enhanced, and more so, when higher values of strain amplitude are considered in Eq. 5-7. The effective reduction of the modulus relates to the linear damage parameters $D_{0}$ as

$$
1-D \approx\left(1-D_{o}\right) \cdot D_{\alpha}(\Delta \varepsilon)
$$

where the nonlinear contribution to the damage parameter $\left(D_{\alpha}\right)$ equals

$$
D_{\alpha}=\frac{1-2 \cdot \alpha_{n} \cdot \Delta \varepsilon}{1-2 \cdot \alpha_{r} \cdot \Delta \varepsilon}
$$

Herein, the damage parameter $D$ was evaluated from the hysteretic parameter corresponding to the flexural mode of vibration $\left(\eta_{\text {flex }}\right)$. Moreover, it is assumed that the proportionality constants relating spectral amplitude and strain amplitude are the equivalent across different damage states $\left(k_{n}=k_{r}\right)$. Consequently, under this assumption the damage parameter $D$ can be evaluated from the spectral amplitude -thus, $\Delta \varepsilon=A^{*} k_{n}=A^{*} k_{r}$, and $\Delta \varepsilon^{*} \alpha=A^{*} \eta$ - The spectral amplitude values were set to 100 arbitrary units; such a value is comprised within the range of spectral amplitudes produced in the NIRAS tests conducted herein. Moreover, the values of the hysteretic parameter corresponding to the flexural mode were used to deriving $D$. Figure 5-8a shows the evolution of the linear and nonlinear damage parameters $\left(D_{0}\right.$ and $\left.D_{A=100}\right)$ upon increasing mechanical damage. Both are plotted as a function of the actual load to the failure load ratio of every mortar $(L)$. In this way, the relative variations of the dynamic parameters with regard those obtained in pristine state can be compared, regardless mortar strength. Both damage parameters escalated as the mechanical damage progressed. However, by including the relative variations of hysteretic behavior between pristine and damaged states, the detection of damage is enhanced. Figure 5 -8b shows one-to-one comparison of the damage parameters $D_{0}$ and $D$. The results show 
that the values of $D$ lay well above the equity line $\left(D=D_{0}\right)$, especially at load to failure ratios higher than 0.40 , while at lower values of $L$, the $D$ and $D_{0}$ are almost equivalent.
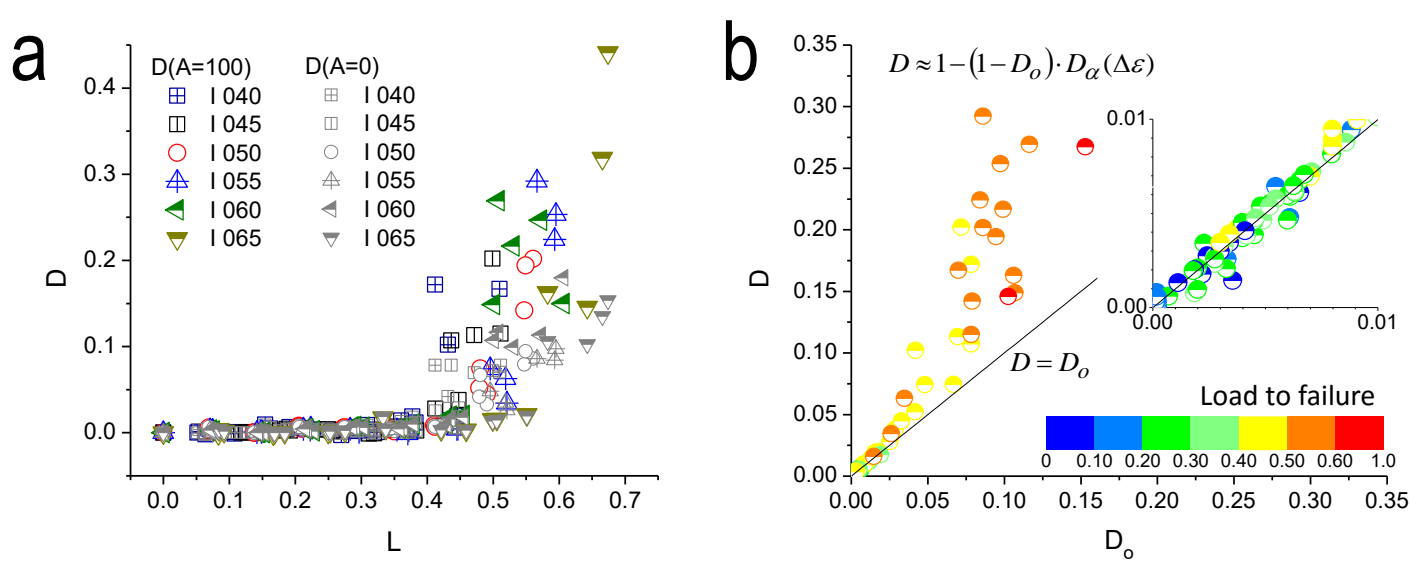

Figure 5-8 a) Comparison between the linear damage parameter $-D_{0}$, thus $A=0$ - and the damage parameter including the variation of the hysteresis behavior $D$ - the amplitude was set to $A=100$ - as a function of the load to failure ratio, and b) one-to-one comparison between $D_{0}$ and $D_{(A=100)}$. Inset plot shows

Up to this point, the incorporation of the hysteretic parameter in the relative modulus of elasticity allowed enhancing the detection of damage. These results suggest that the dynamic parameters vary in different extent as microcracking damage progresses. Figure $5-9$ a to Figure $5-9 \mathrm{c}$ show the evolution of the relative variations of the all three dynamic parameters (resonant frequency, attenuation, and hysteretic parameter) as a function of $L$. Given that resonant frequency and $Q$ decreased with damage, the absolute relative variations for the resonant frequency and $Q$ are bounded between 0 and 1 , while does not exist an upper bound for the relative variations of the hysteretic parameter. This concern can be circumvented by using the reciprocal values of the linear parameters $\left(f_{0}^{-1}\right.$ and $\left.Q^{-1}\right)$. Thereby, their respective relative variations are equitably comparable to the relative variations of the hysteretic parameter, and thus, a saturation of the relative variations of $f$ and $Q$ when their relative variations approach the value of 1 is avoided. The results show that all three parameters raise their values as the mechanical damage progressed. The

\section{$5-22$}


evolution of every single dynamic characteristic exhibited a power-like law behavior with increasing mechanical damage. Indeed, a quasi-static load does not result in a constant damage growth. The relative variations of every dynamic parameter being considered herein were related to the load-failure ratio $(L)$ as

$$
\frac{x(L)-x_{L=0}}{x_{L=0}}=\frac{d \cdot L^{c}}{1-L}
$$

where $d$ and $c$ are fitting coefficients; $x$ stands for whichever dynamic parameter (inverse resonant frequency, attenuation, or $\eta_{\text {flex }}$ ). Table 5-3 lists the fitting coefficients and the adjusted- $R^{2}$ for the relative variations of the dynamic parameters (Eq. 5-10). Figure 5-9d compares the relative variations of all three parameters along with the fitted models (Eq. $5-10)$. The relative variations observed for the hysteretic parameter were far larger than those produced on $Q$, and more so, than those produced on resonant frequency. Indeed, the magnitude of the fitting parameter $d$, corresponding to the relative variations of hysteretic parameter, was considerably greater than those corresponding to resonant frequency and Q. All together, these results confirm that the nonlinear parameter varied in several orders of magnitude upon increasing damage, and enforce the conclusion that nonlinear parameters exhibit enhanced sensitivity to detect microcracking damage in cement-based materials (Shah, Ribakov, \& Hirose, 2009; Stauffer, Woodward, \& White, 2005). 

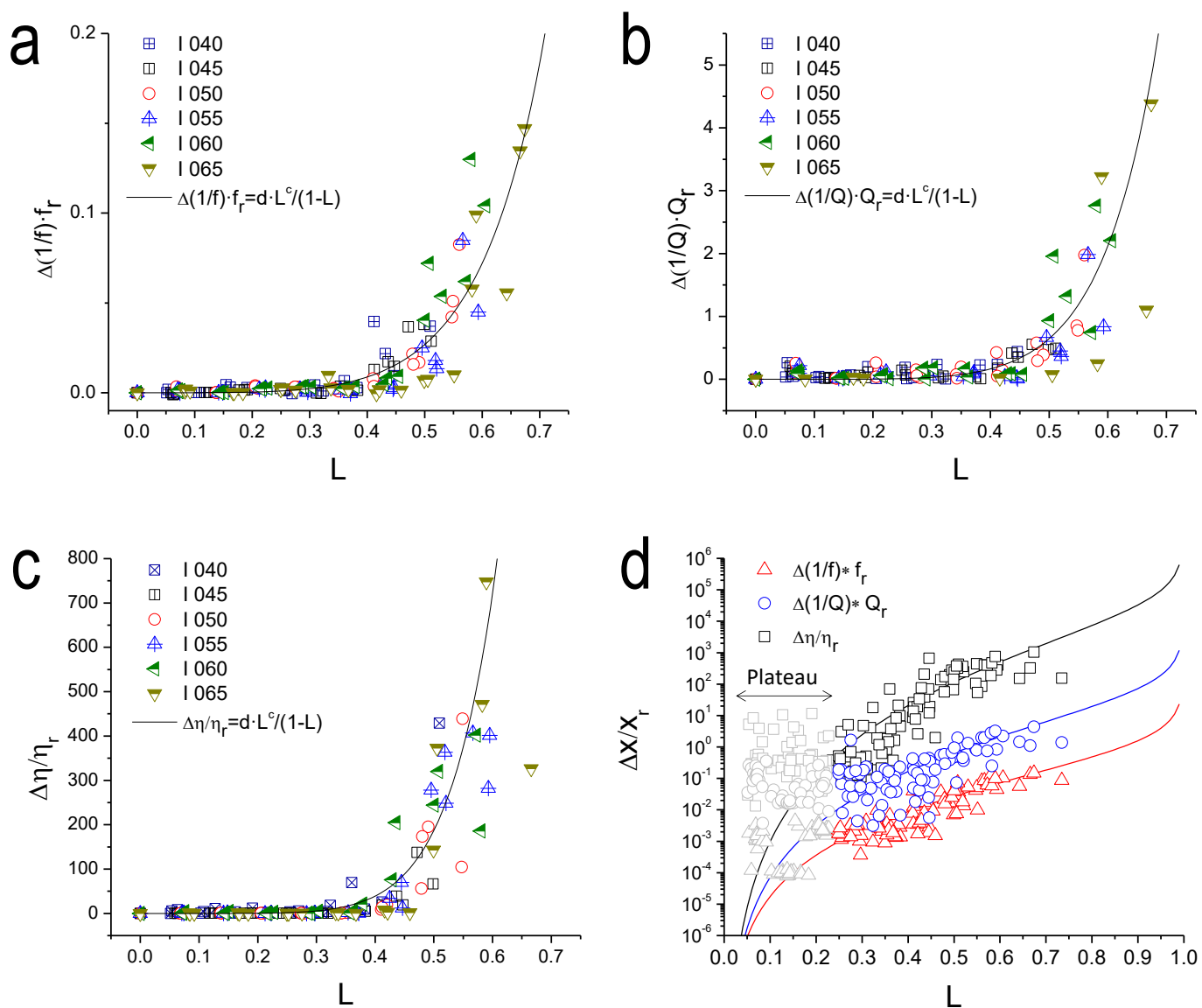

Figure 5-9. Evolution of the relative variation of the linear and nonlinear dynamic properties as $(x-x(L)) / x$ with increasing mechanical damage; a) inverse resonant frequency, b) attenuation, c)_hysteretic parameter, d) comparison of the relative variations of the three dynamic parameters and their corresponding fitted models (Eq. 5-10).

Table 5-3 Fitting parameters obtained for $D D$ and $D$ data, and goodness of the fit.

\begin{tabular}{|lrrr|}
\hline Parameter & d & C & Adjusted $\mathbf{R}^{\mathbf{2}}$ \\
\hline $\mathbf{1 / f}$ & 0.246 & 4.125 & 0.81 \\
$\mathbf{1 / Q}$ & 12.64 & 5.291 & 0.81 \\
$\mathbf{\eta}$ & 6820 & 6.189 & 0.82 \\
\hline
\end{tabular}


The model in Eq. 5-10 allows modeling properly the relative variations of the dynamic parameters for load to failure ratios approximately greater than $25 \%$, while it seems to fall short for describing the evolution of the relative variations at earlier damage states $(L<25 \%)$ -see Figure 5-9d- For low load to failure ratios, the dynamic parameters exhibited almost constant relative variations. In this phase the initial variations are virtually owed to test-totest variations which are intrinsic to each dynamic parameter. These test-to-test variations did not allow determining the existence of an initial damage growth (if any), whereby incipient damage takes place. Indeed, there were not meaningful variations of the dynamic parameters during the firsts load steps. After this initial phase whereby incipient damage occurs, the damage indicators reached a plateau and grew as damage progressed, following a power law behavior as shown in Figure 5-9d. On other hand, the relative variations of the dynamic parameters are expected to growth and asymptotically approach $L=1$ as damage progresses. Herein, there were not experimental observations nearby the failure $(L=1)$, which allow confirming such asymptotic behavior. However, other studies elucidated similar trends to those reported herein, during the nondestructive assessment of mechanical loading and fatigue tests in concrete, for the ultrasonic pulse velocity (Qasrawi \& Marie, 2003), ultrasonic attenuation (Nogueira \& Willam, 2001; Suaris \& Fernando, 1987), cumulative acoustic emission events (Elaqra et al., 2007), and also nonlinear ultrasonic parameters (Antonaci, Bruno, Gliozzi, \& Scalerandi, 2010; Stauffer et al., 2005). Yet, the trends of every damage indicator in such studies were somewhat disparate. In this respect, a comprehensive study that infers the actual microcracking damage, as verified for instance through microscopic observations, to the different damage indicators would provide valuable information regarding the sensitivity and the existence of an eventual critical threshold, from which microcracking damage is detected. 


\subsection{Summary and conclusions}

The relative sensitivity of the standard resonant frequency method and NIRAS technique to detect mechanical damage was compared in mortar samples produced with a range of water-cement ratios. The accumulated microcracking damage as resulted to subject the mortar samples to increasing compressive loading steps, was investigated through the standard resonant frequency method and the NIRAS technique. The dynamic responses were progressively modified in all mortars, as the gradual increase of compressive loading accrued microcracking damage. The growth of microcracking damage causes a reduction of stiffness and favors vibration energy dissipation because of internal friction. As a result, the resonant frequencies and linear mode quality factor decreased. In addition, the microcracking damage exacerbates the mechanical hysteresis. In dynamic experiments the mechanical hysteretic behavior makes resonant frequency and attenuation depend on excitation amplitude (fast dynamic effect).

In standard resonant frequency measurements, the variability of the resonant frequency and $Q$ data increased with damage. In this respect, the variations of resonant frequency and $Q$ within a single test (ten impacts of relatively same impact energy) correlated with the excitation amplitude variations. In addition, it was identified a serial correlation on the measurements within a single test, so that consecutive resonant frequency and $Q$ readings were affected by the preceding ones. Such an effect may be related to a memory effect (socalled slow dynamic effect) whereby the material temporarily memorizes the modulus reduction experienced for each impact event. Consequently, slow dynamic effect also concerns the variability on the measurement of the hysteretic parameter as obtained through NIRAS tests. The impact of the slow dynamic effect on the measurement of the hysteretic parameters can be minimized by increasing the time lapse between consecutive impacts this is further discussed in Chapter 12-. Still, a comprehensive study aiming to evaluate the actual impact of the memory effect on the measurement of the hysteretic parameter would be highly desirable. These results suggest that as a measure that the nonlinear behavior is 
intensified with damage, fast dynamics and slow dynamics contribute to increase the variability on resonant frequency measurements. These effects are overlooked in the standard method ASTM C215 (ASTM C215-14, 2014).

The nonlinear behavior was rather evaluated through NIRAS technique. The particular test configuration conducted herein allowed simultaneous acquisition of flexural and longitudinal modes of vibration. The relative position between both peaks was modified with damage; such effect was quantified through the ratio $f_{\text {long }} / f_{\text {flex. }}$. The attained values of $f_{\text {long }} / f_{\text {flex }}$ hinted at a deviation away of the linear elastic behavior. The slope between the resonant frequencies and their corresponding attained spectral amplitudes at every impact, serve as a relative measure of mechanical hysteresis $\left(\eta_{\text {flex }}\right.$ and $\left.\eta_{\text {long }}\right)$. Interestingly, the values of $\eta_{\text {flex }}$

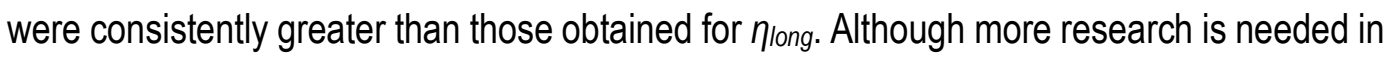
this respect, shear and bulk motions may exhibit different hysteretic behavior. In any event, both parameters increased with damage. A one-dimensional damage parameter was derived including the relative variations of the hysteretic parameter. By including the hysteretic parameter, the damage detection was improved. Indeed, the relative variations of the hysteretic parameter across different damage states were greater than the relative variations of $Q$ and resonant frequency.

\section{References}

Antonaci, P., Bruno, C. L. E., Gliozzi, A. S., \& Scalerandi, M. (2010). Monitoring evolution of compressive damage in concrete with linear and nonlinear ultrasonic methods. Cement and Concrete Research, 40(7), 1106-1113.

ASTM C215-14. (2014). Standard Test Method for Fundamental Transverse , Longitudinal , and Torsional Resonant Frequencies of Concrete.

Eiras, J. N., Popovics, J. S., Borrachero, M. V., Monzó, J., \& Payá, J. (2015). The effects of moisture and micro-structural modifications in drying mortars on vibration-based NDT methods. Construction and Building Materials, 94, 565-571. 
Elaqra, H., Godin, N., Peix, G., R'Mili, M., \& Fantozzi, G. (2007). Damage evolution analysis in mortar, during compressive loading using acoustic emission and X-ray tomography: Effects of the sand/cement ratio. Cement and Concrete Research, 37(5), 703-713.

Etcheverry, J. I., \& Sánchez, G. A. (2009). Resonance frequencies of parallelepipeds for determination of elastic moduli: An accurate numerical treatment. Journal of Sound and Vibration, 321(3-5), 631-646.

Gaberson, H. A. (2012). Pseudovelocity Modal Stress Velocity Proportionality. In R. Allemang (Ed.), Topics in Modal Analysis II, Volume 6, Conference Proceedings of the Society for Experimental Mechanics Series 31 (Vol. 6, pp. 95-110).

Hunt, F. V. (1960). Stress and Strain Limits on the Attainable Velocity in Mechanical Vibration. The Journal of the Acoustical Society of America, 32(7), 1123-1128.

Johnson, P. A. (2006). Nonequilibrium Nonlinear-Dynamics in Solids : State of the Art State of the Art in Nonequilibrium Dynamics. In P. P. Delsanto (Ed.), Universality of Nonclassical Nonlinearity (pp. 49-69). New York: Springer.

Johnson, P. A., \& Rasolofosaon, P. N. J. (1996). Nonlinear elasticity and stress-induced anisotropy in rock. Journal of Geophysical Research, 101, 3113-3124.

Johnson, P., \& Sutin, A. (2005). Slow dynamics and anomalous nonlinear fast dynamics in diverse solids. The Journal of the Acoustical Society of America, 117(1), 124-130.

Jones, R. (1962). Non Destructive Testing of Concrete. (J. Baker, Ed.). London: Cambridge University Press.

Lemaitre, J., \& Chaboche, J.-L. (1994). Mechanics of Solid Materials. London: Cambridge University Press.

Neville, A. M. (1995). Properties of Concrete. 4th and Final Edition. Harlow, Essex England: Longman Scientific and Technical.

Nogueira, C. L., \& Willam, K. J. (2001). Ultrasonic testing of damage in concrete under uniaxial compression. ACl Materials Journal, 98(3), 265-275.

Pickett, G. (1945). Equations for computing elastic constants from flexural and torsional resonant frequencies of vibration of prisms and cylinders. Proceedings of the American 
Society for Testing Materials, 45, 846-865.

Qasrawi, H. Y., \& Marie, I. a. (2003). The use of USPV to anticipate failure in concrete under compression. Cement and Concrete Research, 33(12), 2017-2021.

Shah, A. A., Ribakov, Y., \& Hirose, S. (2009). Nondestructive evaluation of damaged concrete using nonlinear ultrasonics. Materials \& Design, 30(3), 775-782.

Spinner, S., \& Tefft, W. (1961). A method for determining mechanical resonance frequencies and for calculating elastic moduli from these frequencies. Proceedings of the American Society for Testing Materials, 1221-1238.

Stauffer, J. D., Woodward, C. B., \& White, K. R. (2005). Nonlinear Ultrasonic Testing with Resonant and Pulse Velocity Parameters for Early Damage in Concrete. ACI Materials Journal, 102(2), 4-7.

Suaris, W., \& Fernando, V. (1987). Ultrasonic Pulse Attenuation As a Measure of Damage Growth During Cyclic Loading of Concrete. ACI Materials Journal, 84(84), 185-193.

Van Den Abeele, K. E., Sutin, A., Carmeliet, J., \& Johnson, P. a. (2001). Micro-damage diagnostics using nonlinear elastic wave spectroscopy (NEWS). NDT \& E International, 34(4), 239-248.

Van Den Abeele, K. E.-A. (2007). Multi-Mode Nonlinear Resonance Ultrasound Spectroscopy ( MuMoNRUS ) for defect imaging : an analytical approach. Journal of Acoustic Society of America, 122(1),73-90.

Yurtdas, I., Peng, H., Burlion, N., \& Skoczylas, F. (2006). Influences of water by cement ratio on mechanical properties of mortars submitted to drying. Cement and Concrete Research, 36(7), 1286-1293. 


\section{Chapter 6. Freezing-thawing damage}





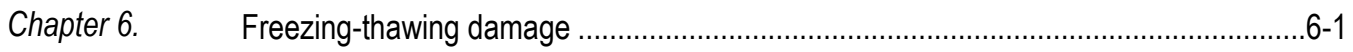

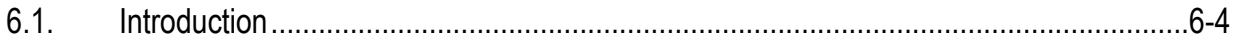

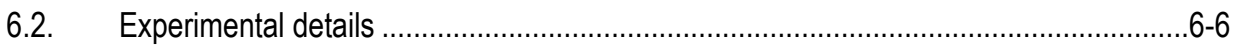

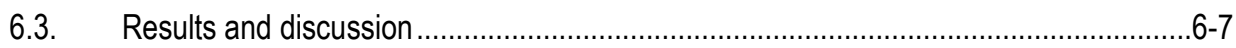

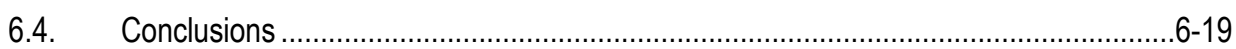

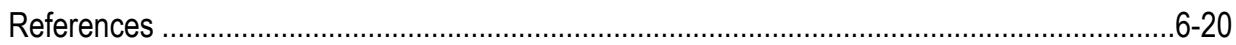




\subsection{Introduction}

One of the challenges of the concrete industry is the durability of concrete in cold regions. Repeated freezing and thawing of water within the pore structure of concrete causes internal deterioration and surface scaling, owing to the pressures generated during crystallization of water within the pore structure of concrete (M. Pigeon \& Pleau, 2010; Scherer, 1999; Sun \& Scherer, 2010). As a result, concrete losses mechanical properties due to accrued microcracking damage. Different material properties and counteracting phenomena control the severity of damage against frost damage. It is generally accepted that providing an adequate pore size distribution by using air-entraining agents, allows accommodation of the stresses generated during freezing of water (Cordon, 1966; Coussy \& Monteiro, 2008; Michel Pigeon, Marchand, \& Pleau, 1996). However, not only airentrainment but low water-cement ratio are needed to endow frost resistance to concrete (Detwiler, Dalgleish, \& Williamson, 1989).

Hitherto, the resistance to frost action in concrete is commonly assessed after accelerated ageing based on freezing-thawing cycles. The integrity of the material with increasing number of cycles is commonly followed up by weighting, measurement of material scaling, and measurement of volumetric changes (Cordon, 1966). In addition, RILEM recommendations (RILEM TC 176-IDC et al., 2004), and ASTM C 666 (ASTM-C666, 2012) recommend the use of one of two linear elastic wave techniques to evaluate frost damage in a non-destructive way. The first alternative is the measurement of ultrasonic pulse velocity (Naik \& Popovics, 2004) (also referred as alternative A), while the second one is based on the resonant vibration test (Malhotra \& Sivasundaram, 2004) (also referred as alternative B). Deriving the dynamic modulus of elasticity $\left(E_{d}\right)$ either from ultrasonic pulse velocity or resonance frequency, a damage parameter $(D)$ is defined as

$$
D=1-\frac{E d_{n}}{E d_{o}}
$$


wherein the ratio between the dynamic modulus for undamaged samples $\left(E d_{0}\right)$ and after $n$ cycles $\left(E d_{n}\right)$ is known as the relative modulus of elasticity. The damage parameter $D$ depends on either resonance frequency or ultrasonic pulse velocity changes, upon freezing thawing cycles. The damage parameter has been broadly used to deem the sufficiency of different cement-based materials against different durability distresses. However, several studies pointed out that attenuation measurements shows improved sensitivity to detect distributed like damage, as it is generated during freezing-thawing cycles (Akhras, 1998; Bellanger, Rémy, \& Homand, 1996; Kesner, Sansalone, \& Poston, 2005; Selleck, Landis, Peterson, Shah, \& Achenbach, 1998). Selleck et al. (Selleck et al., 1998) performed ultrasonic pulse velocity measurements on pristine and freeze-thaw damaged concrete samples. The results reported therein showed that ultrasonic pulse velocity was not as sensitive as the attenuation measurements -therein measured as the relative decrease of peak-to-peak amplitudes in time domain-. Similar observations were made by Akhras et al. (Akhras, 1998). In such study, the attenuation measurements underlay on the spectral energy of the received ultrasonic signal. Figure 6-1 shows representative results obtained by Akhras et al., on 28-days cured concrete samples, subjected to increasing number of freezing-thawing cycles. The results demonstrated that signal energy measurements exhibited greater variations than those observed for wave velocity.

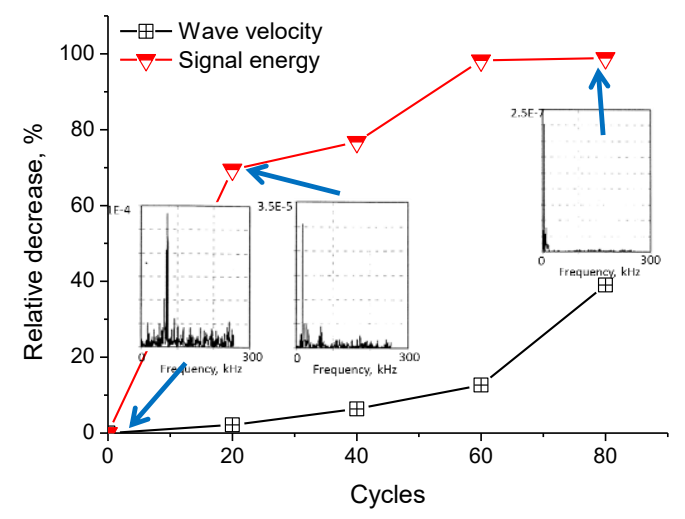

Figure 6-1 Relative reduction of wave velocity and signal energy in 28 days cured concrete samples subjected to increasing number of freezing-thawing cycles. Inset plot show power spectrum for pristine and after 20 and 60 freezing-thawing cycles. Adapted from (Akhras, 1998). 
In this chapter, it is investigated the utility of the NIRAS test to assess freezing-thawing damage. To this end, a set of different Portland cement mortars were produced with varying water to cement ratio. The mortar samples were subjected to repeated freezing-thawing cycles and the degradation process was monitored through NIRAS. Freezing-thawing damage produces distributed-like cracking damage. Therefore, the accrued damage is expected to yield a decrease of resonant frequencies, a decrease of quality factor $(Q)$, and an increase of the hysteretic parameter.

\subsection{Experimental details}

Three prismatic samples $\left(40 \times 40 \times 160 \mathrm{~mm}^{3}\right)$ per type of "series I" mortars were produced -see Chapter 2 Materials and methods-. The samples were cured in water at $20^{\circ} \mathrm{C}$, for more than 90 days after casting. The samples were subjected to freezing-thawing cycles. Figure 6-2 shows a schematic representation of one freezing-thawing cycle. It consisted in reducing the temperature of the water saturated samples to $\sim-25^{\circ} \mathrm{C}$ in a freezing chamber, maintaining that temperature for 24 hours, and then thawing them in water at room temperature during 24 hours. Each sample was placed in individual containers made of plastic. Two thin sticks prevented the sample from contacting the walls of the container. The NIRAS technique was used to track the evolution of freezing-thawing damage - see Chapter 2 Materials and methods-. The test begins by drying the surfaces of the sample with a towel then, the NIRAS test was conducted. Thereafter, the sample was weighted and soaked in water. This process was repeated for each sample. Once all the samples were tested, the samples were placed back to their containers, previous removing any remnant of water from their surfaces. In this way, the samples were tested at saturated surface dry conditions, in pristine state and after 5, 10, 15 and 20 freezing-thawing cycles. Finally, the residual mechanical strength was determined according to EN 196-1 (EN 196-1, 2005). Then, undisturbed fragments from mechanical tests were inspected by scanning electron microscopy. 


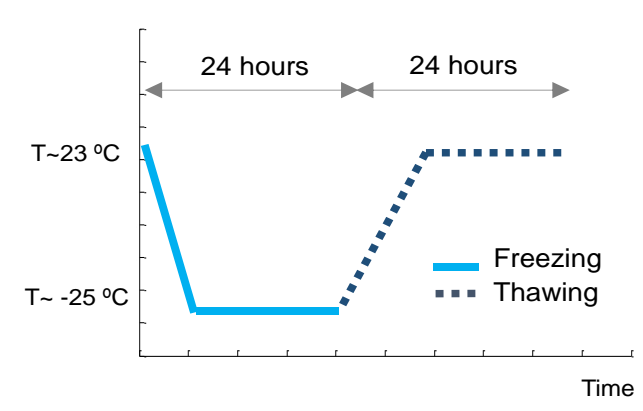

Figure 6-2 Schematic representation of the freezing thawing cycle

\subsection{Results and discussion}

Table 6-1 lists the resonance frequencies, the values of quality factor $(Q)$, and the values of the hysteretic parameters corresponding to the first bending and longitudinal modes of vibration, ( $\eta_{\text {fiex }}$ and $\eta_{\text {long }}$ ), obtained for pristine samples. It can be appreciated that resonance frequencies decrease with increasing $w / c$, as is expected since porosity increases with increasing water-cement ratio. Conversely, no clear dependence of either quality factor or hysteretic parameter can be drawn for pristine mortars. The values of $Q$ corresponding to the first flexural mode were consistently lower than those corresponding to longitudinal mode of vibration. These results show good agreement with those reported by Amick and Monteiro (Amick \& Monteiro, 2006). In such study, the values of $Q$ (inverse loss factor) ranged from $\sim 50$ to $\sim 45$ for flexural mode, and from $\sim 91$ to $\sim 83$ for longitudinal mode, in a set of concrete batches with water-cement ratios varying between 0.35 and 0.82 . Likewise, a weak dependence between water-cement ratio and $Q$ values was found. The values of $Q$ from the vibration signals collected herein should be interpreted with care since multiple modes are acquired. Indeed, it is desirable that only a single mode be excited, and thus not multiple modes can mask the real energy loss corresponding to one determinate vibration mode. For our particular sample geometry, second bending and longitudinal modes lie at 2.24 and $\sim 2.30$ times the resonant frequency corresponding to the flexural mode peak. The flexural mode is thus well separated from other resonant modes. Contrarily, the $Q_{\text {long }}$ values may be affected by the second flexural mode. In addition, the definition of $Q$ remains valid in nothing 
but a linear material (P. A. Johnson \& Rasolofosaon, 1996). Therefore, the definition of $Q$ is not valid when the materials exhibit large departures from linear elastic behavior (as in damaged concrete). Still, bandwidth measurements may be useful for quantifying the evolution of damage, since it is expected that the signal becomes more attenuated, as damage progresses. On other hand, the values of $\eta$ did not depend on $w / c$ for pristine samples; thus, an increase of total porosity does not entail an increase of material nonlinearity. The hysteretic parameter is expected to increase, as a measure that freezingthawing cycles accrue microcracking damage. The values of $\eta$ corresponding to the flexural mode of vibration were found to be consistently higher than those corresponding to the flexural mode. In this respect, different studies reported that the downward frequency shift depends on frequency (Gusev, Tournat, \& Castagnède, 2010), and it is different for different family modes (Remillieux, Guyer, Payan, \& Ulrich, 2016).

Table 6-1. Linear and nonlinear dynamic properties of pristine mortars. Mean and standard deviation.

\begin{tabular}{|c|c|c|c|c|c|c|}
\hline$w / c$ & $\begin{array}{c}f_{\text {flex, }} \\
\mathrm{Hz}\end{array}$ & $\begin{array}{c}f_{\text {long, }} \\
\mathrm{Hz}\end{array}$ & $Q_{\text {flex }}$ & $Q_{\text {long }}$ & $\begin{array}{c}\eta_{\text {flex }} \\
\text { x10-4 a.u. }\end{array}$ & $\begin{array}{c}\eta_{\text {long, }} \\
\text { x10-4 a.u. }\end{array}$ \\
\hline 0.40 & $5692.8 \pm 7.9$ & $12932.9 \pm 22.6$ & $66.9 \pm 10.6$ & $88.2 \pm 4.7$ & $6 \pm 5$ & $4 \pm 2$ \\
\hline 0.45 & $5418.6 \pm 12.1$ & $12395.9 \pm 27.4$ & $52.5 \pm 15.4$ & $71.5 \pm 10.6$ & $15 \pm 7$ & $3 \pm 1$ \\
\hline 0.50 & $5189.8 \pm 12.5$ & $11917.1 \pm 50.9$ & $46.9 \pm 13.8$ & $63.6 \pm 20.0$ & $24 \pm 5$ & $4 \pm 2$ \\
\hline 0.55 & $4999.9 \pm 33.0$ & $11504.1 \pm 56.5$ & $41.6 \pm 3.7$ & $53.5 \pm 5.1$ & $35 \pm 14$ & $7 \pm 3$ \\
\hline 0.60 & $4890.4 \pm 22.9$ & $11343.8 \pm 38.2$ & $46.9 \pm 3.3$ & $58.0 \pm 4.3$ & $24 \pm 5$ & $8 \pm 1$ \\
\hline 0.65 & $4763.6 \pm 65.8$ & $10983.0 \pm 56.8$ & $56.5 \pm 2.5$ & $86.5 \pm 2.4$ & $24 \pm 7$ & $10 \pm 5$ \\
\hline
\end{tabular}

Figure 6-3a-i shows resonance spectra as obtained through NIRAS test, for three mortar samples with water-cement ratios of $0.40,0.50$, and 0.60 (in rows), for undamaged state and after 15, and 20 freezing-thawing cycles (in columns). Three different effects can be readily appreciated. First, resonance frequencies slightly decreased with increasing number of cycles. Second, the signals became more attenuated with damage. Third, the relationship between resonant frequency and spectral amplitude is modified ( $\eta$ increases) with increasing number of cycles. The latter can be appreciated within the inset plots of Figure 6-3. As expected, higher water-cement mortars resulted noticeably more damaged, 
and as a result, the relative variations of their dynamic properties were also extensively larger. For instance, after 15 cycles, mortar $w / c=0.60$ exhibited signals with markedly lower resonant frequencies and highly damped. The resonance frequencies were poorly excited and the longitudinal mode was virtually obliterated. Along with these effects, frequency shifts of $\sim 35 \%$ were observed. In contrast, at the same number of cycles mortars $w / c=0.40$ and $w / c=0.50$ barely varied the resonant frequencies. Remarkably, mortar with $w / c=0.50$ presented frequency shifts of $\sim 2 \%$, but contrariwise, mortar $w / c=0.40$ did not exhibited such effect.
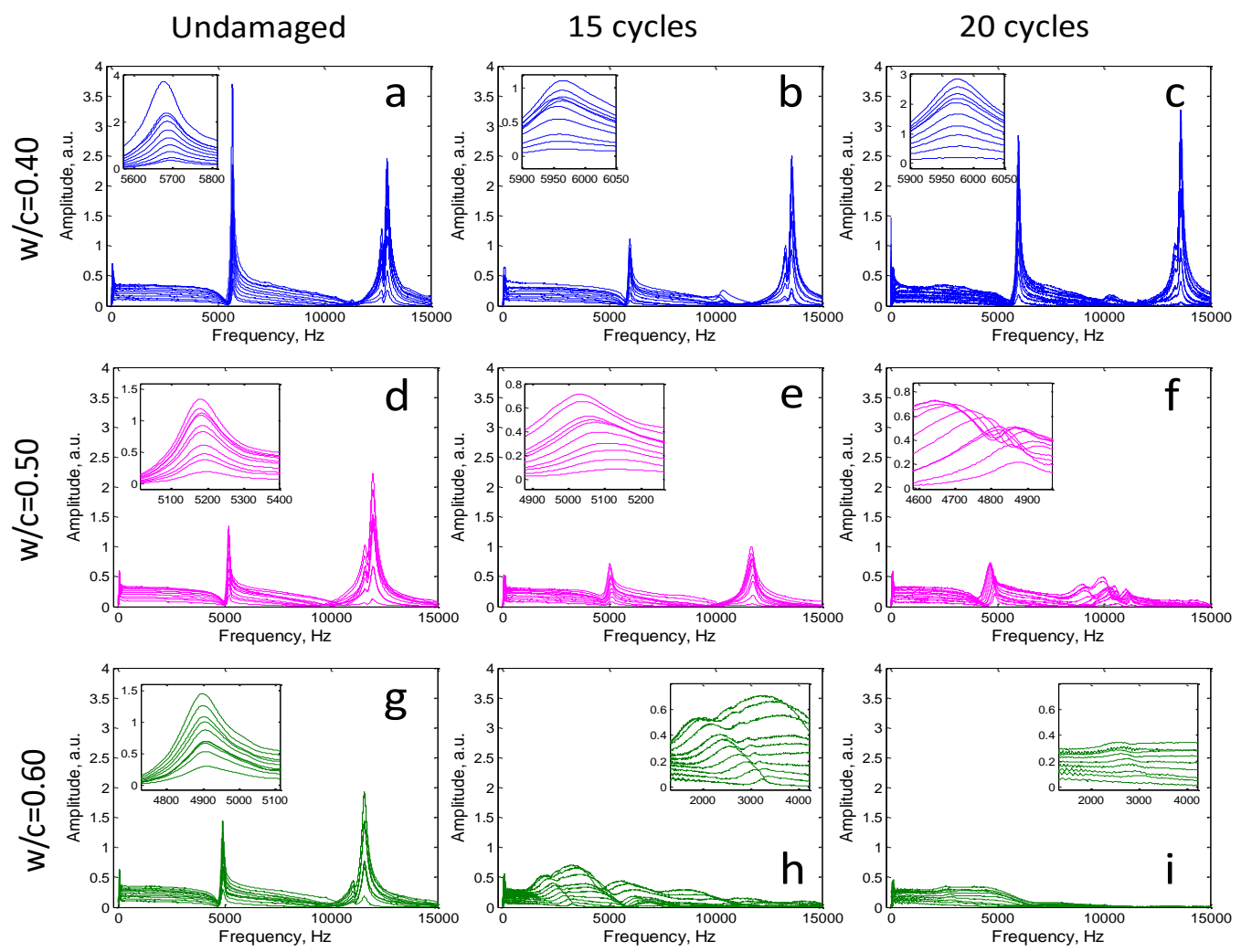

Figure 6-3. Typical resonance spectra obtained during NIRAS test for mortars with w/c of 0.40 (top row), 0.50 (middle row), and 0.60 (bottom row), for pristine mortars (first column), and after 15 (second column) and 20 freezing-thawing cycles (third column). Inset plots show relative frequency shift of the first bending mode. 
Figure 6-4a-f shows the absolute normalized variations of flexural frequency -that is $\left|f-f_{o}\right| / f_{0}-$ as a function of the spectral amplitude for all mortars. The slope $\left(\eta_{f l e x}\right)$ of such a relationship was used to quantify the amplitude-dependent resonant frequency because of material hysteresis. In general, all mortars exhibited variations in the values of $\eta_{\text {flex. }}$. However, different behavior was observed depending on w/c. High water-cement mortars (at and above 0.50 ) were more susceptible to freezing-thawing cycles, thus the values of $\eta_{\text {flex }}$ increased with damage. Contrariwise, low water-cement mortars ( $w / c 0.40$ and 0.45 ), either low values of $\eta_{\text {flex }}$ or poor correlation between resonant frequency and spectral amplitude were obtained. Therefore, the evolution of the hysteretic parameters corresponding to low water-cement mortars, did not allow concluding that freezing-thawing damage was produced. Accordingly, longitudinal mode of vibration also exhibited downward frequency shifts with increasing excitation amplitude. However, the evaluation of the hysteretic parameter corresponding to such mode $\left(\eta_{\text {long }}\right)$ was not possible at all the damage states, since the response at resonance for the longitudinal mode was virtually obliterated for severe damage states, and at relatively earlier damage states than flexural mode. This effect may be owed to the relative higher mechanical impedance of the longitudinal mode when compared to the flexural mode; in other words, it is needed more energy to produce similar displacement in longitudinal than in flexural mode (Jones, 1962). As a result, longitudinal modes were poorly excited at relatively earlier stages of damage, and especially for higher water-cement mortars (at and above 0.55), since these mortars underwent greater cracking growths with freezing-thawing cycles. Notwithstanding, the hysteretic parameter corresponding to the longitudinal mode obtained at early ages of damage (results not shown) was consistently higher than that corresponding to the flexural mode. 

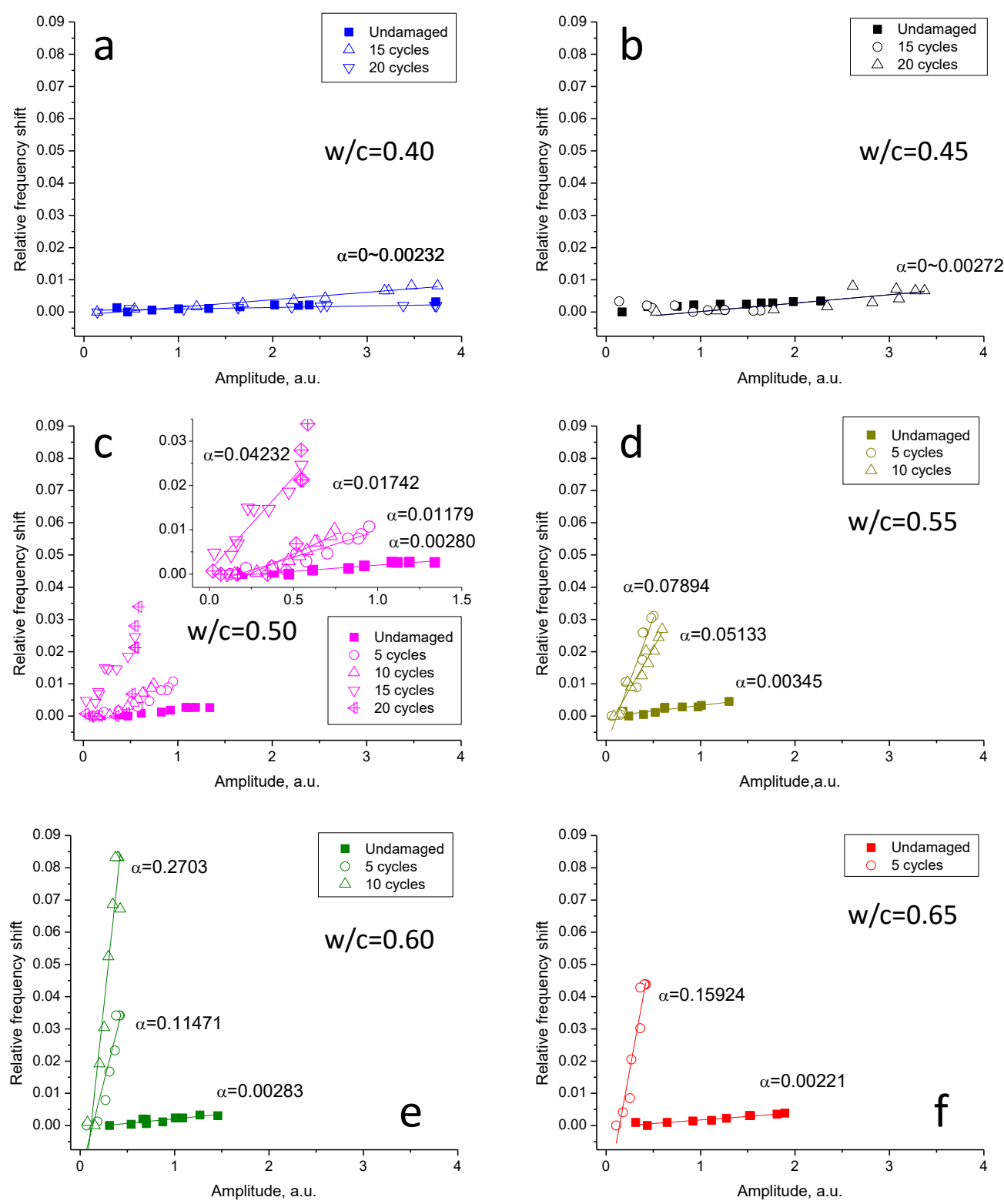

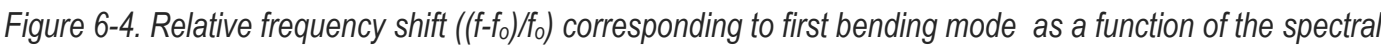
amplitude for one mortar sample: a) $w / c=0.40, b) w / c=0.45, c) w / c=0.50$, d) $w / c=0.55, e) w / c=0.60, f) w / c=$ 0.65 
Another dynamic effect that reveals hysteretic behavior is amplitude-dependent attenuation, which is normally evaluated through the parameter $\eta_{Q}-\eta_{Q}=\left(1 / Q-1 / Q_{0}\right) / A-$. Indeed, both parameters ( $\eta$ and $\eta_{Q}$ ) are presumed to be sensitive to the internal friction within the materials. Therefore, an increase of $\eta$ reflects a direct proportional increase in $\eta_{Q}$ (Van Den Abeele, Sutin, Carmeliet, \& Johnson, 2001). Figure 6-5 shows the evolution of the frequency and attenuation variations, as a function of the spectral amplitude for a mortar $w / c=0.50$ at different damage states for flexural (Figure 6-5a and 6-5c) and longitudinal (Figure $6-5 b$ and 6-5d) modes of vibration. These results demonstrated that the shifts of resonant frequency were paired with shifts in $Q$ values. Johnson and Sutin (P. Johnson \& Sutin, 2005) argued that the ratio $\eta / \eta_{Q}$-that is inverse Read's parameter (Novak, Bentahar, Tournat, El Guerjouma, \& Simon, 2012; Read, 1940)_ varied between 0.28 and 0.66 for diverse solids. Such a ratio measures the importance of the nonlinear elastic behavior over the nonlinear dissipation. For reference, for the results shown in Figure $6-5$, the $\eta / \eta_{Q}$ values were found to be between 0.45 and 0.80 (excluding the anomalous behavior for flexural mode in undamaged state). For undamaged case, $Q_{\text {flex }}$ increased with excitation amplitude (see Figure 6-5c). This particular result may indicate a "hardening" of the material properties. However, the resonant frequency did not reflect such a hardening effect, but the "softening" expected for cement-based materials (Guyer \& Johnson, 1999). Such an effect was reproduced in other undamaged samples and regardless of $w / c$, and interestingly, it was reverted with damage. This behavior is anomalous, and to the author's knowledge, similar behavior has not been previously reported. This effect deserves further study in favor of increasing the robustness of the technique. On other hand, it has been claimed that the determination of $Q$ or damping properties from impact resonant experiments is subjected to different sources of error, and it generally encounters generous error bars (Amick \& Monteiro, 2006; Jones, 1962). These errors are then reasonably translated to the determination of the amplitude-dependent attenuation in the parameter $\eta_{Q}$. 

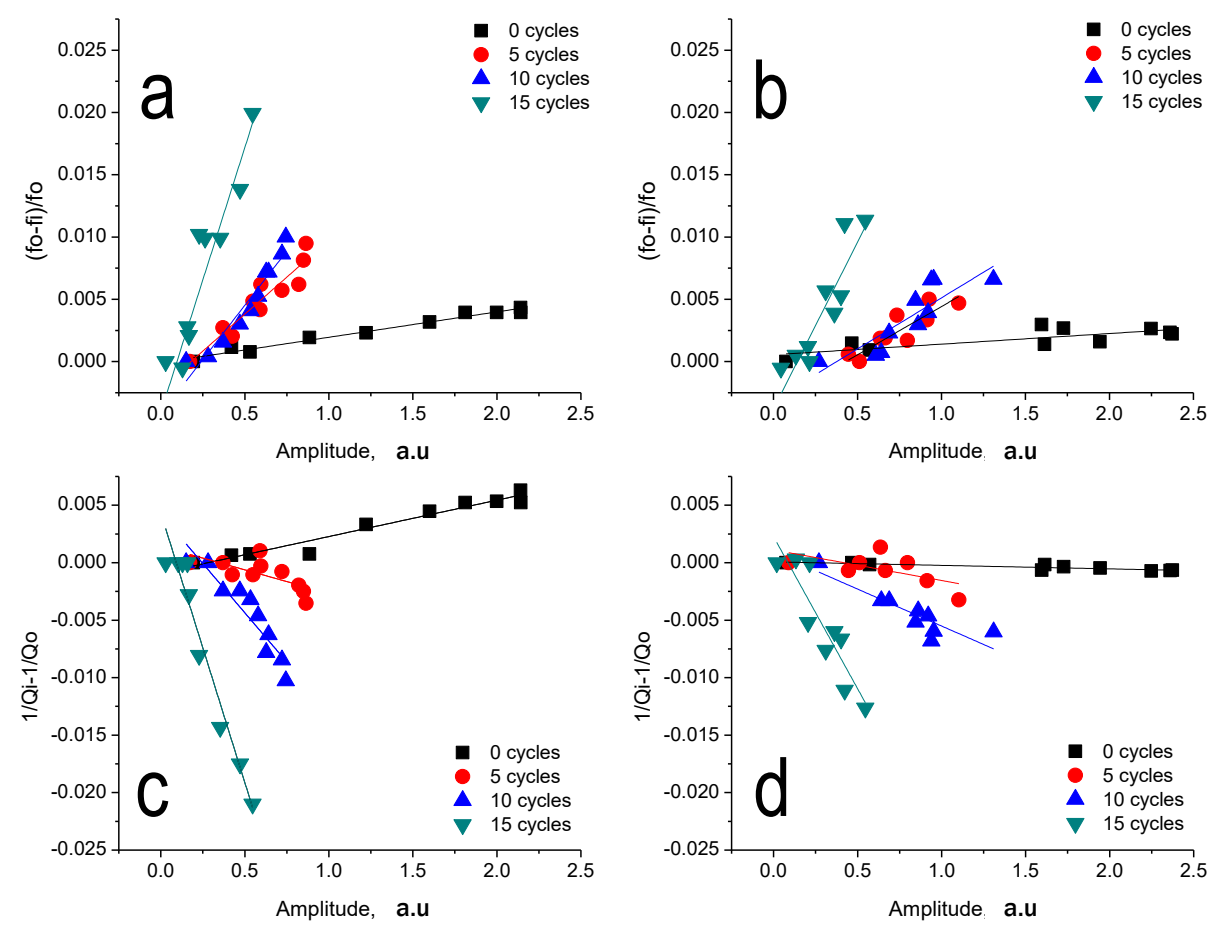

Figure 6-5. Relative frequency shift $\left(\left(f-f_{0}\right) / f_{0}\right)$ as a function of the spectral amplitude for a mortar sample with $w / c=0.50$, after 0, 5, 10 and 15 freezing-thawing cycles: a) first bending mode, b) longitudinal mode, and variation of attenuation as a function of spectral amplitude for c) first bending mode, d) longitudinal mode. Adapted from (Eiras et al., 2014).

In order to investigate the relative sensitiveness of the different linear and nonlinear parameters considered herein, three different damage parameters are proposed. These rely on the relative variations of the dynamic properties underwent upon increasing number of cycles. Such a comparison is conducted for the dynamic properties corresponding to the flexural mode of vibration. First, the relative reduction of stiffness with increasing damage is usually considered as (ASTM-C666, 2012)

$D_{F}=1-\left(\frac{f_{i}}{f_{o}}\right)^{2}$, 
where $f_{0}$ is the resonance frequency of the undamaged sample, and $f_{i}$ those obtained after $i$ cycles; subscript "o" stands for those values obtained at pristine state. Second, the relative variations of $Q$ with increasing damage can be considered as a damage parameter as,

$$
D_{Q}=1-\frac{Q_{i}}{Q_{o}}
$$

It is expected that $f$ and $Q$ decrease with damage. Conversely, the hysteretic parameter increases with damage. Therefore, a fair comparison with the relative variations of $\eta_{\text {flex }}$ can be achieved by considering the relative variations of the inverse hysteretic parameter. Then, third, the relative variations of the inverse hysteretic parameter are considered as

$$
D_{\eta}=1-\frac{\eta_{o}}{\eta_{i}}
$$

In this way all three damage parameters $\left(D_{f}, D_{Q}\right.$, and $\left.D_{\eta}\right)$ are bounded between 0 and 1 . In Figure 6-6 are represented the evolution of the damage parameters $D_{f}, D_{Q}$ and $D_{\eta}$. Mortars with water-cement higher than 0.45 exhibited similar behavior. For these mortars, in general, the variations of $D_{\eta}$ were found consistently higher than $D_{Q}$ and even more so than $D_{f}$. This observation reinforces the conclusion that the relative variations of nonlinear behavior are far more sensitive that the relative variations of linear based dynamic parameters (Chen, Jayapalan, Kim, Kurtis, \& Jacobs, 2010; Payan, Garnier, Moysan, \& Johnson, 2007). Conversely, low w/c mortars exhibited different behavior, which cannot be attributed to microcracking damage. The resonant frequencies increased, and the hysteretic parameter decreased with number of cycles (see Figures 6-6a and 6-6b). These effects may be owed to a progressive water uptake upon increasing number of freezing-thawing cycles. With all, these results confirm that higher w/c mortars were more susceptible to freezing-thawing damage than low $w / c$ ones, and as a result, the variations of their dynamic properties were also extensively larger. 

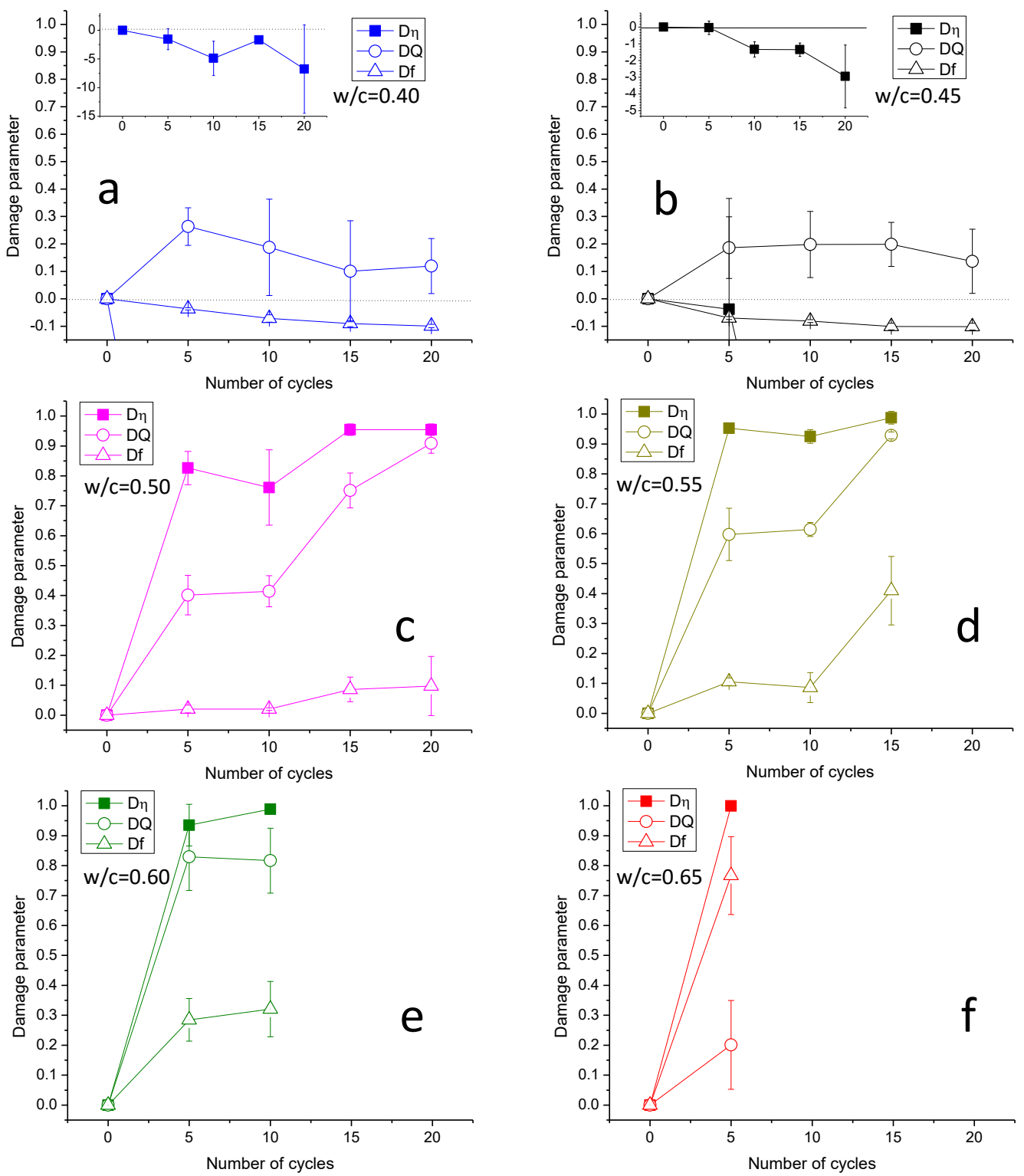

Figure 6-6. Comparison of damage parameters $D_{f}, D_{Q}$ and $D \eta$, a) $\left.\left.w / c=0.40, b\right) w / c=0.45, c\right) w / c=0.50, d$ ) $w / c=0.55, e) w / c=0.60$, and $f) w / c=0.65$. 
Figure 6-7 shows the relative moisture content with increasing number of cycles for all mortars. The relative moisture content $(S)$ was determined as

$$
S=\frac{m_{i}-m_{d r y}}{m_{s a t}-m_{d r y}}
$$

wherein $m_{\text {sat }}$ is the mass obtained at saturated state, $m_{i}$ is the mass of the sample obtained in the moment of test, and $m_{d r y}$ is the dried mass prior freezing-thawing cycles were conducted. These results show that the mass $\left(m_{i}\right)$ of the mortar samples consistently increased with increasing number of cycles, and regardless water-cement ratio. Similar results have been reported for different concrete batches (Tanesi \& Meininger, 2006; Yang, Brown, \& Cheney, 2006). A mass gain can be owed to cracking formation which entails further water absorption, whereas a mass loss normally entails material scaling. Herein, the mortar samples were oven-dried for determining open porosity and dry bulk density of pristine samples. Then the samples were soaked in water during 48 hours before freezingthawing cycles begun. Under such conditions, the rewetting process in low water-cement mortars is expected to progress slower than in higher water-cement mortars. On other hand, to restore pristine fully saturated conditions after an oven-drying process on cement-based materials has been pointed out as irreversible process (Chatterji, 2004). The rewetting process depends on pore size distribution and pore characteristics, so that reasonably, low water-cement mortars are expected to present lower moisture contents because of their lower permeation properties. The mass of the samples increased upon increasing number of freezing-thawing cycles, since microcracking eases the absorption of moisture, and because the samples accumulated more time soaked in water during the damage protocol. The latter is most likely the dominant situation in low water-cement mortars, in view of their dynamic responses (Figures 6-6a and 6-6b). Water within the pore structure of concrete like materials is known to exert a stiffening effect (Yaman, Hearn, Aktan, \& Yaman, 2002; Yurtdas, Peng, Burlion, \& Skoczylas, 2006), which is manifested as an increase of resonant frequencies and a decrease of $Q$ (Eiras, Popovics, Borrachero, Monzó, \& Payá, 2015) — 
see also Chapters 3 and 4-. During succeeding freezing-thawing cycles, the actual reduction of stiffness owed to accrued microcracking competes with the stiffening effect of water within the pore structure because of water uptake. Negative values of $D_{f}$-increase of resonant frequency with damage - in low $\mathrm{w} / \mathrm{c}$ mortars can be then attributed to increasing moisture content. This effect was accompanied by an increase of $D_{Q}$ and a decrease of $D_{\eta}$. As a result of increasing moisture content, viscous damping increases, and the initial (also moisture dependent) material nonlinearity decreases progressively. A decrease of $Q$-thus, $D_{Q}$ increases - can be associated to damage, but internal friction and viscous damping are lumped in a sole parameter $(Q)$, and it is virtually not possible to discern between both mechanisms. In this respect, the hysteretic parameter is sensitive to internal friction, and it seems to be insensitive to internal pore moisture content. All dynamic parameters, taken together, indicate that the dynamic responses in low water-cement mortars were dominated by internal moisture variations. In contrast, high water-cement mortars, microcracking dominated the dynamic responses while they remained less sensitive to moisture variations.

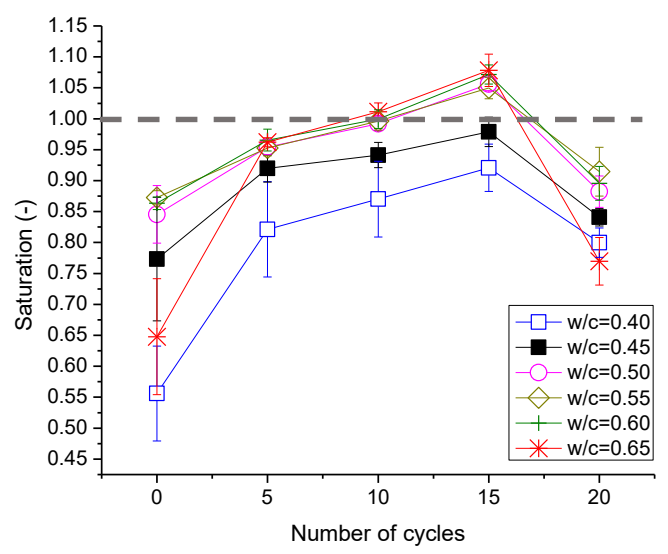

Figure 6-7. Relative moisture content (S) as a function of the number of freezing-thawing cycles. Values above the dashed line $(S>1)$ overpassed the mass obtained at pristine state (fully saturated). 
Figure 6-8 shows the values of compressive strength for undamaged replicates, and those obtained after 20 cycles. The mechanical properties confirmed what was revealed through NIRAS test results. High water-cement mortars (at and above 0.50 ) resulted in a reduction between 35 and $40 \%$. Conversely, mortars with water-cement 0.40 and 0.45 shown similar compressive strength after 20 cycles. Finally, to further investigate the freezing-thawing damage, scanning electron micrographs were performed on damaged samples (after 20 cycles) damaged mortars with $w / c=0.50$. Figure 6-9 shows two micrographs wherein unbounded interfaces between aggregates and cement paste can be appreciated. Microcracking damage occurred very frequently on the interface transition zone between aggregates and cement paste. Similar results were pointed out by Yang (Yang, 2004). In the study conducted therein SEM micrographs of mortars subjected to freezingthawing cycling, revealed that freezing-thawing damage microcracks occurred distributed across the specimens and frequently at aggregate-paste interfaces and around air voids. That results in a modification of the bound properties between cement paste and aggregates, and thus given rise to the mechanisms of material nonlinearity such as clapping and rubbing within microcracks and unbounded interfaces. This type of damage is very frequent in cement-based materials since most of the threats to concrete durability produce distributedlike cracking damage. Thus the nonlinear based dynamic measurements may enhance the detection of damage.

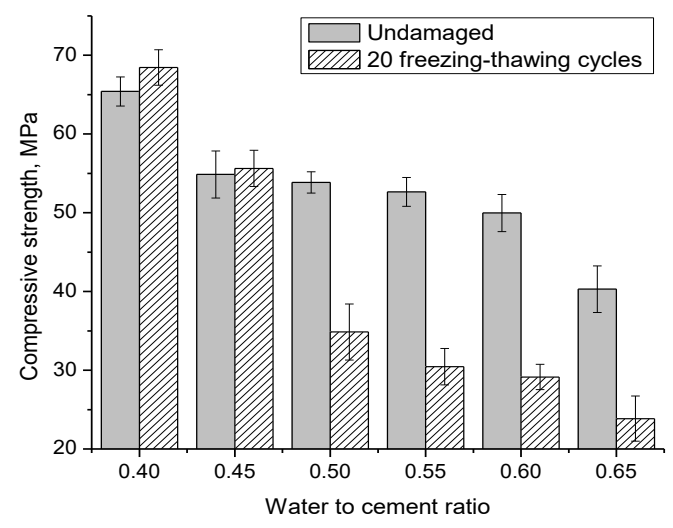

Figure 6-8. Compressive strength for pristine, mortar replicates cured during 28 days, and after 20 freezing-thawing cycles

\section{6-18}



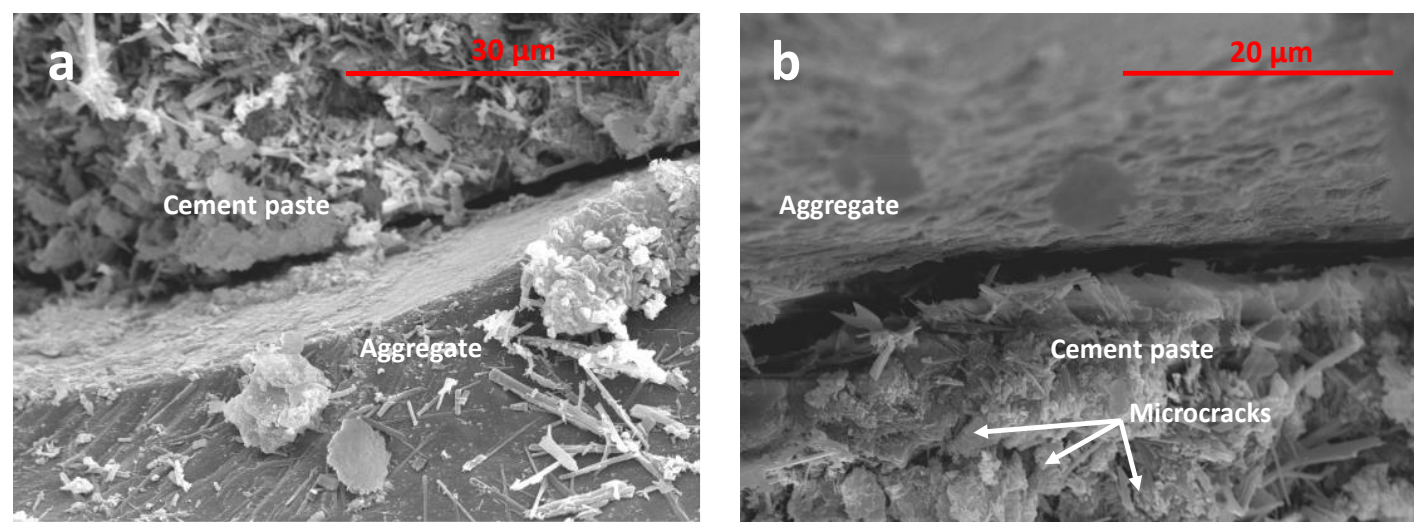

Figure 6-9 Scanning electron micrographs showing unbounded aggregate-cement paste interface on mortar with w/c of 0.50 after 20 freezing-thawing cycles, a) cement paste and aggregate interface, and b) unbounded interface and distributed microcracking in the cement paste.

\subsection{Conclusions}

Freezing-thawing damage in mortar was assessed through NIRAS technique. Linear (resonant frequencies and quality factor), and nonlinear hysteretic parameters corresponding to first bending and longitudinal modes of vibration were investigated. Freezing-thawing cycles imparted a range of damage states for the different mortars investigated herein. The microcracking growths upon increasing number of cycles led to a modification of the linear and nonlinear dynamic properties. From the stand view of damage detection, nonlinear parameters exhibited extensively larger variations than linear parameters. However, the interpretation of the dynamic properties must be complimented by the interpretation of linear and nonlinear properties. For instance, in those damage mechanisms that involve microcracking and moisture uptake, since both processes cause variations in the dynamic properties. In this respect, nonlinear parameters complement the interpretation of standard linear based measurements. Finally, it has been demonstrated that NIRAS is suitable for laboratory tests to characterize damage through the interpretation of linear and nonlinear parameters, and thus is a feasible alternative to freezing-thawing damage evaluation of concrete-like materials.

\section{6-19}




\section{References}

Akhras, N. M. (1998, September). Detecting freezing and thawing damage in concrete using signal energy. Cement and Concrete Research.

Amick, H., \& Monteiro, P. J. M. (2006). Experimental Determination of Modal Damping in Concrete Beams. ACl Material Journal, 103(3), 153-160.

ASTM-C666. (2012). Standard Test Method for Resistance of Concrete to Rapid Freezing and Thawing.

Bellanger, M., Rémy, J. M., \& Homand, F. (1996). Ultrasonic wave attenuation as a tool for estimating frost action on limestone rocks, 29(November), 552-561.

Chatterii, S. (2004). An explanation for the unsaturated state of water stored concrete. Cement and Concrete Composites, 26(1), 75-79.

Chen, J., Jayapalan, A. R., Kim, J. Y., Kurtis, K. E., \& Jacobs, L. J. (2010). Rapid evaluation of alkali-silica reactivity of aggregates using a nonlinear resonance spectroscopy technique. Cement and Concrete Research, 40(6), 914-923.

Cordon, W. A. (1966). Freezing and thawing of concrete: mechanisms and control. American Concrete Institute.

Coussy, O., \& Monteiro, P. J. M. (2008). Poroelastic model for concrete exposed to freezing temperatures. Cement and Concrete Research, 38(1), 40-48.

Detwiler, R. J., Dalgleish, B. J., \& Williamson, R. B. (1989). Assessing the Durability of Concrete in Freezing and Thawing. ACl Material Journal, 86, 29-35.

Eiras, J. N., Kundu, T., Popovics, J. S., Monzó, J., Soriano, L., Payá, J., (2014). Evaluation of frost damage in cement-based materials by a nonlinear elastic wave technique. In T. Kundu (Ed.), Proceedings of SPIE Conference (Vol. 9064, p. 90641G).

Eiras, J. N., Popovics, J. S., Borrachero, M. V., Monzó, J., \& Payá, J. (2015). The effects of moisture and micro-structural modifications in drying mortars on vibration-based NDT methods. Construction and Building Materials, 94, 565-571.

EN 196-1. (2005). Methods of testing cement. Part 1: Determination of strength. 
Gusev, V., Tournat, V., \& Castagnède, B. (2010). Nonlinear Acoustic Phenomena in Microinhomogeneous Media. In M. Bruneau \& C. Potel (Eds.), Materials and Acoustics Handbook (pp. 433-471). Wiley.

Guyer, R. A., \& Johnson, P. A. (1999). Nonlinear Mesoscopic Elasticity: Evidence for a New Class of Materials. Physics Today, 52(4), 30-36.

Johnson, P. A., \& Rasolofosaon, P. N. J. (1996). Resonance and elastic nonlinear phenomena in rock. Journal of Geophysical Research, 101(B5), 553-564.

Johnson, P., \& Sutin, A. (2005). Slow dynamics and anomalous nonlinear fast dynamics in diverse solids. The Journal of the Acoustical Society of America, 117(1), 124.

Jones, R. (1962). Non Destructive Testing of Concrete. (J. Baker, Ed.). London: Cambridge University Press.

Kesner, K., Sansalone, M. J., \& Poston, R. W. (2005). Detection and Quantification of Distributed Damage in Concrete Using Transient Stress Waves. ACI Material Journal, (101), 318-326.

Malhotra, V. M., \& Sivasundaram, V. (2004). Resonant Frequency Methods. In Handbook on Nondestructive Testing of Concrete (pp. 167-188).

Naik, T. R., \& Popovics, J. S. (2004). The Ultrasonic Pulse Velocity Method. In V. M. Malhotra \& N. J. Carino (Eds.), Handbook on Nondestructive Testing of Concrete (2nd ed.). Boca Raton: CRC Press.

Novak, A., Bentahar, M., Tournat, V., El Guerjouma, R., \& Simon, L. (2012). Nonlinear acoustic characterization of micro-damaged materials through higher harmonic resonance analysis. NDT \& E International, 45(1), 1-8.

Payan, C., Garnier, V., Moysan, J., \& Johnson, P. a. (2007). Applying nonlinear resonant ultrasound spectroscopy to improving thermal damage assessment in concrete. The Journal of the Acoustical Society of America, 121(4), EL125-L130.

Pigeon, M., Marchand, J., \& Pleau, R. (1996). Frost resistant concrete. Construction and Building Materials, 10(5), 339-348.

Pigeon, M., \& Pleau, R. (2010). Durability of Concrete in Cold Climates. CRC Press. 
Read, T. A. (1940). The Internal Friction of Single Metal Crystals. Physical Review, 58, $371-$ 380.

Remillieux, M. C., Guyer, R. A., Payan, C., \& Ulrich, T. J. (2016). Decoupling Nonclassical Nonlinear Behavior of Elastic Wave Types. Physical Review Letters, 116(11), 115501.

RILEM TC 176-IDC, Setzer, M. J., Heine, P., Kasparek, S., Palecki, S., Auberg, R., ... Siebel, E. (2004). Final Recommendation of RILEM TC 176-IDC "Internal Damage of Concrete due to frost action" Test methods of frost resistance of concrete: CIF-Test: Capillary suction, internal damage and freeze thaw test) - Reference method and alternative methods A and B. Materials and Structures, 37(274), 743-753.

Scherer, G. W. (1999). Crystallization in pores. Cement and Concrete Research, 29(8), 1347-1358.

Selleck, S. F., Landis, E. N., Peterson, M. L., Shah, S. P., \& Achenbach, J. D. (1998). Ultrasonic Investigation of Concrete with Distributed Damage. ACl Materials, (95), 2736 .

Sun, Z., \& Scherer, G. W. (2010). Pore size and shape in mortar by thermoporometry. Cement and Concrete Research, 40(5), 740-751.

Tanesi, J., \& Meininger, R. (2006). Freeze-Thaw Resistance of Concrete with Marginal Air Content. Transportation Research Record: Journal of the Transportation Research Board.

Van Den Abeele, K. E., Sutin, A., Carmeliet, J., \& Johnson, P. a. (2001). Micro-damage diagnostics using nonlinear elastic wave spectroscopy (NEWS). NDT \& E International, 34(4), 239-248.

Yaman, L. O., Hearn, N., Aktan, H. M. I., \& Yaman, I. O. (2002). Active and non-active porosity in concrete Part I: Experimental evidence. Materials and Structures, 35(2), 102-109.

Yang, Z. (2004). Assessing cumulative damage in concrete and quantifying its influence on life cycle performance modeling. Purdue University.

Yang, Z., Brown, H., \& Cheney, A. (2006). Influence of Moisture Conditions on Freeze and 
Thaw Durability of Portland Cement Pervious Concrete. In Concrete Technology Forum: Focus on Pervious Concrete (pp. 1-15).

Yurtdas, I., Peng, H., Burlion, N., \& Skoczylas, F. (2006). Influences of water by cement ratio on mechanical properties of mortars submitted to drying. Cement and Concrete Research, 36(7), 1286-1293. 


\section{Chapter 7. Reinforced cement composites: case of glass reinforced concrete (GRC)}



Chapter 7. Reinforced cement composites: case of glass reinforced concrete (GRC) .................7-1

7.1. Introduction .................................................................................................

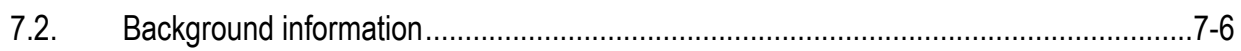

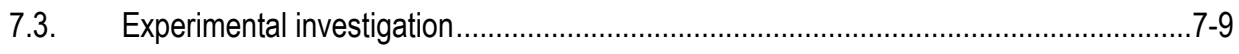

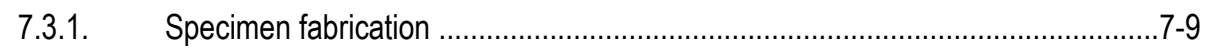

7.3.2. Nonlinear Impact Resonance Acoustic Spectroscopy .................................

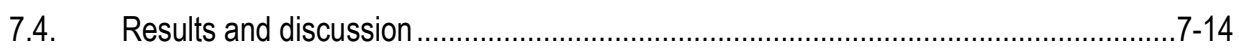

7.4.1. Nonlinear Impact Resonance Acoustic Spectroscopy .....................................

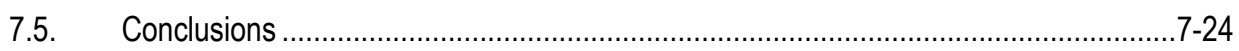

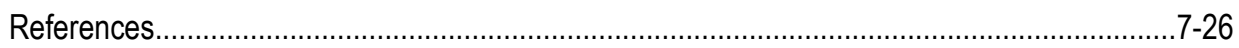




\subsection{Introduction}

Fiber-reinforced composites are materials that consist of fibers which strengthen the mechanical properties of the matrix wherein they are built-in. The final properties of the composite depend on the mechanical and physical properties of the individual components (fibers and matrix), their volume fractions and the interactions between them. Composite materials are intrinsically nonlinear, as the interaction between matrix and fibers give rise to amplitude dependent internal friction effects (amplitude dependent resonant frequency and nonlinear dissipation) in dynamic experiments (Chakrapani, Barnard, \& Dayal, 2015). Under dynamic loading, the nonlinear behavior arises from the interfacial friction, debonding, and subsequent interfacial slip between fibers and matrix (Nelson \& Hancock, 1978). With this behavior, the mechanical strain-stress relationship becomes hysteretic and hence, the material is prone to exhibit nonlinear dynamic behavior.

In the case of fiber-reinforced cement based composites, the literature reporting nonlinear dynamic behavior is scarce. In these materials, besides of the eventual material nonlinearity of cement based materials, the interaction between fibers and the matrix further enhances the nonlinear mechanical behavior. Yan, Jenkins and Pendleton (Yan, Jenkins, \& Pendleton, 2000a, 2000b) investigated the dynamic properties of polyolefin reinforced concrete. Different batches were produced with varying volume fraction of fiber. Figure 7-1 shows the amplitude dependent resonant frequency and attenuation observed for plain (without fibers) and fiber-reinforced concretes (Yan et al., 2000a). The authors observed an "anomalous" amplitude dependent resonant frequency and attenuation, which depended on fiber volume fraction, and on fiber morphology. These effects were enhanced in those batches containing fibers, when compared to plain concrete (without fibers). The authors argued that such a behavior arise from the interfacial friction between fibers and matrix. Such effects are indeed, an acoustic signature of nonlinear mesoscopic elastic materials (Guyer \& Johnson, 1999). 

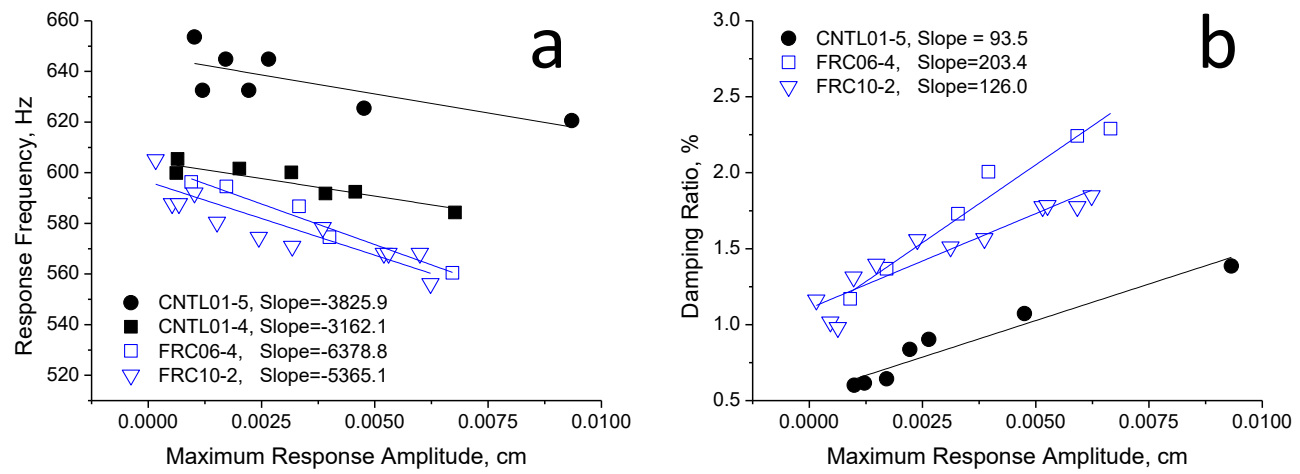

Figure 7-1 Amplitude dependent dynamic properties for plain concrete (samples CNTL01, closed markers) and polyolefin fiber reinforced concrete (samples FRC10 - 25x50.8 crimped-, FRC06 - 15x1 crimped-, open markers: a) variation of resonant frequency as a function of the maximum attained displacement amplitude, and b) variation of damping ratio as function of the maximum displacement amplitude. Adapted from (Yan et al., 2000a).

The investigation of the dynamic properties of fiber reinforced concrete are of interest when not only stiffness and strength but damping of the material wants to be engineered, so the materials can be designed to accomplish a prescribed level of damping (Amick \& Monteiro, 2006). The damping properties can be enhanced by incorporating fibers. In this case, the energy dissipation underlies in the friction arising from the relative displacement between fibers and matrix. In general, the incorporation of fibers increases the damping properties, which in turn depends on the properties of the fiber and its interface, the volume fraction, and the orientation within the matrix (Giner, Baeza, Ivorra, Zornoza, \& Galao, 2012; Noushini, Samali, \& Vessalas, 2013). The energy dissipation have commonly assessed in fiber-reinforced concrete through the linear mode damping or quality factor (Giner et al., 2012; Noushini et al., 2013). However, nonlinear amplitude dependent internal friction phenomena can also be used to assess these properties (Van Den Abeele \& De Visscher, 2000). In this chapter, the linear and nonlinear dynamic characteristics of fiber-glass reinforced cement (GRC) are investigated through vibration based techniques. The special aging mechanisms of the GRC with subsequent hardening of the bonding strength, and 
embrittlement of the fibers caused by their chemical degradation makes of special interest such material. It is thus expected that the material nonlinearity decreases with aging. The objective is therefore twofold: i) assess the internal friction mechanisms in a type of fiberreinforced concrete, and ii) assess the durability of the fibers in the alkaline environment $(\mathrm{pH}>12)$ provided by the cement matrix. The latter, also concerns different types of fibers whose durability is compromised at usual levels of $\mathrm{pH}$ in concrete. The aging process in GRC is assessed using Nonlinear Impact Resonance Acoustic Spectroscopy (NIRAS). GRC specimens were subjected to accelerated aging by placing them in water baths at elevated temperatures. NIRAS tests were conducted on aged and un-aged specimens to study the effect of aging on different parameters measured by these tests. The specimens were then loaded to failure and fragments from the fracture surface of the specimens were inspected under the electron microscope to investigate the effect of aging on the strength, toughness and internal composition of GRC specimens.

\subsection{Background information}

Glass fiber Reinforced Cement (GRC) is a cement based composite composed by cement mortar and AR-glass (alkali resistant) fibers randomly distributed. The incorporation of the fiber to the brittle cement matrix endows enhanced ductility, toughness and bending strength when compared to plain concrete, and helps to control microcracking shrinkage processes at early ages (Bentur \& Mindess, 2007). However, GRC undergoes an aging process that adversely affects the mechanical integrity of glass fibers. The alkaline environment proportioned by the rich portlandite matrix ( $\mathrm{pH}>12)$, the pre-existence of flaws in as-received fibers, and the susceptibility of the AR-glass - despite its improved chemical composition when compared to E-glass (Bentur, 1985) - complete the necessary triad for a particular case of stress corrosion cracking, known as static fatigue (Purnell, Short, \& Page, 2001a). Figure 7-2 schematically illustrates the chemical degradation process. Along with chemical degradation of the fiber, the growth of hydration products around the single 
filaments in the strand further contributes to the degradation of the fibers. This process is dominant at the early stages of aging while chemical degradation is dominant when the individual strands that compose the fiber are individually separated, and the entire surface is exposed to the alkaline environment (Bentur \& Mindess, 2007). These concerns relegate GRC mainly to nonstructural applications, such as facade panels, acoustic barriers, permanent formwork or cladding tunnels.

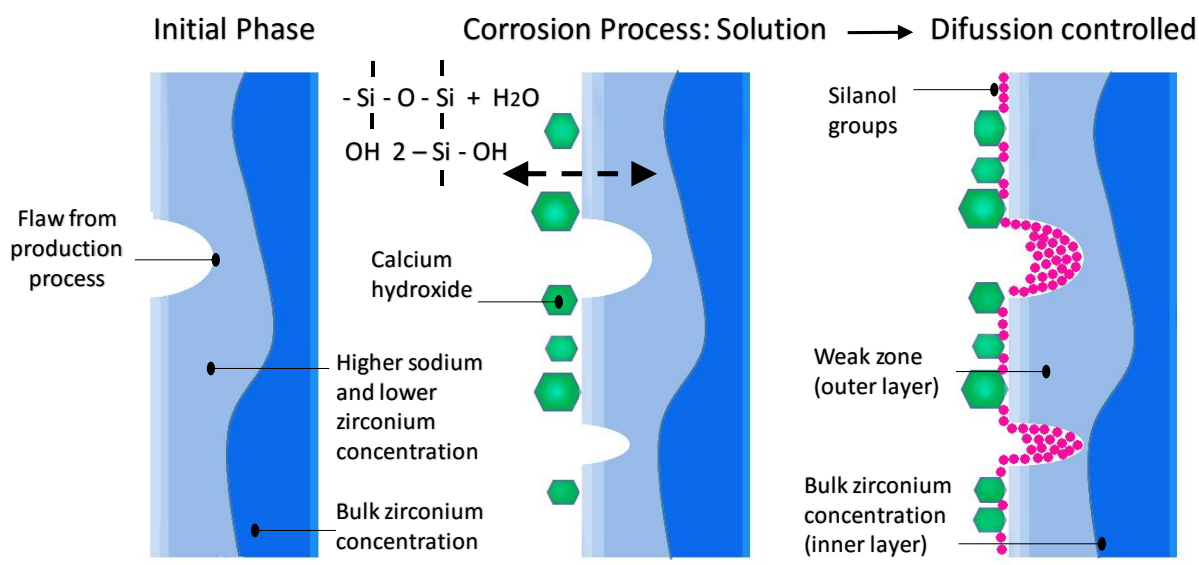

Figure 7-2 Mechanism of degradation of AR-Glass fibers in the alkaline environment provided by the Portland cement matrix. Adapted from (Bentur \& Mindess, 2007)

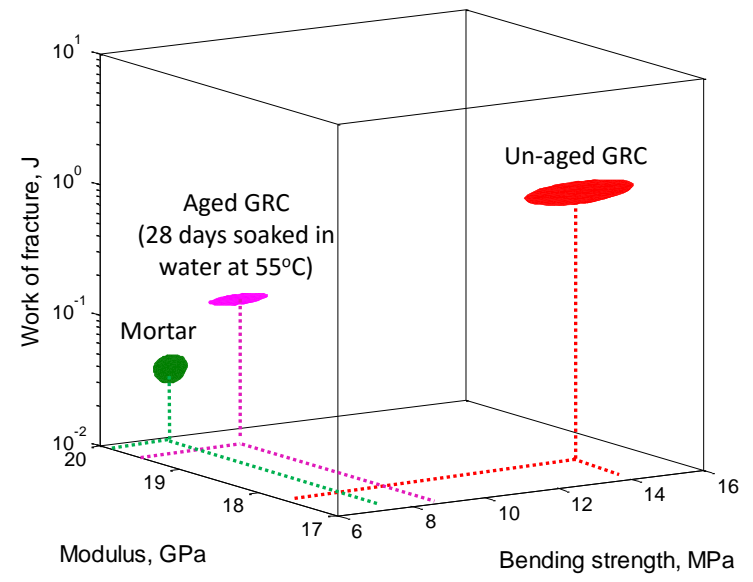

Figure 7-3 Mechanical properties of un-aged and aged GRC samples, and plain mortar. Adapted from (Roy, 1987) 
Different strategies for improving the durability of GRC have been attempted by modifying the fibers or its interface, and by altering the alkalinity of the matrix. Table 7-1 summarizes the improvements previously investigated to improve the mechanical performance of the GRC with time. These improvements can be classified as i) those that improve the fiber or its interface with the cementing matrix, new chemical compositions have been proposed since the first generation of AR (Bentur, 1985), and coatings based on solgel technique have demonstrated to be efficient even using E-Glass (Cheng, Liang, Hu, Chen, \& Frischat, 2003) and ii) those that decrease the high alkalinity by carbonation of the matrix (Purnell, Short, \& Page, 2001b), by using pozzolanic materials (Payá et al., 2007), or sulfoaluminate cement (Péra \& Ambroise, 2004).

Table 7-1 Strategies to improve GRC durability. Adapted from (Shah, Ludirdja, Daniel, \& Mobasher, 1988).

\begin{tabular}{|lll|}
\hline Matrix modification & $\begin{array}{l}\text { Super-critical carbonation } \\
\text { Use of pozzolans } \\
\text { Sulfoaluminate cement }\end{array}$ & $\begin{array}{l}\text { (Short, Purnell, \& Page, 2001) } \\
\text { (Payá et al., 2007; Zhang, Sun, Shang, \& } \\
\text { Pan, 1997) } \\
\text { (Péra \& Ambroise, 2004) }\end{array}$ \\
\hline $\begin{array}{lll}\text { Fiber and interface } \\
\text { modification }\end{array}$ & $\begin{array}{l}\text { New fiber formulations } \\
\text { Sol gel coatings } \\
\text { Pozzolan treatment }\end{array}$ & $\begin{array}{l}\text { (Bentur, 1985) } \\
\text { (Cheng et al., 2003) } \\
\text { Nanocoatings }\end{array}$ \\
& (Eiras, 2008) \\
(Gao, Mäder, \& Plonka, 2004)
\end{tabular}

All these improvements have been evaluated by mechanical tests after accelerated aging which have been broadly accepted for testing the durability of GRC. They can be classified as i) deemed to satisfy tests, (EN 1170-8, 2008) where the GRC specimens have been exposed to severe conditions, and ii) predictive accelerated aging tests (Purnell, 2004) that have been commonly used to predict the service life of the material, in real weather conditions. For example, Purnell et al. (Purnell et al., 2001a) established that GRC soaked for 1 day in water at $55^{\circ} \mathrm{C}$, corresponds to 100 days of exposure to the real weather conditions in the United Kingdom. However, the correspondence between the accelerated aging tests and the real aging conditions is still being investigated, especially when different matrix compositions are to be compared (Enfedaque, 2012; Purnell, 2004). Conventional 
methods for studying GRC aging or for evaluating the effectiveness of different treatments of either matrix or fibers typically include destructive methods such as the strand in cement test (EN 14649, n.d.), or determination of flexural strength. Different parameters obtained from the resulting stress-strain or stress-displacement curves, as modulus of rupture (MOR), flexural strength at limit of proportionality (LOP), strain at MOR, strain at LOP (EN 1170-5, 1998), and work of fracture (WOF) (Bentur, 1985; Shah et al., 1988) are used to evaluate the behavior of GRC with aging and the effectiveness of the matrix and fiber treatments for improving the composite material durability.

\subsection{Experimental investigation}

\subsubsection{Specimen fabrication}

GRC specimens of dimension $225 \times 50 \times 10 \mathrm{~mm}^{3}$ were produced. The samples were made from cement of type CEM I/52.5R (EN 197-1, 2011) and siliceous aggregate with cement-aggregate proportion of $1: 1$. The fineness modulus of the sand was 3.1. The water to cement ratio was taken as 0.35 and Glenium ACE 32 superplasticizer was added $(0.43 \%$ of cement weight) to obtain a slump of $165 \mathrm{~mm}$ as instructed in EN 1170-1 (EN 1170-1, 1998). Non dispersible AR-Glass fibers CemFil@ with a length of $12 \mathrm{~mm}$ were added to the mortar. The fiber content was set to $3 \%$ of the mortar weight. The Figure $7-4$ shows the determination of the slump in fresh state.

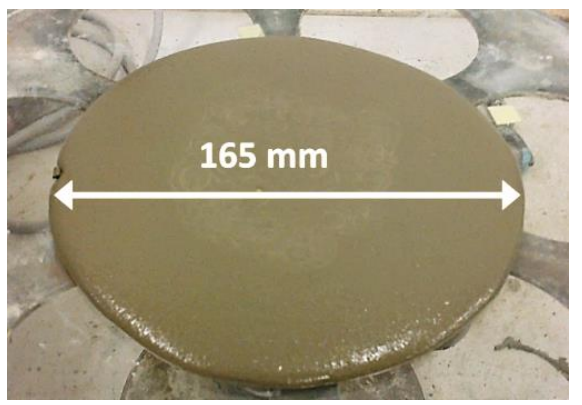

Figure 7-4. Slump test to optimize fiber content in concrete according to EN 1170-1 (EN 1170-1, 1998) 
The specimens were stored at $20^{\circ} \mathrm{C}$ and relative humidity of $100 \%$, during 28 days. After more than 28 days of curing, the specimens were soaked in hot water at $65^{\circ} \mathrm{C}$. The progress of the aging process is monitored using Nonlinear Impact Resonance Acoustic spectroscopy (NIRAS).

\subsubsection{Nonlinear Impact Resonance Acoustic Spectroscopy}

Nonlinear Impact Resonance Acoustic Spectroscopy (NIRAS) tests were conducted on un-aged and aged specimens after 40,80,120 and 150 hours of aging. An impact hammer (Bruel \& Jaer 8206, $22.7 \mathrm{mV} / \mathrm{N}$ ) with an aluminum tip struck the prismatic sample, to excite the resonant frequencies of vibration. The computer program acquired 8192 points, with a sampling frequency of $50 \mathrm{KHz}$. An accelerometer $\left(0.956 \mathrm{mV} / \mathrm{m} / \mathrm{s}^{2}\right)$ sensed the excitation. Two different test configurations, as shown in Figure 7-5, were conducted in order to generate the resonant modes. Test configuration 1 generated five resonant frequencies while test configuration 2 showed only three resonant peaks.
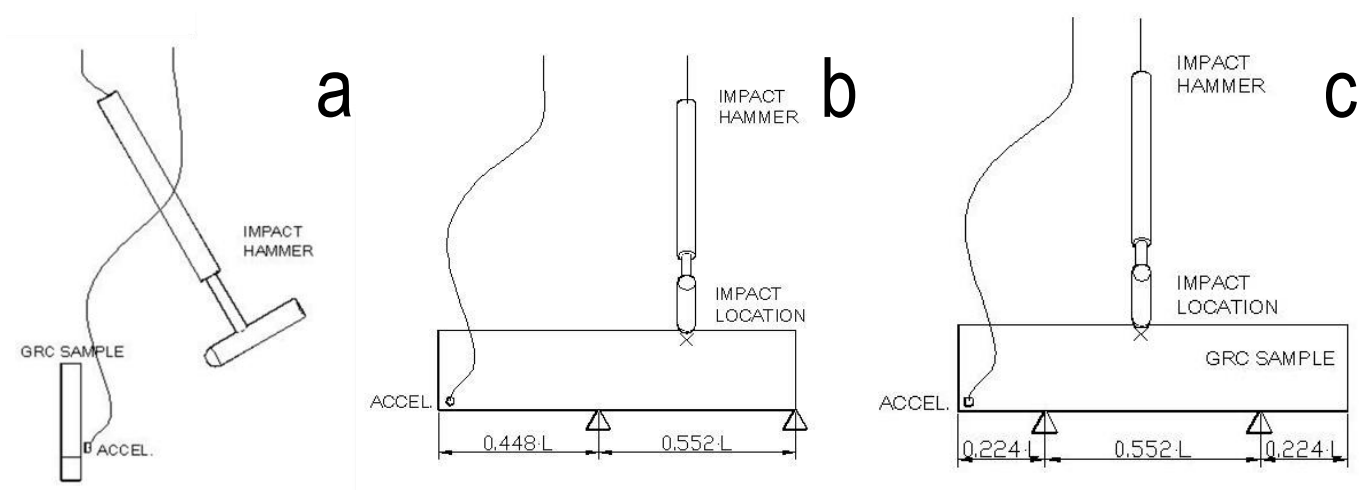

Figure 7-5. Schematic diagram of NIRAS test: a) Lateral view of set-up b) Configuration 1 c) Configuration 2. Adapted from (Eiras, Kundu, Bonilla, \& Payá, 2013)

The eigen-frequencies were determined numerically for the sample geometry being investigated, using ANSYS 13.0 software. The model considered GRC as a linear isotropic 
material (density $=2100 \mathrm{~kg} / \mathrm{m}^{3}$, Poisson's ratio 0.2 , and $\mathrm{E}=32 \mathrm{GPa}$ ). The results within the frequency range 0 to $7 \mathrm{kHz}$ are shown in Figure 7-6. Comparing the computed eigenfrequency values with the frequency peaks obtained in the experimental spectra different vibration modes associated with the recorded frequency peaks were identified. The eigenfrequency solution is a particular case of singular value decomposition problem.

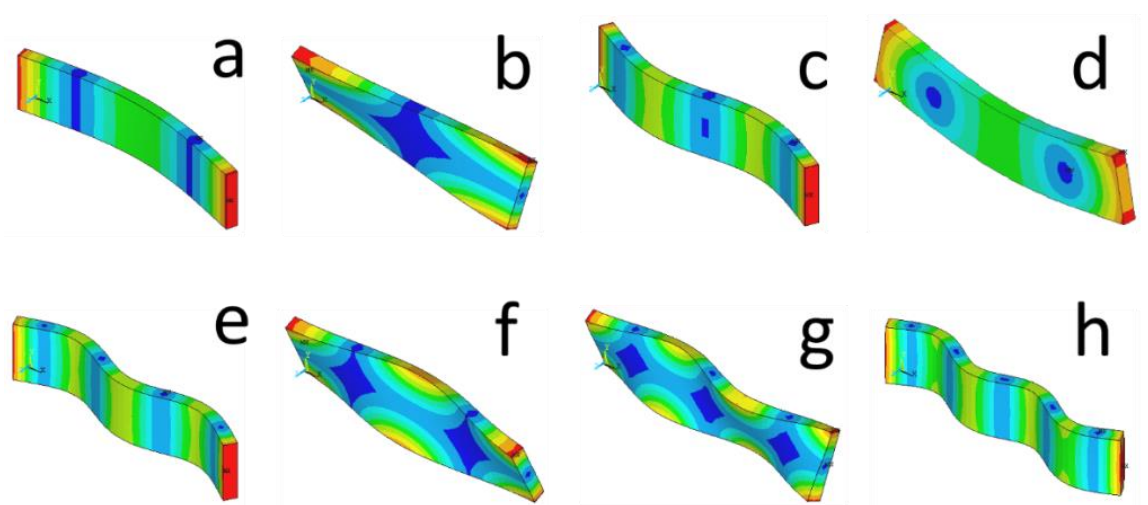

Figure 7-6. Vibration mode shapes for eigen-frequencies below $7 \mathrm{kHz}$. Flexural and torsional modes are denoted by FLEX and TOR: a) C1FLEX=787.913 Hz, b) C1TOR=2068.05 Hz, c) C2FLEX=2149.44 Hz, d) C1FLEXYZ= $3444.57 \mathrm{~Hz}$, e) C3FLEX=4148.94 Hz, f) C2TOR=4218.57 Hz, g) C3TOR=6524.11 Hz, h) C4FLEX $=6719.18 \mathrm{~Hz}$. Adapted from (Eiras et al., 2013)

Theoretical and experimental values are compared in Figure 7-7. The identification of higher flexural and torsional resonance modes is difficult since at the higher frequency range several modes show very close resonance frequencies, e.g. first torsional and second flexural (experimental values F1TOR and F2FLEX or theoretical values C1TOR and C2FLEX) or third flexural and second torsional (F3FLEX and F2TOR). To discern among resonance modes that are very close two test configurations were tried out as shown in Figure 7-5. Since the test configuration 2 struck the sample at nodal points of F1TOR, F2FLEX and F3TOR these modes were poorly excited by this strike. However F3FLEX and F2TOR were properly excited. In this manner from the resonance peaks generated by the two test configurations one can determine the resonance frequencies corresponding to all 
vibration modes. Experimental peaks for flexural and torsional modes are denoted as $F_{j} F L E X$ and $F_{j} T O R$ ( $j=1,2$ or 3 ), respectively. On the same graph theoretical values are plotted by dashed lines and denoted as $\mathrm{C}_{\mathrm{j}} F L E X$ and $\mathrm{C}_{\mathrm{j}}$ TOR. After matching the experimental and theoretical values of resonance frequencies the first and second flexural modes (F1FLEX, F2FLEX), and first, second and third torsional modes (F1TOR, F2TOR, F3TOR) were identified in the experimental spectra. Finally, the test configuration 1 was adopted since with this configuration it can be obtained five resonance peaks of relatively high amplitude, against only three resonance modes in the test configuration 2.
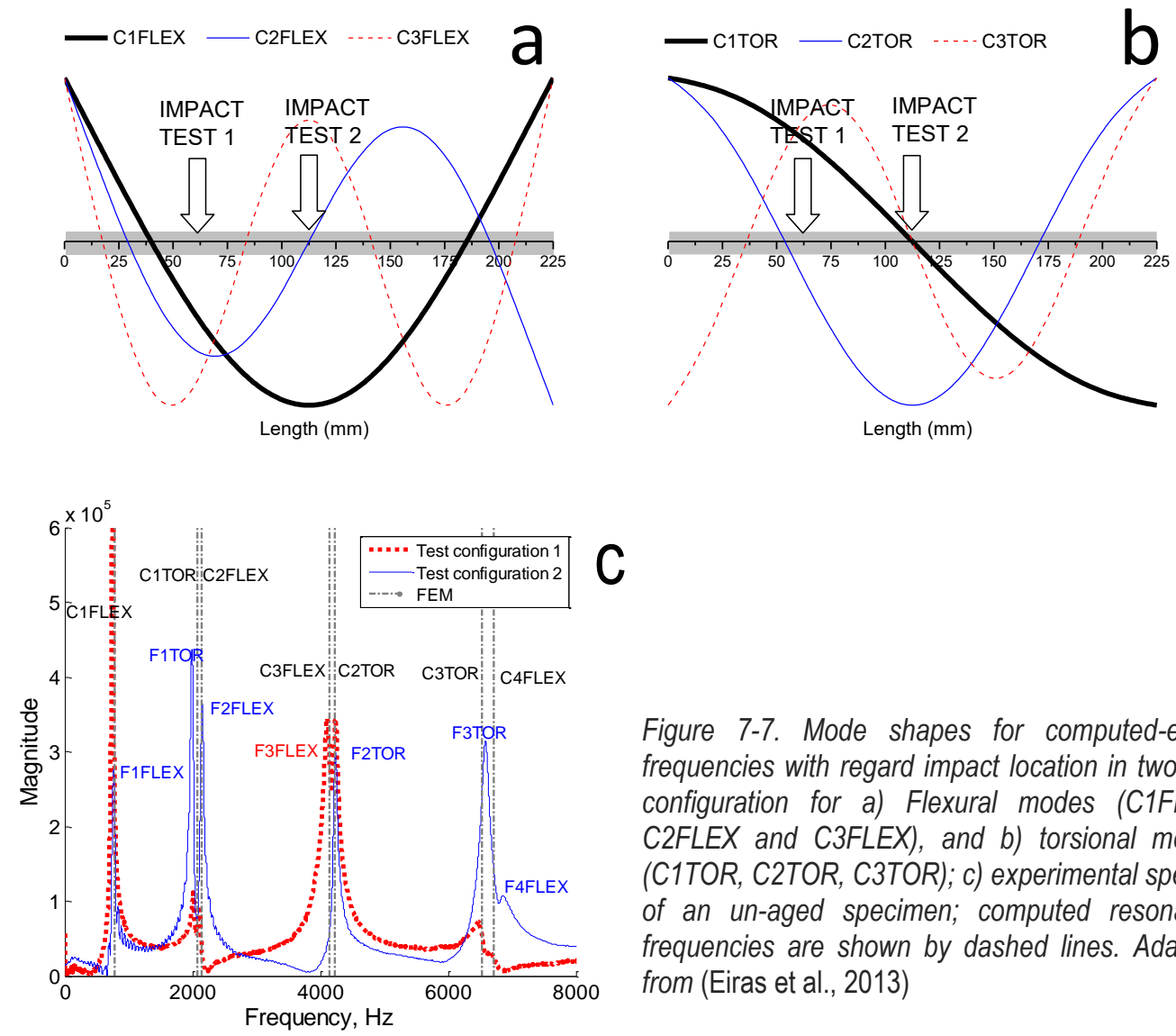

Figure 7-7. Mode shapes for computed-eigen frequencies with regard impact location in two test configuration for a) Flexural modes (C1FLEX, C2FLEX and C3FLEX), and b) torsional modes (C1TOR, C2TOR, C3TOR); c) experimental spectra of an un-aged specimen; computed resonance frequencies are shown by dashed lines. Adapted from (Eiras et al., 2013) 
The selected test configuration allows investigation of resonance torsional modes. Therefore, the dynamic Poisson's ratio can also be determined. Since dynamic modulus (E) depends on the Poisson's ratio, an iterative process was employed to determine the Poisson's ratio, as that instructed in ASTM C1548 (ASTM C1548-02, 2012). Figure 7-8 depicts the iterative process for determining the dynamic Poisson's ratio from the sample dimensions, mass and resonance frequency (F1TOR and F1FLEX).

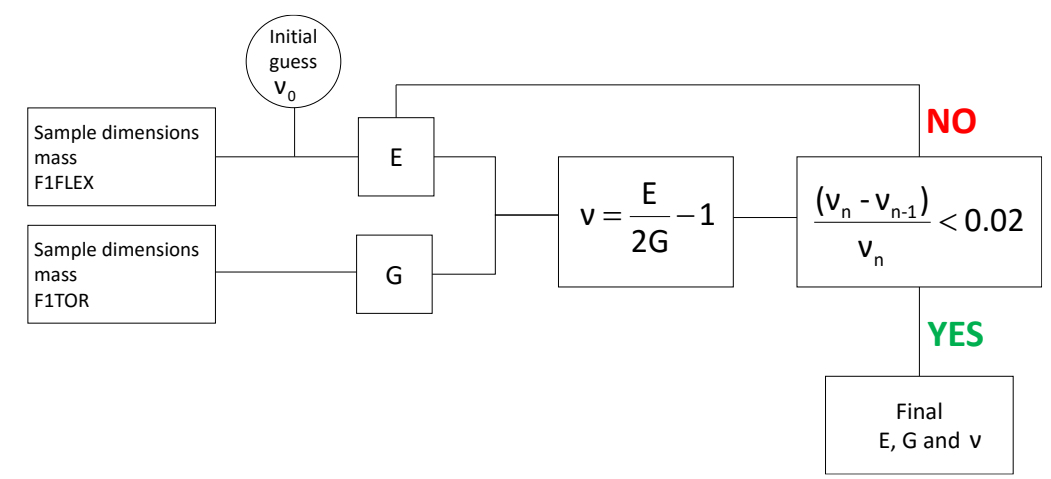

Figure 7-8 Flow chart for iterative determination of the dynamic Poisson's ratio.

\subsubsection{Mechanical test}

Four point bending test was performed in accordance with the European standard EN 1170-5 (EN 1170-5, 1998). Two un-aged and two aged (150 hours) specimens were tested in INSTRON universal testing machine (Model 3382) as shown in Figure 7-9. They were loaded in the displacement control environment at a rate of $1 \mathrm{~mm} / \mathrm{min}$.

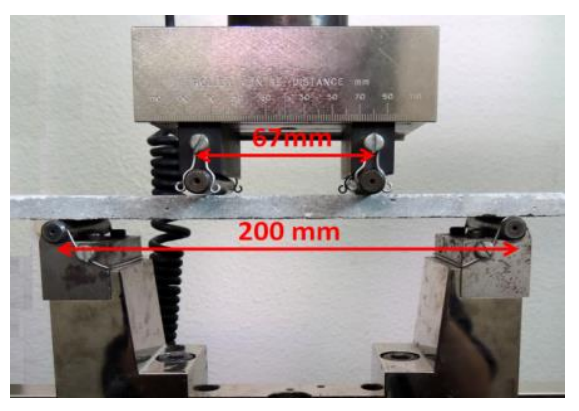

Figure 7-9 Mechanical test of GRC samples $225 \times 50 \times 10 \mathrm{~mm}$. Four point bending test EN $1170-5$ (EN 1170-5, 1998) 


\subsubsection{Scanning electronic microscope (SEM) observations}

The microstructure evolution and the integrity of the fiber with aging were studied by scanning electron microscopy (SEM, JEOL JSM6300).

\subsection{Results and discussion}

\subsubsection{Nonlinear Impact Resonance Acoustic Spectroscopy}

NIRAS measurement allows monitoring of a number of resonance frequencies and shift in these frequency values with increasing level of impact energy. The main advantage of obtaining the resonance frequencies by a hammer impact is that it excites several modes of vibration simultaneously, since the impact has a wide range of frequencies. Figure 7-10 shows resonance frequencies for un-aged and aged (after 150 hours) specimens at ten different levels of impact energy for each NIRAS test. Three observations can be made from the spectra presented here: i) in all cases the resonance frequencies increase with the time of aging. For example, the resonance frequency for F1FLEX increases from $750 \mathrm{~Hz}$ to 800 $\mathrm{Hz}$ (see Figure 7-10a). (ii) In Figure 7-10b peaks corresponding to F2FLEX and F1TOR are shown; note that the gap between the frequency peaks changes with aging. The increase of frequency is higher for F1TOR than that for F2FLEX, and iii) the variation of the resonance frequency with the striking force amplitude is different for aged and un-aged specimens. 

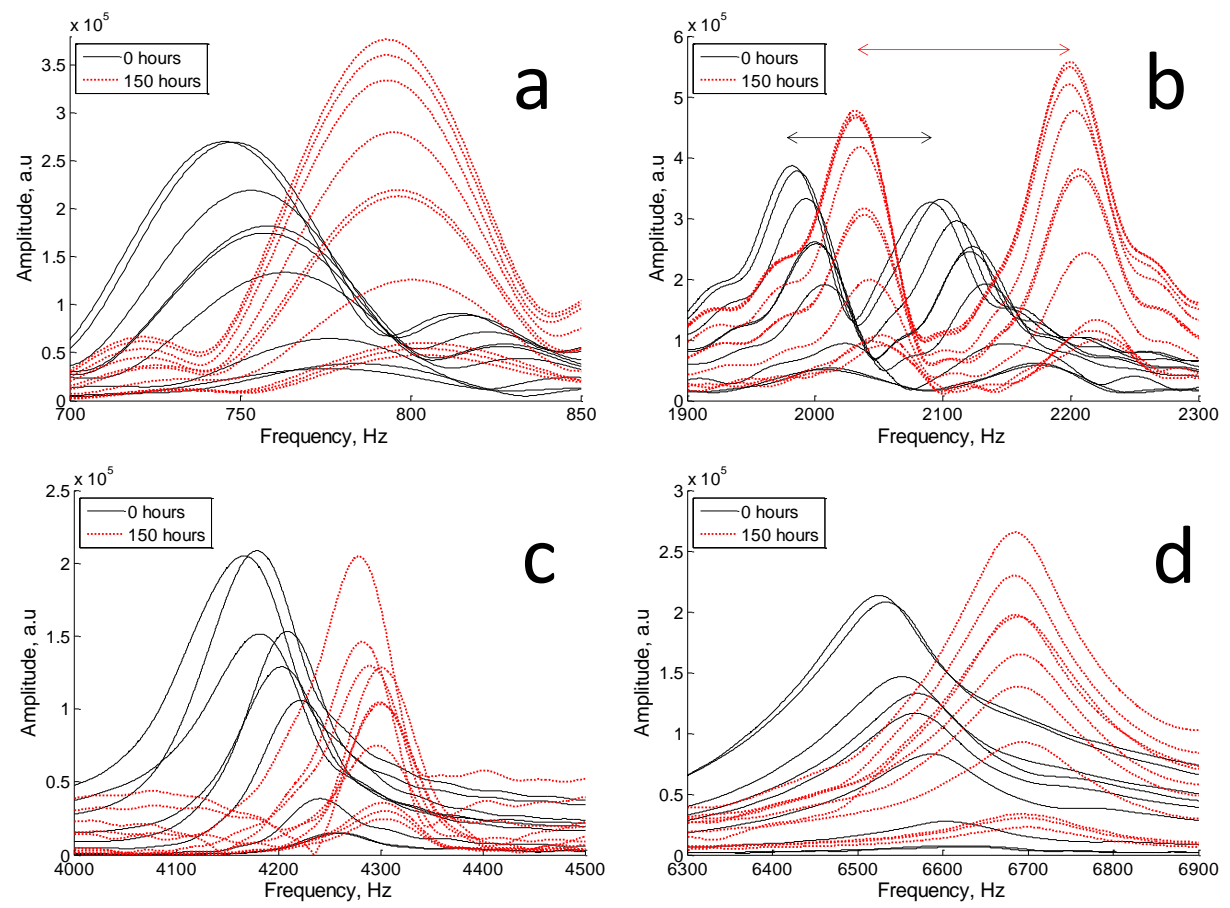

Figure 7-10 Resonance peaks for un-aged and aged specimens (i.e. 0 and 150 hours of accelerated aging). a) F1FLEX, b) F1TOR (peaks on the right) and F2FLEX (peaks on the left), c) F2TOR and d) F3TOR. Adapted from (Eiras et al., 2013)

An analysis of variance (ANOVA) was carried out taking every resonance frequency as the dependent variable (F1FLEX, F1TOR, F2FLEX, F2TOR, F3TOR) in order to observe the qualitative differences between different durations of aging considered in this investigation. Slight deviations from hypothesis of homoscedasticity and normal distribution of the data as required for ANOVA were noted. Nevertheless, the ANOVA is robust to such deviations. The null hypothesis is that the mean values between aging times remain the same while the alternative hypothesis is that there exists an aging time that is statistically different with a significance level of $95 \%$. If the null hypothesis is rejected, the least significant difference (LSD) intervals are computed for each treatment following Eq. 7-1 to determine for what aging times the significant difference exists. 
$\overline{x_{i}} \pm L S D$

$L S D=\sqrt{2} \cdot / 2 t_{g l r}^{0.95} \cdot \sqrt{M S r} / n$

where $\mathrm{x}_{\mathrm{i}}$ is the mean frequency peak to be investigated, $t_{\text {glr }}^{0.95}$ is the Student's-t distribution, $M S_{r}$ is the mean square of residuals and $n$ is the number of observations. A total of 5 samples were tested at 5 aging times $0,40,80,120$ and 150 hours. The frequency spectrum was recorded at 10 different energy levels. Figure 7-11 shows the mean values and the $95 \%$ LSD intervals for the identified frequency peaks. In all cases, the ANOVA rejects the null hypothesis of mean equivalency at different times of aging $(p<0.05)$. The identified resonance flexural modes F1FLEX, F2FLEX and torsional modes F1TOR, F2TOR, F3TOR show similar behavior. However, while the flexural modes can better distinguish between un-aged and 40 hours long aged specimens in comparison to torsional modes, the torsional modes can differentiate better between the intermediate times of aging $(40,80$ and 120 hours). The natural frequencies of flexural and torsional modes increase with time of aging indicating an increase of stiffness of the material. This effect can be attributed to the combined effect of the evolution of the hydration products in the matrix and the degradation of the fibers in the cement matrix. 

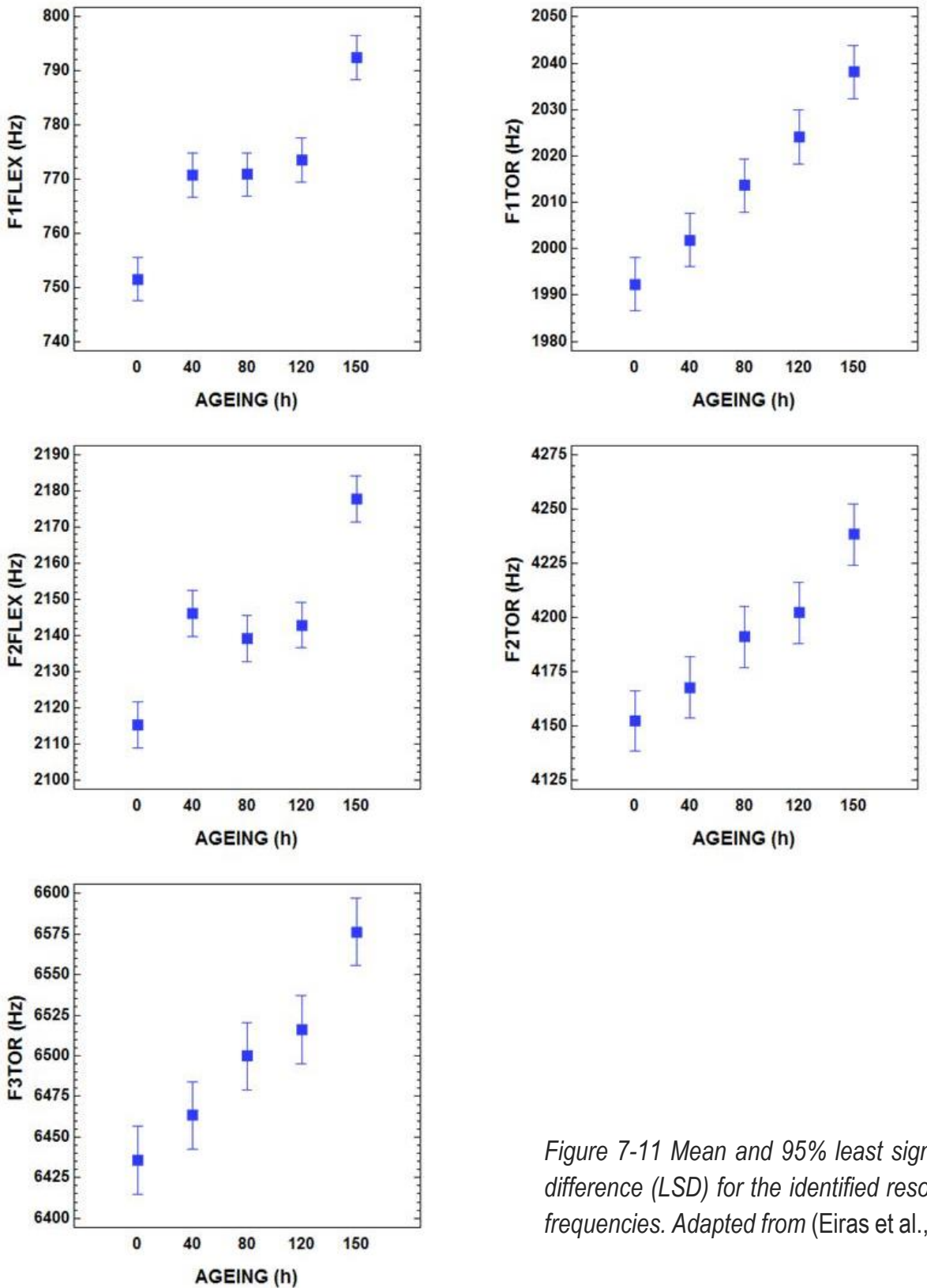

Figure 7-11 Mean and 95\% least significant difference (LSD) for the identified resonance frequencies. Adapted from (Eiras et al., 2013) 
The second aforementioned effect listed above is that the relative distances between the torsional and flexural peaks change with aging as it can be seen in Figure 7-10 b. The Poisson's ratio $v$, of a linear elastic isotropic material is a function of the Young's modulus $E$ and the shear modulus $G$ as

$$
v=\frac{E}{2 G}-1
$$

Since the Young's modulus $E$ is related to the flexural mode (F1FLEX) and the shear modulus $G$ affects the torsional mode (F1TOR), it can be shown that the Poisson's ratio is a function of the ratio of these two resonance frequencies F1TOR/F1FLEX. Given that $E$ and $G$ are proportional to the squares of these frequencies (F1FLEX and F1TOR), the lower ratio F1TOR/F1FLEX indicates higher Poisson's ratio. Values of $E, G$ and $v$ computed from the low impact excitation in NIRAS test, using equations provided in ASTM C 215 (ASTM C21514, 2014) are listed in Table 7-2.

Table 7-2 Dynamic elastic modulus (E), shear modulus ( $G$ ) and Poisson's ratio (v)

\begin{tabular}{|llll|}
\hline Aging, hours & E, GPa & G, GPa & v \\
\hline $\mathbf{0}$ & $32.70 \pm 1.94$ & $13.77 \pm 0.52$ & $0.187 \pm 0.041$ \\
$\mathbf{4 0}$ & $33.78 \pm 2.60$ & $13.77 \pm 0.20$ & $0.225 \pm 0.034$ \\
$\mathbf{8 0}$ & $33.84 \pm 1.82$ & $13.94 \pm 0.80$ & $0.213 \pm 0.027$ \\
$\mathbf{1 2 0}$ & $34.14 \pm 1.89$ & $14.07 \pm 0.62$ & $0.213 \pm 0.029$ \\
$\mathbf{1 5 0}$ & $35.72 \pm 2.06$ & $14.27 \pm 0.61$ & $0.251 \pm 0.022$ \\
\hline
\end{tabular}

During the hydration of Portland cement, the hydration products are formed as a coherent matrix enclosing remnants of anhydrous cement and interspersed porosity (Hewlett \& Massazza, 2003). A major quantity of anhydrous cement is expected for low water to cement ratio, $w / c=0.35$ in this study. Therefore, a densification of the matrix is most likely taking place with aging process what causes an increase of the elastic constants $(E, G$ and v) owing to further hydration can be achieved. Results reported by (Payá et al., 2007) on $40 \times 40 \times 160 \mathrm{~mm}$ samples showed that aging increases the compressive strength as a result 
of a completion of the hydration and the pozzolanic reaction. However, the increase of compressive strength it is not observed in non-pozzolanic GRC thus discarding the hypothesis that the chemical degradation of the fiber contributes to increase the compressive strength (Eiras, 2008; Eiras et al., 2012).

The resonance frequencies vary noticeably with increasing energy of impact for unaged specimens, but this variation is very small for fully aged specimens. The resonance frequency shift was assessed for every peak through the hysteretic parameter $\eta$. Figure 7-12 shows the F1FLEX peaks identified at different energy levels and corresponding $\eta$ calculations (HYST1FLEX).

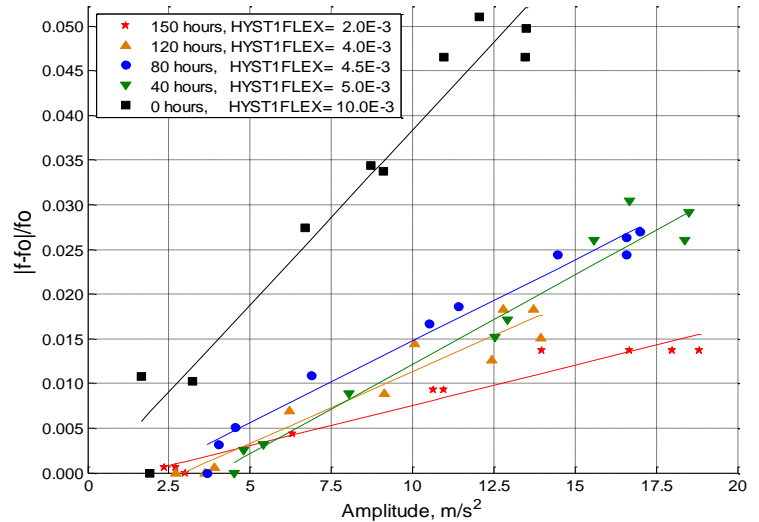

Figure 7-12. Resonance Frequency shift for the first flexural mode (F1FLEX) as a function of the impact energy level for different aging times and hysteretic parameter computation HYST1FLEX. Adapted from (Eiras et al., 2013)

In a similar analysis conducted on the resonance frequencies, an ANOVA was performed on the obtained hysteretic parameter for every resonance peak (HYST1FLEX, HYST1TOR, HYST2FLEX, HYST2TOR, and HYST3TOR). Figure 7-13 shows the mean and $95 \%$ LSD intervals for every time of aging. It is found that the hysteretic parameter computed for every resonance frequency decreases with aging. With the exception of the hysteretic parameter for the third torsional frequency (HYST3TOR), it is found that the hysteretic nonlinear parameters can only distinguish between un-aged and aged specimens but they are not very sensitive to the variations in the time of aging $(40,80,120$ or 150$)$. 

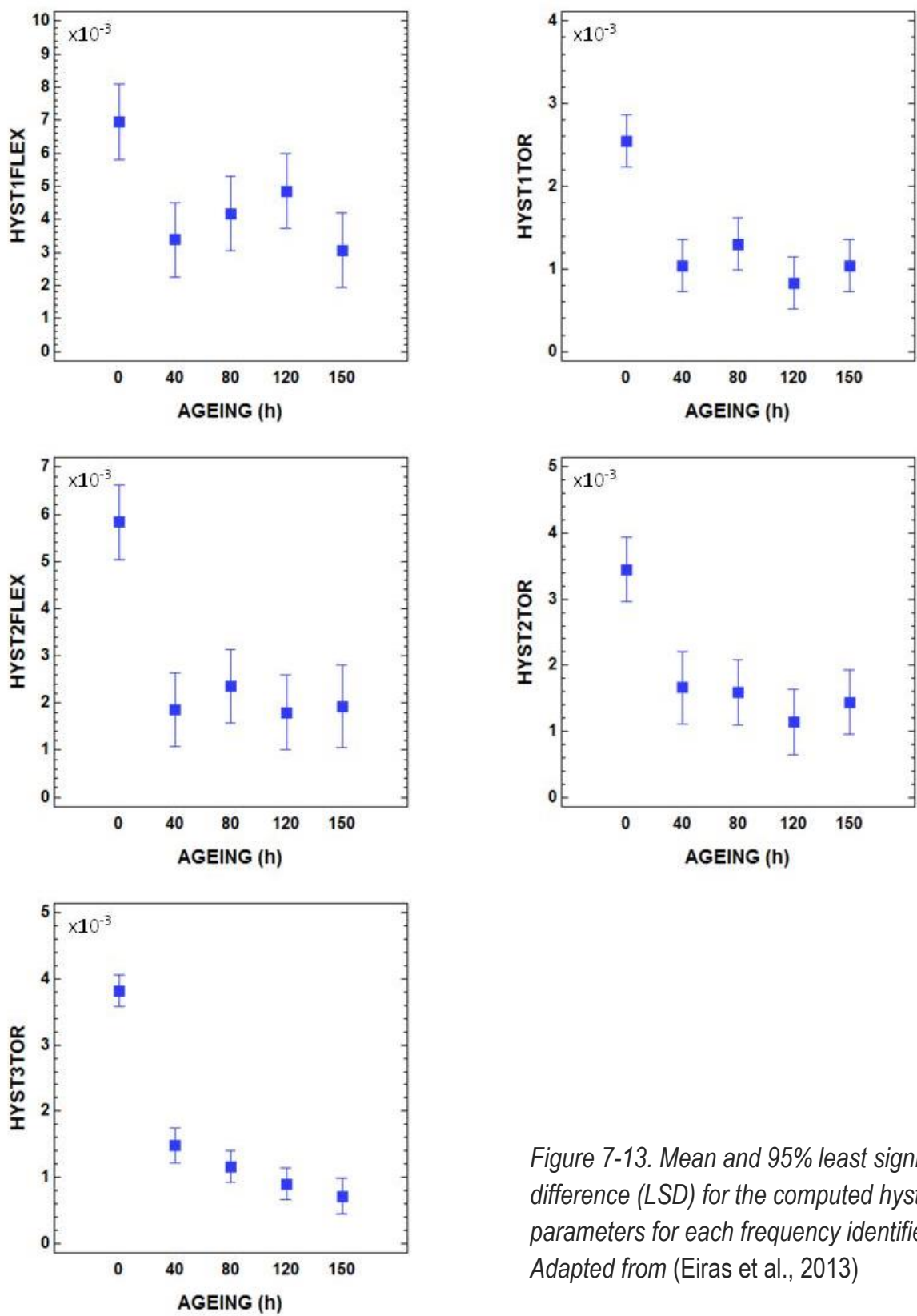

Figure 7-13. Mean and 95\% least significant difference (LSD) for the computed hysteretic parameters for each frequency identified. Adapted from (Eiras et al., 2013) 
Nonlinear dynamic hysteretic behavior is related to the amount of mesoscopic defects like pores, cracks, and rough contacts between neighboring grains (Guyer \& Johnson, 1999). The incorporation of glass fiber in cement based materials represents a mesoscopic defect itself. Zhu and Bartos (Zhu \& Bartos, 1997) demonstrated by the micro-indentation experiments that the interfacial bond of individual filaments is weaker in the fiber bundle than that at the bundle matrix interface. Similar findings were reported by Purnell et al. (Purnell, Buchanan, \& Short, 2000) who studied the interface transition zone by petrographical analysis. After aging, the inner microstructure within the strand becomes denser and stronger. These findings are in agreement with the measurement of the nonlinear hysteretic parameter $\eta$. Since the mesoscopic defects created by the presence of the fibers activate fast dynamic effect in resonance tests, it is mitigated with aging. Therefore, the precipitation of dense hydration products around the fibers improves the bonding between matrix and fiber. This phenomenon is detected nondestructively by NIRAS measurements.

\subsubsection{Mechanical properties}

The mechanical properties were evaluated for two aged and two un-aged specimens. Figure 7-14 shows the load-displacement curves for these four specimens when they were subjected to displacement control loading in four-point bending configuration.

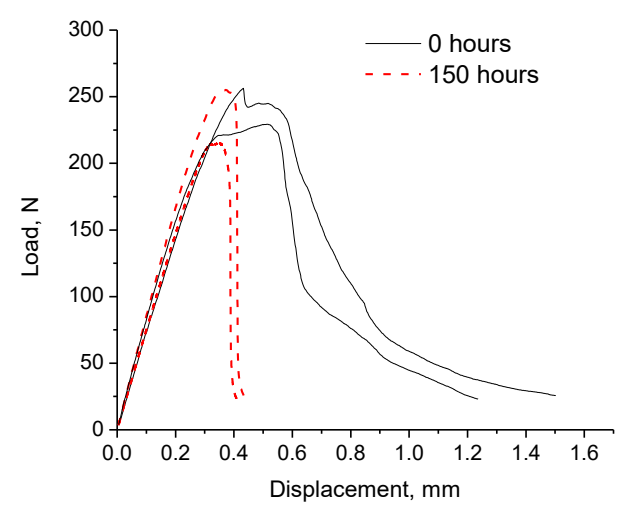

Figure 7-14. Force-displacement curves for GRC specimens - un-aged (continuous lines) and aged for 150 hours (dashed lines). Adapted from (Eiras et al., 2013) 
From load-displacement curves, different parameters can be obtained such as the modulus of rupture (MOR), the modulus at the limit of proportionality (LOP), and the work of fracture (WOF) (EN 1170-5, 1998). The MOR is obtained from the maximum attained stress $\left(\sigma_{M O R}\right)$, and strain at MOR $\left(\varepsilon_{\text {MOR }}\right)$. These are

$$
\begin{gathered}
\sigma_{M O R}=\frac{F_{M O R} \cdot L}{b \cdot d^{2}}, \text { and } \\
\varepsilon_{M O R}=\frac{27}{5} \cdot \frac{\Delta_{M O R} \cdot d}{L^{2}}
\end{gathered}
$$

wherein $b, d$, and $L$ are the sample dimensions (width, height, and length), $F_{M O R}$ is the maximum load, and $\triangle_{M O R}$ is the maximum displacement. The mechanical properties listed in Table 7-3 are calculated from the load-displacement curves shown in Figure 7-14. Also, the WOF was obtained by integrating the load-displacement curves. These results confirm the findings reported by others that GRC becomes more brittle with aging time (Bentur \& Mindess, 2007). Although there is no important difference between flexural strength and static modulus of aged and un-aged samples, the most interesting observations are the toughness decreasing with aging and the decrease of strain at maximum load ( $\left.\varepsilon_{M O R}\right)$. The fracture behavior of fiber reinforced cement-based materials can be described by the bridged crack model (Visalvanich \& Naaman, 1983) and the toughening mechanisms of fiber reinforced cement-based materials are based on fiber/matrix interactions. These mechanisms include interfacial debonding, frictional sliding and inclined angle effects. The bridging effect of the fibers restricting the opening and propagation of microcracks ends when the fibers rupture, in the case of brittle fibers like carbon or glass (Li \& Maalej, 1996). Despite the low toughness obtained for aged GRC samples, this value is still higher than the unreinforced cement-based material (see also Figure 7-3). 
Table 7-3 Mechanical properties for un-aged (U1 and U2) and aged specimens (A1 and A2)

\begin{tabular}{|lllllr|}
\hline Sample & $\begin{array}{l}\text { Aging } \\
\text { (hours) }\end{array}$ & $\begin{array}{l}\sigma_{\text {MOR }} \\
(\mathrm{MPa})\end{array}$ & $\begin{array}{l}\boldsymbol{\varepsilon}_{\text {MOR }} \\
\left(\mathbf{1 0 ^ { - 4 }} \mathbf{m m} / \mathbf{m m}\right)\end{array}$ & $\begin{array}{l}\text { Static } \\
\text { Modulus } \\
(\mathbf{G P a})\end{array}$ & $\begin{array}{l}\text { Work of fracture } \\
\mathbf{N} \cdot \mathbf{m m} \text { at 10\% of } \\
\sigma_{\text {MOR }}\end{array}$ \\
\hline U1 & 0 & 10.25 & 5.84 & 21.27 & 169.49 \\
U2 & 0 & 9.17 & 6.95 & 24.29 & 139.24 \\
A1 & 150 & 8.61 & 4.73 & 22.08 & 52.16 \\
A2 & 150 & 10.21 & 5.00 & 25.21 & 65.59 \\
\hline
\end{tabular}

\subsubsection{Optical and SEM observations}

The fibers in the un-aged matrix are shown in Figure 7-15a and Figure 7-15b. In Figure $7-15 a$, it can be seen that the multifilament fiber is surrounded by cement hydrated products. These products do not completely fill the voids adjacent to the filaments. Figure $7-15 \mathrm{~b}$ shows a typical surface of the filament in which damage is not evident - showing smooth surface of the filament and compact hydration products surrounding it. Figure $7-15 \mathrm{c}$ shows that after aging the multifilament structure is maintained, and more cement hydration products appear near the filaments. The most noticeable change is the formation of unevenly distributed small spots (diameter $<1 \mu \mathrm{m}$ ) on the surface of the filament (Figure 7-15d). Sometimes several spots appear very close to one another, forming relatively bigger flaws, as shown in Figure $7-15 \mathrm{~d}$. This figure shows that the aging at $65^{\circ} \mathrm{C}$ produced a severe level of corrosion on the surface of the filaments, despite relatively short aging time (150 hours). Similar high degree of corrosion in filaments under accelerated aging environment was reported by Litherland, Maguire and Proctor (Litherland, Maguire, \& Proctor, 1984). Such accelerated aging is needed to predict the long term strength of GRC composites. It has been reported in the literature (Litherland et al., 1984) that aging temperatures greater than $50^{\circ} \mathrm{C}$ produce significant reduction in flexural strength in less than 10 days because the corrosion rate is high. 


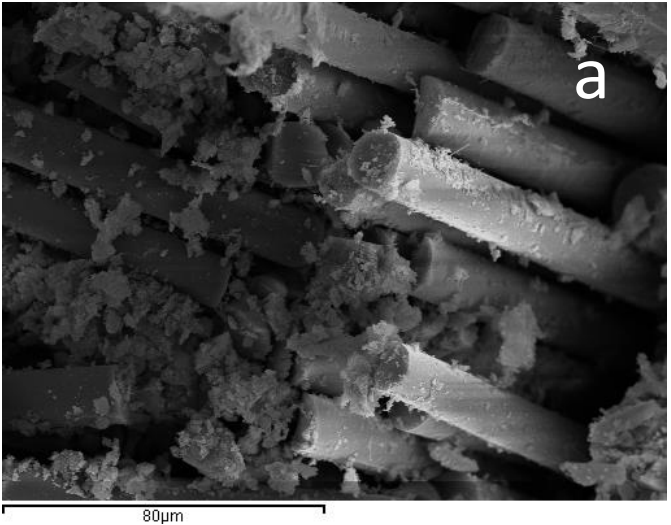

$80 \mu \mathrm{m}$

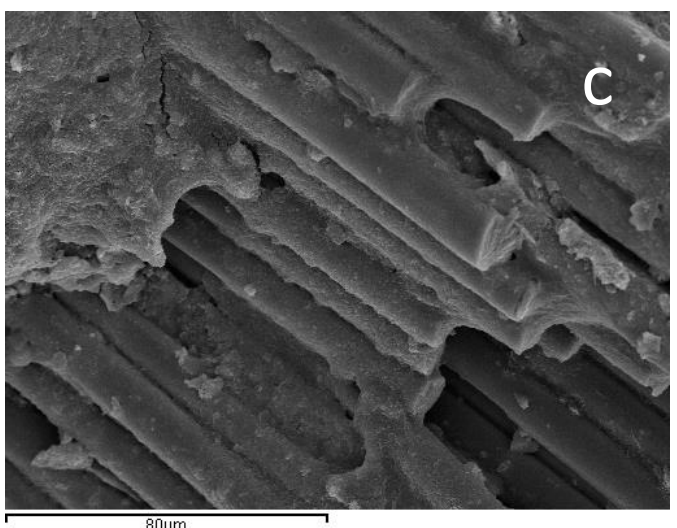

Figure 7-15 Scanning electron micrographs: a) and b): Un-aged samples; c) and d) 150 hours aged. Adapted from (Eiras et al., 2013)
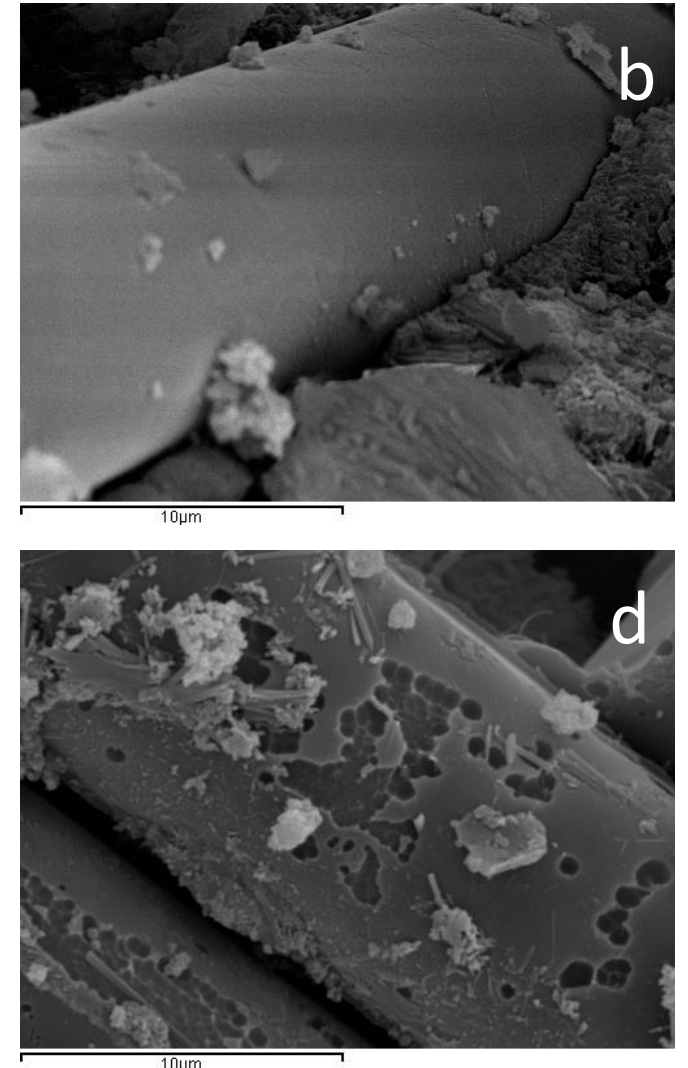

\subsection{Conclusions}

Variations in the degree of material nonlinearity of glass fiber reinforced cement (GRC) with age are investigated by two nondestructive testing techniques. Destructive testing is then performed to verify the nondestructive testing results. The scanning electron microscope (SEM) images confirm that the aging from the hot water immersion deteriorates the glass fibers. As a result of this deterioration the toughness of the specimen that was 
gained from the presence of the fibers is lost after aging. The decrease of toughness with aging is confirmed by the mechanical testing using universal testing machine. However, in contrast to the common wisdom it is observed in this investigation that as the material deteriorates it becomes more linear instead of being more non-linear that is observed during other types of material degradation such as fatigue. Deterioration of the fibers makes the material weaker but more linear. NIRAS tests confirmed that the material becomes more linear with aging from the hot water immersion.

NIRAS measurements allow us to monitor several resonance modes simultaneously, allowing a complete overview of the mechanical integrity of the material. The dynamic signatures of aged GRC specimens were closely studied and the following observations were made.

i) With aging an increase in the resonance frequencies of the flexural and torsional modes were observed. The ANOVA results could distinguish between different times of aging. The flexural modes can detect accurately the shorter time of aging while the torsional modes can distinguish between different times of aging.

ii) The increase of resonance frequencies corresponding to flexural and torsional nodes indicates an increase of $E$ and $G$ respectively.

iii) The gap between the resonance peaks and the ratio $E / G$ were found to increase with aging. It implies that the Poisson's ratio also increases with aging.

iv) The first two observations (i and ii) indicate a densification of the matrix as is expected due to the completion of the hydration process and to the hardening of the interfaces during the aging process.

v) The hysteretic nonlinear parameters identified for every peak is a sensitive indicator of the degradation of fibers with aging. The hysteretic parameter computed from the highest frequency was identified. It was observed that this 
parameter could be computed more accurately from the third torsional mode than other resonance peaks at lower frequencies.

NIRAS test is suitable for laboratory inspection of specimens and it can provide reliable information about GRC aging. Likewise, this test can be applied in the assessment of the durability of other fiber-reinforced types of concrete, such as cellulosic or vegetable fibers. Nonlinear parameters inform on internal friction within the material, so that these observations may also have relevance on the design of materials where the damping properties want to be engineered.

\section{References}

Amick, H., \& Monteiro, P. J. M. (2006). Experimental Determination of Modal Damping in Concrete Beams. ACI Material Journal, 103(3), 153-160.

ASTM C1548-02. (2012). Standard Test Method for Dynamic Young's Modulus, Shear Modulus, and Poisson's Ratio of Refractory Materials by Impulse Excitation of Vibration. West Conshohocken, PA (USA).

ASTM C215-14. (2014). Standard Test Method for Fundamental Transverse , Longitudinal , and Torsional Resonant Frequencies of Concrete.

Bentur, A. (1985). Durability of Glass-Fiber-Reinforced Cements with Different AlkaliResistant Glass Fibers. Journal of the American Ceramic Society, 10(1), 46-208.

Bentur, A., \& Mindess, S. (2007). Fibre Reinforced Cementitious Composites (Second Edi). London and New York: Taylor \& Francis Group.

Chakrapani, S. K., Barnard, D. J., \& Dayal, V. (2015). Influence of fiber orientation on the inherent acoustic nonlinearity in carbon fiber reinforced composites. The Journal of the Acoustical Society of America, 137(February), 617-624.

Cheng, J., Liang, W., Hu, Y., Chen, Q., \& Frischat, G. H. (2003). Development of a new alkali resistant coating. Journal of Sol-Gel Science and Technology, 27(3), 309-313. 
Eiras, J. N. (2008). Efecto de la adicion de puzolanas activas en la durabilidad del GRC fabricado con fibras de vidrio tipo $E$. Universitat Politècnica de València.

Eiras, J. N., Gaona, F., Monzó, J., Kundu, T., Popovics, J. S., Payá, J., \& Bonilla, M. (2012). Caracterización de GRC y evaluación del proceso de envejecimiento por medio del análisis de espectros de vibración. In XIII Congreso nacional de propiedades mecánicas de sólidos, PMS2012 (pp. 1-6). Alcoy (Spain).

Eiras, J. N., Kundu, T., Bonilla, M., \& Payá, J. (2013). Nondestructive Monitoring of Aging of Alkali Resistant Glass Fiber Reinforced Cement ( GRC ). Journal of Nondestructive Evaluation, 32(3), 300-314.

EN 1170-1. (1998). Precast concrete products. Test method for glass-fibre reinforced cement. Measuring the consistency of the matrix. "Slump test" method.

EN 1170-5. (1998). Precast concrete products. Test method for glass-fibre reinforced cement. Measuring bending strength, "complete bending test" method.

EN 1170-8. (2008). Test method for glass-fibre reinforced cement. Cyclic weathering type test.

EN 14649. (2006). Precast concrete products. Test method for strength retention of glass fibres in cement and concrete (SIC test).

EN 197-1. (2011). Cement. Composition, specifications and conformity criteria for common cements.

Enfedaque, A. (2012). An alternative methodology to predict aging effects on the mechanical properties of glass fiber reinforced cements (GRC). Construction and Building, 27(1), 425-431.

Gao, S. L., Mäder, E., \& Plonka, R. (2004). Coatings for glass fibers in a cementitious matrix. Acta Materialia, 52(16), 4745-4755.

Giner, V. T., Baeza, F. J., Ivorra, S., Zornoza, E., \& Galao, Ó. (2012). Effect of steel and carbon fiber additions on the dynamic properties of concrete containing silica fume. Materials and Design, 34, 332-339.

Guyer, R. A., \& Johnson, P. A. (1999). Nonlinear Mesoscopic Elasticity: Evidence for a New 
Class of Materials. Physics Today, 52(4), 30-36.

Hewlett, P. C., \& Massazza, F. (2003). Lea's Chemistry of Cement and Concrete. Lea's Chemistry of Cement and Concrete. Butterworth-Heinemann.

Li, V. C., \& Maalej, M. (1996). Toughening in cement based composites. Part II: Fiber reinforced cementitious composites. Cement and Concrete Composites, 18(4 SPEC. ISS.), 239-249.

Litherland, K., Maguire, P., \& Proctor, B. (1984). A test method for the strength of glass fibres in cement. International Journal of Cement 6(1), 39-45.

Nelson, D. J., \& Hancock, J. W. (1978). Interfacial slip and damping in fibre reinforced composites. Journal of Materials Science, 13(11), 2429-2440.

Noushini, A., Samali, B., \& Vessalas, K. (2013). Effect of polyvinyl alcohol (PVA) fibre on dynamic and material properties of fibre reinforced concrete. Construction and Building Materials, 49, 374-383.

Payá, J., Bonilla, M., Borrachero, M. V., Monzó, J., Peris-Mora, E., \& Lalinde, L. F. (2007). Reusing fly ash in glass fibre reinforced cement: A new generation of high-quality GRC composites. Waste Management, 27(10), 1416-1421.

Péra, J., \& Ambroise, J. (2004). New applications of calcium sulfoaluminate cement. Cement and Concrete Research, 34(4), 671-676.

Purnell, P. (2004). Interpretation of climatic temperature variations for accelerated aging models. Journal of Materials Science, 39(1), 113-118.

Purnell, P., Buchanan, A., \& Short, N. (2000). Determination of bond strength in glass fibre reinforced cement using petrography and image analysis. Journal of Materials, 35(18), 4653-4659.

Purnell, P., Short, N. R., \& Page, C. L. (2001a). A static fatigue model for the durability of glass fibre reinforced cement. Journal of Materials Science, 36(22), 5385-5390.

Purnell, P., Short, N. R., \& Page, C. L. (2001b). Super-critical carbonation of glass-fibre reinforced cement. Part 1: Mechanical testing and chemical analysis. Composites Part A: Applied Science and Manufacturing, 32(12), 1777-1787. 
Roy, D. M. (1987). New strong cement materials: chemically bonded ceramics. Science (New York, N.Y.), 235(4789), 651-8.

Shah, S. P., Ludirdja, D., Daniel, J. I., \& Mobasher, B. (1988). Toughness-Durability of Glass Fiber Reinforced Concrete Systems. ACI Materials Journal, 85(5), 352-360.

Short, N. R., Purnell, P., \& Page, C. L. (2001). Preliminary investigations into the supercritical carbonation of cement pastes. Journal of Materials Science, 36(1), 35-41.

Van Den Abeele, K., \& De Visscher, J. (2000). Damage assessment in reinforced concrete using spectral and temporal nonlinear vibration techniques. Cement and Concrete Research, 30(9), 1453-1464.

Visalvanich, K., \& Naaman, A. E. (1983). Fracture Model for Fiber Reinforced Concrete. ACl Journal Proceedings, 80(2), 128-138.

Yan, L., Jenkins, C. H., \& Pendleton, R. L. (2000a). Polyolefin fiber-reinforced concrete composites Part I. Damping and frequency characteristics. Cement and Concrete Research, 30, 391-401.

Yan, L., Jenkins, C. H., \& Pendleton, R. L. (2000b). Polyolefin fiber-reinforced concrete composites Part II . Damping and interface debonding. Cement and Concrete Research, 30, 403-410.

Zhang, Y., Sun, W., Shang, L., \& Pan, G. (1997). The effect of high content of fly ash on the properties of glass fiber reinforced cementitious composites. Cement and Concrete Research. Retrieved from

Zhu, W., \& Bartos, P. J. M. (1997). Assessment of interfacial microstructure and bond properties in aged GRC using a novel microindentation method. Cement and Concrete Research. 
Chapter 8. Nonlinear Single Impact Resonance Acoustic Spectroscopy (NSIRAS): Frequency domain analysis 

Chapter 8. Nonlinear Single Impact Resonance Acoustic Spectroscopy (NSIRAS): Frequency domain

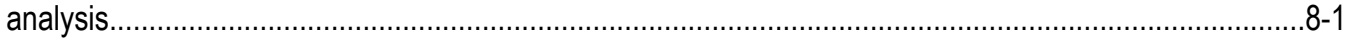

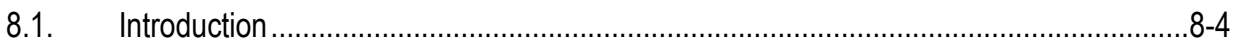

8.1.1. Effect of window type and window length .......................................................

8.2. Assessment of freezing-thawing damage ............................................................ 8 -10

8.2.1. Experimental details ............................................................................ 8 -10

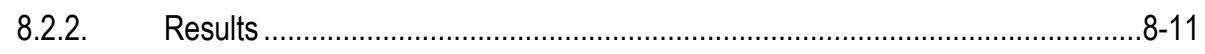

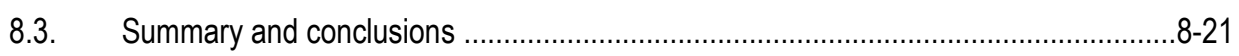

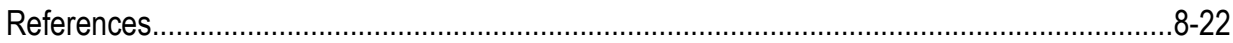




\subsection{Introduction}

The resonance frequency method was the first nondestructive test standardized by American Society for Testing Materials (Carino N. J., 1994). Since pioneer work conducted by Powers (Powers, 1938) to determine the dynamic modulus of elasticity on concrete samples, it was used to monitor freezing-thawing damage (Hornibrook, 1939) and later adopted by the standard ASTM C666 (ASTM-C666, 2012) as an alternative method to check material conformity of concrete against frost damage. However, its use has not only been limited to freezing-thawing damage, rather it has been broadly used to assess alkali-silica reaction (Askegaard \& Langsœ, 1986; N. R. Swamy \& Al-Asali, 1988), sulfate attack (ASTM C1012-13, 2013), or mechanical damage (Ito, Uomoto, \& Uomotot, 1997; Subramaniam, Goldstein, Popovics, \& Shah, 1999). In general, the main scopes for resonance frequency method include determination of engineering properties such as dynamic modulus ( $\mathrm{N}$. Swamy \& Rigby, 1971), Poisson's ratio (R. N. Swamy, 1971) or damping constant (Amick \& Monteiro, 2006), and laboratory tests, where material conformity after accelerated durability tests in aggressive media want to be checked.

In recent years, nonlinear mechanical wave propagation techniques are showing promise for sensitive early damage detection, in a wide range of materials and damage mechanisms. Such techniques underlie on the nonlinear and hysteretic stress-strain in materials and lead to so-called non-classical effects. Since the origin of hysteresis is related to damage features such as microcracks, considerable effort has been conducted to develop nondestructive tests to interrogate non-classical effects pursuing damage identification. These techniques have collectively been termed as nonlinear wave elastic spectroscopies (NEWS) (K. E. Van Den Abeele, Sutin, Carmeliet, \& Johnson, 2001). The hysteretic stressstrain relationship in cement-based materials leads to resonant frequency and attenuation depend on excitation amplitude. These premises have been leveraged by several researchers for investigating the frequency and attenuation properties over the ring down of the acoustic response, in forced vibration experiments. Different methods have been 
proposed which include either a burst excitation wherein the signal is analyzed after switching off the power source (K. Van Den Abeele \& De Visscher, 2000), or a controlled impact (Dahlén, Ryden, \& Jakobsson, 2015; Eiras, Monzó, Payá, Kundu, \& Popovics, 2014; Neild, Williams, \& McFadden, 2003). Such techniques pursue the extraction of frequency and attenuation parameters as the forced vibration naturally dissipates with time.

In this chapter, it is presented a short-time Fourier transform (STFT) based approach which was applied on standard vibration data as obtained through the standard test configuration ASTM C215 (ASTM C215-14, 2014). Figure 8-1a and Figure 8-1b show the workflow for obtaining the frequency variation over the ring down of the signal, and a schematic representation of the signal processing. The method consists of a sliding window with length $w /$ that moves through a single time response signal, and transforms the time segment within the window to the frequency domain (amplitude spectrum) at every window position. The window shift unit (ws) is shorter than the window length $(w s<w)$, so that consecutive windows overlap. The moving window analysis is stopped when the spectral amplitude is reduced below a preset threshold value (th). The approach is demonstrated on a synthetic signal in subsection 8.2.1 Effect of window length and window type (page 8-6), wherein the effects of mathematical parameters such as window length $(w)$ and window type are also investigated. In section 8.2 Assessment of freezing-thawing damage (page 8-10), the proposed method is used on experimental vibration data, as obtained through the ASTM C215-14 (ASTM C215-14, 2014). To this end, the mortars I-050 and I-060 were subjected to increasing number of freezing-thawing cycles. Along with the common linear parameters, linear resonant frequency and quality factor (Jones, 1962), the standard vibration signals were processed to extract the nonlinear behavior. 


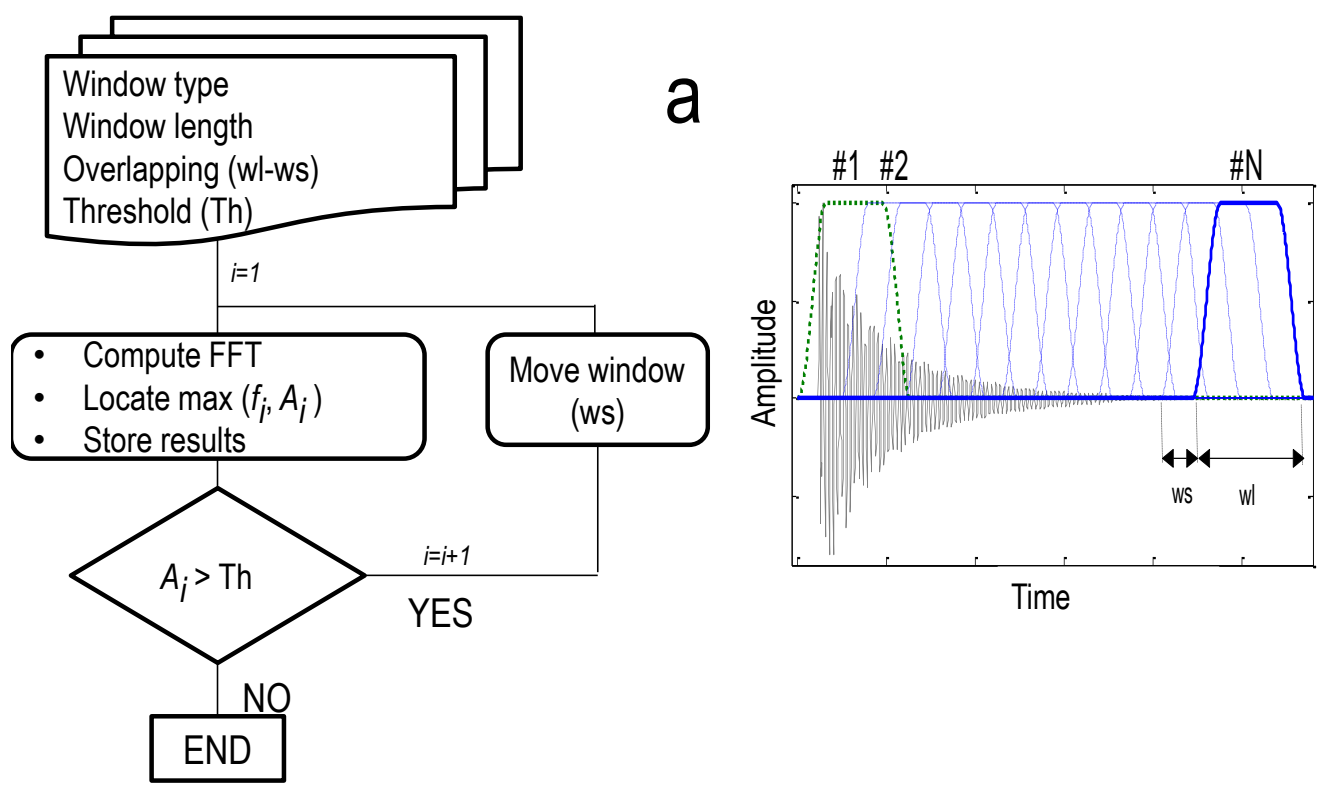

Figure 8-1 a) Algorithm workflow to obtain time-varying resonant frequency shift through the short-time Fourier transform of the vibration signal, b) schematic representation of the signal processing.

\subsubsection{Effect of window type and window length}

The nonlinear analysis of the signal, as obtained through the STFT, depends on mathematical parameters such as window length and window type. In this subsection it is performed a parametric study to better understand the effects of window length and window type parameters. To this end, a synthetic signal similar to those produced in resonant impact vibration measurements was used. The synthetic signal is an exponentially decay sine function with a time-varying phase

$$
y(t)=100 \cdot \exp (-250 \cdot t) \cdot \sin \left(2 \pi \cdot\left(5000 \cdot t+25000 \cdot t^{2}\right)\right) .
$$

In this way, the time-varying phase simulates the upward resonant frequency shift observed during the analysis of the ring-down signal in resonant frequency tests. Figure 8-2a shows the synthetic signal $\left(y(t)=100 \cdot \exp (-250 \cdot t) \cdot \sin \left(2 \pi \cdot\left(5000 \cdot t+25000 \cdot t^{2}\right)\right)\right.$. 
Eq. 8-1) wherein the initial and final window positions are shown, and Figure 8-2b shows the corresponding stacked spectra as a result of the STFT analysis. For reference, the FFT of the entire signal is shown in Figure 8-2c. The FFT of the entire signal does not permit time-frequency localization, so the spectra lumps the frequency variation in a sole value. In Figure 8-2c are also shown the cutoff frequencies corresponding to the definition of quality factor (Jones, 1962), in order to remark the peak asymmetry $-\left(f-f_{a}\right)>\left(f_{b}-f\right)-$. The peak asymmetry is a typical signature observed in damaged materials in resonant experiments (Johnson \& Rasolofosaon, 1996). This result confirms that a time-varying resonant frequency within the signal produces asymmetry in the frequency spectra.
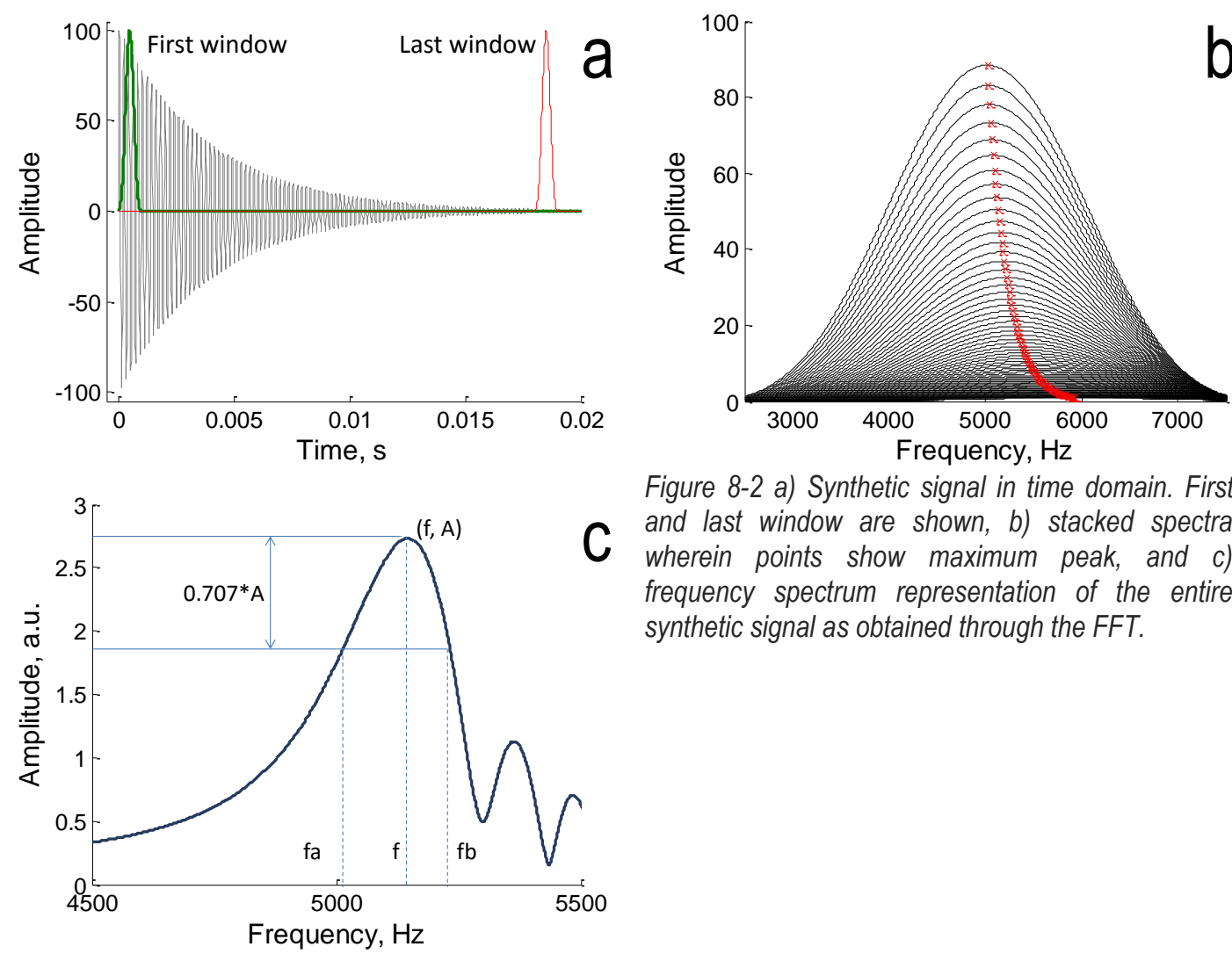

Figure 8-2 a) Synthetic signal in time domain. First C and last window are shown, b) stacked spectra wherein points show maximum peak, and c) frequency spectrum representation of the entire synthetic signal as obtained through the FFT. 
By setting different window type and window length values, different sets of frequency and amplitude can be obtained. The synthetic signal $y(t)=100 \cdot \exp (-250 \cdot t) \cdot \sin \left(2 \pi \cdot\left(5000 \cdot t+25000 \cdot t^{2}\right)\right) . \quad$ Eq. 8-1) was analyzed according to the algorithm described in the previous section (Figure 8-1). Two different windows Tukey and Blackman were used which were set with window lengths encompassing approximately 4, 5, 10, 20 and 50 cycles -these window lengths correspond to $0.75,1,2,4$, and 10 milliseconds respectively-. Note that the number of cycles within one sliding window will vary with time. These results ("predicted") were compared with the synthetic signal parameters (instantaneous frequency and amplitude) which are henceforth termed as "observed" values. Figure 8-3a to Figure 8-3d show the residuals corresponding to the extracted frequency, and spectral amplitude values using both windows and set with different window lengths. The residuals were obtained as observed minus predictedresidual $=x_{n}-x_{n}$ ' frequency or the amplitude. From results, it can be drawn that longer windows tend to underestimate the actual instantaneous frequency. On other hand, the amplitude values were overestimated for relatively short windows ( 20 cycles and below), whereas longer windows ( $\sim 50$ cycles) lead to an underestimation. Figure 8-3e and Figure 8-3f compare the goodness of the extracted frequency and amplitude by using both window types (Blackman and Tukey) for a range of window lengths. The "goodness" of the extracted frequency and amplitude values was evaluated through the root mean square error (RMSE) as

$$
R M S E=\sum_{n=1}^{n=N} \sqrt{\left(x_{n}-x_{n}^{\prime}\right)^{2}}
$$

wherein $N$ is the number of observations. In general, both windows provided similar estimations of instantaneous frequency for windows lengths of $\sim 20$ cycles and below. On other hand, the Blackman window provided more accurate estimations of amplitude regardless window length. With all, shorter windows ( 5 cycles and below) provided closer 
values to the actual synthetic signal parameters, and the RSME values were somewhat scattered (see inset plot in Figure 8-3c). In this sense, window lengths containing more than 10 cycles resulted more robust, and provided frequency and amplitude values still fairly close to the actual ones. In general, Blackman window performed better than Tukey window, especially regarding amplitude estimation. These assertions were also confirmed on experimental signals. In the following, the STFT based approach is used to evaluate the material nonlinearity on a set of mortars subjected to a number of freezing-thawing cycles. The extent of the material nonlinearity is quantified as function of the instantaneous signal characteristics.
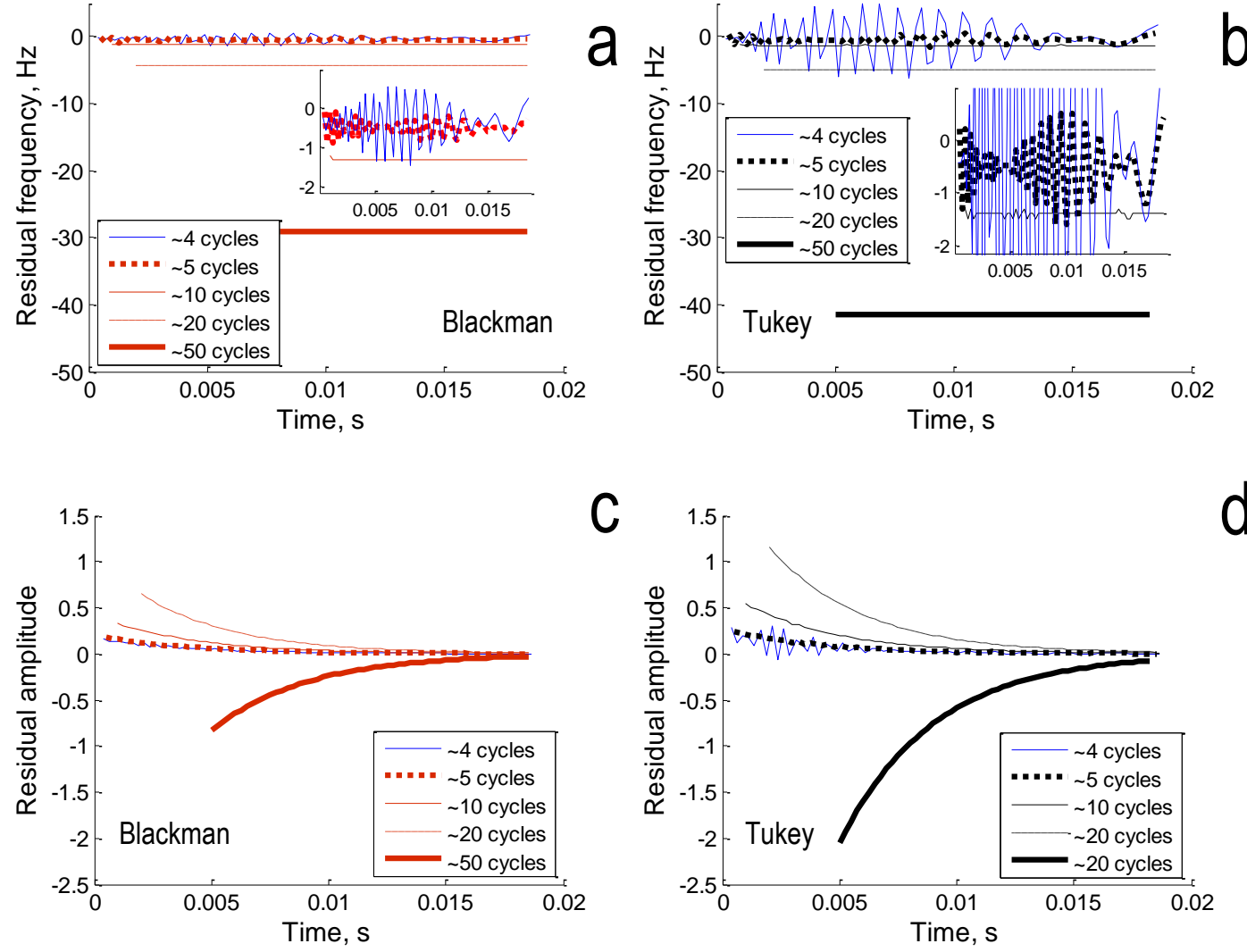

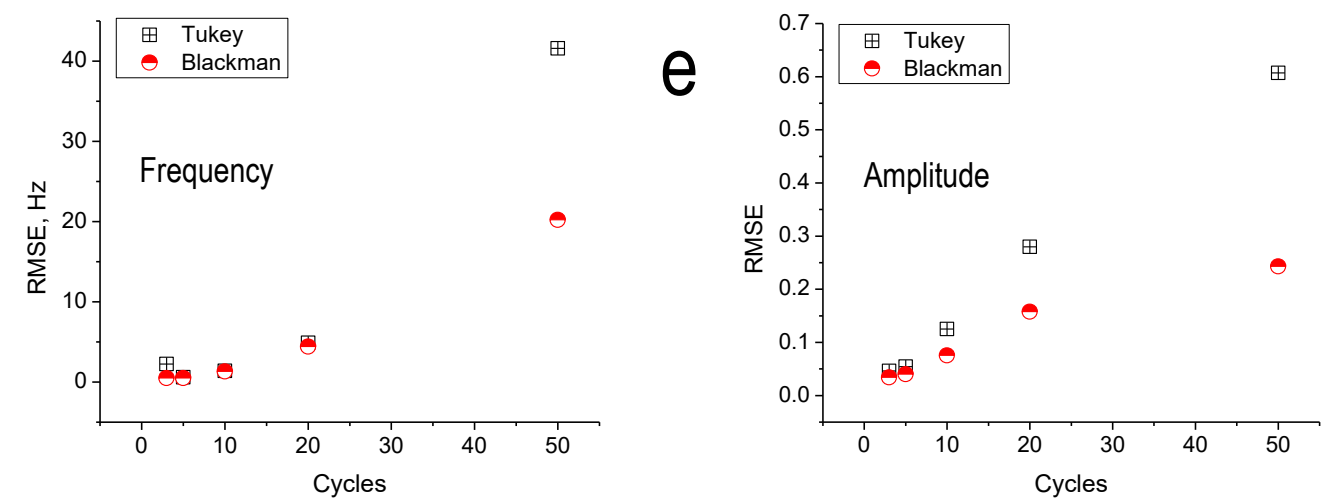

Figure 8-3 Residual instantaneous frequency by using a) Blackman, and b) Tukey windows; residual instantaneous amplitude by using c) Blackman, and d) Tukey windows. e) RMSE obtained for frequency and e) RMSE obtained for amplitude by using Tukey and Blackman windows.

\subsection{Assessment of freezing-thawing damage}

\subsubsection{Experimental details}

Prismatic samples measuring $40 \times 40 \times 160 \mathrm{~mm}^{3}$ were prepared with water-cement ratios of 0.50 and 0.60 , and aggregate-cement ratio of 3 . These mortars correspond to the mortars I-050 and I-060 - see Chapter 2 Materials and methods-. The samples were cured in $20^{\circ} \mathrm{C}$ water for 90 days after casting. Then the test samples were subjected to freezing-thawing cycles, as described in Chapter 6 Freezing-thawing damage. The freezing-thawing damage produces distributed microcracking damage, and the damage severity largely depends on pore size distribution (Pigeon \& Pleau, 2010). The disadvantageous pore-size distribution and porosity content on mortar I-060, make it more susceptible to frost damage than mortar I-050. Therefore, it is expected a greater reduction of mechanical properties in mortar I-060 upon freezing-thawing cycles. Figure 8-4 shows a photo of two representative samples of mortars I-050 (above) and I-060 (below) after 5 cycles. Noticeable crack patterns stood out on the surface of the mortar sample I-060, in contrast to mortar sample I-050, wherein any visible crack was seen. 


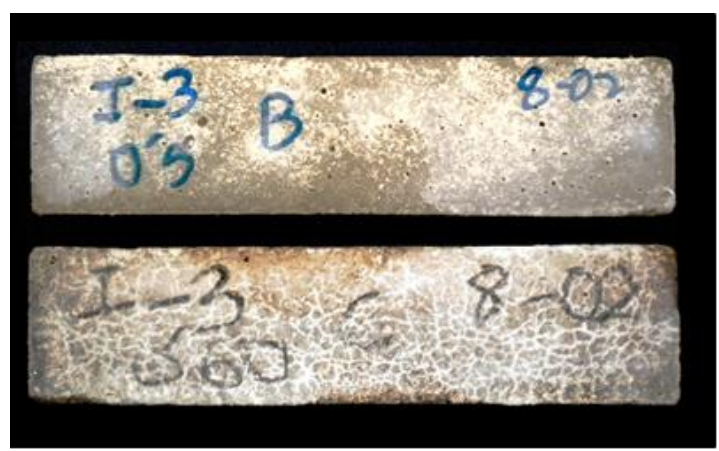

Figure 8-4 Surface of mortar samples 1-050 (above) and 1-060 (below) after 5 freezing-thawing cycles. Prismatic samples measuring $4 \times 4 \times 16 \mathrm{~cm}^{3}$.

The evolution of microcracking damage was monitored through the standard resonant frequency method, which was configured to promote the first bending mode of vibration see section 2.2.1.1 Resonant frequency method in Chapter 2 for detailed description-. However, the standard vibration data was interpreted to investigate the nonlinear behavior of the material using the short-time Fourier transform based approach. To this end, a sliding window moves through a single time response signal, and transforms the time segment within the window to the frequency domain at every window position. The window length was set to 10 cycles of the first bending mode, and the window shift unit was set to the $10 \%$ of the window length. The analysis was stopped when the spectral amplitude was reduced below the $10 \%$ of the initial spectral amplitude. At every window position the time domain signal was zero-padded, so a spectral line spacing of $0.05 \mathrm{~Hz}$ was obtained.

\subsubsection{Results}

Figure 8-5a and Figure 8-5b show representative resonance spectra for mortars I-050 and 1-060 with increasing number of freezing-thawing cycles. Three effects can be distinguished in the spectra presented here: i) the resonance frequency decreased, ii) the signal became more attenuated with increasing cycles, and iii) the resonant peak became noticeably asymmetric — so that $\left(f_{b}-f_{o}\right)<\left(f_{0}-f_{a}\right)$, see Figure 8-2c in subsection 8.1.1 (page 8$6)$ - especially, in severely damaged samples —at 15 cycles and above for mortar I-050, and at 5 cycles and above for mortar 1-060-. In general, the reduction of mechanical 
properties in mortar samples I-060 was significantly greater than in I-050. After 5 cycles, the resonant frequency values obtained for mortar I-050 were similar to those obtained before the freezing-thawing test. Conversely, the resonant frequency of mortar 1-060 was significantly reduced. On other hand, the responses at resonance of the samples were dramatically reduced after 20 cycles for I-050 and after 15 cycles for I-060. After 20 cycles, the resonant frequency test was unfeasible for mortar I-060 so that the impact excitation was not sensed by the accelerometer.
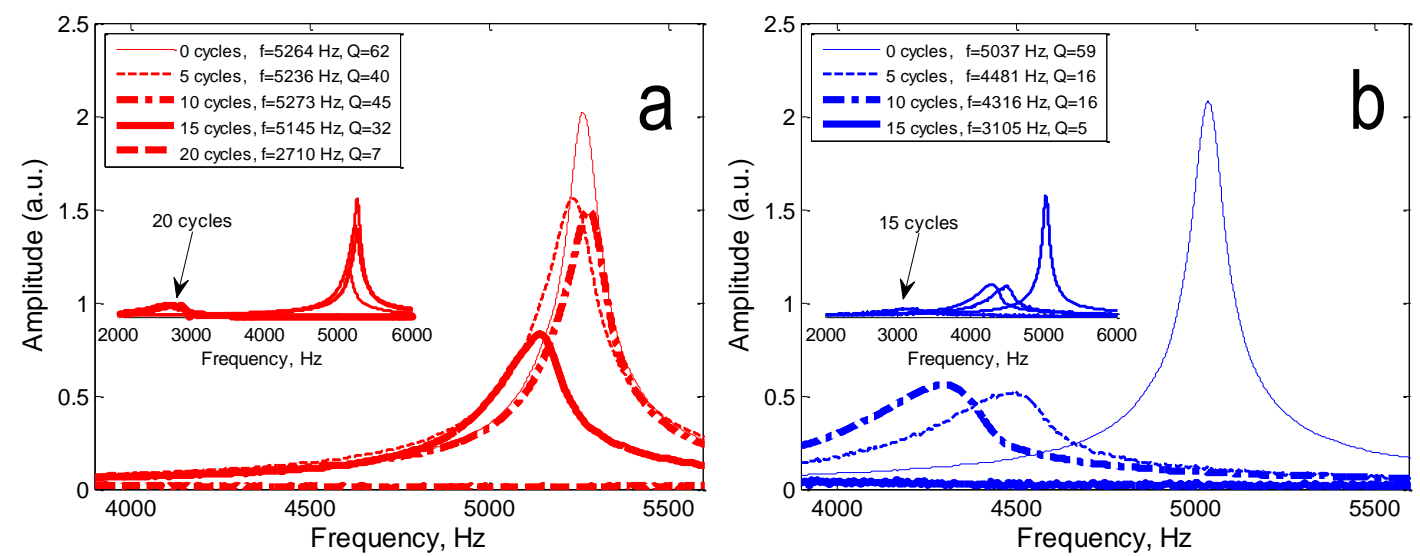

Figure 8-5 Resonance spectra after 0 (thin continuous line), 5 (thin short dashed line), 10 (thick dash-dotted line), 15 (thick continuous line) and 20 cycles (thick dashed line) for mortar with a) w/c=0.5 and b) w/c=0.6.

The nonlinear behavior was extracted through a short-time Fourier transform based approach. Figure 8-6a to Figure 8-6d show the stacked spectra obtained for a representative vibration response in pristine samples (bottom row), and after 5 freezing-thawing cycles (middle row) for both mortars; the variation of the maximum peak amplitude is shown as points in the same plot. The resonant frequency barely varied during the ring-down of the signal in undamaged samples, meaning that the same extent of material nonlinearity was observed regardless of water-cement ratio. Unlike linear based measurements (resonant frequency and linear mode damping), nonlinear based measurements are not affected by relatively higher pore volume content (Eiras, Popovics, Borrachero, Monzó, \& Payá, 2015) 
- see also Chapter 3 Effect of drying and internal moisture content (I)- - Conversely, after 5 cycles despite of resonant frequency values corresponding to the mortar I-050 were similar to that obtained in pristine state, the resonant frequency shifted to relatively higher values during the ring down of the vibration signal. Such behavior was even more prominent in mortar 1-060. Figure 8-6e and Figure 8-6f show the relative frequency shift variations normalized with regard the frequency obtained in the first time window $f_{1}$. The results show that the resonant frequency shifts to greater values with time, and that the extent of the upward shift increases with cycles. The variations of frequency over the ring down of the signals were less than $0.003 \%$ in pristine state in the samples being studied here. The frequency variations raised by about $0.005 \%$ after 5 and 10 cycles, and $1 \%$ after 15 cycles in mortar I-050. The nonlinear behavior was more prominent in mortar I-060, wherein the frequency variations raised by about $3 \%$ after only 5 cycles. The resonance frequency is varying with time, and hence with decreasing amplitude, showing that the nonlinear effects arose after only 5 cycles even when not visible damage was shown. Therefore, for this particular case the linear resonant frequency measurement was insensitive to early damage detection, whereas the nonlinear based interpretation of the signal was able to discriminate the incipient damage occurred after 5 cycles. In case of mortar 1-060, both, linear and nonlinear based measurements were able to discern damage (see Figure 8-6b and Figure 8-6d). However, the damage was noticed visually —-see sample I-060 in Figure 8-4- . 

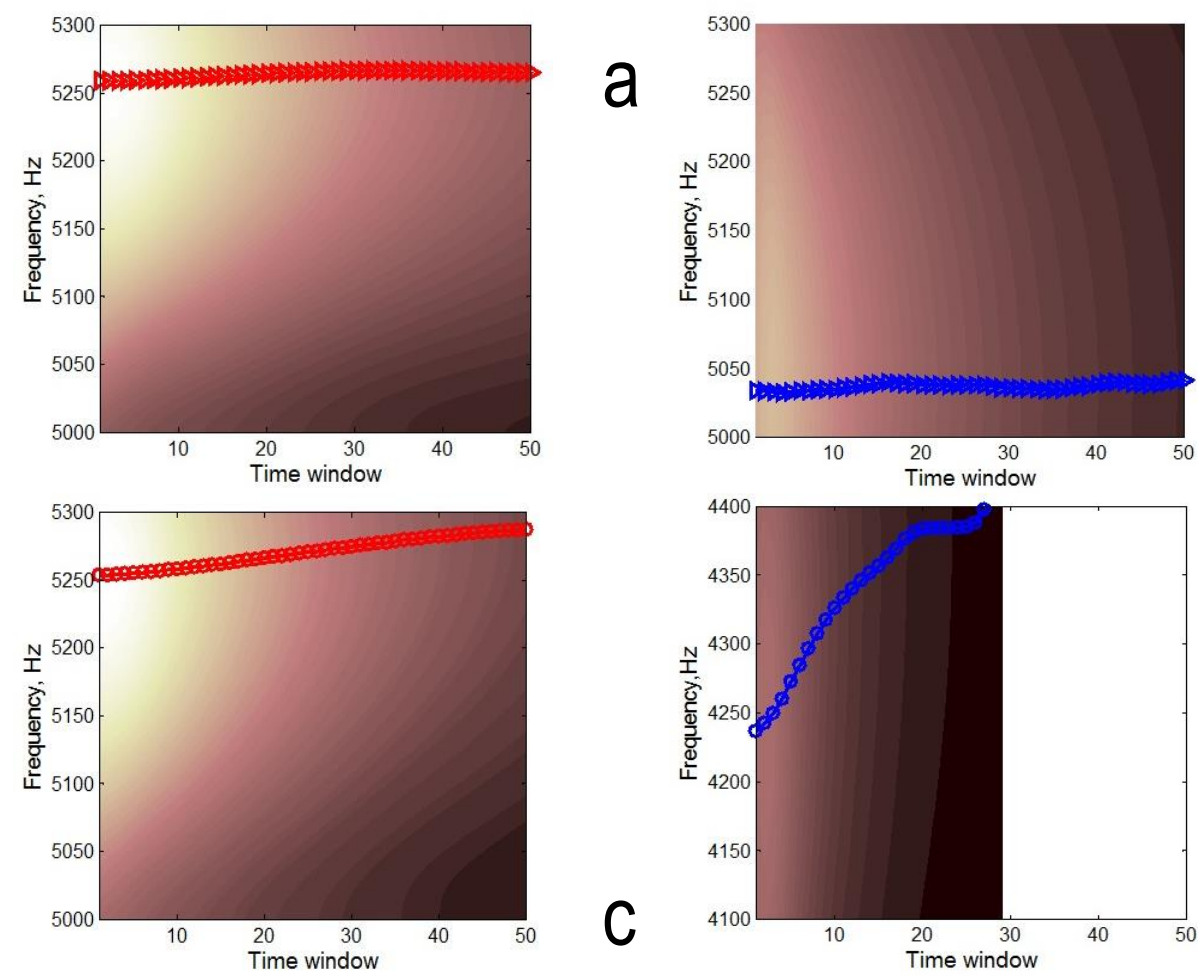

b
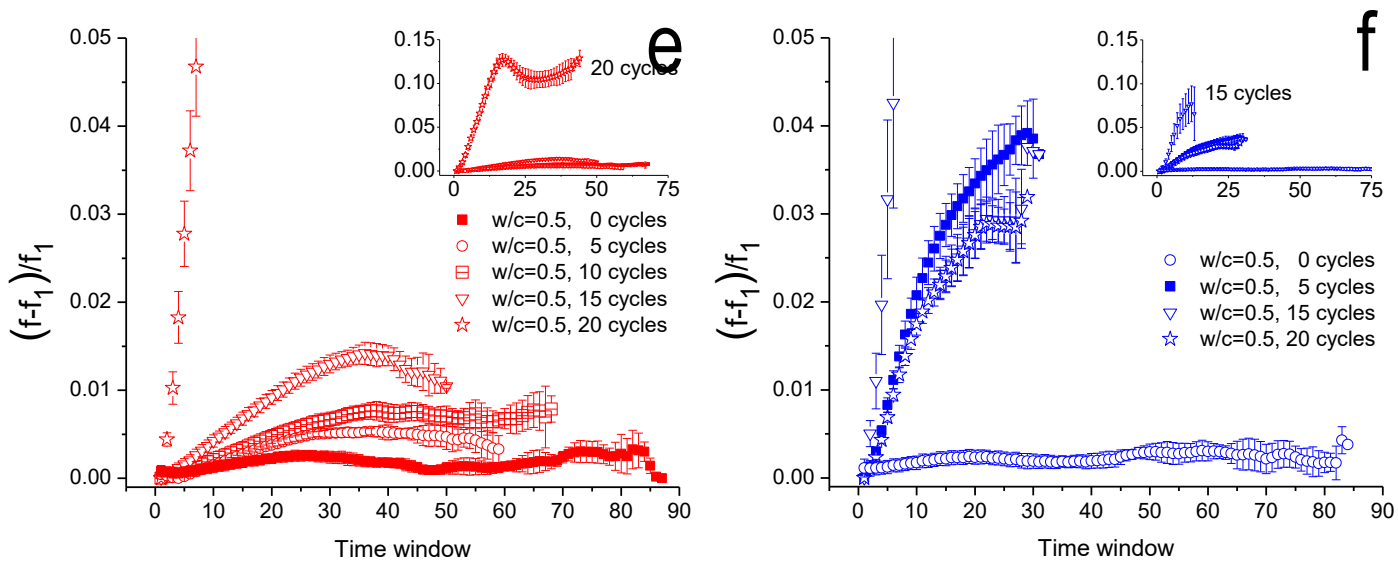

Figure 8-6 Stacked spectra as a function of time window position for pristine mortars a) mortar $1-50$, and b) I060, and after 5 cycles c) mortar I-50, and d) I-060; e) normalized frequency recovery as a function of time window in mortar I-050, and f) I-060; Mean value of ten impacts, error bars standard deviation. 
Normally, the material nonlinearity is evaluated through the slope $(\eta)$ of the relation between the normalized resonant frequency shift $\left(\Delta f / f_{0}\right)$ with the spectral amplitude $(A)-$ $\Delta f / f_{0}=\eta^{*} A$, wherein the $f_{0}$ is the linear resonant frequency-. Thus, the changes in resonant frequency with varying spectral amplitude can be evaluated through the model

$$
f=f_{\text {int }}+A \cdot \lambda
$$

where $f_{\text {int }}$ is the intercept, and $\lambda$ is the slope of the relation between frequency $(f)$ and spectral amplitude $(A)$. The frequency-amplitude data across different damage states was fitted to the linear model in $f=f_{\text {int }}+A \cdot \lambda$

Eq. 8-3. In this way, the parameter $\lambda$ represents a relative quantification of material nonlinearity in $\mathrm{Hz} /\left(\mathrm{m}_{\mathrm{s}} \mathrm{s}^{-2}\right)$. Figure 8-7a to Figure 8-7e show the relation between resonant frequency and spectral amplitude for one sample I-050 at increasing number of cycles, and the best fitted line in every damage state. The absolute value of $\lambda$ (shown within Figure 8-7a to Figure 8-7e) gradually increased with cycles. However, the relations between frequency and spectral amplitude were rather nonlinear, so the data would had been better represented by including higher order terms -thus, $f=f_{\text {int }}+\lambda_{1} \cdot A+\lambda_{2}{ }^{*} A^{2}+\ldots$, wherein $\lambda_{i}(i=1$, $2, \ldots)$ are the fitting parameters - This was especially true for damaged samples, whereas undamaged ones still exhibited a fairly linear relation between resonant frequency and spectral amplitude. Therefore, the frequency shift observed in ring down analyses differed from the linear relation $\left(f=f_{\text {int }}+A \cdot \lambda\right.$

Eq. 8-3), which is expected using a nonlinear impact resonant acoustic spectroscopy based approach (K. E.-A. Van Den Abeele, Carmeliet, Ten Cate, \& Johnson, 2000). That is, investigating the resonant frequency shift from multiple impacts over a range of impact forces. Similar effects were previously noticed by Van Damme and Van Den Abeele (Van Damme \& Van Den Abeele, 2014) wherein the frequency-amplitude dependence traced different trends when the material nonlinearity was investigated through the ring down of the signal, and when it was investigated through increasing energy excitation levels. The authors pointed out the slow dynamics as the origin of the differences between both techniques. In 
this sense, the slow dynamic effect produces a deviation of the frequency-amplitude relationship, away from the proportional relation.
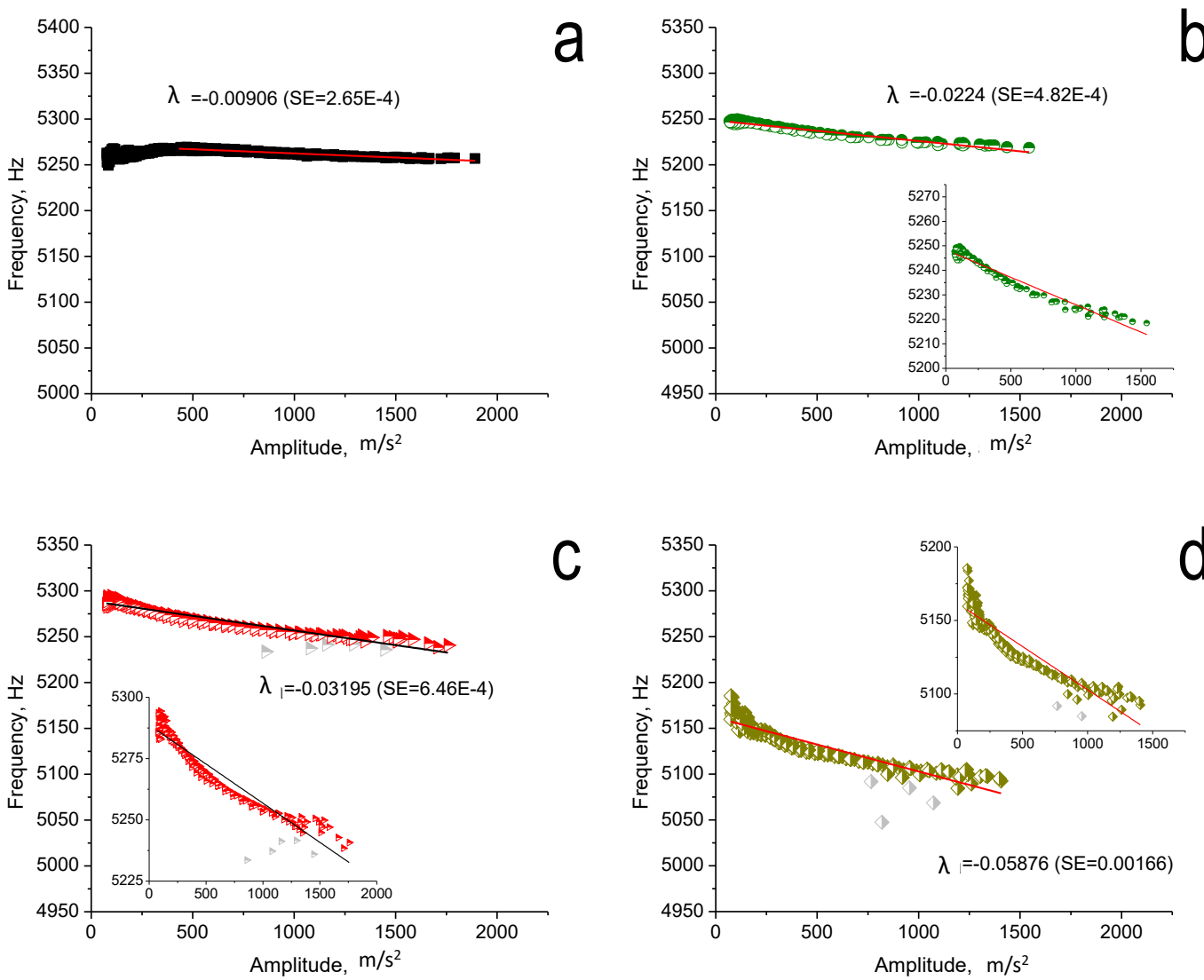


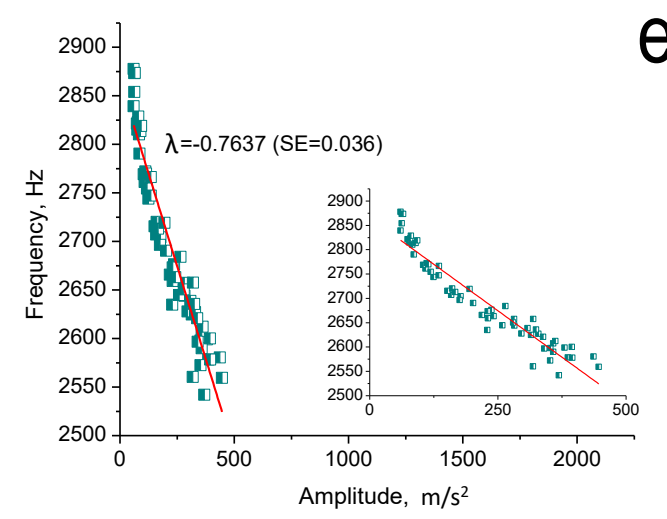

Figure 8-7 Frequency shift observed over the ringdown as a function of the spectral amplitude obtained in on a representative sample 1-050; a) pristine state, $\Lambda=-0.009\left( \pm 2.65 \cdot 10^{-4}\right)$ (standard error on the estimation of $\lambda$ is shown in parenthesis), b) 5 cycles $\lambda$ $=-0.022\left( \pm 4.82 \cdot 10^{-4}\right)$, c) 10 cycles $\lambda=-0.031$ $\left( \pm 6.46 \cdot 10^{-4}\right)$, d) 15 cycles $\lambda=-0.0319\left( \pm 6.5 \cdot 10^{-4}\right)$, and e) 20 cycles $\lambda=-0.7637$ ( \pm 0.036$)$; Grey colored symbols represent discarded data.

Alternatively, a measure of the material nonlinearity can be defined as the cumulative normalized frequency recovery over time (Eiras et al., 2014). The cumulative frequency recovery with time, or integrated frequency-time (IFT), is defined as

$I F T=\int_{1}^{T} \frac{f_{t}-f_{t=1}}{f_{t=1}} \cdot d t$

where $f_{t=1}$ is the frequency at the first time window and $f_{t}$ those from the subsequent time windows up to a preset time $t=T$. In this way, the IFT value of a nearly linear material is zero, and it will increase as a measure that the material nonlinearity increases. The parameter IFT represents a relative material nonlinearity parameter that is appropriate for comparison for samples collected from a single test set-up and signal processing approach Herein, the upper limit $T$ in $I F T=\int_{1}^{T} \frac{f_{t}-f_{t=1}}{f_{t-1}} \cdot d t$

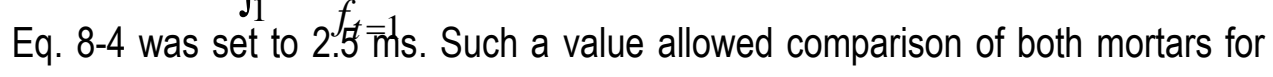
cycles at 10 cycles and below. The signal ring down of mortar I-060 did not lasted more than $2.5 \mathrm{~ms}$ thus the parameter IFT was not computed in such cases. Table 8-1 lists the linear and nonlinear dynamic properties of the mortars being investigated herein. The results showed that the resonant frequency decreased, and material damping, and hysteretic 
behavior -that is frequency-amplitude, and frequency-time dependence in ring-down analyses- increased.

Table 8-1 Linear and nonlinear dynamic properties of mortars 1-050 and 1-060 with increasing number of freezing-thawing cycles. Mean \pm standard deviation of three samples (ten data per sample).

\begin{tabular}{|c|c|c|c|c|c|c|c|c|c|}
\hline \multirow{2}{*}{$\begin{array}{l}\text { Mortar } \\
1-050\end{array}$} & \multirow{2}{*}{$\begin{array}{l}\text { Cycles } \\
0\end{array}$} & \multicolumn{2}{|c|}{ Frequency, $\mathrm{Hz}$} & \multicolumn{2}{|c|}{$Q$} & \multicolumn{2}{|c|}{$\begin{array}{c}\text { Lambda } \\
* 10^{-3} \mathrm{~Hz} /\left(\mathrm{m} . \mathrm{s}^{-2}\right)\end{array}$} & \multicolumn{2}{|c|}{$\begin{array}{c}\text { IFT }(T=2.5 \mathrm{~ms}) \\
* 10^{-6}\end{array}$} \\
\hline & & 5231.2 & \pm 25.14 & 67.5 & \pm 13.9 & -7.6 & \pm 6.9 & 1.2 & \pm 0.7 \\
\hline & 5 & 5159.5 & \pm 62.12 & 38.5 & \pm 1.6 & -26.4 & \pm 4.9 & 7.5 & \pm 1.7 \\
\hline & 10 & 5180.2 & \pm 67.84 & 43.1 & \pm 3.2 & -38.6 & \pm 1.0 & 7.1 & \pm 1.9 \\
\hline & 15 & 4953.2 & \pm 154.7 & 24.6 & \pm 6.0 & -93.1 & \pm 1.8 & 10.9 & \pm 6.6 \\
\hline & 20 & 2515.4 & \pm 186.2 & 7.9 & \pm 1.5 & -907.2 & \pm 367.6 & 100.4 & \pm 34.2 \\
\hline \multirow[t]{4}{*}{ I-060 } & 0 & 4980.3 & \pm 43.1 & 61.7 & \pm 2.2 & -4.8 & \pm 0.7 & 1.3 & \pm 0.7 \\
\hline & 5 & 4320.8 & \pm 116.6 & 16.4 & \pm 1.4 & -20.3 & \pm 3.4 & 50.2 & \pm 10.5 \\
\hline & 10 & 4119.3 & \pm 204.6 & 13.6 & \pm 2.6 & -311.2 & \pm 126.4 & 63.3 & \pm 13.3 \\
\hline & 15 & 2802.2 & \pm 248.8 & 4.7 & \pm 0.5 & -2277.0 & \pm 716.1 & -- & 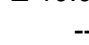 \\
\hline
\end{tabular}

Figure 8-8a and Figure 8-8b compare the relative variations $(D)$ of the linear and nonlinear signal parameters being considered herein, for mortars I-050 and I-060 respectively. They can be obtained as

$$
D_{x}=\frac{x_{n}-x_{0}}{x_{0}}
$$

wherein $x_{0}$ and $x_{n}$ stand for whichever signal parameter (frequency, $Q, \lambda$ or IFT) obtained at pristine state (subscript " 0 "), and after $n$ cycles. Linear and nonlinear parameters increase with increasing damage. All four parameters start at zero for pristine samples and increase as damage is imparted. However, the relative variations of the nonlinear parameters showed at least two orders of magnitude greater sensitivity than those corresponding to resonant frequency and $Q$. These results confirm that nonlinear parameters are far more sensitive for detecting material changes than the standard parameters such as linear resonant frequency or $Q$. Moreover, the mortar I-060 exhibited greater values of $D$ in all four parameters, than those obtained in mortar I-050. 

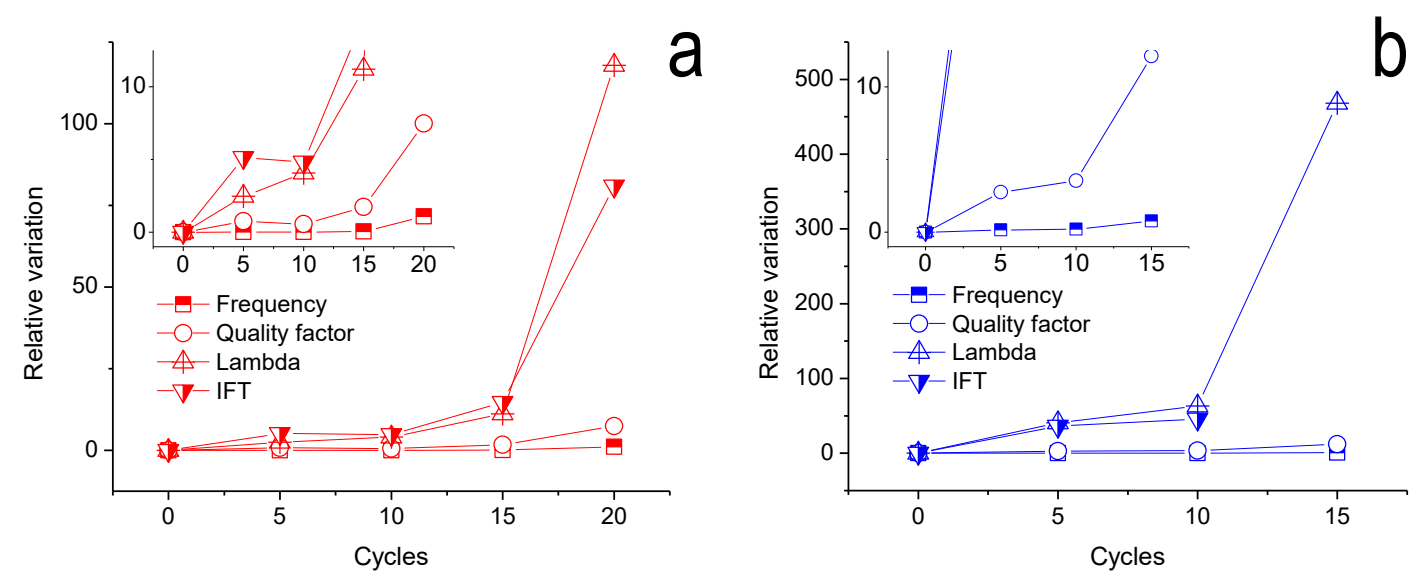

Figure 8-8 Relative variations of linear and nonlinear dynamic properties with increasing freezing-thawing cycles, in mortars a) I-050, and b) I-060.

Nonlinear parameters demonstrated greater variations upon increasing microcracking damage. However, the nonlinear parameters presented greater variability (see standard deviation results in Table 8-1) which indeed, concerns the sensitivity of the parameters. To this end, an analysis of variance (ANOVA) was conducted, so that pairwise comparisons between the linear and nonlinear parameters obtained at pristine state and after 5 cycles (the earliest damage state being studied herein). In this way, not only the relative variation of the mean values but the variability of each parameter is considered. Only one value per sample in every damage condition was used in the analysis. The null hypothesis states that 5 freezing-thawing cycles has no effect on the mean value of the dynamic parameters (resonance frequency, $Q, \lambda$ or IFT). Figure 8-9 shows pairwise comparisons for all four parameters; mean value with Tukey's honesty significant difference intervals at $95 \%$ of confidence level. All four parameters were able to discern the parameter variations between pristine and damaged (after 5 cycles) conditions in mortar 1-060. More interesting are however, the results concerning the mortar I-050. In mortar I-050, the mean value of resonant frequency was statistically the same after 5 cycles, with a confidence level of $95 \%$. Conversely, the difference between the values of $Q$ resulted significant $(p \sim 0.05)$, so that the 
measurement of material damping resulted more sensitive to microcracking damage. These results confirm previous researches that claimed that the investigation of the attenuation properties were more sensitive to evaluate distributed microcracking damage (Akhras, 1998; Kesner, Sansalone, \& Poston, 2005; Selleck, Landis, Peterson, Shah, \& Achenbach, 1998; Suaris \& Fernando, 1987). On other hand, the measurement of material nonlinearity through either $\lambda$ or IFT parameters, discerned the presence of damage with a confidence level higher than $95 \%$, and hence, revealing unequivocal presence of damage after 5 cycles.
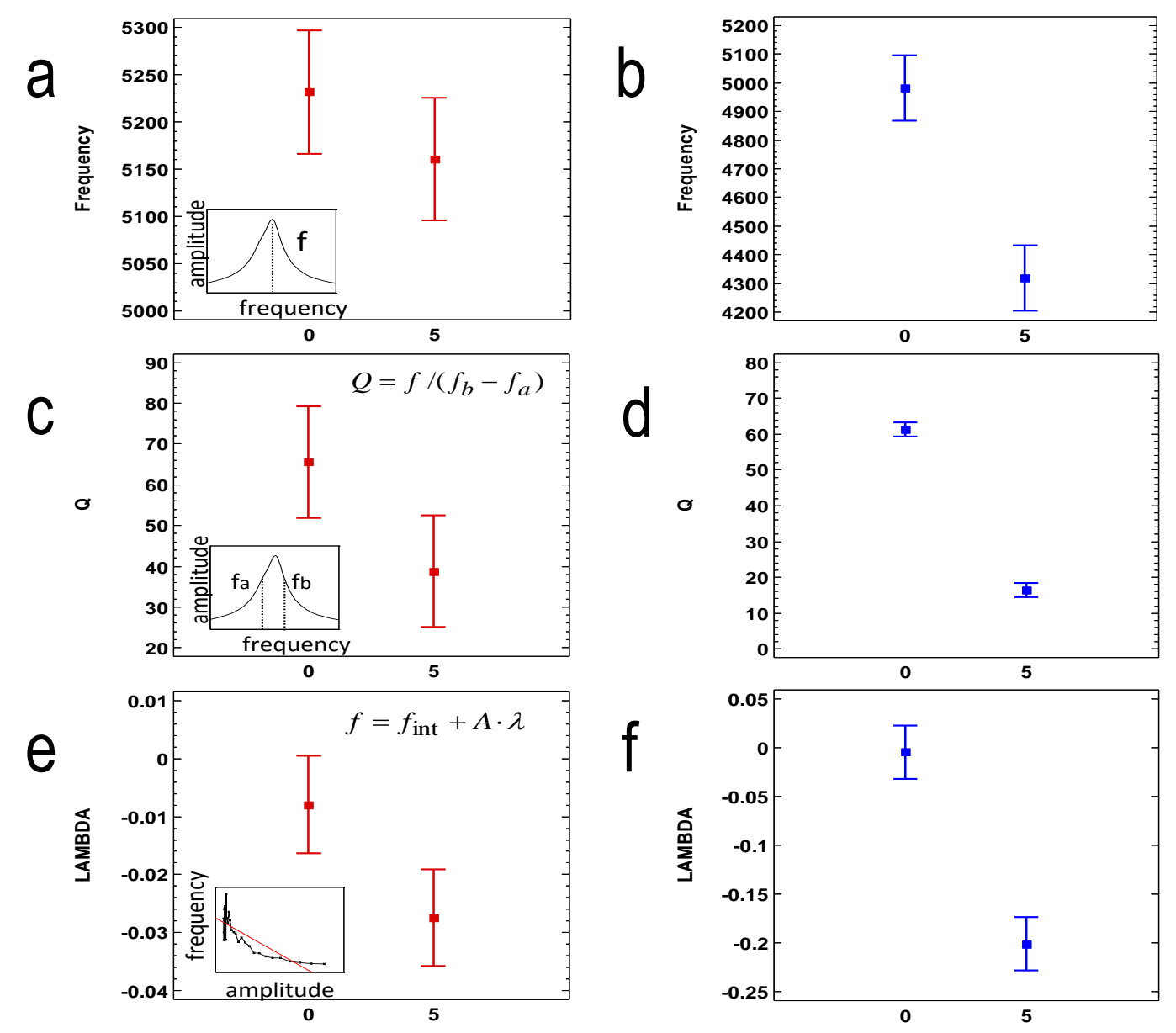

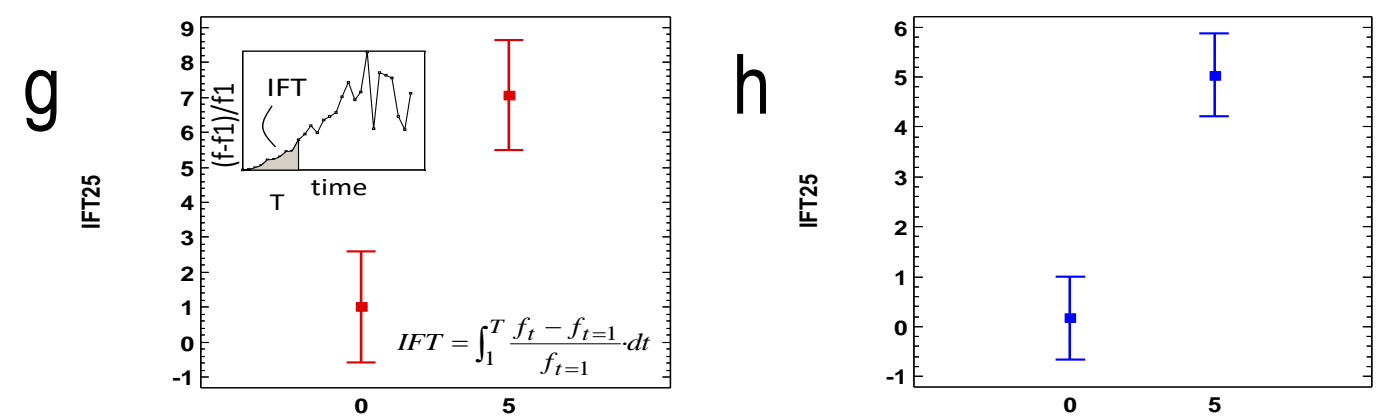

Figure 8-9 ANOVA plots for the dynamic parameters for mortars I-050 (first column) and I-060 (second column a) and b) resonant frequency, c) and d) quality factor, e) and f) best-fitted slope $\lambda, g$ ) and $h$ ) IFT.

\subsection{Summary and conclusions}

In this chapter is demonstrated that the nonlinear behavior can be extracted from information contained in one signal obtained from standard vibration tests, in a straightforward and robust manner, using the proposed moving-window-analysis. The results depend on window size and window type. A parametric study was conducted on a synthetic signal, by setting two different windows types (Blackman and Tukey), and by varying window length. The results demonstrated that window lengths comprising approximately 10 cycles provided a fairly good estimation of instantaneous frequency and amplitude. Also, Blackman window performed better than Tukey window, with regard amplitude and frequency estimation. The moving-window approach was performed on standard vibration data obtained from mortars samples (water-cement ratios 0.50 and 0.60 ) undergoing increasing number of freezing-thawing cycles. The resonant frequency tests were conducted according the ASTM C215 standard. Unlike Nonlinear Impact Resonant Acoustic Spectroscopy approach, the investigation of the instantaneous signal characteristics over the ringdown allows estimation of the physical units of the signal amplitude, and hence, quantifying the material nonlinearity which will allow comparison of the material nonlinearity obtained across different studies. Yet, the amplitude estimation is expected to be down biased, given that the STFT analysis, still provides a weighted average 
of the true physical amplitude. On other hand, the frequency-amplitude dependence was found to be nonlinear, especially in damaged samples, which was attributed to the slow dynamic effect in recent studies (Van Damme \& Van Den Abeele, 2014). From the standpoint of damage detection, the nonlinear parameters demonstrated high sensitivity to internal distributed damage, and complement linear material parameters extracted from the same signals. This technique uses a well-vetted and standard test configuration which has been broadly used to evaluate the mechanical integrity of cement based materials upon different durability distresses. The application of other techniques for laboratory inspection such as those based in higher harmonic generation or nonlinear wave modulation are debatable, since they are cumbersome and relatively more expensive than the standard resonant frequency test. Still, a comprehensive study comparing the sensitivity to damage features of different techniques on the same set of concrete samples would be desirable.

\section{References}

Akhras, N. M. (1998, September). Detecting freezing and thawing damage in concrete using signal energy. Cement and Concrete Research.

Amick, H., \& Monteiro, P. J. M. (2006). Experimental Determination of Modal Damping in Concrete Beams. ACl Material Journal, 103(3), 153-160.

Askegaard, V., \& Langsœ, H. E. (1986). Correlation between changes in dynamic properties and remaining carrying capacity. Materials and Structures, 19(1), 11-20.

ASTM C1012-13. (2013). Standard Test Method for Length Change of Hydraulic-Cement Mortars Exposed to a Sulfate Solution. Retrieved from http://www.astm.org/Standards/C1012.htm

ASTM C215-14. (2014). Standard Test Method for Fundamental Transverse , Longitudinal , and Torsional Resonant Frequencies of Concrete.

ASTM-C666. (2012). Standard Test Method for Resistance of Concrete to Rapid Freezing and Thawing. 
Carino N. J. (1994). Nondestructive Testing of Concrete: History and Challenges. In Concrete Technology - Past, Present and Future.

Dahlén, U., Ryden, N., \& Jakobsson, A. (2015). Damage identification in concrete using impact non-linear reverberation spectroscopy. NDT and $E$ International, 75, 15-25.

Eiras, J. N., Monzó, J., Payá, J., Kundu, T., \& Popovics, J. S. (2014). Non-classical nonlinear feature extraction from standard resonance vibration data for damage detection. The Journal of the Acoustical Society of America, 135(2), EL82-EL87.

Eiras, J. N., Popovics, J. S., Borrachero, M. V., Monzó, J., \& Payá, J. (2015). The effects of moisture and micro-structural modifications in drying mortars on vibration-based NDT methods. Construction and Building Materials, 94, 565-571.

Hornibrook, F. B. (1939). Application of sonic method to freezing and thawing studies of concrete. ASTM Bulletin, 101.

Ito, Y., Uomoto, T., \& Uomotot, T. (1997). Nondestructive testing method of concrete using impact acoustics. NDT \& E International, 30(4), 217-222.

Johnson, P. A., \& Rasolofosaon, P. N. J. (1996). Resonance and elastic nonlinear phenomena in rock. Journal of Geophysical Research, 101(B5), 553-564.

Jones, R. (1962). Non Destructive Testing of Concrete. (J. Baker, Ed.). London: Cambridge University Press.

Kesner, K., Sansalone, M. J., \& Poston, R. W. (2005). Detection and Quantification of Distributed Damage in Concrete Using Transient Stress Waves. ACl Material Journal, (101), 318-326.

Neild, S. a., Williams, M. S., \& McFadden, P. D. (2003). Nonlinear Vibration Characteristics of Damaged Concrete Beams. Journal of Structural Engineering, 129(2), 260-268.

Pigeon, M., \& Pleau, R. (2010). Durability of Concrete in Cold Climates. CRC Press.

Powers, T. C. (1938). Measuring Young's Modulus of elasticity by means of sonic vibrations. In Proceedings ASTM (Vol. 38, p. 460).

Selleck, S. F., Landis, E. N., Peterson, M. L., Shah, S. P., \& Achenbach, J. D. (1998). 
Ultrasonic Investigation of Concrete with Distributed Damage. ACI Materials, (95), 2736.

Suaris, W., \& Fernando, V. (1987). Ultrasonic Pulse Attenuation As a Measure of Damage Growth During Cyclic Loading of Concrete. ACI Materials Journal, 84(84), 185-193.

Subramaniam, K. V, Goldstein, G., Popovics, J. S., \& Shah, S. P. (1999). Monitoring Crack Length in Concrete Beams using Resonance Measurements, 3586(March), 129-136.

Swamy, N. R., \& Al-Asali, M. M. (1988). Engineering Properties of Concrete Affected by Alkali-silica Reaction. ACI Material Journal, 85(5), 367-374.

Swamy, N., \& Rigby, G. (1971). Dynamic properties of hardened paste, mortar and concrete. Matériaux et Constructions, 4(1), 13-40.

Swamy, R. N. (1971). Dynamic Poisson's ratio of portland cement paste, mortar and concrete. Cement and Concrete Research, 1, 559-583.

Van Damme, B., \& Van Den Abeele, K. (2014). The application of nonlinear reverberation spectroscopy for the detection of localized fatigue damage. Journal of Nondestructive Evaluation, 33(2), 263-268.

Van Den Abeele, K., \& De Visscher, J. (2000). Damage assessment in reinforced concrete using spectral and temporal nonlinear vibration techniques. Cement and Concrete Research, 30(9), 1453-1464.

Van Den Abeele, K. E., Sutin, A., Carmeliet, J., \& Johnson, P. a. (2001). Micro-damage diagnostics using nonlinear elastic wave spectroscopy (NEWS). NDT \& E International, 34(4), 239-248.

Van Den Abeele, K. E.-A., Carmeliet, J., Ten Cate, J. A., \& Johnson, P. A. (2000). Nonlinear Elastic Wave Spectroscopy (NEWS) Techniques to Discern Material Damage, Part II: Single-Mode Nonlinear Resonance Acoustic Spectroscopy. Research in Nondestructive Evaluation, 12(1), 31-42. 


\section{Chapter 9. Nonlinear Single Impact Resonance Spectroscopy (NSIRAS). Time domain analysis}



Chapter 9. Nonlinear Single Impact Resonance Spectroscopy (NSIRAS). Time domain analysis .........9-1

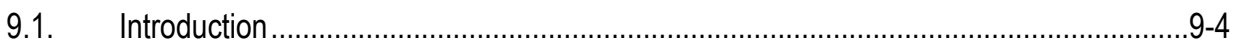

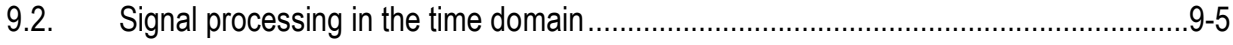

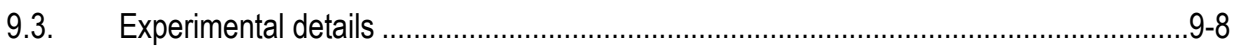

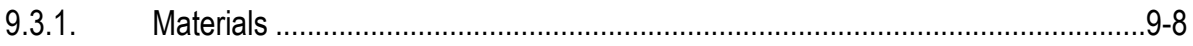

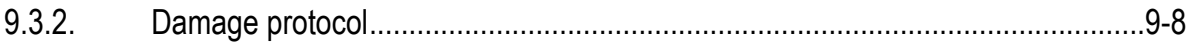

9.3.3. Inspection techniques and signal processing ...............................................

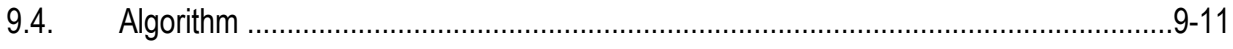

9.5. Comparison between NIRAS and NSIRAS approaches ......................................

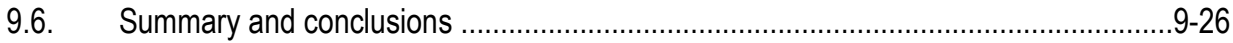

$\begin{array}{lr}\text { References } & 9-27\end{array}$ 


\subsection{Introduction}

The hysteretic parameters as derived through the NIRAS technique demonstrated improved sensitivity to detect subtle microcracking, especially at early stages of damage, where the sole measurement of the resonant frequency failed to discern it. However, as still many nonlinear techniques, the material nonlinearity as extracted through NIRAS measurements falls in relative characteristics. The vibration signal has to be transformed to the frequency domain, so the amplitude of the resonant peak signal is a weighted average of the true physical magnitude of the signal amplitude. Therefore, the hysteretic parameter obtained from NIRAS test underlies on the arbitrary units of the spectral amplitude. In this way, the measurement of the hysteretic parameter underlies on a proportional relation between strain amplitude $(\Delta \varepsilon)$ and spectral amplitude. This concern makes not possible the comparison among the yet reported studies on the evaluation of the nonlinear elastic behavior of cement-based materials (Bouchaala, Payan, Garnier, \& Balayssac, 2011; Chen, Jayapalan, Kim, Kurtis, \& Jacobs, 2010; Lesnicki, Kim, Kurtis, Jacobs, \& Jacobs, 2013). Therefore, a baseline measurement for sound concrete is always needed. In a recent study, Dahlén et al. (Dahlén, Ryden, \& Jakobsson, 2015) pointed out these concerns, and established a methodology which allowed relating the true physical magnitude of the signal amplitude, to the instantaneous variations of frequency and attenuation from a single impact event. The method consists in analyzing the transient vibration signal, as those produced by an impact, in the time domain. Therefore, the material nonlinearity is investigated from the vibration signal of a single impact event.

In this chapter, the material nonlinearity as extracted through NIRAS and NSIRAS techniques are compared on a set of prismatic concrete samples subjected to increasing number of thermal-shock loads. The evolution of the microcracking damage was monitored through NIRAS technique. However, every signal was analyzed separately to evaluate the information that a single impact response contains about the nonlinear mechanical behavior - that is, Nonlinear Single Impact Resonant Acoustic Spectroscopy (NSIRAS) technique- 
. A methodology to extract the material nonlinearity in time domain from a single impact event is proposed. The time domain method is also compared with the extraction of the nonlinear behavior in the frequency domain - see Chapter 8-. Finally, the relative sensitivity of the linear (linear resonant frequency and quality factor) and nonlinear parameters (hysteretic nonlinearity) to detect damage is compared.

\subsection{Signal processing in the time domain}

The time domain fitting method was first approached by Abeele et al. (Koen Van Den Abeele \& De Visscher, 2000). The method analyzes the signal in successive time segments $(\tau)$ which contain a preset number of cycles and fitting the signal within $L$ time segments $\left(\left.x(t)\right|_{\tau}\right)$ to an exponentially decaying sine function as

$$
\left.y(t)\right|_{\tau}=A_{\tau} \cdot \exp \left(-b_{\tau} \cdot t\right) \cdot \sin \left(2 \pi \cdot f_{\tau} \cdot t+\varphi_{\tau}\right),
$$

where $A_{\tau}$ is the signal amplitude, $b_{\tau}$ is the attenuation coefficient, $f_{\tau}$ is the resonant frequency, $t$ is time, $\varphi_{\tau}$ is the phase. The model in Eq. 9-1 performs well when a monochromatic signal is driven in the material under inspection and the ring down of the signal is analyzed after switching off the acoustic source, or when only a resonant frequency mode dominates the vibration response. This method was successfully applied to investigate fatigue damage in titanium alloys (K. Van Den Abeele, Campos-Pozuelo, Gallego-Juarez, Windels, \& Bollen, 2002), and fatigue and thermal damage in carbon-fiber composites (Van Damme \& Van Den Abeele, 2014; K. Van Den Abeele, Le Bas, Van Damme, \& Katkowski, 2009). Otherwise, when several modes are present within the signal, as in those produced by an impact, a short-time Fourier transform based approach can be preferred (J. N. Eiras, Monzó, Payá, Kundu, \& Popovics, 2014) —see also Chapter 8-. More recently, Dahlén and coworkers (Dahlén et al., 2015) proposed to fit the impact vibration signal to an exponentially decaying sine function, which is extended as a superposition of $M$ vibration modes as 


$$
y(t)=\sum_{m=1}^{m=M} A_{m} \cdot \exp \left(\theta_{m}(t)\right) \cdot \sin \left(\phi_{m}(t)\right)
$$

where the functions $\theta_{m}(t)$ and $\phi_{m}(t)$ are polynomial-based descriptions of order $N_{m}$, and $K_{m}$, for the time-varying phase and attenuation corresponding to a given mode of vibration $m$ as

$$
\begin{aligned}
& \phi_{m}(t)=\varphi_{m}+2 \pi\left(\sum_{n=1}^{n=N} \frac{f_{m, n}}{n} \cdot t^{n}\right), \\
& \theta_{m}(t)=\sum_{k=1}^{k=K} \frac{b_{m, k}}{k} \cdot t^{k}
\end{aligned}
$$

$n$ and $\mathrm{k}$ stand for the $\mathrm{n}$-order and k-order coefficients of their respective functions. By fitting the whole signal, the instantaneous variations of amplitude are precisely related to the instantaneous variations of frequency and attenuation. Thus, the amplitude values do not depend on mathematical parameters such as window length and window type, as they do so, when the signal is analyzed through the FFT algorithm. The material nonlinearity is then investigated by relating the instantaneous amplitude $-A_{m} \cdot \exp \left(\theta_{m}(t)\right)$ - to the instantaneous frequency $-F_{m}(t)=\partial \phi_{m} / \partial t$, and to the instantaneous attenuation $-B_{m}(t)=\partial \theta_{m} / \partial t$.

The least-squares minimization of the function in Eq. 9-2 is highly dimensional and nonlinear. Therefore, the fitting process requires a good initial estimation of the fitting parameters, in order to obtain a feasible modelling of the vibration signal. Dahlén and coworkers (Dahlén et al., 2015) proposed a relaxed-based algorithm to find the least-squares solution. First, the experimental signal is fitted, as if it contained only one mode -thus, the function being fitted becomes $y(t)=A_{m} \cdot \exp \left(\theta_{m}(t)\right) \cdot \sin \left(\phi_{m}(t)\right)-$. After the first fitting, the residuals contain the information of the rest of vibration modes, and the yet non-captured information corresponding to the current mode being fitted. Next, the residuals are fitted to the single-mode model for obtaining the solution of a second vibration mode. The solution for the second mode is then subtracted to the original vibration signal, and the resulted data 
is again fitted to the single-mode model, so that the estimation of the first mode is improved. The residuals obtained from the second fit allow improving the estimation of the second mode. This process is recursively repeated until no further improvement is achieved, and by extending the process to new vibration modes (if needed). Finally, the individual solutions obtained for each single-mode model, serve as an initial estimation for fitting the experimental vibration signal to the Eq. 9-2. Thereafter, the whole process is repeated by setting different polynomial orders in the functions $\phi_{m}(t)$ and $\theta_{m}(t)$ for every mode. The final solution is deemed through the sum of squares error (sse) and the total number of parameters in the model as a "best set selection" approach — see References (Dahlén et al., 2015) and also (Dahlén, 2013) for detailed description-.

Alternatively to previous efforts, in this chapter is proposed an algorithm to form the least-squares solution of the Eq. 9-2. A detailed description of the algorithm is described in the subsection 9.4 Algorithm. The algorithm, firstly discretizes $L$ times, the frequency and attenuation variations over the ring down of the signal, so the data sets $\left\{\left(t_{1}, f_{m, 1}\right), \ldots,\left(t_{L}, f_{m, L}\right)\right\}$ and $\left\{\left(t_{1}, b_{m, 1}\right), \ldots,\left(t_{L}, b_{m, L}\right)\right\}$ for every vibration mode are obtained. These data sets are used to estimate the polynomial order of the functions $\phi_{m}(t)$ and $\theta_{m}(t)$. By doing so, we not only avoid a "best set selection" approach for the sets of polynomial orders of phase and attenuation of every mode, but the particular arithmetic shape of both functions does not have to meet a polynomial-based description so that whichever integrable function can be considered. Finally, the functions obtained from the initial discretization are used to form the initial estimation of the parameters, which are used for fitting the experimental signals to the model in Eq. 9-2. The approach is demonstrated in prismatic concrete samples subjected to increasing number of thermal-shock cycles. For more comprehensive analysis, the signals were acquired at different impact energies, so that the material nonlinearity was investigated from multiple impact events (NIRAS), and from the feature extraction of every single impact (NSIRAS). In section 9.5 Comparison between frequency and time domain analyses, the time domain approach is compared with the analyses of the signal conducted in the 
frequency domain. In section 9.6 Comparison between NIRAS and NSIRAS, the nonlinear parameters obtained with the NIRAS and NSIRAS approaches are compared.

\subsection{Experimental details}

\subsubsection{Materials}

A set of three prismatic concrete samples measuring $10 \times 10 \times 35.5 \mathrm{~cm}^{3}$ were produced. The concrete batch was provided by the Illinois Department of Transportation (IDOT). For reference, the air content in fresh state was 7\%, measured according to ASTM C231 (ASTM C231, 2014). The compressive strength was measured in cylinders (diameter $15 \mathrm{~cm}$ and height $30 \mathrm{~cm}$ ) produced from the same concrete batch, and according to ASTM C39-14 (ASTM C39, 2014). After 28 days of curing in fog room at $20^{\circ} \mathrm{C}$, the compressive strength was $45 \mathrm{MPa}$.

\subsubsection{Damage protocol}

The prismatic concrete samples were subjected to increasing number of thermal-shock cycles to impart different levels of distributed cracking damage. The samples initially soaked in a thermostatic water bath at $\sim 80^{\circ} \mathrm{C}$ were removed and quenched in cold water at $\sim 4^{\circ} \mathrm{C}$. Figure 9-1 shows schematic depiction of the thermal shock cycle. The temperature was recorded by thermocouples that were placed in hot and cold water containers, for recording simultaneously the temperature histories in both containers. Each thermal-shock cycle is expected to progressively increase the internal volume of cracking damage. Figure 9-2 shows representative surfaces of the samples before thermal cycles were applied, and after 3 and 10 thermal-shock cycles, where visible cracks are seen. 


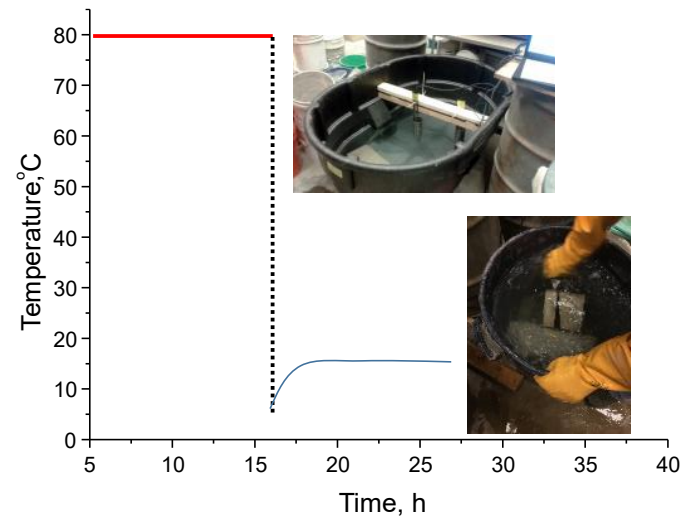

Figure 9-1 Schematic description of the thermal shock cycle. Inset photos show hot and cold water containers.
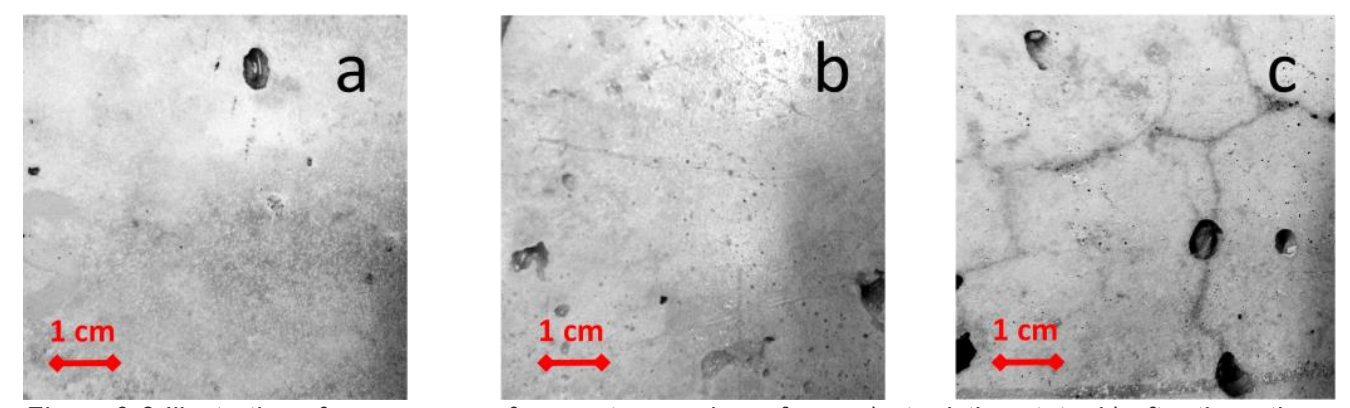

Figure 9-2 Illustration of appearance of concrete sample surfaces a) at pristine state, b) after three thermal cycles and c) after ten thermal cycles.

\subsubsection{Inspection techniques and signal processing}

After every thermal-shock cycle, the evolution of damage was monitored through resonant vibration measurements while maintaining saturated internal moisture conditions to avoid the internal moisture variations affect the dynamic responses (J.N. Eiras, Popovics, Borrachero, Monzó, \& Payá, 2015; Somaratna, 2014). Figure 9-3a shows a photo of the experimental test configuration. The relative position of the impact is configured to promote and sense the first bending mode of vibration. An instrumented hammer (model PCB $086 \mathrm{C} 03,2.25 \mathrm{mV} / \mathrm{N}$ ) with an aluminum tip (diameter of $0.63 \mathrm{~cm}$ ), was used to strike the sample at its center, while an accelerometer (model PCB $352 \mathrm{C} 15,10 \mathrm{mV} / \mathrm{g}$ ) placed on the top face at the end of the axial dimension and aligned with the impact location with respect 
to sample width, sensed the excitation. The two signals, force and acceleration, were acquired with a sampling frequency of $0.5 \mathrm{MHz}$. Twenty hammer blows were conducted with varying impact energy, from $\sim 0.1 \mathrm{kN}$ to $\sim 2 \mathrm{kN}$, as monitored by the load cell on the hammer. For every signal, the resonant frequency ( $f$ ) was obtained after transform the entire time signal as obtained by the accelerometer to the frequency domain, using the FFT algorithm. The quality factor $(Q)$ was also derived from the resonance spectra. Figure 9-3b shows representative resonant spectra for the accelerometer signal at two representative impact forces $(\sim 0.5 \mathrm{kN}$ and $\sim 1.9 \mathrm{kN})$. Figure 9-3b shows the occurrence of multiple modes of vibration. The first bending mode dominates the signal, although the second bending, second torsional and third bending modes of vibration are seen. For the given impact types and sensing locations, only the first mode of vibration is expected to be meaningful within the broadband excitation attained by the hammer blows. Therefore, the presence of such modes can be attributed to variabilities (eccentricities) on the impact location.
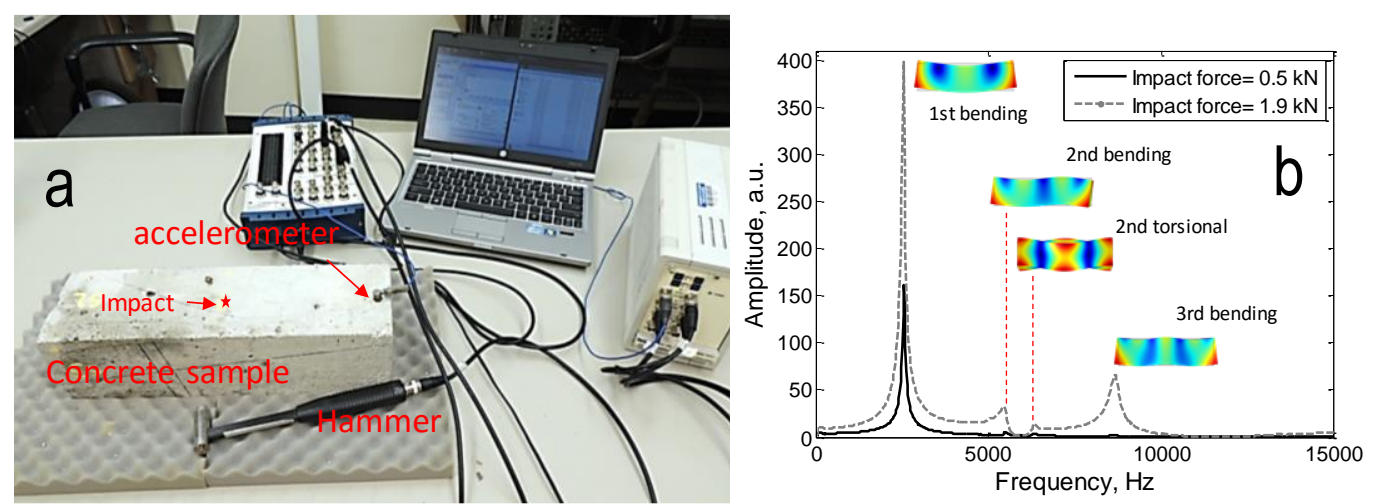

Figure 9-3 Testing configuration: a) testing equipment, and b) representative resonance of spectra. These signals correspond to a concrete sample subjected to 10 thermal-shock cycles 


\subsection{Algorithm}

First, the signal is analyzed in $L$ successive time segments with duration $\tau$ and overlapped a duration $\Delta \tau$, so that $\Delta \tau<\tau$. The signal within each time segment $\left(\left.x(t)\right|_{\tau}\right)$ is fitted to an exponentially decaying curve that includes $M$ vibration modes as

$$
\left.y(t)\right|_{\tau}=\sum_{m=1}^{m=M} A_{m, \tau} \cdot \exp \left(-b_{m, \tau} \cdot t\right) \cdot \sin \left(2 \pi \cdot f_{m, \tau} \cdot t+\varphi_{m, \tau}\right)
$$

where $A_{m, \tau}$ is the signal amplitude, $b_{m, \tau}$ is the attenuation coefficient, $f_{m, \tau}$ is the resonant frequency, $t$ is the sampled time, $\varphi_{\tau}$ is the phase; subscript $m$ stands for a particular mode of vibration. As a result, the values of $A_{m}, f_{m}$, and $b_{m}$ are discretized $L$ times during the ringdown of the time signal, with a down sampled time $\delta t$, namely, the time lapse between two consecutive time segments. Given an experimental vibration data $x(t)$ with a sampling frequency $1 / d t$, the number of modes that must be considered in the model (Eq. 9-5) can be deemed through the minimum value of the Schwarz-Bayesian information criterion $(B / C)$ (Schwarz, 1978) as

$$
B I C=T \cdot \ln \left(\frac{s s e}{T}\right)+P \cdot \ln (T)
$$

where sse is the sum of squares error obtained after a least-squares minimization of the signal within a time segment, $T$ is the number of experimental points - thus the length of the signal within every time segment-, and $P$ is the number of parameters in the model. The $B I C$ prioritize models that better represent the experimental observations, and at same time, penalizes the selection of alternative models in favor of parsimony -namely, with lesser number of parameters-. To do so, the first time segment $\left(\left.x(t)\right|_{\tau 1}\right)$ is fitted to the model of Eq. 9-5 considering only one mode of vibration, thus $M=1$. This solution is compared with the solution with $M=2$. If $B I C_{(M=2)}<B I C_{(M=1)}$, thus an additional mode $(M=3)$ is considered. This process is iteratively repeated $j$ times until $B I C_{(M=j)}<B I C_{(M=j-1)}$. Figure $9-4$ shows the 
workflow for determining the proper number of modes to consider within the fit of the first time segment.

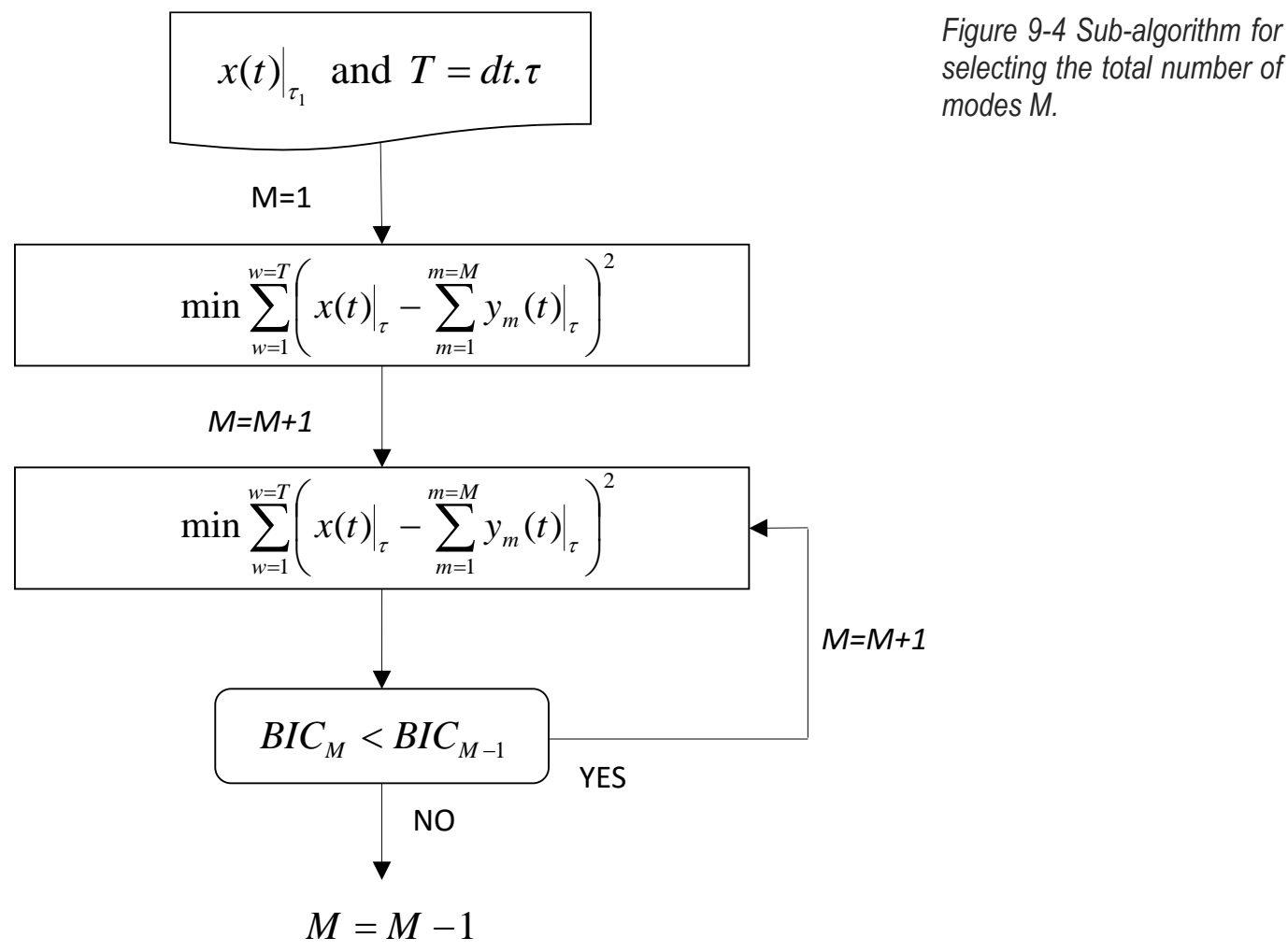

If the foregoing analysis is repeated across all time segments of the experimental signal, it can be noticed that the number of modes that are present in the signal is not constant across all time segments. The first time segments may contain higher order modes that will vanish earlier upon mechanical energy dissipation. This effect is illustrated using an experimental signal obtained on a concrete sample after 10 thermal shock cycles - see subsection Experimental details, page 9-8-. Figure 9-5a shows the experimental resonance spectrum wherein the first bending mode of vibration dominates the vibration of the signal, and minor contributions (almost negligible) corresponding to the second bending and second torsional modes of vibration. Figure 9-5b shows the values of $B / C$ obtained after fitting the 
Eq. 9-5, considering $M=1,2$ and 3 , in time segments (here $\tau$ set to $4 \mathrm{~ms}$ ). The minimum value of $B I C$ is obtained for $M=3$ within the first ten time segments $(10 \mathrm{~ms})$, but at later parts of the signal, only one resonant mode is meaningful (from 20ms onward). Therefore, the total number of modes $(M)$ is determined in the first time segment.
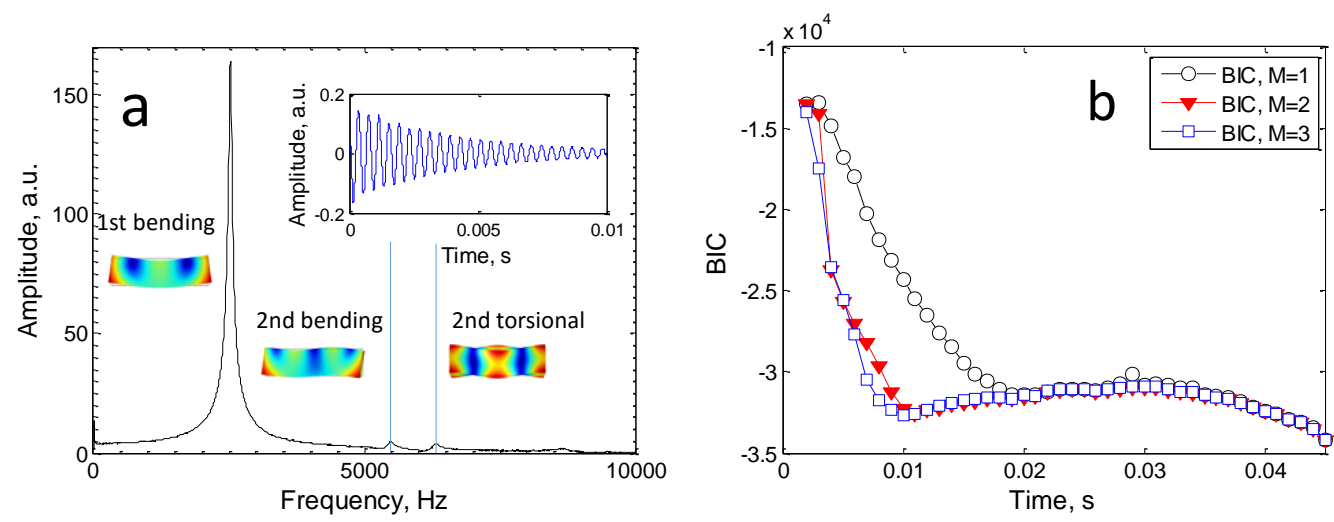

Figure 9-5 a) Resonant time and spectral signals obtained from a concrete sample after 10 thermal-shock cycles, and b) values of BIC after fitting the signal in time segments of $4 \mathrm{~ms}$ with a spacing of $1 \mathrm{~ms}$, for $M=1$, 2 and 3.

Once the number of modes has been determined, and as a result of fitting $L$ time segments, the amplitude, frequency and attenuation values are discretized over the ring down of the signal $L$ times. These are the data sets $\left\{\left(t_{1}, A_{m, 1}\right), \ldots,\left(t_{L}, A_{m, L}\right)\right\},\left\{\left(t_{1}, f_{m, 1}\right), \ldots,\left(t_{L}, f_{m, L}\right)\right\}$ and $\left\{\left(t_{1}, b_{m, 1}\right), \ldots,\left(t_{L}, b_{m, L}\right)\right\}$. In base of these data sets, the instantaneous variations of resonant frequency and attenuation for every mode, can be obtained by fitting the data sets to polynomial functions of order $N_{m}-1$ and $K_{m}-1$ as

$$
\begin{aligned}
& F^{\prime}{ }_{m}(t)=\sum_{n=0}^{n=N_{m}-1} f_{m, n+1} \cdot t^{n}, \text { and } \\
& B^{\prime}{ }_{m}(t)=\sum_{k=0}^{k=K_{m}-1} b_{m, k+1} \cdot t^{k} .
\end{aligned}
$$


The functions $F_{m}^{\prime}(t)$ and $B_{m}^{\prime}(t)$ are initial estimations obtained from the discretization of the instantaneous frequency and attenuation. The Figure 9-7 shows the workflow to obtain the proper polynomial orders for the instantaneous frequency $\left(F_{m}^{\prime}(t)\right)$ and attenuation $\left(B_{m}^{\prime}(t)\right)$ functions-note, it is analogous to the sub-algorithm for selecting $M$ (Figure 9-4)-.

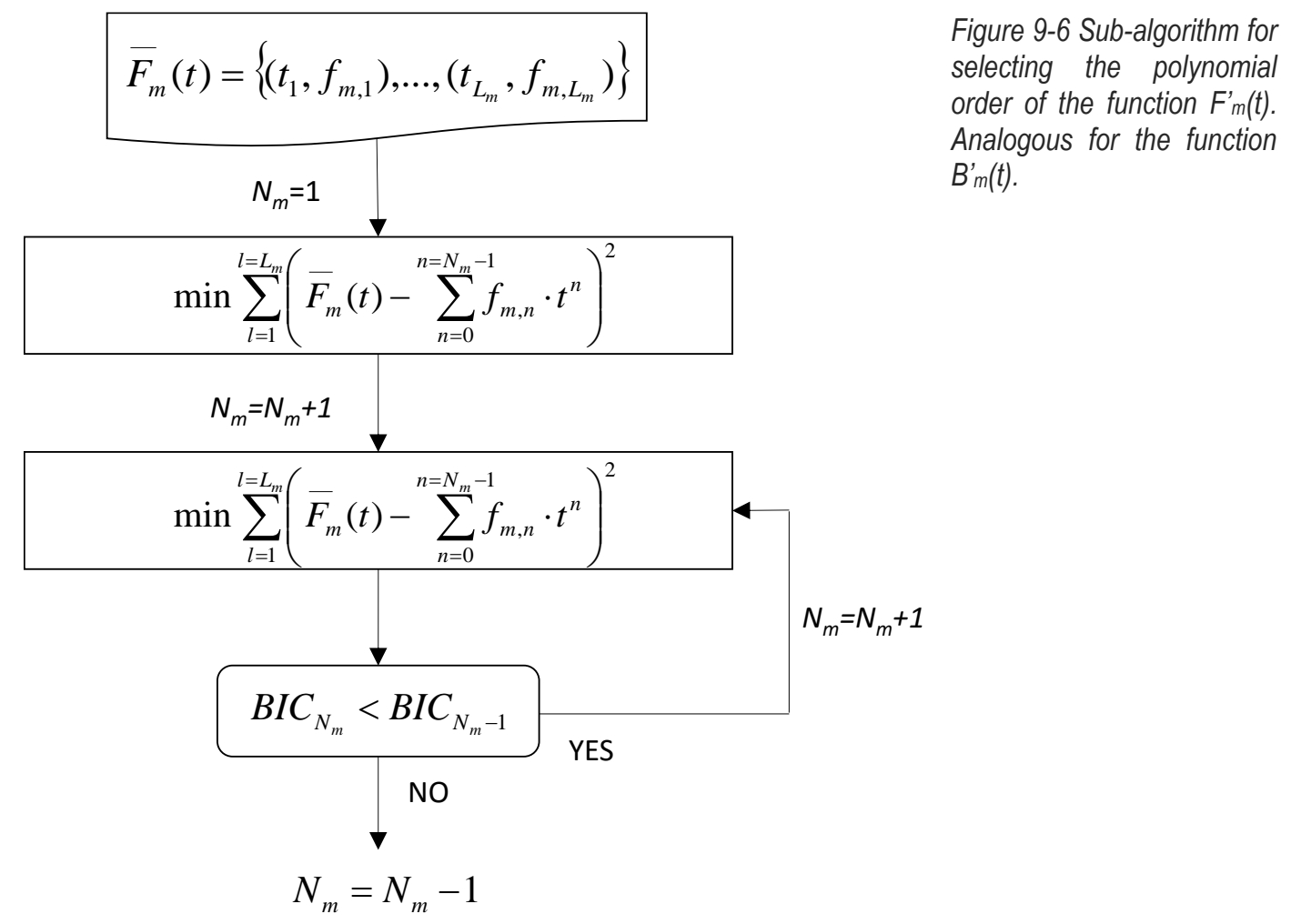

In order to avoid misfits on the estimation of the functions $F_{m}^{\prime}(t)$ and $B_{m}^{\prime}(t)$ the number of observations from the initial data sets obtained for each mode (with $L$ observations), has to be reduced according to the noise level of the experimental signals, given that the estimated signal parameters result very scattered as a measure that the amplitude of the signal reaches the noise level. To this end, a threshold amplitude $\left(A_{t h}\right)$, is defined as three times the standard deviation of the noise -thus, $A_{t h}=3 \cdot \operatorname{std}\left(x_{\text {noise }}(t)\right)$ - The algorithm follows by finding the cutoff time $t_{m}\left(A_{t h}\right)$ within the data sets of amplitude $\left\{\left(t_{1}, A_{m, l}\right), \ldots,\left(t_{L}, A_{m, L}\right)\right\}$ for 
every mode, and by identifying the subsets of data for frequency $\left\{\left(t_{1}, f_{m, l}\right), \ldots,\left(t_{L}, f_{m, L m}\right)\right\}$ and attenuation $\left\{\left(t_{1}, b_{m, l}\right), \ldots,\left(t_{L}, b_{m, L m}\right)\right\}$. The data sets are therefore reduced to $L_{m}$ observations, so that $L-L_{m}$ observations are dismissed from the data sets of frequency and attenuation of each mode. This process is schematically shown in Figure 9-7. Figure 9-7a shows the experimental time domain signal together with the discretized amplitude values for the first and second bending modes. The cutoff times corresponding to these two modes are determined as a function of the threshold amplitude (shown as a red dashed line in Figure 9-7a). The cutoff time for the first bending mode $\left(t_{1}\left(A_{t h}\right)\right)$ is $0.022 \mathrm{~s}$ and $t_{2}\left(A_{t h}\right)$ equals $0.005 \mathrm{~s}$ - see inset plot in Figure 9-7a - The values of the discretized values of frequency and attenuation beyond these cutoff times are then dismissed, so that only $L_{m}$ observations are used for every mode $m$. Thereafter, the selection of the polynomial order corresponding to the instantaneous variations of attenuation and frequency of every mode, can be based on the minimum value of $B I C$ as,

$$
B I C=L_{m} \cdot \ln \left(\frac{s s e}{L_{m}}\right)+P \cdot \ln \left(L_{m}\right)
$$

-this process is described in Figure 9-6- Figures 9-7b and 9-7c show the estimation of the functions $F_{1}^{\prime}(t)$ and $F_{2}^{\prime}(t)$ which are shown in dashed lines. The values of resonant frequency obtained beyond the cutoff times are dismissed. 

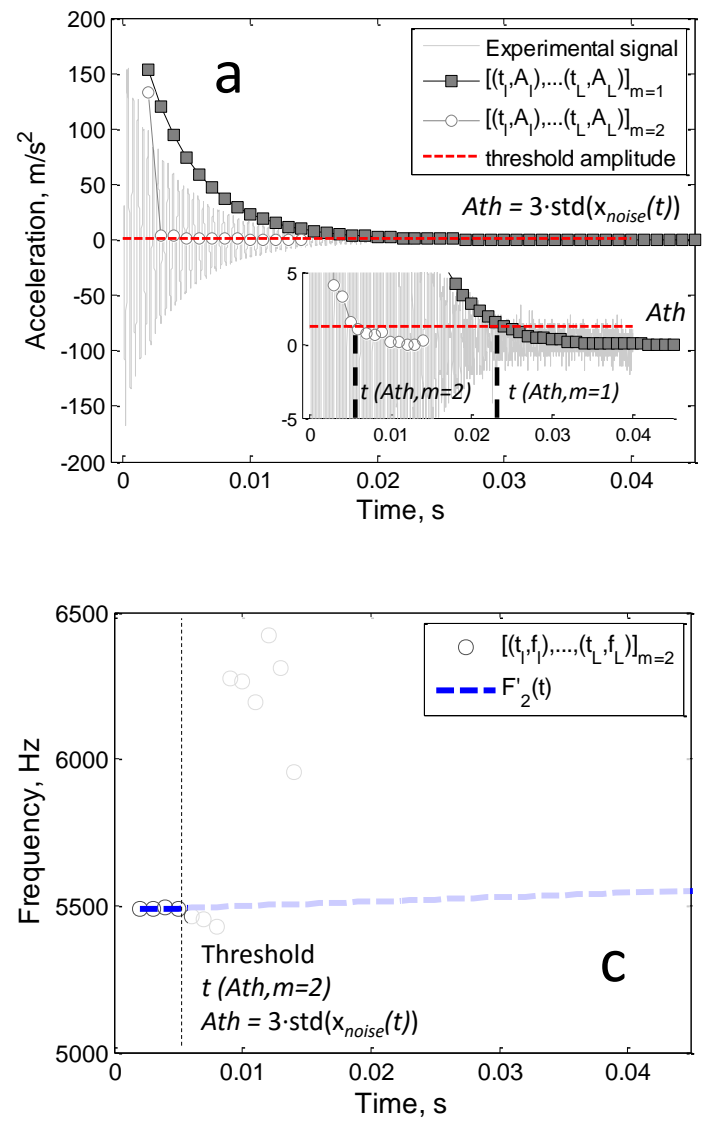

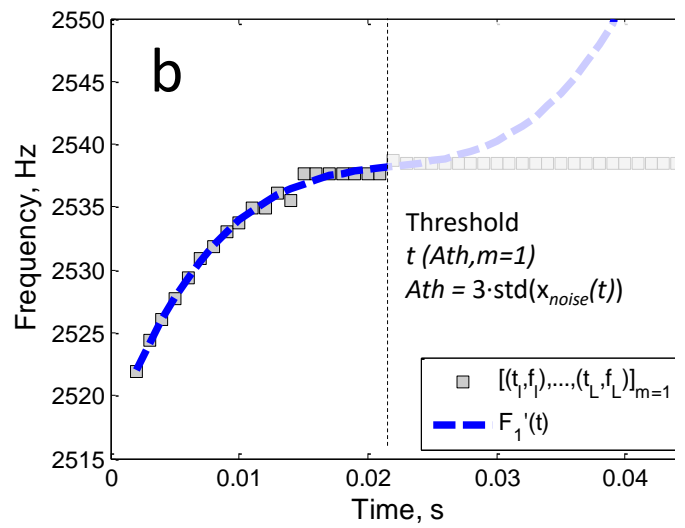

Figure 9-7 a) Experimental time domain signal and the sets of discretized signal amplitude for the first and second bending modes of vibration ( $m=1$ and $m=2$ respectively). Inset plot shows the time at $A_{t h}$ for $m=1$ and $m=2 ; b)$ estimation of the function $F_{1}^{\prime}(t)$ from the subset of data $\left\{\left(t_{l}, f_{i}\right), \ldots,\left(t_{L}, f_{L m}\right)\right\}$, whose polynomial order $\mathrm{Nm}_{\mathrm{m}}-1$ has been determined through the BIC, and c) estimation of the function $F_{2}^{\prime}(t)$. The signals were analyzed within a time segment of $4 \mathrm{~ms}$ and the time between consecutive time segments was $1 \mathrm{~ms}$.

Once the proper polynomial orders of the phase and attenuation functions for every mode are determined, $N_{m}$ and $K_{m}$, the initial estimates of the functions that describe the phase and attenuation variations with time $\left(\phi_{m}^{\prime}(t)\right.$ and $\left.\theta_{m}^{\prime}(t)\right)$ can be found by integrating both, the instantaneous variations of frequency and attenuation for a given mode $m$ as

$\phi_{m}^{\prime}(t)=\int F_{m}^{\prime}(t) \cdot d t$ Eq. $9-10$

and

$\theta_{m}^{\prime}(t)=\int B^{\prime}{ }_{m}(t) \cdot d t$ Eq. 9-11 
The functions $\phi_{m}^{\prime}(t)$ and $\theta_{m}^{\prime}(t)$, are used as starting point for fitting the entire vibration signal to the model of Eq. 9-2, and for obtaining the final estimation of $\phi_{m}(t)$ and $\theta_{m}(t)$. The instantaneous variations of frequency and attenuation can thus be found by differentiating over time the functions $\phi_{m}(t)$ and $\theta_{m}(t)$ as

$$
\begin{aligned}
& F_{m}(t)=\frac{\partial \phi_{m}}{\partial t}, \text { and } \\
& B_{m}(t)=\frac{\partial \theta_{m}}{\partial t} .
\end{aligned}
$$

The Figure 9-8 shows this final step using the same experimental signal used in the analysis conducted within this section. Figure 9-8a-b show the final estimation of the instantaneous frequency and attenuation functions, after differentiating $\phi_{m}(t)$ and $\theta_{m}(t)$ respectively. It can be noted that the final estimation of $F_{1}(t)$ and $B_{1}(t)$ barely differ from the initial starting point obtained from the functions $F_{1}^{\prime}(t)$ and $B_{1}^{\prime}(t)$. Figures $9-8 \mathrm{c}$ and $9-8 \mathrm{~d}$ show the dependence of the instantaneous frequency and attenuation with acceleration amplitude. In this case, it can be observed that the initial discretization of the amplitude values over time, usually results in an overestimation of the true amplitude. Finally, Figure 9-8e shows the experimental signal and the modeled signal plotted together. The residuals obtained after fitting the entire signal are shown in Figure 9-8f. The Fourier transform of the residual signal (inset plot in Figure 9-8f) allows concluding that these small contributions, that were not captured by the model, correspond to the second bending (around $5 \mathrm{kHz}$ ), second torsional (around $6 \mathrm{kHz}$ ) and third bending (around $9 \mathrm{kHz}$ ) modes. Conversely, the main contribution corresponding to the first bending mode is properly modeled since trivial contributions are observed around $2.5 \mathrm{kHz}$. 

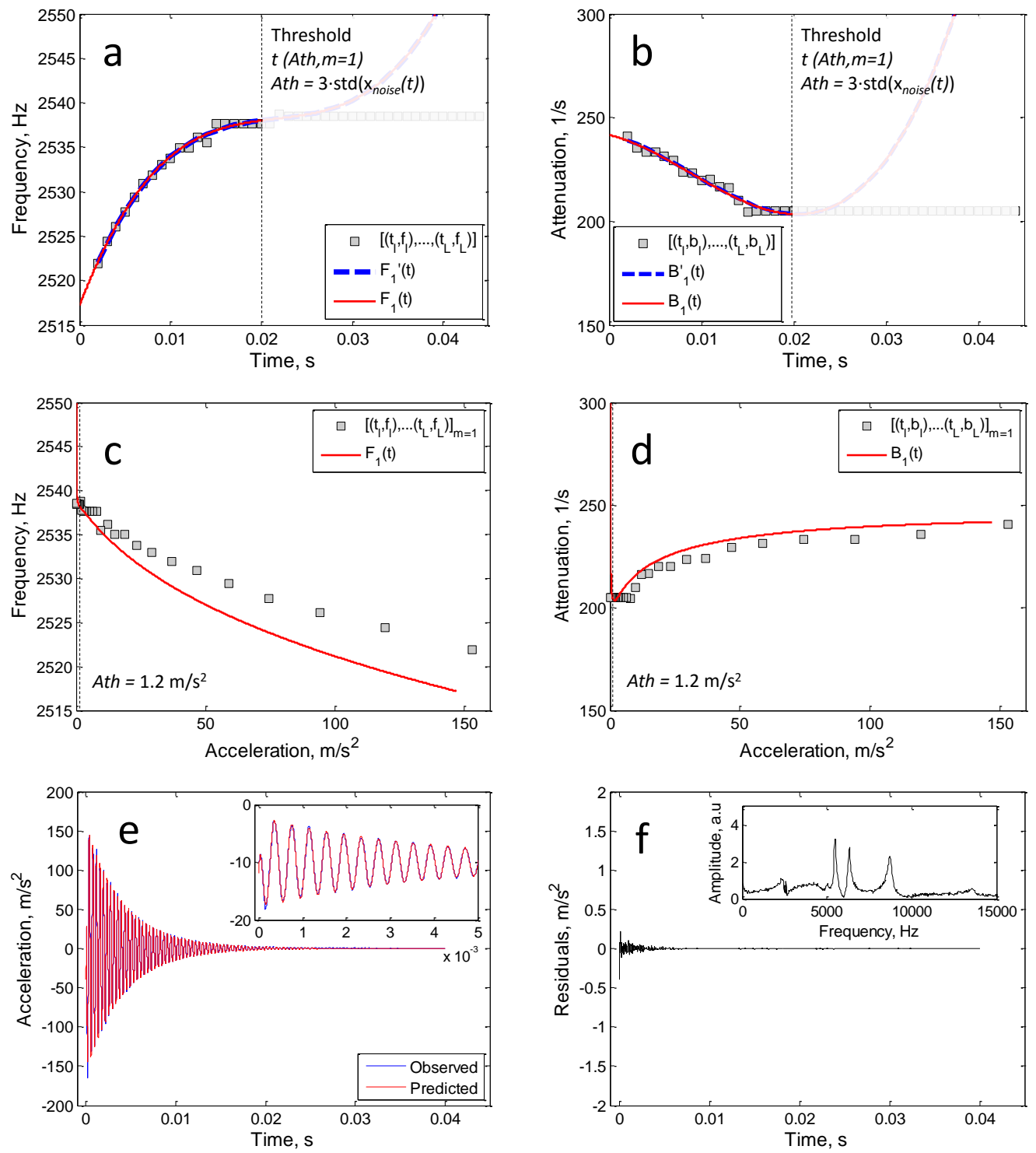

Figure 9-8 Final results after fitting the experimental signal used within this section to Eq. 9-2. a) Estimation of the function $F_{1}(t)$ from the initial estimation $\left.F_{1}^{\prime}(t) ; b\right)$ estimation of the function $B_{1}(t)$ from the initial estimation $B^{\prime}{ }_{1}(t)$; c) frequency variation in function of acceleration amplitude $-A_{1} \cdot \exp \left(\theta_{1}(t)\right)$ - d d) Attenuation variation versus acceleration amplitude, e) experimental signal and modeled signals f) residuals after fitting the entire signal. Inset plot shows small contributions that were not captured by the model. 
With all, the algorithm presented herein differs from that reported by Dahlén et al. (Dahlén et al., 2015), on the strategy to form the initial estimations of the polynomial phase and attenuation, which later on are used to fit the experimental signal to the model in Eq. 9-2. Moreover, the algorithm proposed herein avoid a "best set selection" approach -as those conducted in Reference (Dahlén et al., 2015) — to find the set of polynomial orders of the phase and attenuation functions of every mode. The latter requires running the algorithm using different combination of polynomial orders for the polynomial phase and attenuation functions, and choosing the combination that better describes the vibration data. Conversely, the method presented herein first surveys the frequency and attenuation variations over time for several vibration modes, and then the polynomial order is ascertained from the initia parametrization of the signal. More interestingly, the particular arithmetic shape of the functions does not have to meet a polynomial-based description but, whichever integrable function can be evaluated as well.

In Figures 9-9a and 9-9b the instantaneous variations of resonant frequency and amplitude are compared, in the same experimental signal used along subsection 9.4 Algorithm, and comparing time and frequency domain feature extraction methods (NSIRAS). For reference, the values of resonant frequency and amplitude obtained through the FFT of the entire signal —as it is conducted in NIRAS and ASTM C215-14 (ASTM C215-14, 2014) tests - are represented as time-independent lines in Figures 9-9a and 9-9b. The instantaneous frequency and amplitude responses obtained through the frequency and time domain feature extraction methods are coincident. However, the performance of the frequency domain method (STFT based approach) depends on window length. In Figures 9-9a and $9-9 b$ the instantaneous frequency and amplitude obtained through the STFT based approach have been obtained using a Blackman window with two different lengths: 4 ms and $1.5 \mathrm{~ms}$, which approximately correspond to 10 and 4 cycles of the first bending mode of vibration of the signal. The comparison of the two window lengths shows that the instantaneous frequency results more scattered at lower amplitudes for the shorter window, whereas the longer one tend to underestimate the initial values of amplitude. In any case, 
frequency domain method is unable to precisely resolve the amplitude of the signal at the signal arrival (see inset plot of Figure 9-9b). The selection of the window length has to meet a compromise between both, frequency and amplitude resolution. At overall, the time domain provides a better estimation of the true physical magnitude, whereas the frequency domain method is computationally faster and straightforward, especially, when the signal contains multiple vibration modes.
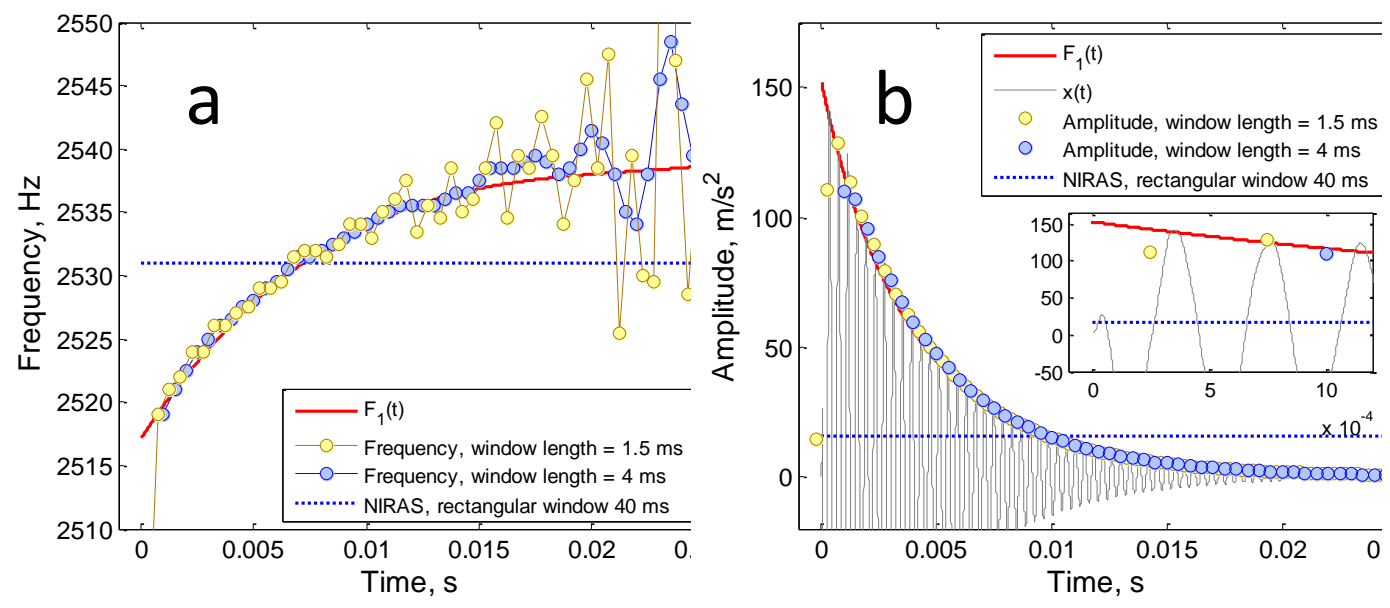

Figure 9-9 Comparison between frequency (circle points) and time domain (continuous line) signal analysis: a) instantaneous frequency, and b) instantaneous amplitude. The STFT approach compares the effect of two window lengths: $4 \mathrm{~ms}$ and $1.5 \mathrm{~ms}$ which correspond to $\sim 10$ and $\sim 4$ cycles of the first bending mode of vibration respectively.

\subsection{Comparison between NIRAS and NSIRAS approaches}

Figures $9-10$ a to $9-10$ c show representative resonance spectra obtained at different impact energies for one concrete sample at pristine state, and after 1 and 10 thermal-shock cycles. The cracking damage produced with increasing number of thermal-shock cycles, resulted in a progressive decrease of the resonant frequency, an increase of signal bandwidth - here measured through the quality factor $(Q)$ - , and at last, a downward shift 
of the resonant frequency with increasing impact energy. The relation between the normalized frequency shift $\left(\Delta f / f_{0}\right)$ with increasing excitation amplitude exhibits a linear relation for most materials (P. Johnson \& Sutin, 2005). In NIRAS technique, the slope $(\eta)$ of the linear relation between the normalized frequency shift with the spectral amplitude attained at every impact is normally used as a measurement of the material hysteretic nonlinearity. In this way, the measurement of material nonlinearity underlies on the relative units of the spectral amplitude, which in turn are proportional to the strain amplitude -and hence, $\eta$ is proportional to $\alpha_{f}$, see Chapter 2 Materials and methods-.
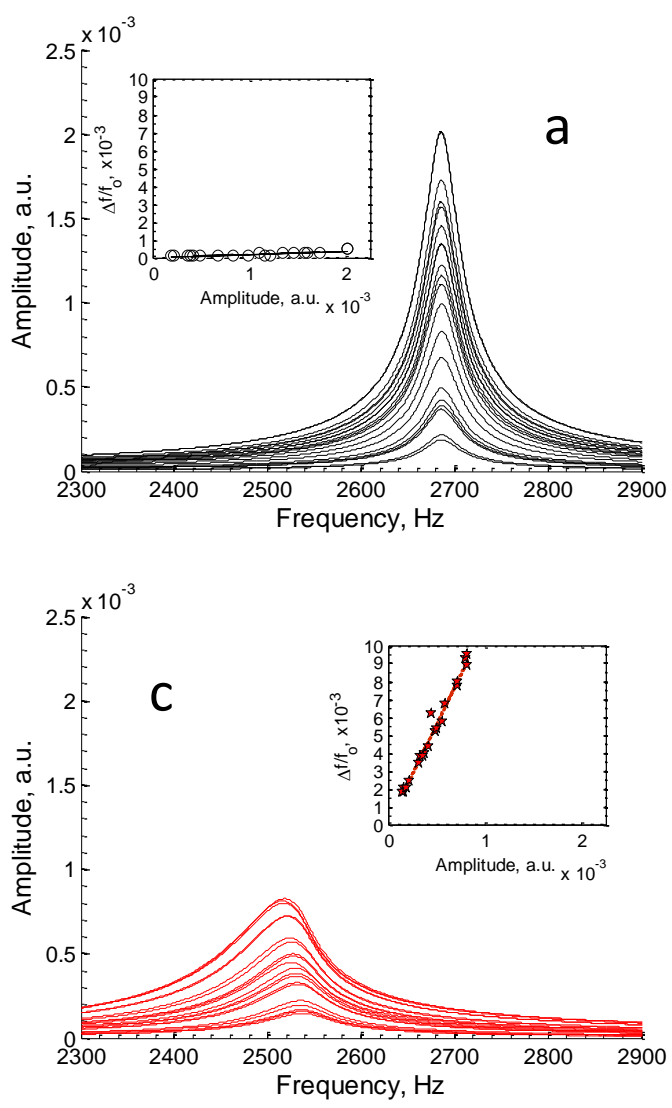

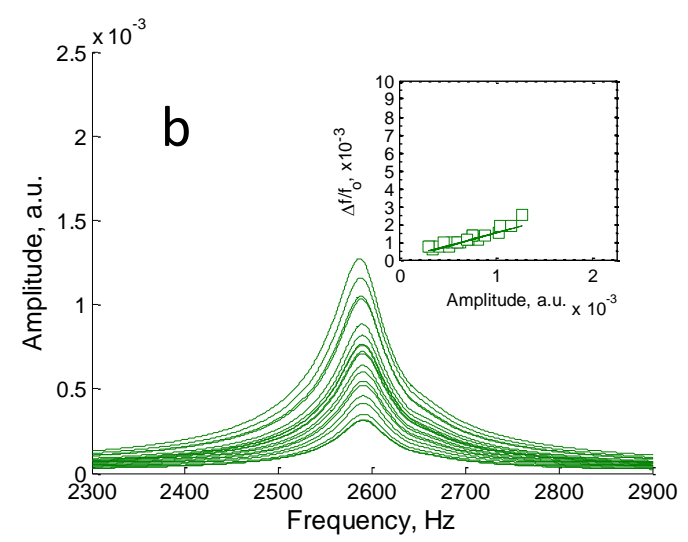

Figure 9-10 Representative resonant spectra obtained at increasing impact energy levels for a) pristine state and b) after 1 thermal-shock cycle, and c) after 10 thermal-shock cycles. Inset plots show the normalized frequency shift in function of the spectral amplitude. 
Unlike NIRAS technique, NSIRAS method investigates the material nonlinearity in a single impact event, which allows reducing the total number of impacts and provides a more reliable estimation of the signal amplitude. Figures 9-11a-c show the instantaneous frequency variation obtained for different impacts, in the representative dynamic responses obtained at pristine state, and after1 and 10 thermal-shock cycles. At pristine state, the resonant frequency is almost constant with increasing energy impact, and this behavior is consistently reproduced when the instantaneous frequency is investigated over the ring down of every impact (Figure 9-11a). However, with increasing thermal-shock cycling damage, while the dependence of the resonant frequency shift with regard excitation amplitude is linear (see inset plots in Figure 9-10), it becomes nonlinear when it is investigated through a single impact event (Figure 9-11). Moreover, the resonant frequency attained at the maximum amplitude of every impact (shown with circle markers in Figure 9-11) recovers over the ring down of the signal following different paths. This behavior was previously noted in (Dahlén et al., 2015; Van Damme \& Van Den Abeele, 2014). It can be related to a memory effect of the strain history attained at every impact energy. Concrete like materials present soft regions that are eventually broken and recovered upon mechanical wave propagation, resulting in a softening of the elastic modulus that is proportional to the excitation amplitude, so-called fast dynamic effect (P. Johnson \& Sutin, 2005). The growing of microcracks upon increasing number of thermal-shock cycles, causes that some of these induced asperities temporarily remain in a metastable equilibrium upon mechanical wave excitation, since the time that the material takes to recover towards the linear elastic modulus (prior impact excitation) is far greater than the duration of the signal response (TenCate, 2011). This manifestation of slow dynamic effect deviates away from the proportional relation between the instantaneous resonant frequency and the instantaneous amplitude. Such effect seems to be enhanced as a measure that the microcracking damage progresses.

Although the slow dynamic effect informs of an increase of the material nonlinearity with regards that obtained at pristine state, it makes difficult the quantification of the material 
nonlinearity on a single and quantifiable parameter regardless of energy impact. From a single impact, the fast dynamic behavior, as that is obtained through multiple impact events, can be found, by simply relating the minimum downward shift of the resonant frequency to its correspondent maximum acceleration amplitude $\left(A_{\max }\right)$ as

$$
\eta=\frac{\min \left(\frac{f_{0}-f}{f_{0}}\right)}{A_{\max }} .
$$

In this way, the nonlinear parameter $\eta$ is measured in the reciprocal units of the excitation amplitude (herein $\mathrm{s}^{2} / \mathrm{m}$ ), and regardless energy impact. Indeed, it represents also the slope of the relation between the maximum amplitude and the maximum frequency shift for every impact (dashed lines in Figure 9-11a-c). In this way, the slow dynamic effect which seems to depend on impact energy impact is untangled. We believe this side effect, that at same time are unperceived or usually dismissed in other nonlinear based techniques (for instance in NIRAS), will be affected by the particular chemo-mechanical interactions of the different degradation mechanisms that cause microcracking like damage in concrete, (sulfate attack, alkali silica reaction, freeze-thawing damage, etc). More research is still needed however, to understand the physical origins in whose the slow dynamic effect underlies ( $P$. Johnson \& Sutin, 2005; TenCate, 2011).

Separate discussion requires the determination of the linear frequency $\left(f_{0}\right)$ of the concrete samples at every damage stage, given that it clearly affects the computation of the hysteretic parameter -this is further discussed in Chapter 12-. The linear frequency $\left(f_{0}\right)$ can be assumed, that approached when the signal amplitude reaches the noise level in NSIRAS measurements. Because of the slow dynamic condition of the material, especially at severe damage stages, the determination of the linear frequency will be down-biased as a measure that the microcracking damage progresses. Therefore, the robustness of the measurements depends in some extent on the slow dynamic effect. The effects of slow 
dynamics on the estimation of the hysteretic parameter $\eta$ can be minimized by controlling the elapsed time between consecutive impacts, and by determining a priori the resonant frequency in the linear elastic regime. In this study the $f_{0}$ was obtained from the average of the resonant frequency values obtained at the signal amplitude of $3 \cdot \sigma\left(A_{\text {noise }}\right)$.
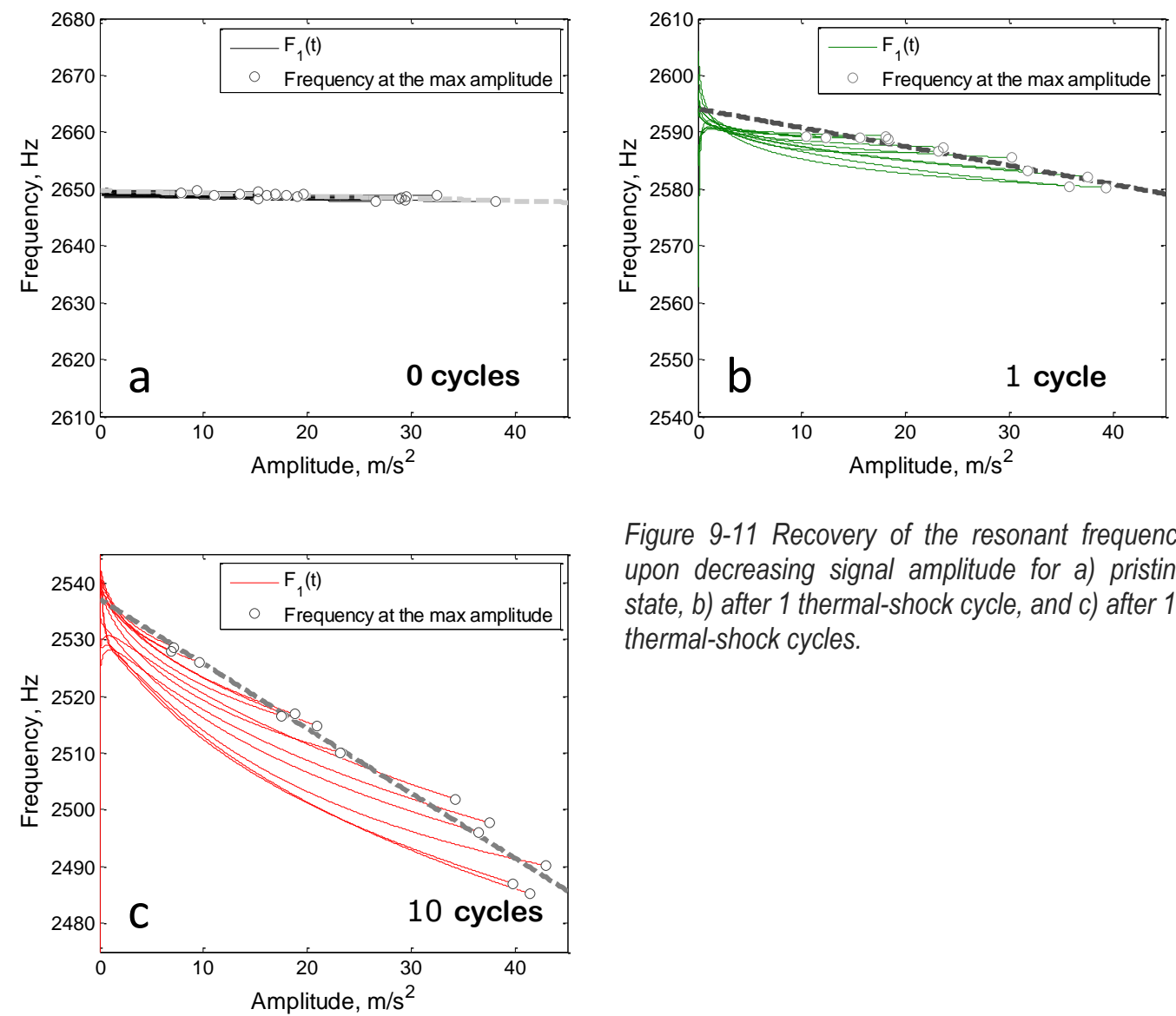

Figure 9-11 Recovery of the resonant frequency upon decreasing signal amplitude for a) pristine state, b) after 1 thermal-shock cycle, and c) after 10 thermal-shock cycles.

Finally, the Figure 9-12a to 9-12d shows the evolution of the resonant frequency, quality factor $(Q)$ and the hysteretic parameter $(\eta)$ obtained through NIRAS technique (Figure 9-12c) and though NSIRAS (Figure 9-12d). The results show the expected decrease of resonant frequency and quality factor with increasing damage and a monotonic increase of the 
hysteretic parameter with increasing number of thermal-shock cycles. It can be observed that the hysteretic parameter obtained using a STFT approach is consistently greater than the same parameter derived from the analysis of the signal using the time domain fitting method. This effect is owed to the fact that the maximum amplitude of the signal results underestimated when the signal is analyzed using the STFT approach.

The hysteretic parameter has been pointed out as a quality parameter as the resonant frequency and quality factor have been yet established (P. A. Johnson, Zinszner, Rasolofosaon, Cohen-Tenoudji, \& Van Den Abeele, 2004). However, the quantification of the hysteretic parameter from impact vibration based nondestructive methods needs some considerations: i) determination of the true physical amplitude of the signal, ii) proper determination of the resonant frequency in elastic regime $\left(f_{0}\right)$ in order to minimize the slow dynamic effect; and according to previous studies, iii) controlled moisture environment (J.N. Eiras et al., 2015). The extraction of the material nonlinearity from standard resonant measurements provides additional insight of the mechanical integrity of the material, and its measurement is far more sensitive than the standard measurements of dynamic modulus of elasticity and quality factor (Chen et al., 2010; J N Eiras et al., 2014; Jesús N Eiras, Popovics, Borrachero, Monzó, \& Payá, 2012). For reference, the first thermal-shock cycle caused a reduction of the elastic modulus between 4 and $5 \%$, and a reduction of $33 \%$ of the quality factor, whereas the hysteretic parameter escalated in one order of magnitude; from values of $\sim 10^{-6}$ at pristine state to values of $\sim 10^{-5}$. These values increased up to $\sim 10^{-4}$ in subsequent stages of damage (after 5 and 10 thermal-shock cycles). 

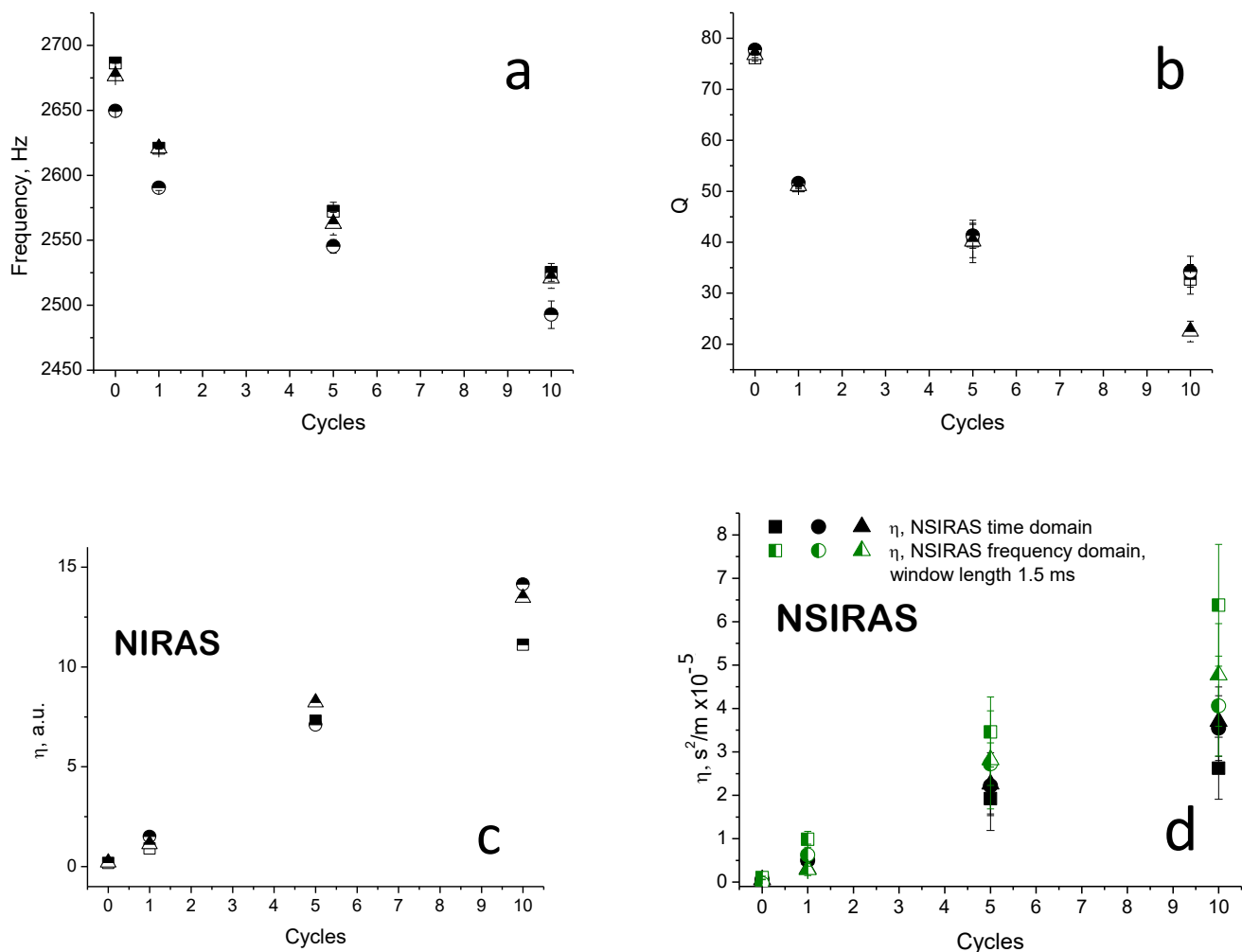

Figure 0-12 Evolution of the dynamic parameters obtained from the standard resonant frequency test configuration a) resonant frequency, mean of 20 impacts, b) quality factor, mean of 20 impacts, c) hysteretic parameter obtained from 20 impact events (NIRAS), thus only one value per concrete sample, and d) hysteretic parameter obtained from a single impact event (NSIRAS): mean of twenty impact events. Error bars represent standard deviation.

\subsection{Summary and conclusions}

The present study investigates the feasibility of the standard test configuration ASTM C215-14 to quantify the material nonlinearity owed to distributed-like damage in concrete. The methods presented herein show promise for enhanced assessment of different durability distresses of concrete, using a relatively inexpensive and well-vetted standard test 
configuration, when compared to other nonlinear-based techniques. The determination of the material nonlinearity from a single impact event reduces the operating time, and the number of impacts needed to investigate the material nonlinearity, which can lead to local damage in the concrete samples. Yet, several impacts are recommended to provide certain confidence on the reported values of the hysteretic parameter for each damage state. Unlike NIRAS approach, the investigation of the instantaneous variations of the signal parameters (amplitude, frequency and also attenuation), allows quantitative measurements of the material nonlinearity. Two different approaches for extracting and quantifying the material nonlinearity from a single impact were compared. At overall, the time domain analysis of the signals provides better estimation of the actual signal amplitude when compared to the STFT approach. However, the STFT is computationally faster and straightforward. On other hand, the computation of the hysteretic parameter $\eta$ (owing to fast dynamic effect), namely a quantitative factor regardless impact energy from the vibration signal, needs an accurate estimation of the maximum amplitude of the vibrating mode. Finally, the consideration of the slow dynamic response on the investigation of the material nonlinearity from a single vibration response deserves further research, not only for enhancing the robustness of the measurements of the hysteretic parameter $\eta$, but also to provide additional valuable information about the mechanical integrity of the material.

\section{References}

ASTM C215-14. (2014). Standard Test Method for Fundamental Transverse , Longitudinal , and Torsional Resonant Frequencies of Concrete.

ASTM C231 / C231M - 14. (2014). Standard Test Method for Air Content of Freshly Mixed Concrete by the Pressure Method. .

ASTM C39. (2014). Standard Test Method for Compressive Strength of Cylindrical Concrete Specimens 1. West Conshohocken, PA (USA).

Bouchaala, F., Payan, C., Garnier, V., \& Balayssac, J. P. P. (2011). Carbonation assessment 
in concrete by nonlinear ultrasound. Cement and Concrete Research, 41(5), 557-559.

Chen, J., Jayapalan, A. R., Kim, J. Y., Kurtis, K. E., \& Jacobs, L. J. (2010). Rapid evaluation of alkali-silica reactivity of aggregates using a nonlinear resonance spectroscopy technique. Cement and Concrete Research, 40(6), 914-923.

Dahlén, U. (2013). Damage identification in concrete using nonlinear reverberation. Lund University.

Dahlén, U., Ryden, N., \& Jakobsson, A. (2015). Damage identification in concrete using impact non-linear reverberation spectroscopy. NDT and $E$ International, 75, 15-25.

Eiras, J. N., Kundu, T., Popovics, J. S., Monzó, J., Soriano, L., Payá, J. (2014). Evaluation of frost damage in cement-based materials by a nonlinear elastic wave technique. Proceedings of SPIE Conference, 9064, 1-8.

Eiras, J. N., Monzó, J., Payá, J., Kundu, T., \& Popovics, J. S. (2014). Non-classical nonlinear feature extraction from standard resonance vibration data for damage detection. The Journal of the Acoustical Society of America, 135(2), EL82-EL87.

Eiras, J. N., Popovics, J. S., Borrachero, M. V., Monzó, J., \& Payá, J. (2012). Nonlinear impact resonant acoustic spectroscopy to discern mechanical damage in cement based materials. 15th International Conference on Experimental Mechanics, Porto (Portugal) 1-6.

Eiras, J. N., Popovics, J. S., Borrachero, M. V., Monzó, J., \& Payá, J. (2015). The effects of moisture and micro-structural modifications in drying mortars on vibration-based NDT methods. Construction and Building Materials, 94, 565-571.

Johnson, P. A., Zinszner, B., Rasolofosaon, P. N. J., Cohen-Tenoudji, F., \& Van Den Abeele, K. (2004). Dynamic measurements of the nonlinear elastic parameter a in rock under varying conditions. Journal of Geophysical Research, 109(B2), B02202.

Johnson, P., \& Sutin, A. (2005). Slow dynamics and anomalous nonlinear fast dynamics in diverse solids. The Journal of the Acoustical Society of America, 117(1), 124-130.

Lesnicki, K. J., Kim, J.-Y., Kurtis, K. E., Jacobs, L. J., \& Jacobs, and L. J. (2013). Accelerated Determination of ASR Susceptibility During Concrete Prism Testing Through Nonlinear 
Resonance Ultrasonic Spectroscopy.

Schwarz, G. (1978). Estimating the dimension of a model. The Annals of Statistics, 6(2), 461-464.

Somaratna, J. (2014, September 16). Evaluation of linear and nonlinear vibration methods to characterize induced microstructural damage in portland cement-based materials. University of Illinois at Urbana-Champaign.

TenCate, J. a. (2011). Slow Dynamics of Earth Materials: An Experimental Overview. Pure and Applied Geophysics, 168(12), 2211-2219.

Van Damme, B., \& Van Den Abeele, K. (2014). The application of nonlinear reverberation spectroscopy for the detection of localized fatigue damage. Journal of Nondestructive Evaluation, 33(2), 263-268.

Van Den Abeele, K., Campos-Pozuelo, C., Gallego-Juarez, J., Windels, F., \& Bollen, B. (2002). Analysis of the nonlinear reverberation of titanium alloys fatigued at high amplitude ultrasonic vibration. In Proceedings Forum Acustica Sevilla.

Van Den Abeele, K., \& De Visscher, J. (2000). Damage assessment in reinforced concrete using spectral and temporal nonlinear vibration techniques. Cement and Concrete Research, 30(9), 1453-1464.

Van Den Abeele, K., Le Bas, P.-Y., Van Damme, B., \& Katkowski, T. (2009). Quantification of material nonlinearity in relation to microdamage density using nonlinear reverberation spectroscopy: Experimental and theoretical study. The Journal of the Acoustical Society of America, 126(3), 963-72. 


\section{Chapter 10: Assessment of carbonation of Portland cement mortar}



Chapter 10: Assessment of carbonation of Portland cement mortar $.10-1$

10.1. Background on carbonation .................................................................. 10-4

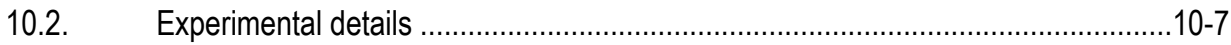

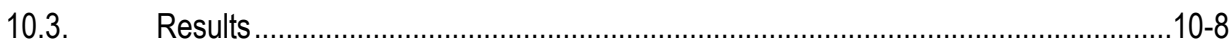

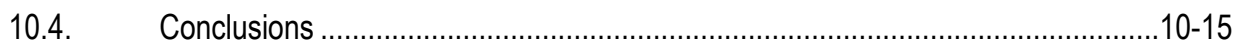

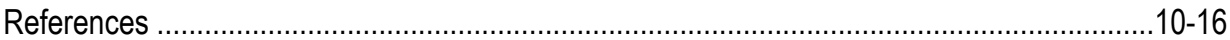




\subsection{Background on carbonation}

Carbonation is one of the processes that adversely affect the durability of concrete structures. It consists of a neutralization process, in which the carbon dioxide present in the atmosphere diffuses through concrete and reacts, in the presence of moisture, with the constituents of the cementing matrix. Different constituents are carbonated during the diffusion of carbon dioxide through concrete, yielding mainly calcium carbonate $\left(\mathrm{CaCO}_{3}\right)$. However, the escalating content of calcium carbonate during carbonation under natural conditions is mainly due to its reaction with portlandite $(\mathrm{CH})$ (Hidalgo et al., 2008) Carbonation is expressed by the following reaction

$$
\mathrm{CH}+\mathrm{CO}_{2} \longrightarrow \mathrm{CaCO}_{3}+\mathrm{H}_{2} \mathrm{O}
$$

In addition to portlandite, eventually unhydrated $\mathrm{C}_{3} \mathrm{~S}$ and $\mathrm{C}_{2} \mathrm{~S}$, and hydrated phases such as $\mathrm{CSH}$ reacting with carbon dioxide, are carbonated which produces silica gel in additional to calcium carbonate (Kobayashi, Suzuki, \& Uno, 1994; Papadakis, Vayenas, \& Fardis, 1991; Šauman, 1971) as

$$
\begin{aligned}
& \mathrm{C}_{x} \cdot \mathrm{S}+x \mathrm{CO}_{2}+n \mathrm{H}_{2} \mathrm{O} \longrightarrow \mathrm{SiO}_{2} \cdot n \mathrm{H}_{2} \mathrm{O}+x \mathrm{CaCO}_{3}, \\
& \mathrm{C}_{x} \cdot \mathrm{S}_{y} \cdot \mathrm{H}_{z}+x \mathrm{CO}_{2} \longrightarrow y \mathrm{SiO}_{2} \cdot z \mathrm{H}_{2} \mathrm{O}+x \mathrm{CaCO}_{3} .
\end{aligned}
$$

Other cement compounds are also decomposed producing alumina and ferric oxide (Fernández-Carrasco, Puertas, Blanco-Varela, \& Vázquez, 2001; Neville, 1981; Zornoza, Garcés, Monzó, Borrachero, \& Payá, 2009). As a result, the pH of the pore water in noncarbonated cement paste matrix of concrete (usually $\mathrm{pH}>12$ ) decreases to $\mathrm{pH} \sim 9$, which affects the integrity of steel reinforcing bars in reinforced concrete. In such conditions, the thin oxide film that protects steel from corrosion is no longer stable, making it more susceptible to corrosion by aggressive agents (McCafferty, 2010). Moreover, as a 
consequence of the progressive carbon dioxide absorption during carbonation, the effective solid phase volume of the material increases, what results in a decrease of the total porosity, a decrease of the permeability and an increase of the mechanical properties, if strengthgiving phases such as CSH, are not severely degraded (Johannesson \& Utgenannt, 2001; Neville, 1981; Ngala \& Page, 1997; Pham \& Prince, 2013). Unlike in reinforced concrete, such microstructural modifications are desirable to improve the durability of cement based materials. Different industrial carbonation treatments have been proposed for the production of precast concrete blocks (Rostami, Shao, \& Boyd, 2012) and to enhance the durability of some fiber reinforced cement composites in which the durability of the fibers is compromised at usual levels of pH in concrete (Santos, Schmidt, Almeida, Tonoli, \& Savastano, 2015; Short, Purnell, \& Page, 2001). Such treatments aiming to carbonate the cement matrix could endow additional value added because of carbon dioxide sequestration

Previous research conducted by Bouchaala et al. (Bouchaala, Payan, Garnier, \& Balayssac, 2011) investigated the linear and nonlinear dynamic properties of fully carbonated and non-carbonated concrete samples, using the Nonlinear Impact Resonance Acoustic Spectroscopy (NIRAS) technique. The concrete samples were cored from concrete slabs which were previously subjected to controlled $\mathrm{CO}_{2}$ and relative humidity conditions, so that the carbonation front as measured by phenolphthalein solution reached values of $\sim 15$ $\mathrm{mm}$ and $\sim 20 \mathrm{~mm}$. Figure 10-1a and Figure 10-1b compare the relative variations of dynamic modulus and material nonlinearity as evaluated through resonant experiments. The results showed therein demonstrated an increase of dynamic modulus, and a decrease of material nonlinearity with regard non-carbonated samples (Figure 10-1b). In addition, no meaningfu differences were observed between the carbonation depths $\sim 15 \mathrm{~mm}$, and $\sim 20 \mathrm{~mm}$. More recently, the work conducted by Kim and coworkers (Kim et al., 2014) showed that the second harmonic generation offers a potential method for in situ characterization by using Rayleigh waves. The results showed therein, also confirmed a decrease of the material nonlinearity with increasing extent of carbonation.

\section{$10-5$}



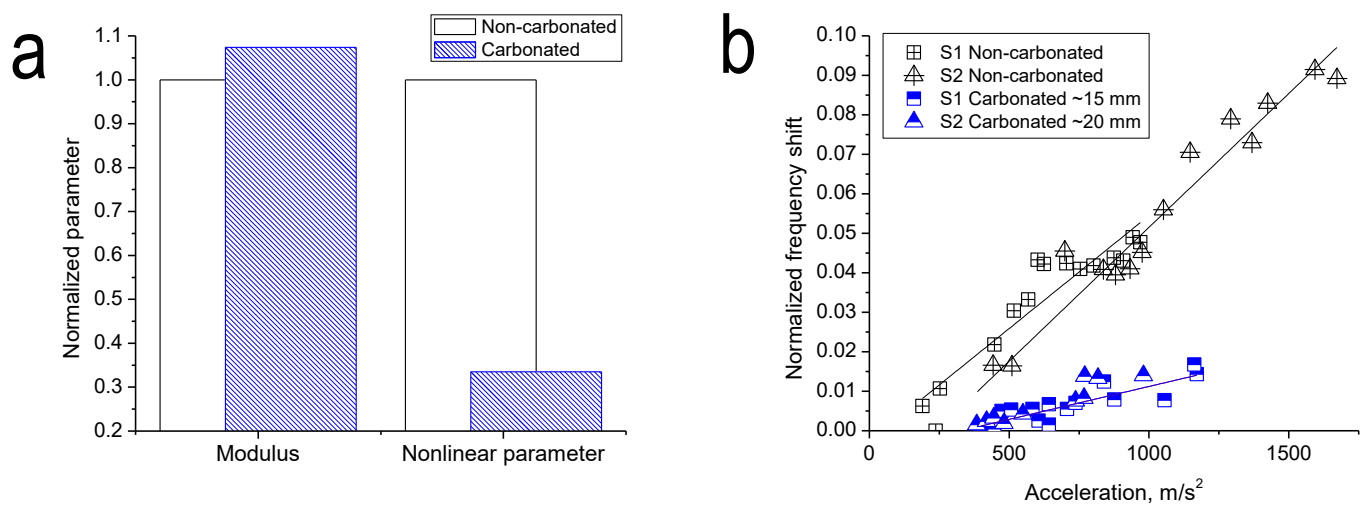

Figure 10-1 a) Normalized dynamic modulus of elasticity and normalized hysteretic parameter with regard that obtained in non-carbonated samples, and b) normalized frequency shift as a function of acceleration amplitude. The slope of such a relation is the hysteretic parameter. Adapted from Bouchaala et al. (Bouchaala et al., 2011)

Further to previous efforts, in this study the carbonation process was investigated on Portland cement mortar samples, where the linear and nonlinear properties were derived using the standard resonant frequency method (ASTM C215-14, 2014). Unlike the standard approach based only on a linear analysis, previous research conducted by the authors (Eiras, Monzó, Payá, Kundu, \& Popovics, 2014) showed how to extract and quantify the nonlinear behavior owing to mechanical hysteresis. The approach was demonstrated on freezing-thawing damaged mortar which enhances the mechanisms of material hysteresis due to increasing damage with increasing number of cycles. Conversely, a progressive decrease of material nonlinearity is expected, as a measure that carbonation progresses. Additional verification tests were conducted, such as mechanical test -three point bending and compressive strengths - and depth of carbonation by spraying with phenolphthalein solution on fractured surfaces obtained from the three point bending test. 


\subsection{Experimental details}

Five series of three prismatic mortar samples of $40 \times 40 \times 160 \mathrm{~mm}^{3}$ were produced following the procedure described in EN 196-1 (EN 196-1, 2005). The water-cement ratio was set to $1: 2$ and the aggregate-cement ratio was $3: 1$ by weight. The aggregate was of siliceous nature and the cement was type CEM I-52.5R. The samples were cured at $20^{\circ} \mathrm{C}$ and $95 \%$ of relative humidity $(\mathrm{RH})$ for 315 days after casting. The samples were subjected to an accelerated carbonation process in a carbonation chamber with a $>95 \% \quad \mathrm{CO}_{2}$ atmosphere, and $55 \%$ RH. Figure 10-2a-b show schematic diagram of the carbonation setup and the carbonation chamber. The system consists of a desiccator connected to a $\mathrm{CO}_{2}$ pressure vessel tank that allows $\mathrm{CO}_{2}$ gas to flow through the desiccator. The $\mathrm{RH}$ value of $55 \%$ was set because of the rate of carbonation is maximum between $55 \%$ and $65 \%$ (Basheer, Rankin, Long, \& Russell, 2001). An aqueous solution of glycerin (75\% by weight) helps to provide a $55 \%$ RH within the desiccator. However, since the samples were initially at $95 \% \mathrm{RH}$, and because the carbonation process involves releasing of water, the $\mathrm{RH}$ within the desiccator increased, as the samples naturally reach the hygroscopic equilibrium in the desiccator. Nonetheless, a periodic renovation of the $\mathrm{CO}_{2}$ atmosphere was conducted every 24 hours to help to keep the $>95 \% \mathrm{CO}_{2}$ atmosphere and $55 \% \mathrm{RH}$.

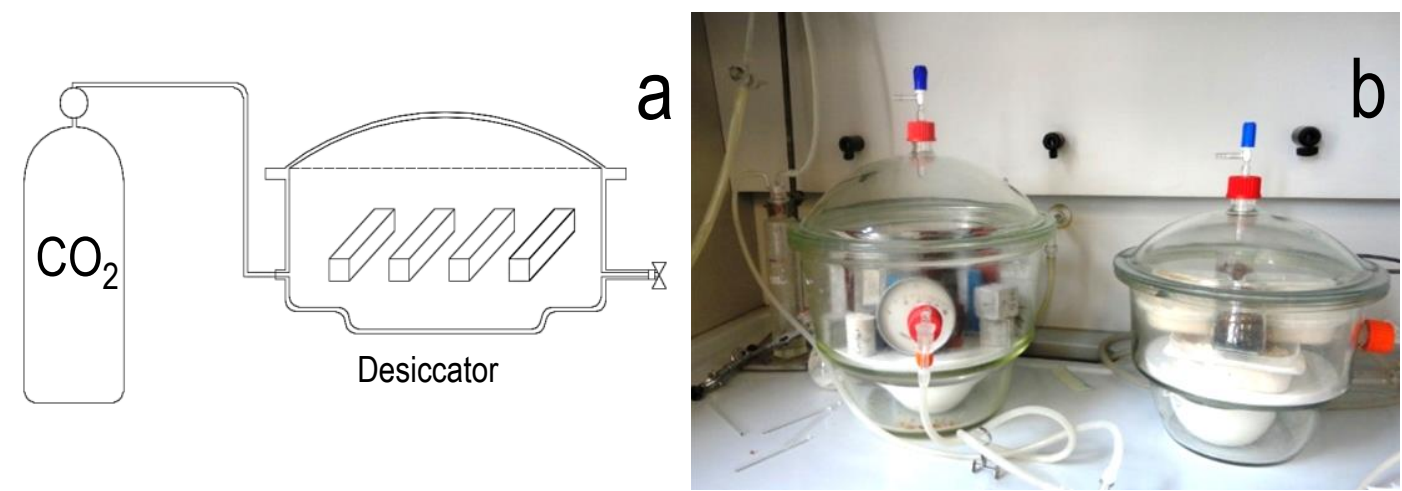

Figure 10-2 a) Schematic depiction and, b) general overview of the carbonation chamber. 
Three samples were tested through the standard resonant frequency method, configured to promote the first bending mode — see section 2.2.1.1 Resonant frequency method in Chapter 2 for detailed description of the test configuration-. The samples were tested before starting the carbonation process, and as the carbonation progressed for 7,28 , 56, 79 and 94 days. The acquired signals were transformed to the frequency domain using the Fast Fourier Transform (FFT) algorithm; then flexural frequency and quality factor (Q) were derived. The material nonlinearity was investigated using a short-time Fourier transform (STFT) based approach, to track frequency changes as the signal amplitude decays naturally, following the procedure proposed in (Eiras et al., 2014). Moreover, the mechanical properties are determined according to EN 196-1 (EN 196-1, 2005) on the additional replicates at $0,7,28,79$ and 94 days of carbonation. $\mathrm{A} \mathrm{pH}$ indicator (phenolphthalein in ethanol solution) is used to distinguish between carbonated ( $\mathrm{pH}$ lower than 10) and noncarbonated areas on the fractured surfaces.

\subsection{Results}

Figure 10-3 shows the gradual increase on compressive strength upon prolonged carbonation exposure duration. The results confirmed the increase of mechanical properties observed in Portland cement based materials. The compressive strength at pristine state (53.5 MPa) becomes almost twice after 94 days of carbonation (92.6 MPa). The mechanisms of mechanical strength increase due to carbonation of Portland cement based materials, described in the literature (Neville, 1981), include the progressive deposition of calcium carbonates within the pore structures that reduces the capillary-sized porosity within the samples and additional hydration, since carbonation reaction releases water molecules, mainly from the carbonation of $\mathrm{Ca}(\mathrm{OH})_{2}$, that can combine with yet unhydrated Portland cement particles. 


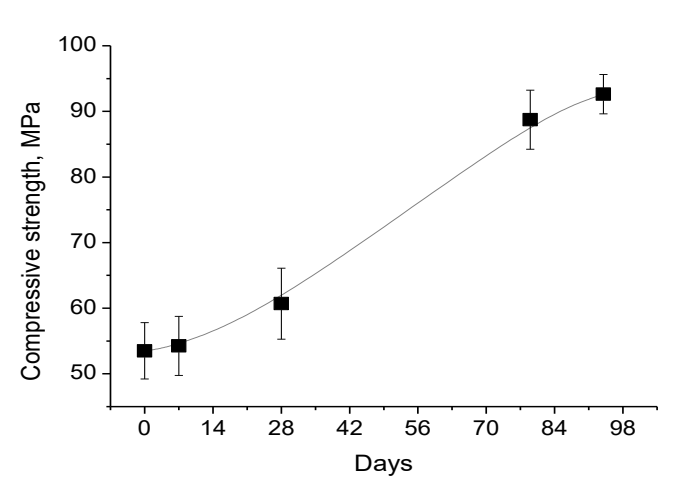

Figure 10-3 Evolution of compressive strength with carbonation exposure duration; error bars represent standard deviation.

Carbonation depth is normally measured with phenolphthalein solution (Rilem Recommandations, 1988), which turns non-carbonated concrete areas red $(\mathrm{pH}>12)$, and makes it colorless for carbonated concrete $(\mathrm{pH}<10)$. Herein, the carbonation depth was measured by image analysis, after thresholding and binarizing the images of fractured surfaces sprayed with phenolphthalein. The thresholding process differentiated between colored and non-colored areas; then non-carbonated areas are represented in black color. Figure 10-4 shows representative fractured surfaces sprayed with phenolphthalein, and the respective binary images. After 7 days no noticeably presence of carbonation was observed on the fractured surfaces (Figure 10-4, first column). This complementary test allows relating the actual progress of carbonation to the observed variation of the dynamic properties upon carbonation. 

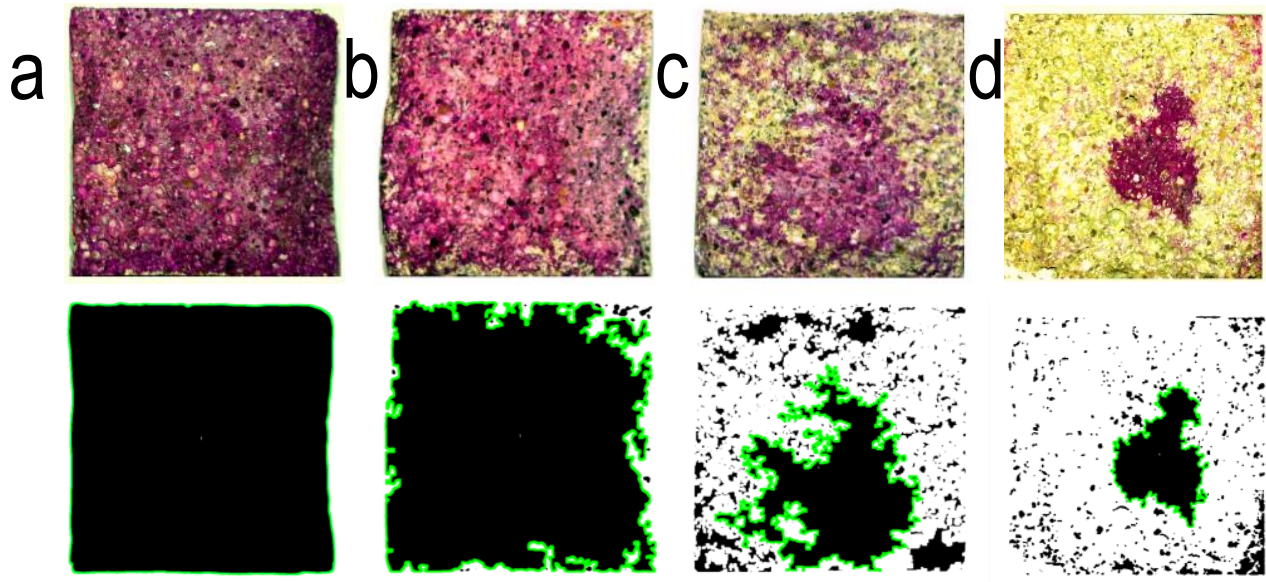

Figure 10-4 Images of test samples exposed to different extents of carbonation exposure. Top row - Fractured surfaces $\left(4 \times 4 \mathrm{~cm}^{2}\right)$ sprayed with phenolphthalein solution indicator. Bottom row - Binary representation of images with non-carbonated areas indicated by black color; a) 7 days, $0.00 \%$ carbonated, b) 28 days, $10.13 \%$ carbonated c) 79 days, $72.83 \%$ carbonated, and d) 94 days of carbonation, $89.36 \%$ carbonated.

Figure 10-5a and Figure 10-5b show representative frequency spectra of a mortar sample at non-carbonated state, and after carbonation for 28, 56, 79 and 94 days. Figure $10-5 \mathrm{c}$ and Figure $10-5 \mathrm{~d}$ show the mean value of flexural frequency and quality factor for all samples. First 28 days of carbonation resulted in a reduction of the resonance frequency, and an increase of $Q$ (Figure 10-5a). At early stages of carbonation (from 0 to 28 days), it is observed that the resonance frequency decreased. The samples, initially at $95 \% \mathrm{RH}$, dried naturally inside the desiccator to $55 \% \mathrm{RH}$, thus the internal moisture content of the samples was reduced. The carbonation rate during that period was very slow, since $\mathrm{CO}_{2}$ could not diffuse into the samples when the pore structure was clogged with water. Indeed, the carbonation depth barely progressed (see Figure 10-4, second column). Previous research (Eiras, Popovics, Borrachero, Monzó, \& Payá, 2015) demonstrated that the presence of moisture within the pore structure of mortar samples gives rise to a stiffening effect that increases the resonance frequency, and viscous damping of the material (decrease of $Q$ ), whereas subsequent water removal caused a decrease of the resonance frequency, and an increase of $Q$ - see also Chapters 3 and 4 - Therefore, the initial variations of the 
resonance frequency and $Q$ were most likely owed to the variation of the moisture content within the sample, rather than carbonation of the samples. Further carbonation (time of exposure above 28 days) resulted on a monotonic increase of both resonance frequency and $Q$. From 28 to 94 days of carbonation an increase of the material stiffness and a greater decrease of damping properties were obtained.
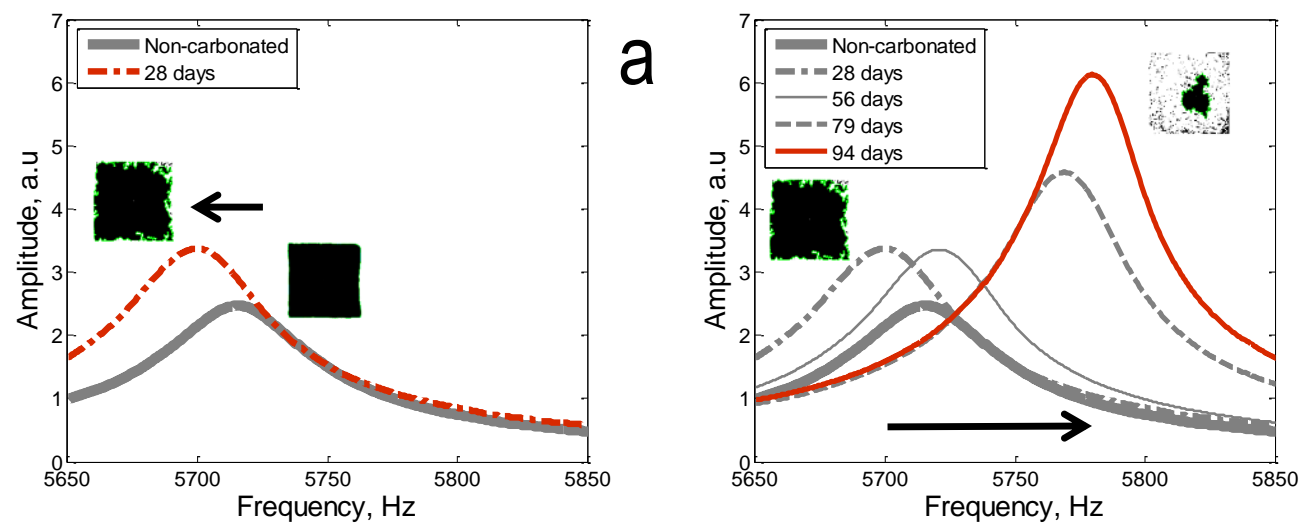

b
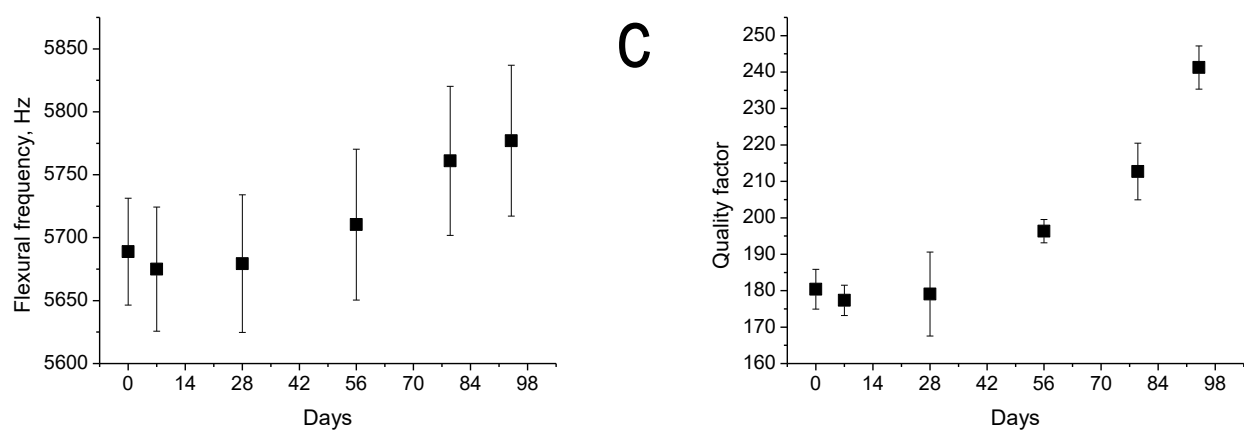

Figure 10-5 Linear vibration resonance responses of the fundamental flexural mode obtained from varying degrees of carbonation exposure; inset images indicate non-carbonated areas as black on a $4 \times 4 \mathrm{~cm}^{2} \mathrm{cross}$ section area: a) Representative resonance spectra of non-carbonated and after 28 days of carbonation.; b) resonance spectra for non-carbonated and after 28, 56, 79, and 94 days of carbonation; c) mean values of the resonance frequency, and d) mean values of $Q$. Error bars represent standard deviation. 
The hysteretic material nonlinearity can be evaluated through a least-squares solution of the model

$f=f_{\text {int }}+A \cdot \lambda$

where $f_{\text {int }}$ is the intercept, and $\lambda$ the slope of the relation between frequency $(f)$ and spectral amplitude $(A)$. Figure 10-6a to Figure 10-6e illustrate the measurement of $\lambda$, where the relation between the upward frequency shift with decreasing spectral amplitude on ring-down for ten vibrational responses are shown; the estimated values of $\lambda\left(f=f_{\text {int }}+A \cdot \lambda\right.$,

Eq. 10-4) are also displayed across a range of carbonation durations. In order to discern if the relative changes of $\lambda$ were meaningful, a pairwise comparison was performed. The null hypothesis is that the value of $\lambda$ for is statistically the same across two different carbonation durations. The pairwise comparisons can be tested as (Paternoster, Brame, Mazerolle, \& Piquero, 1998)

$t=\frac{\lambda_{1}-\lambda_{2}}{\sqrt{S E_{1}^{2}+S E_{2}^{2}}} \sim t_{d f}^{\alpha / 2}$,

where $\lambda_{1}$ and $\lambda_{2}$ are the values of the regression parameters that want to be compared, $S E_{1}$ and $S E_{2}$ their respective standard errors, and $t$ the critical value of the t-student distribution for a confidence level of $95 \%$; thus $\alpha=0.05$. During the first 28 days of carbonation the nonlinear parameter varied from $\lambda=-0.0050$ to $\lambda=-0.0043$. The pairwise comparison revealed that no significant differences between the values of $\lambda$ were found for carbonation durations below 28 days. However, for longer carbonation periods (56 days and above), the value of $\lambda$ decreased significantly, where the parameter $\lambda$ raised their values to -0.002 . From the measurement of $\lambda$ upon carbonation, it can be drawn that the carbonation results in a reduction of material nonlinearity and the samples reach an almost constant value of $\lambda$, even if the sample is not fully carbonated, so further carbonation does not modify the material 
nonlinearity. Indeed, no significant differences between the values of $\lambda$ were found for carbonation periods longer than 56 days.
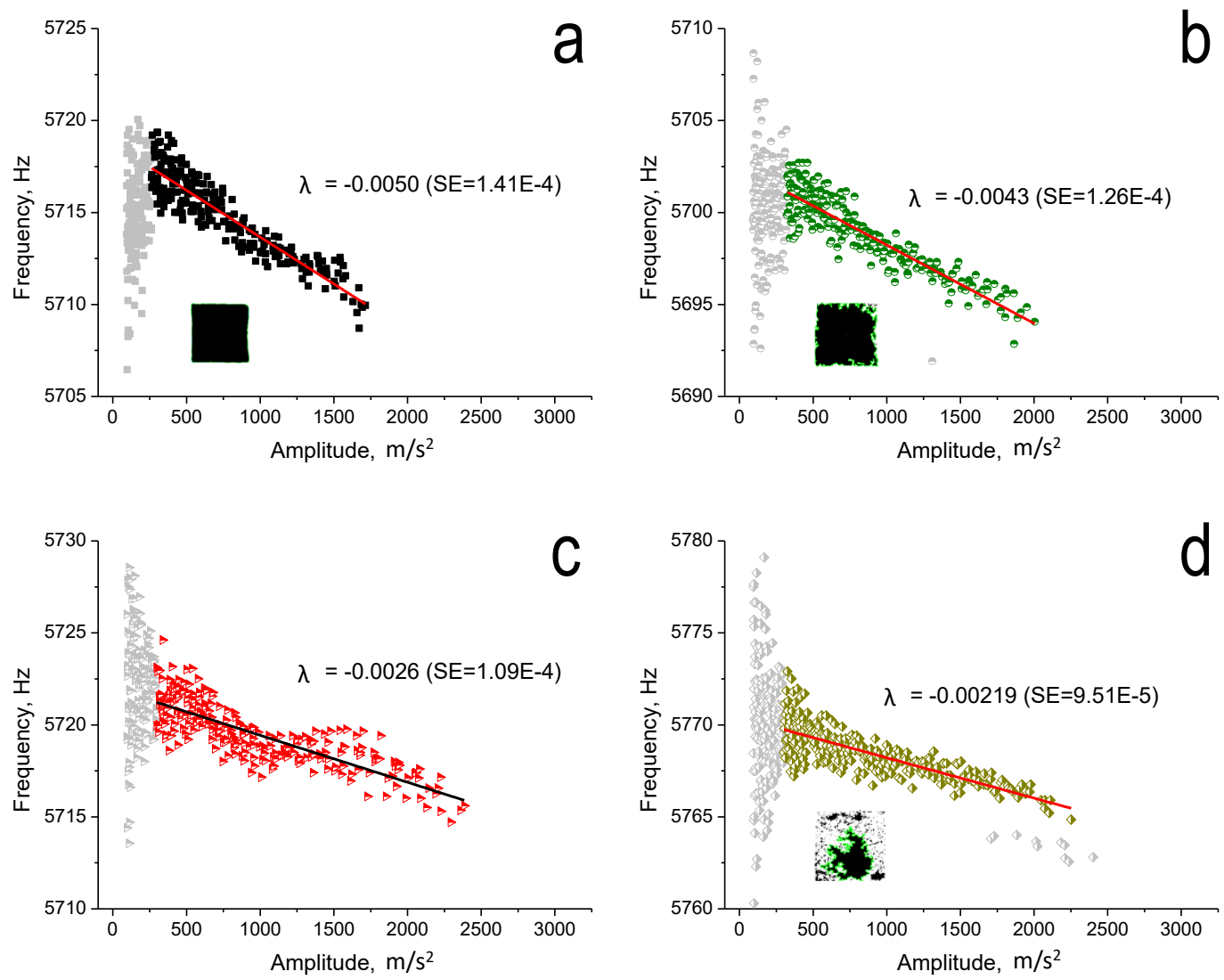


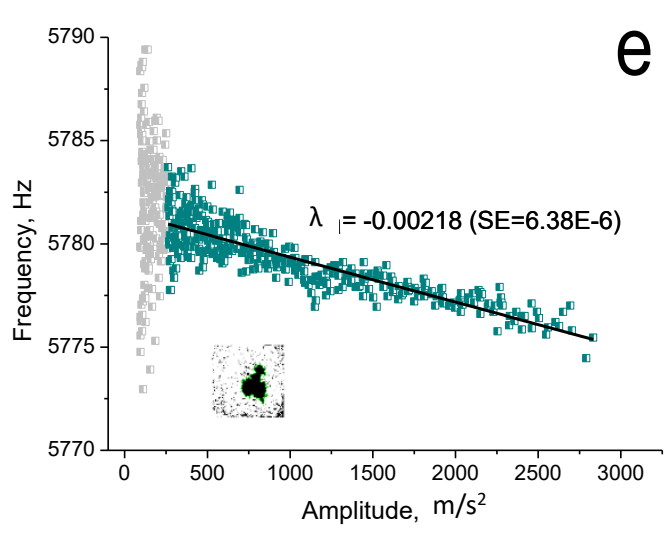

Figure 10-6 Frequency shift observed on ring-down versus spectral amplitude for a) pristine sample -0 days $\lambda=-0.0050\left( \pm 1.41 \cdot 10^{-4}\right)$ (standard error on the estimation of $\lambda$ is shown in parenthesis), b) 28 days $\lambda=-0.0043\left( \pm 1.26 \cdot 10^{-4}\right)$, c) 56 days $\lambda=-0.0026$ $\left.\left( \pm 1.09 \cdot 10^{-4}\right), d\right) 79$ days $\lambda=-0.00219\left( \pm 9.51 \cdot 10^{-5}\right)$, and e) 94 days $\lambda=-0.00218\left( \pm 6.38 \cdot 10^{-6}\right)$; Grey colored symbols represent discarded data.

Figure 10-7 summarizes the linear and nonlinear dynamic phenomena observed for progressive carbonation. At early stages of carbonation (from 0 to 28 days), it is observed that the resonance frequency moderately decreases, and $Q$ and the material nonlinearity remains almost same. The samples, initially at $95 \% \mathrm{RH}$, dry naturally inside the desiccator at $55 \% \mathrm{RH}$, reaching progressively the hydric equilibrium. Variations of the dynamic properties at early stages of carbonation are most likely due to variations of internal moisture content in the material. The material nonlinearity was not sensitive to such moisture reduction in the samples during the first 28 days of carbonation. The values of $\lambda$ remained almost constant during this period. It implies that the features that caused the material nonlinearity are not significantly affected by the moisture loss and slight carbonation during the first 28 days. Once the internal moisture within the samples equilibrated at $55 \% \mathrm{RH}$, the carbonation process progressed at a higher rate. During advanced stages of carbonation, the resonance frequency and $Q$ increased, and the material nonlinearity decreased. During these stages, the modification of the dynamic properties is most likely due to progressive carbon dioxide absorption and formation of calcium carbonate within the pore structure that increases the mechanical stiffness, decreases its compressibility, and also decreases the nonlinearity of the material. No significant differences in material nonlinearity are observed, however, for the carbonation durations between 56 to 94 days. Further carbonation, after 56

\section{$10-14$}


days did not cause significant variations of material nonlinearity but a decrease of material damping (increase of $Q$ ) and still, a slightly increase of the material stiffness (increase of resonant frequency).

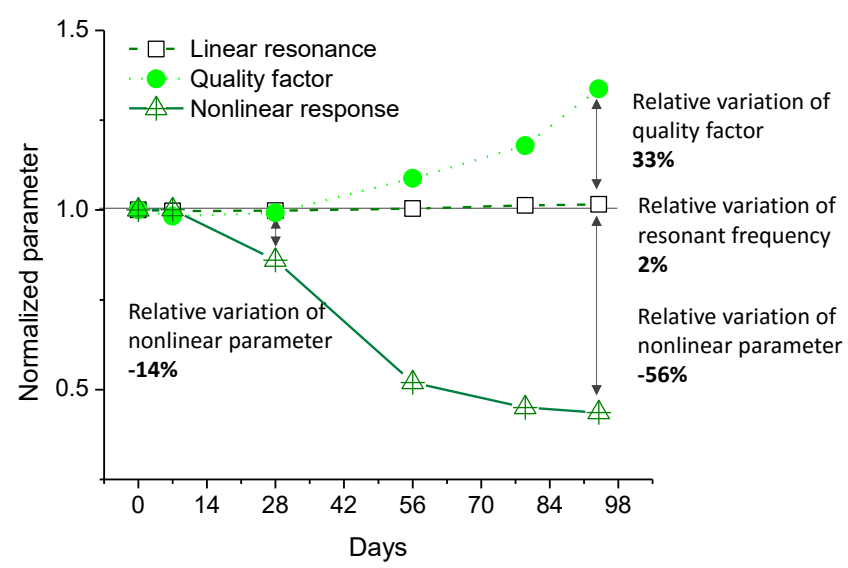

Figure 10-7 Comparison of the evolution of the linear and nonlinear dynamic normalized parameters upon progressive carbonation.

\subsection{Conclusions}

Microstructural changes caused by carbonation in mortar were assessed by linear and nonlinear vibrational response data obtained using the standard resonance frequency test configuration. The three dynamic parameters investigated here exhibited different evolutions with, and sensitivities to, the material changes brought about by carbonation. Both $Q$ and $\lambda$ showed meaningful changes in value with increasing extents of carbonation, although $\lambda$ showed significant changes early in the carbonation process (first 56 days), while $Q$ showed significant changes later (after 56 days). Resonant frequency showed only modest change in value with carbonation. The nondestructive test used here is suitable for laboratory monitoring of test samples because of its ease of use and implementation; in particular $Q$ and $\lambda$ together serve as sensitive measures of material modifications brought about by 
carbonation across all stages of the process. Thus the suitability of the material against carbonation can be deemed in base of the linear and nonlinear dynamic properties in laboratory tests. Further, these findings may also have relevance, more indirectly, for in situ tests with regard to the nature of linear and nonlinear dynamic test data as carbonation progresses. In this sense, the solely observation of the dynamic properties would inform about the mechanical integrity of the samples, since under natural weathering conditions, different degradation mechanisms take place. Therefore, since the variation of the physical properties of the samples is not specifically related to a carbonation process, additional complementary tests would be needed.

\section{References}

ASTM C215-14. (2014). Standard Test Method for Fundamental Transverse , Longitudinal , and Torsional Resonant Frequencies of Concrete.

Basheer, P. A. M., Rankin, G. I. B., Long, A. E., \& Russell, D. (2001). Effect of relative humidity and air permeability on prediction of the rate of carbonation of concrete. Proceedings of the ICE - Structures and Buildings.

Bouchaala, F., Payan, C., Garnier, V., \& Balayssac, J. P. P. (2011). Carbonation assessment in concrete by nonlinear ultrasound. Cement and Concrete Research, 41(5), 557-559.

Eiras, J. N., Monzó, J., Payá, J., Kundu, T., \& Popovics, J. S. (2014). Non-classical nonlinear feature extraction from standard resonance vibration data for damage detection. The Journal of the Acoustical Society of America, 135(2), EL82-EL87.

Eiras, J. N., Popovics, J. S., Borrachero, M. V., Monzó, J., \& Payá, J. (2015). The effects of moisture and micro-structural modifications in drying mortars on vibration-based NDT methods. Construction and Building Materials, 94, 565-571.

EN 196-1. (2005). Methods of testing cement. Part 1: Determination of strength.

Fernández-Carrasco, L., Puertas, F., Blanco-Varela, M. T., \& Vázquez, T. (2001). Carbonation of calcium aluminate cement pastes. Materiales de Construcción.

Hidalgo, A., Domingo, C., Garcia, C., Petit, S., Andrade, C., \& Alonso, C. (2008). Microstructural changes induced in Portland cement-based materials due to natural 
and supercritical carbonation. Journal of Materials Science, 43(9), 3101-3111.

Johannesson, B., \& Utgenannt, P. (2001). Microstructural changes caused by carbonation of cement mortar. Cement and Concrete Research, 31(6), 925-931.

Kim, G., Kim, J.-Y., Kurtis, K. E., Jacobs, L. J., Le Pape, Y., \& Guimaraes, M. (2014) Quantitative evaluation of carbonation in concrete using nonlinear ultrasound. Materials and Structures.

Kobayashi, K., Suzuki, K., \& Uno, Y. (1994). Carbonation of concrete structures and decomposition of C-S-H. Cement and Concrete Research, 24(1), 55-61.

McCafferty, E. (2010). Thermodynamics of Corrosion: Pourbaix Diagrams. Introduction to Corrosion Science, 1, 1-575.

Neville, A. (1981). Elasticity, shrinkage and creep. In Properties of Concrete (3rd ed., pp. 359-432). Harlow Essex, England: Longman Scientific and Technical.

Ngala, V. T., \& Page, C. L. (1997). Effects of carbonation on pores structuer and diffusional properties of hydrated cement pastes. Cement and Concrete Research, 27(7), 9951007.

Papadakis, V. G., Vayenas, C. G., \& Fardis, M. N. (1991). Fundamental Modeling and Experimental Investigation of Concrete Carbonation. ACl Materials Journal, 88(4), 363-373.

Paternoster, R., Brame, R., Mazerolle, P., \& Piquero, A. (1998). Using the correct statistical test for the equality of regression coefficients. Criminology, 36(4), 859-866.

Pham, S. T., \& Prince, W. (2013). Effects of Carbonation on the Microstructure and Macro Physical Properties of Cement Mortar. Journal of Materials Science and Chemical Engineering, 2(7), 40-52.

Rilem Recommandations. (1988). CPC-18 Measurement of hardened concrete carbonation depth. Materials and Structures, 21(6), 453-455.

Rostami, V., Shao, Y., \& Boyd, A. J. (2012, September 23). Carbonation Curing versus Steam Curing for Precast Concrete Production. Journal of Materials in Civil Engineering. American Society of Civil Engineers.

Santos, S. F., Schmidt, R., Almeida, A. E. F. S., Tonoli, G. H. D., \& Savastano, H. (2015). Supercritical carbonation treatment on extruded fibre-cement reinforced with vegetable fibres. Cement and Concrete Composites, 56, 84-94. 
Šauman, Z. (1971). Carbonization of porous concrete and its main binding components. Cement and Concrete Research, 1(6), 645-662.

Short, N. R., Purnell, P., \& Page, C. L. (2001). Preliminary investigations into the supercritical carbonation of cement pastes. Journal of Materials Science, 36(1), 35-41.

Zornoza, E., Garcés, P., Monzó, J., Borrachero, M. V., \& Payá, J. (2009). Accelerated carbonation of cement pastes partially substituted with fluid catalytic cracking catalyst residue (FC3R). Cement and Concrete Composites, 31(2), 134-138. 


\section{Chapter 11. Dynamic acousto-elastic test using continuous probe wave and hammer blow}



Chapter 11. Dynamic acousto-elastic test using continuous probe wave and hammer blow ..........11-1

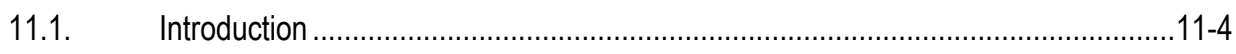

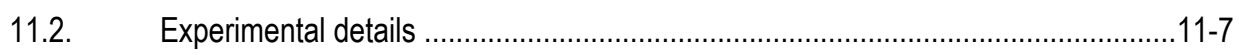

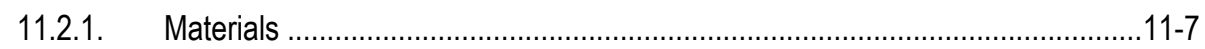

11.2.2. Experimental configuration ......................................................................11-8

11.2.3. Signal processing .........................................................................11-10

11.2.4. Estimation of strain from acceleration response .........................................11-13

11.3. Results and discussion ............................................................................11-15

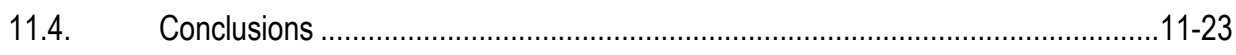

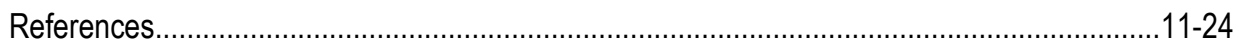




\subsection{Introduction}

Recent research on the application of nonlinear acoustics for the characterization of biological tissues allowed investigation of the whole range of nonlinear phenomena with the technique termed dynamic acousto-elastic test (DAET) (Renaud, Callé, Remenieras, \& Defontaine, 2008). The DAET consists in monitoring the variations of the speed of sound through the material, normally through variations in the time of flight of ultrasonic pulses (probe wave), while a low frequency burst that matches a fundamental resonant mode perturbs the media (pump wave). Assuming that the variations of the speed of sound $(\Delta c)$ with respect to the speed of sound in the linear elastic regime $\left(c_{0}\right)$ are so small that $c \approx c_{0}$, the corresponding relative variations of time of flight $\left(\Delta t / t_{0}\right)$ are approximately related to the material nonlinearity as

$$
\frac{M-M_{o}}{M_{o}} \approx-2 \cdot \frac{\Delta t}{t_{o}} \approx C_{E}(\Delta \varepsilon)+\beta \varepsilon+\delta \varepsilon^{2}+\ldots+U(\varepsilon, \dot{\varepsilon})
$$

where, additional to the quadratic and cubic nonlinear classical parameters ( $\beta$ and $\delta$ ) and strain rate-dependent hysteresis $U(\varepsilon, \dot{\varepsilon})$, the function $C_{E}(\Delta \varepsilon)$ takes into account the material conditioning effect; the apparent mix of slow and fast dynamics (P. Johnson \& Sutin, 2005) which offsets the relation between strain and the relative variation of modulus. In addition, the variations of material attenuation are also derived from the amplitude variation of the ultrasonic pulses over the low frequency burst excitation (Renaud et al., 2008; Renaud, Le Bas, \& Johnson, 2012; J. Rivière, Renaud, Guyer, \& Johnson, 2013) as

$$
\bar{\alpha}-\bar{\alpha}_{o} \approx C_{D}(\Delta \varepsilon)+\beta_{D} \varepsilon+\delta_{D} \varepsilon^{2}+\ldots+U_{D}(\varepsilon, \dot{\varepsilon})
$$

where $\bar{\alpha}$ is the ultrasonic attenuation and $\bar{\alpha}_{o}$ is the ultrasonic attenuation at linear strain regime. The variations of the ultrasonic attenuation exhibit similar behavior to that shown for the variations of modulus (Eq. 11-1). Therefore, in a similar way, the amplitude modulation can be expressed including higher order terms of strain $\left(\beta_{D}\right.$ and $\left.\delta_{D}\right)$ and functions describing 
the phase lag between the variation of attenuation and strain $(U(\varepsilon, \dot{\varepsilon}))$ and material conditioning . All these terms are denoted with subscript $D$.

Two conditions must be accomplished in DAET experiments. First, the time of flight $\left(t_{0}\right)$ of the ultrasonic probe wave must be less than 1/10 times the value of the low frequency excitation (J. Rivière et al., 2013). In this way, the instantaneous variations of time of flight can be precisely related to the strain amplitude of the pump wave excitation. Second, the repetition rate of the ultrasonic pulse generator has to be set so that the ultrasonic wave is completely attenuated between pulses. Therefore, the succeeding ultrasonic pulses are not affected by the coda wave of the preceding ones (Renaud et al., 2008, 2012; J. Rivière et al., 2013). In consequence of the last, the variations of time of flight and amplitude are obtained for few values of strain in several cycles of the low frequency burst (constant strain amplitude excitation). Therefore, the test has to be repeated after changing the phase of the ultrasonic pulse generator to obtain more experimental data and describe properly such variations over the whole strain range excitation -see also Chapter 1 - These drawbacks make unpractical to leverage the potential of DAET in structural health monitoring applications, and complicates the use of ambient vibrations and transient events (variable strain amplitude excitation) to monitor passively the dynamic properties of structures (Paultre, Proulx, \& Talbot, 1995; Yang, Lin, \& Yau, 2004), or in on-site assessment of structures. Previous attempts were made by using a hammer blow and ultrasonic pulses (Bui, Kodjo, Rivard, \& Fournier, 2013). In these cases, given that the strain amplitude is variable over time, the measurement of the material nonlinearity underlies on the maximum lag produced by the transient load (maximum time shift). This application was later on devised for structural health application. Figure 11-1 illustrates an application of wherein traffic loads are intended to be used as pump wave excitation (Moradi-Marani, Kodjo, Rivard, \& Lamarche, 2012). 

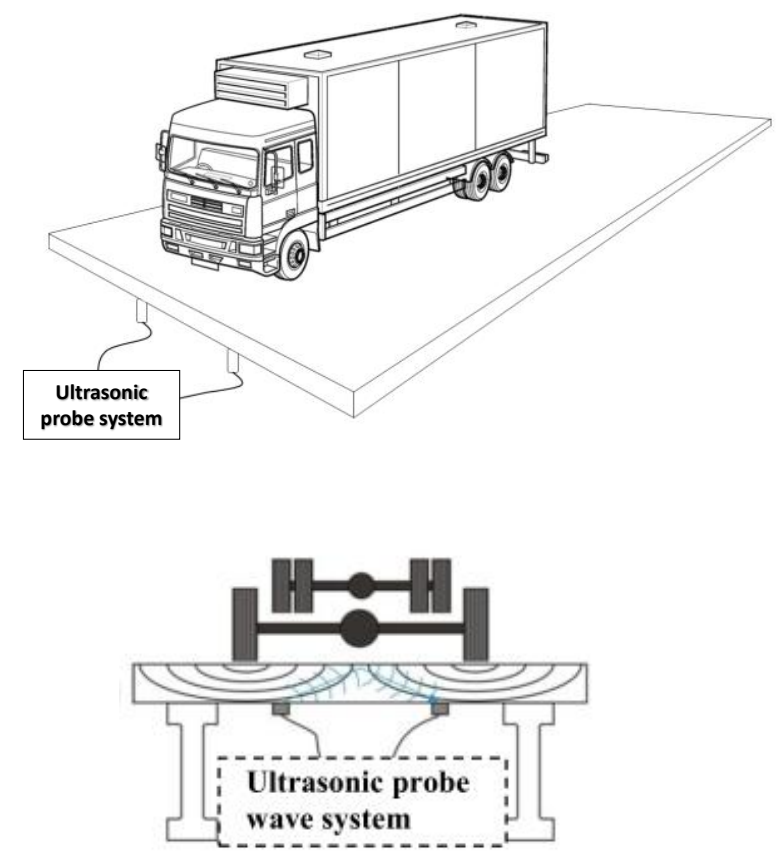

Figure 11-1 Schematic representation of passive structural health monitoring using the load of a passing vehicle as source of the pump wave excitation. Adapted from (Moradi-Marani et al., 2012)

In this chapter, a DAET is conducted by modulating a continuous sinusoidal high frequency probe that propagates through the material. The modulation of the signal is achieved by a hammer blow configured to promote the first bending mode of vibration of the sample. Unlike previous DAET configurations (Renaud et al., 2012; Renaud, Rivière, Haupert, \& Laugier, 2013; Renaud, Rivière, Le Bas, \& Johnson, 2013; J. Rivière et al., 2013; Jacques Rivière, Shokouhi, Guyer, \& Johnson, 2015), the continuous sine wave excitation allows investigation of the discrete time variation of material nonlinearity over only one low frequency cycle. Therefore, the variations of modulus can be investigated during the ring down of the mechanical energy introduced by a hammer blow. Recently, Fröjd and Ulriksen (Fröjd \& Ulriksen, 2016) pointed out the potential of using continuous wave excitation in structural health monitoring applications. In particular, the signal transmission is enhanced when compared to the propagation of ultrasonic pulses. However, the analysis of the signal 
underlies on phase changes of the probe wave as an indication of change of velocity in the medium. Herein, the dynamic acousto-elastic effect on continuous waves is investigated through a short-time Fourier transform based approach. The signal analysis is based on extracting the phase and amplitude variations by the simultaneous comparison between a reference (non-modulated) and an impact-modulated signal. Such data analysis overcomes the inconvenience of changing the phase of the high frequency probe (in case of ultrasonic pulses) in consecutive experiments, to discretize the variations of material nonlinearity over the whole range of strain excitation. Otherwise, when a hammer blow is used as low frequency source and ultrasonic pulses as probe wave (Bui et al., 2013; Moradi-Marani, Kodjo, Rivard, \& Lamarche, 2014), the only measurable parameter is the maximum offset of the normalized time shift $\left(\Delta t / t_{0}\right)$, since the strain amplitude is variable over time. Conversely, the parameters extracted herein show similarity with the nonlinear acoustic behavior derived from Eq.4, and previously observed in compressional mode DAET experiments (Renaud et al., 2012; J. Rivière et al., 2013; Jacques Rivière et al., 2015). These are: 1) an offset of the material modulus upon low frequency excitation, 2) a phase delay between the onset of the strain amplitude and the relative variations of modulus, and 3) an incomplete recovery of the dynamic properties of the material when the strain energy of the low frequency signal is completely damped.

\subsection{Experimental details}

\subsubsection{Materials}

The approach was demonstrated on a concrete sample measuring $15 \times 15 \times 60 \mathrm{~cm}^{3}$. The composition of concrete is listed in Table 11-1. At the moment of test, the concrete sample was fully matured. For reference, the compressional and shear wave velocities were determined using direct transmission of an ultrasonic pulse, along the straight-line path respect to the sample width. For compressional wave velocity measurement, two ultrasonic transducers GE-Measurement \& Control (model G 0,25 G code 67422, central frequency of 
$250 \mathrm{kHz}$ ) were used. For shear wave velocity measurement, two transducers PanametricsNDT (model V151, central frequency of $250 \mathrm{kHz}$ ) were used. The compressional and shear wave velocities were $4056 \mathrm{~m} / \mathrm{s}$ and $2483 \mathrm{~m} / \mathrm{s}$. The density of the sample was $\rho=2350 \mathrm{~kg} / \mathrm{m}^{3}$; thus $M_{0}=37.8 \mathrm{GPa}$, and Poisson's ratio $v=0.20$.

Table 11-1 Mix design of concrete and properties (Audrey Quiviger, 2012).

\begin{tabular}{|lr|}
\hline Cement CEM I/52.5N $\left(\mathrm{kg} / \mathrm{m}^{3}\right)$ & 370 \\
\hline Water $\left(1 / \mathrm{m}^{3}\right)$ & 212 \\
\hline Fine aggregates $0 / 4\left(\mathrm{~kg} / \mathrm{m}^{3}\right)$ & 774 \\
\hline Coarse aggregates $4 / 14\left(\mathrm{~kg} / \mathrm{m}^{3}\right)$ & 1069 \\
\hline Compressive strength at 28 days $(\mathrm{MPa})$ & 53 \\
\hline
\end{tabular}

\subsubsection{Experimental configuration}

Figure 11-2 shows a schematic diagram of the experimental configuration. Two ultrasonic transducers (Panametrics-NDT model V101, central frequency of $500 \mathrm{kHz}$ ) were placed on the sample at its middle span with a distance $(d)$ between them, center to center of $10 \mathrm{~cm}$. A continuous sinusoidal high frequency probe $\left(f_{u}=500 \mathrm{kHz}\right)$ was modulated by a hammer blow, while an accelerometer (Bruel \& Kjaer model 4525B, sensitivity of 1.046

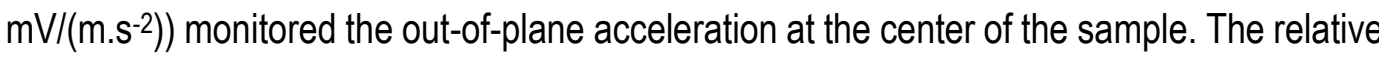
position between impact and accelerometer was configured to promote the first bending mode of vibration. The strain amplitude owed to the first bending mode of vibration was derived from the accelerometer response - see section 11-13 - An instrumented hammer (Bruel \& Kjaer model 8207 , sensitivity of $0.230 \mathrm{mV} / \mathrm{N}$ ) with a polymeric tip was used to perform the measurements. Five different energy impacts were conducted (between $1 \mathrm{kN}$ to $5 \mathrm{kN}$ ), and the time lapse between different acquisitions was set at one minute. For the measurement of the cracked samples, the relative position of the crack was configured to facing the floor and facing one side. 


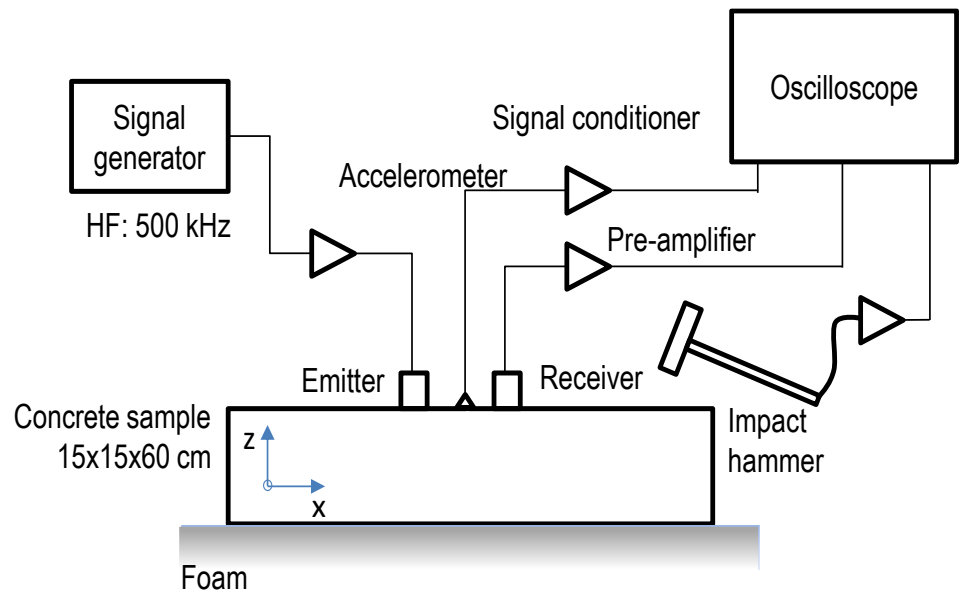

Figure 11-2 Schematic representation of the experimental setup.

A continuous wave source is expected to produce a steady-state diffuse field which consists of direct propagation, scattered waves, and reflections from the boundaries of the concrete sample (Fröjd \& Ulriksen, 2016). In this study, the frequency of the continuous ultrasonic probe was set to $500 \mathrm{kHz}$. At such a frequency, multiple scattering effects occur in concrete and a strong attenuation of the energy in every direction is produced (Larose et al., 2006; A. Quiviger, Payan, Chaix, Garnier, \& Salin, 2012). Thus, the resulted field is mainly dominated by direct propagation, but reflection contributions from sample boundaries are dramatically minimized. For reference, the amplitude of the continuous wave excitation in a through-thickness continuous wave measurement was reduced more than $80 \%$ that obtained by using the original test configuration (as shown in Figure 11-2). Therefore, the reflected energy recorded by the receiver in the original position is not a significant contribution to the total received energy. The continuous wave is then perturbed by a hammer blow and as a result, the amplitude and phase of the continuous probe are modulated because of the material nonlinearity. The signal processing consists of a sliding window that simultaneously transforms the time segment of the reference $\left(y_{r}\right)$-in absence of hammer blow - and perturbed $\left(y_{p}\right)$ signals, and computes the relative time shift and amplitude variations between them. 
The distance between the transducers has to be set, so that the instantaneous variations of phase and amplitude can be precisely related to the strain values derived from the acceleration response. Despite, any specific bulk wave can be attributed to a continuous wave excitation, the time of flight obtained for compressional wave was used to meet this requirement. To this end, the distance between the transducers was set to $d=10 \mathrm{~cm}$. Then, indirect propagation (as shown in Figure 11-2) of five cycles at $500 \mathrm{kHz}$ provided a time of flight of $t_{0}=26.8 \mu \mathrm{s}$ (p-wave arrival). Such a value ensured that the instantaneous variations of amplitude and phase correspond to less than 1/10 times the period of the low frequency excitation (J. Rivière et al., 2013). On other hand, it can be noticed that the value of $t_{0}$ was significantly lower than that obtained using direct transmission (see section 11.2.1 Materials). This effect is most likely due to the different material properties in the near-surface regions with respect to the inner core of the concrete samples (Naik \& Popovics, 2004; Turgut \& Kucuk, 2006).

\subsubsection{Signal processing}

The out-of-plane particle displacement because of the continuous monochromatic probe wave before a hammer blow excitation $\left(y_{r}(t)\right)$ can be written as

$$
y_{r}(t)=B \cdot \sin \left(\omega_{r} \cdot t\right) \cdot e^{-\gamma_{r} \cdot d}+\Psi_{r}(t)
$$

where $B$ is the amplitude of the signal, $\omega_{r}$ is the angular frequency of the probe, $\gamma_{r}$ is the ultrasonic attenuation, and $\Psi_{r}(t)$ is a function containing the non-coherent information of the multiple scatters recorded on propagation from the emitter to the receiver. Subscript $r$ stands for "reference", whereby the ultrasonic probe is assumed to propagate through the medium in the linear elastic regime. Namely, in absence of hammer blow. The high frequency probe $y_{r}(t)$ is then perturbed by a hammer blow. As a result of the presence of contact-like defects within the imperfect microstructure of concrete, the modulus of the material varies upon compression and tension cycles induced by the pump wave excitation (Donskoy, Sutin, \& 
Ekimov, 2001). Then, the phase and amplitude of the probe wave signal are modulated. The resulting impact-modulated signal $y_{p}(t)$ can be written as

$$
y_{p}(t)=B \cdot \sin \left(\omega_{r} \cdot t+\Omega(t)\right) \cdot e^{-\left(\gamma_{r}+\Gamma(t)\right) \cdot d}+\Psi_{p}(t)
$$

The functions $\Omega(t)$ and $\Gamma(t)$ are the phase and amplitude modulation contributions. Both functions must consider the periodic variations of phase and attenuation, as well as the instantaneous offsets produced with the onset of the strain amplitude. Phase and amplitude modulation manifest as sideband peaks with respect to the frequency of the probe wave, when the whole modulated probe signal is transformed to the frequency domain. The relative energy of the sideband components, with respect to the energy of the probe wave, has been used as a measurement of material nonlinearity (Donskoy et al., 2001; K. E. Van Den Abeele, Sutin, Carmeliet, \& Johnson, 2001). However, a more detailed description is proposed herein. The variation of material modulus because of the presence of contact-like defects can be quantified through the instantaneous phase difference of the impact-modulated probe (Eq. 11-3) with respect the reference (Eq. 11-4). The resulting instantaneous phase difference between both signals is the function $\Omega(t)$. To this end, a sliding window moves through the time domain signals of the probe waves (Eqs. 11-3 and 11-4) and transforms the time segments within the window to the frequency domain. At every windowed time segment $(\tau)$, the time shift $(\Delta t)$ between perturbed and reference signals is obtained from their spectral phases $\left(\Phi_{p}(\omega)\right.$ and $\left.\Phi_{r}(\omega)\right)$ at the probe frequency $\left(\omega_{r}\right)$ as

$$
\frac{\left.\Delta t\right|_{\tau}}{t_{0}}=\frac{\left.\phi_{p}(\omega)\right|_{\omega_{r}}-\left.\phi_{r}(\omega)\right|_{\omega_{r}}}{t_{0} \cdot \omega_{r}}
$$

A continuous probe wave lacks a clear wave path, and it does not allow extraction of phase velocity. It is then assumed that the time shift variations between reference and modulated signals are related to the variations of modulus. Therefore, the relative time shift modulation 
obtained from Eq. 11-5 provides insight into the relative variation of the modulus as deduced in Eq. 11-1. A normalization of the time shift $(\Delta t)$ by $t_{0}$ is still needed, especially when different materials are to be compared (Moradi-Marani et al., 2014). The time of flight obtained for indirect propagation of 5 cycles at $500 \mathrm{kHz}$ was selected as the reference value ( $t_{0}=26.8 \mu \mathrm{s}$ ). In addition, at every window position, the variation of the attenuation properties between reference and impact-modulated probe can be considered as (Renaud et al., 2012)

$\gamma_{p}-\left.\gamma_{r}\right|_{\tau}=-\ln \left(\frac{\left|F_{p}(\omega)\right|_{\omega_{r}}}{\left|F_{r}(\omega)\right|_{\omega_{r}}}\right) / d$

where $\left|F_{r}(\omega)\right|$ and $\left|F_{p}(\omega)\right|$ stand for the spectral amplitude at the probe frequency $\omega_{r}$, corresponding to the windowed time segment $\tau$ of the signals $y_{r}(t)$ and $y_{p}(t)$. The instantaneous variations of attenuation are $\Gamma(t)$, since $\gamma_{p}(t)=\gamma_{r}(t)+\Gamma(t)$.

Overall, the signal processing consists in a sliding window that simultaneously transforms the time segment of the reference $\left(y_{r}\right)$ and perturbed $\left(y_{p}\right)$ signals, and computes the relative time shift and amplitude variations between them. Then, time shift and amplitude variations are related to the in-plane strain averaged over the length of every window, which is derived from the accelerometer response (see section 11.2.4). Figure 11-3a-f shows typical recorded signals and a schematic representation of the signal processing. Herein, the window length was set to five cycles of the high frequency probe that corresponds to 1/69 times the resonant frequency corresponding to the first bending mode of vibration. Such a window length provides an almost constant value of acceleration (see Figure 11-3b). Then, time shift and amplitude variations can be precisely related to the in-plane strain which is derived from the accelerometer response. Figures 11-3d and 11-3f compare a time segment of $y_{r}$ and $y_{p}$, before and after an impact event. Before the impact event, the phase differences between the signals $y_{r}$ and $y_{p}$ are close to zero (Figure 2e), whereas they become evident after the hammer blow (Figures 11-3f). 

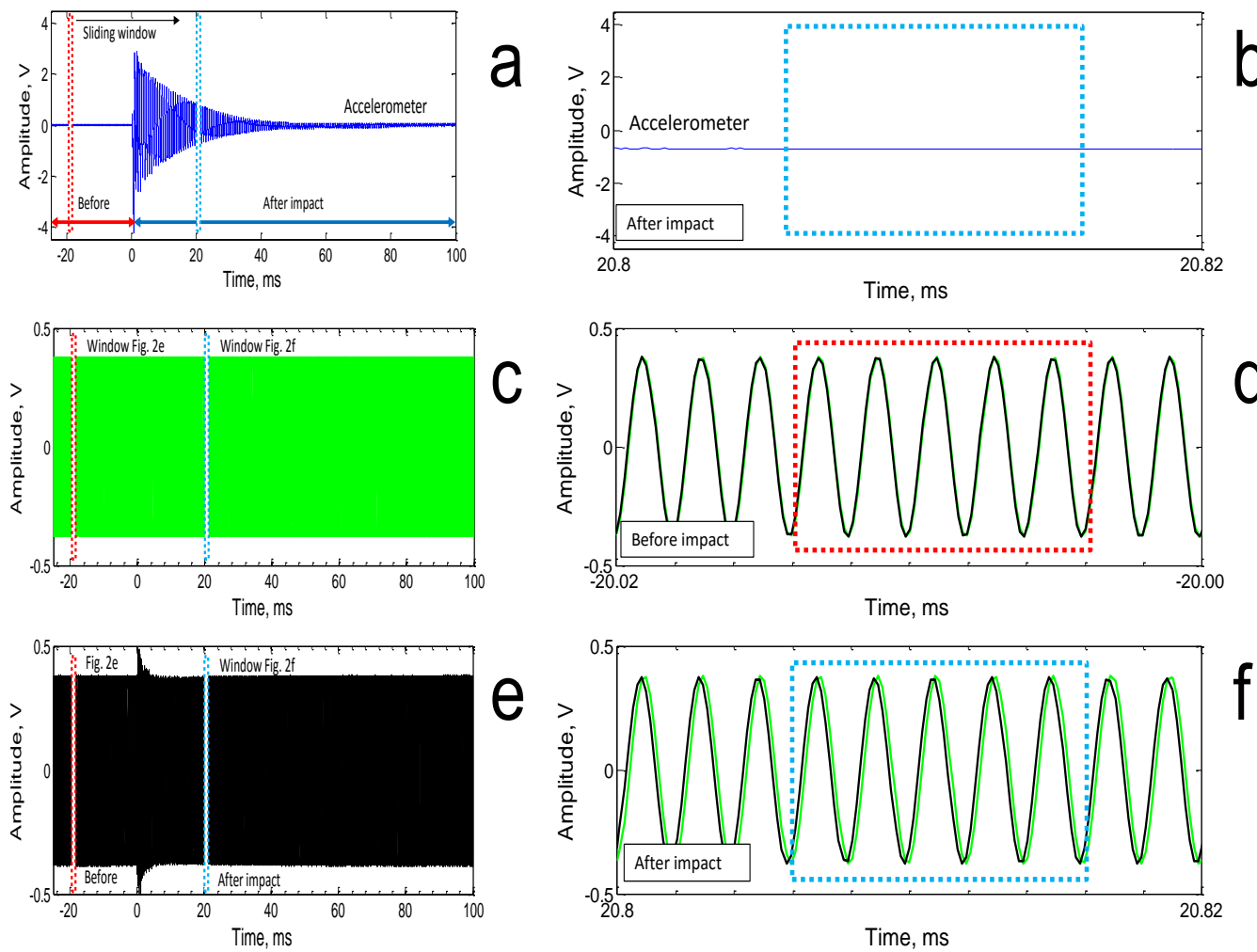

Figure 11-3 Typical time domain signals and schematic representation of the signal processing: a) signal recorded by the accelerometer, b) a time segment of the acceleration signal after the hammer blow; it shows an almost constant value of acceleration (and hence strain) within the length of the window $(10 \mu s), c)$ ultrasonic monochromatic reference signal, d) a time segment of the ultrasonic probes $y_{r}$ and $y_{p}$ before the hammer blow (the window is shown in red), e) impact-modulated ultrasonic signal $\left.\left(y_{p}\right), f\right)$ a time segment the ultrasonic probes $y_{r}$ and $y_{p}$ after impact (the window is shown in blue).

\subsubsection{Estimation of strain from acceleration response}

Different resonant modes are generated upon hammer blow excitation. For reference, the frequency domain spectra for the five hammer blows are represented in Figure 11-4. The broadband excitation generated upon a hammer blow ranges from 0 to nearly $2 \mathrm{kHz}$. A numerical eigen-frequency analysis of linear isotropic material, and for the specific sample 
the geometry and material properties of the concrete sample $-M o, v$ and $\rho$, see section 11.2.1 Materials - leads to the first bending mode occurring at $1449 \mathrm{~Hz}$, the first torsional mode at $1981 \mathrm{~Hz}$, the second bending mode at $3249 \mathrm{~Hz}$, and the longitudinal mode at 3335 $\mathrm{Hz}$. For the given impact point and frequency band generated, only the first bending mode (1442 Hz obtained experimentally) contributes to the strain field, and other fundamental and higher order modes will not be excited (Figure 11-4).

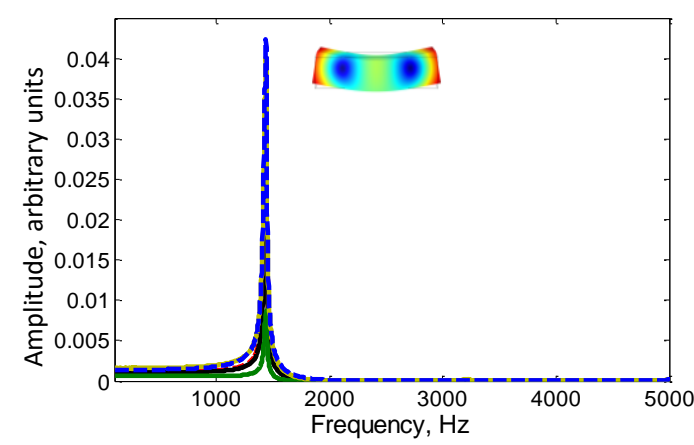

Figure 11-4 Frequency spectra from acceleration signals. Inset figure show the mode shape obtained by the numerical eigen-frequency analysis.

From the acceleration response, the dynamic strain on the outermost fiber of the beam owed to the first bending mode of vibration can be derived from the solution of the EulerBernouilli beam equation (Hunt, 1960). However, the assumptions of the Euler-Bernouilli beam theory do not apply in the case of short beams (Gerandin \& Rixen, n.d.). Alternatively, Payan and colleagues (Payan, Ulrich, Le Bas, Saleh, \& Guimaraes, 2014) proposed deriving the strain from a numerical finite element model (FEM), relating the out-of-plane acceleration $\left(a_{z z}\right)$ to the in-plane strain $\left(\varepsilon_{x x}\right)$, in this case those owed to the first bending mode of vibration, as

$$
\varepsilon_{x x}=\frac{K \cdot \varepsilon_{\text {num }}}{K \cdot a_{z z \text { num }}} \cdot a_{z z \exp }
$$

where $K$ is an amplification factor used by the FEM software to display relative values of strain and acceleration in the solution of free boundary conditions. The factor $K$ is then 
divided out, $\varepsilon_{n u m}$ and $a_{z z, n u m}$ are the in-plane strain and out-of-plane acceleration obtained in the eigen-frequency analysis; $a_{z z, \text { exp }}$ is the out-of-plane acceleration obtained experimentally. In the following, negative strains are adopted for compression stresses.

\subsection{Results and discussion}

Figure 11-5a-f shows representative results of the relative variations of time shift and the variation of signal amplitude as the mechanical energy input naturally decreases. The results reveal a sudden softening of the material produced after a hammer blow, which manifests as a decrease of material modulus and an increase of attenuation (decrease of signal amplitude). The instantaneous variations of both extracted signals - derived from Eqs. 11-5 and 11-6, and shown in Figures 11-5a and 11-5b- are mainly driven by the first resonant bending mode of the sample, and harmonics at twice the fundamental resonance frequency (Figure 11-5c and 11-5d). Simultaneously, the signals are instantaneously offset because of the non-classical contributions: the fast and slow hysteretic motions. For better understanding of the classical and non-classical contributions, the signals were decomposed, to untangle the effect of material conditioning from the relative variation of time shift and the variation of attenuation properties: $C_{E}$ and $C_{D}$ respectively. Such decomposition can be attained by applying a low pass filter to the resulting time shift and amplitude variation signals (J. Rivière et al., 2013). Herein, the cutoff frequency was set to $1 / 3$ of the low frequency excitation. The instantaneous offsets $\left(C_{E}(t)\right.$ and $\left.C_{D}(t)\right)$ were then subtracted from the whole time shift and amplitude variation curves. Such decomposition allows one to analyze separately the relaxation kernel (material conditioning) after a hammer blow, and the instantaneous modification of the classical material nonlinearity $(\beta$ and $\delta)$ with decreasing strain amplitude $(\Delta \varepsilon)$. Once the relaxation kernels (the instantaneous offsets $C_{E}$ and $C_{D}$ ) of the signals have been untangled, the resulting mean-centered variations of the time shift signal include the low frequency excitation ( $h=1)$, and $H$ harmonics (see Figure $11-5 c$ ). The resulting signal can be described as

\section{$11-15$}


$-2 \cdot \frac{\Delta t}{t_{0}}(t)-C_{E}(t)=\sum_{h=1}^{h=H} A_{p} e^{i h \omega_{M} \cdot t+\xi_{h} \cdot t}$

where $A_{p}$ is the amplitude of the signal corresponding to the harmonic $h$; the variable $\xi_{h}$ takes into account the decaying energy for every harmonic $h$ of the relative variation of modulus as the strain naturally decreases (see inset plot in Figure 11-5d). On other hand, the strain owed to the first bending mode resonant frequency $\left(\omega_{M}\right)$ can be described as

$$
\varepsilon_{x x}(t)=S_{1} \cdot e^{i \omega_{M} \cdot t+\xi_{M} \cdot t}
$$

where $S_{1}$ is the amplitude of the strain signal, and $\xi_{M}$ is the modal damping ratio. For simplicity, Eq. 11-8 and Eq. 11-9 do not consider time-dependent frequency and attenuation behavior, which are normally observed during the ring down of the signals in concrete (Dahlén, Ryden, \& Jakobsson, 2015; Eiras, Monzó, Payá, Kundu, \& Popovics, 2014). After substituting Eq. 11-8 and Eq. 11-9 into Eq. 11-1, a relative quantification of the classical higher order terms can be obtained as $\beta^{\prime}=A_{1} / S_{1}$ and $\delta^{\prime}=A_{2} / S_{1}{ }^{2}$. Herein, the amplitudes $A_{1}$, $A_{2}$, and $S_{1}$ were estimated using a sliding window that computes the spectral amplitude over ten cycles of their corresponding signals (Figure 11-5c and 11-5d). Therefore, these amplitudes are weighted averaged values obtained through a Fourier transform. The obtained values are $\beta^{\prime}=-300$ and $\delta^{\prime}=-7.4 \cdot 10^{7}$, within the strain amplitudes of $S_{1}=3 \cdot 10^{-6}$ and $1 \cdot 10^{-6}$. Such analysis leads to similar values of $\beta^{\prime}$ and $\delta^{\prime}$ and $C_{E}$ obtained through a second order polynomial fit of the relation between the relative time shift (as $-2 \cdot \Delta t / t_{0}$ ) and strain (see polynomial fit in Figure 11-5e). The main drawback of the polynomial fit method (Renaud et al., 2012; Renaud, Rivière, Haupert, et al., 2013; Renaud, Rivière, Le Bas, et al., 2013; Jacques Rivière et al., 2015) is the lack of fit of the second order polynomial to the typical bow-tie fashion observed in DAET experiments (see Figure 11-5e). Therefore, a Fourier analysis can be preferred. Conversely, the amplitudes $A_{1}, A_{2}$ and $S_{1}$ obtained from the Fourier analysis of transient response signals are weighted averaged values of the actual amplitude, which can result in an underestimation of the actual amplitudes. 
Normally, the relation between time shift variations and strain resembles a bow tie, and likewise for the attenuation variations, since both signals are delayed in phase with respect to the strain signal (Figures 11-5e and 11-5f). Such phase delay depends on the storage and loss modulus of the material, namely the relation between the real and imaginary parts of the frequency domain signals (Trarieux, Callé, Moreschi, Renaud, \& Defontaine, 2014), as well as on the hysteretic contribution $U(\varepsilon, \dot{\varepsilon})$. Further, by integrating the relation between the relative variations of modulus with strain, the stress-strain relationship can be obtained as

$$
\sigma(\varepsilon)=\sigma_{L}(\varepsilon)+\sigma_{N L}(\varepsilon)=M_{o} \cdot \varepsilon+M_{o} \int \frac{\Delta M}{M_{o}} \cdot d \varepsilon
$$

Eq. $11-10$

where $\sigma_{L}$ and $\sigma_{N L}$ are the linear and nonlinear contributions to the stress-strain relationship. However, because of the relative characteristic of the measure of material nonlinearity conducted herein, the nonlinear stress-strain counterpart can be quantified as

$$
\sigma_{N L}^{\prime}(\varepsilon)=\int-2 \cdot \frac{\Delta t}{t_{0}} \cdot d \varepsilon
$$

where the nonlinear stress counterpart $\sigma_{N L}$ is proportional to $\sigma_{N L}^{\prime}$ (results shown in Figure $11-5 \mathrm{~g})$. On other hand, the energy dissipated $(\Delta E)$ during a hysteretic stress-strain cycle because of internal friction can be quantified as (Kolsky, 1963)

$$
\frac{\Delta E}{E_{o}}=\frac{\int \sigma_{N L} \cdot d \varepsilon}{M_{o} \varepsilon^{2}}
$$

where $E_{0}$ is the elastic energy stored in the specimen when the strain is a maximum. The results obtained from the analysis conducted through Eqs. 11-11 and 11-12 show how the hysteretic behavior progressively vanishes, as a measure that the strain amplitude 
decreases. As a result, the energy dissipated in every cycle (Figure 11-5h) decreases with decreasing strain amplitude.
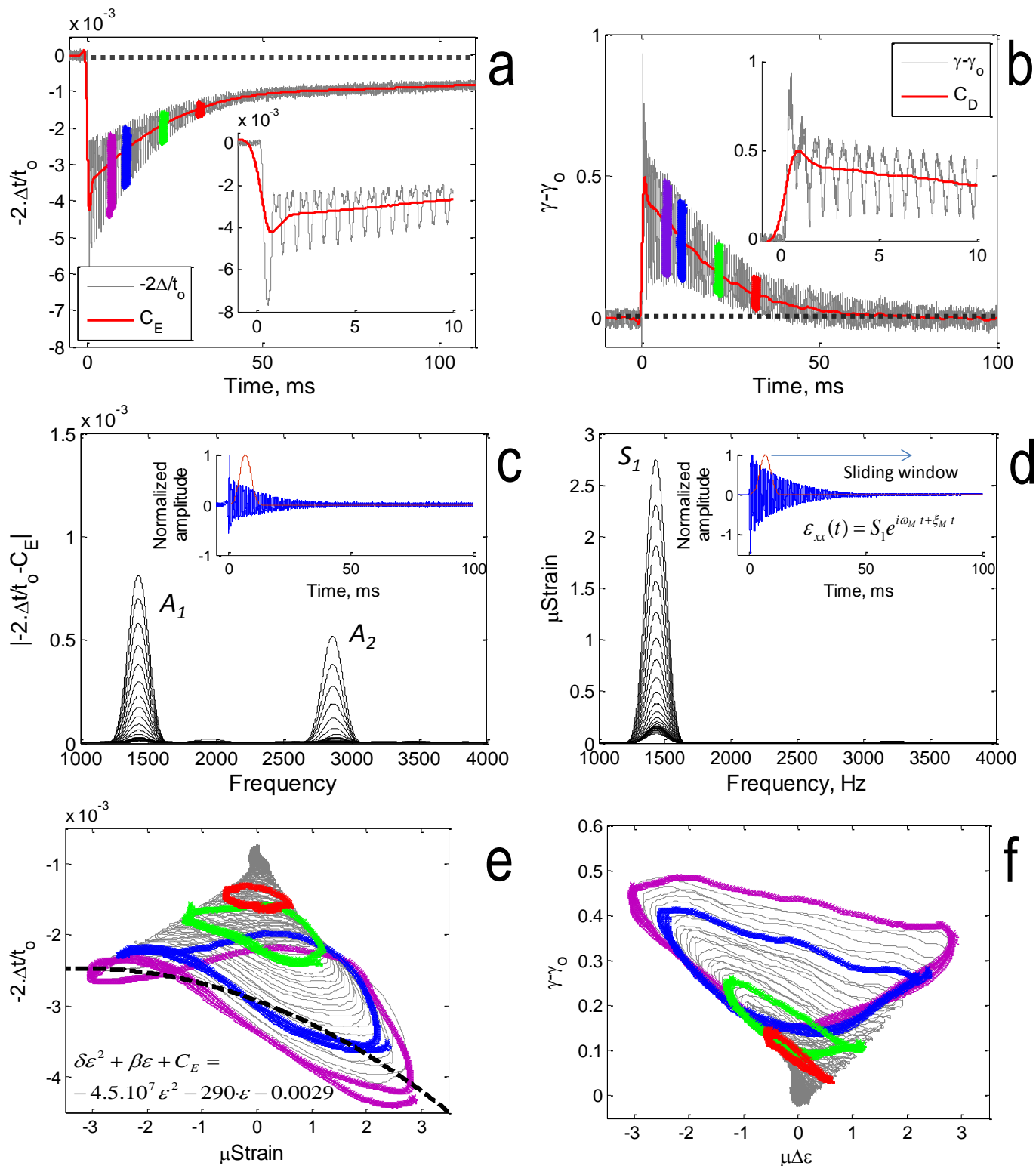

e

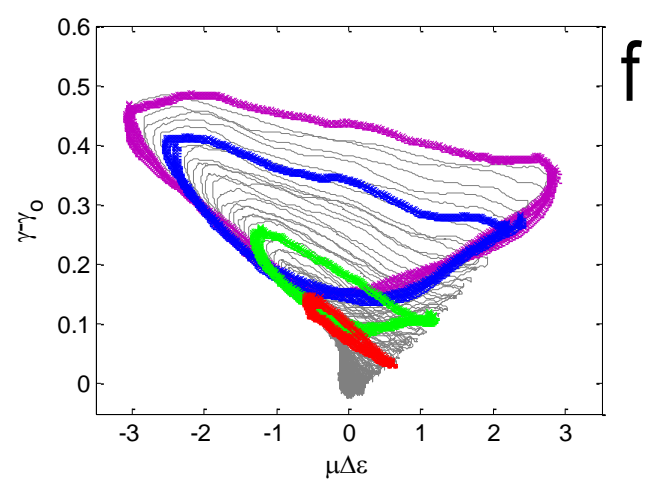



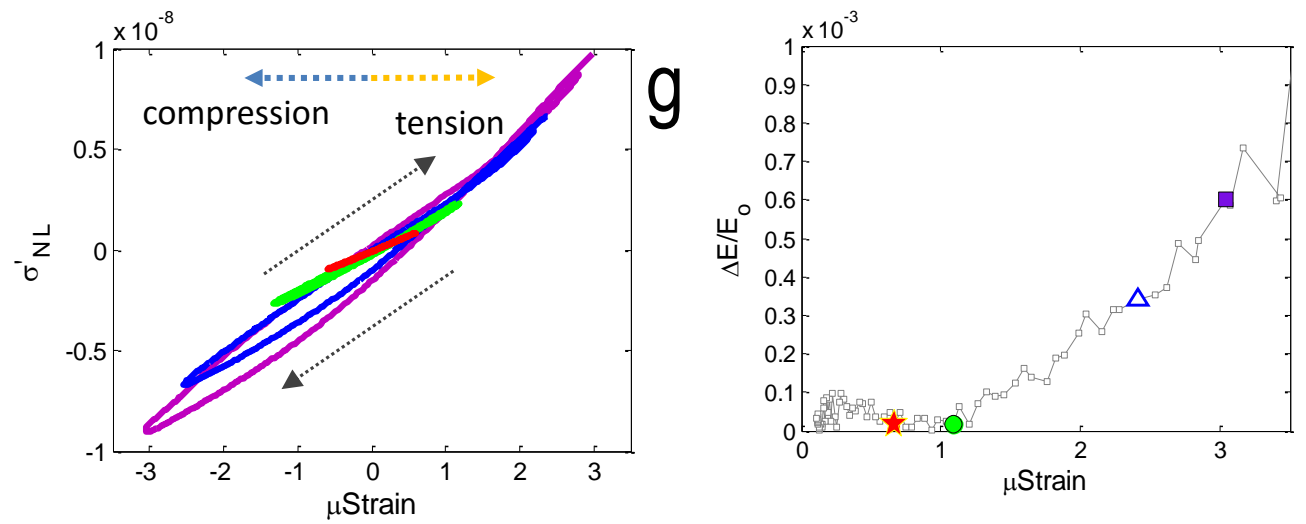

h

Figure 11-5. Dynamic properties extracted for a single impact (force $=4.7 \mathrm{kN})$ : a) relative variation of time shift as a function of time; inset plot shows the cyclic response whose frequency matches the first bending mode of vibration, b) relative variations of time shift as a function of strain; dashed line shows a second order polynomial fit as $-2 \cdot \Delta t / t_{o}=\delta^{\prime} \cdot \varepsilon^{2}+\beta^{\prime} \cdot \varepsilon+C_{E}$, c) variation of ultrasonic attenuation with time, d) variation of ultrasonic attenuation as a function of strain, e) untangled mean-centered variations of the relative variations of time shift in frequency domain, and analyzed in short windows of 10 cycles; inset plot shows the corresponding time domain signal and the sliding window, f) strain signal in frequency domain, g) relative nonlinear stress ( $\left.\sigma^{\prime}{ }_{N L}\right)$-strain relationship, and $h$ ) specific loss as a consequence of the hysteretic behavior. Dashed lines in a) and c) show that the recovery of the modulus takes a longer time than that found for the variation of the ultrasonic attenuation.

When the material is investigated at different impact energies, the same behavior as presented in Figure 11-5 is consistently reproduced. However, the more energy is introduced by the hammer blow, the more the material modulus and attenuation are offset. Figure 11-6a and 11-6b show the maximum offset of the relaxation kernels $\left(C_{E, \min }\right.$ and $C_{D, \max }$, shown as square symbols), and the behavior of $C_{E}$ and $C_{D}$ as a function of the strain amplitude during the ring down. As regards the elastic softening of the material, it is observed that the minimum value of $C_{E}$ at every impact exhibits an inverse proportionality to the attained strain amplitude as

$$
\min \left\{C_{E}(\Delta \varepsilon)\right\}=\alpha_{C E} \cdot \Delta \varepsilon \text {, }
$$


which leads to a value of $\alpha_{C E}=-800$. This approach is in fact equivalent to the nonlinear resonance spectroscopy-based techniques -those based in measuring $\Delta f / f_{0}=\alpha^{*} \Delta \varepsilon$ (K. E.A. Van Den Abeele, Carmeliet, Ten Cate, \& Johnson, 2000)-, since the variable $C_{E}$ represents the time-averaged relative variations of modulus $\left(\Delta M / M_{0}\right)$, as shown in previous studies (Renaud, Rivière, Haupert, et al., 2013). However, the behavior of $C_{E}(\Delta \varepsilon)$ and $C_{D}(\Delta \varepsilon)$ observed during ring down differs from the simple observation of their maximum absolute offsets (Eq. 11-15 and Figures 11-6a and 11-6b), most likely because of the contribution of the slow dynamic effect. Similar results were anticipated by Van Damme and Van Den Abeele (Van Damme \& Van Den Abeele, 2014) in the investigation of fatigue damage in carbon fiber-reinforced polymer plates. In that study, the dependence between resonant frequency and strain amplitude followed different trends when the material nonlinearity was investigated at increasing excitation amplitudes, and when it was investigated through the upward frequency recovery observed during the ring down of the sample (see Figure 3 in (Van Damme \& Van Den Abeele, 2014). These findings suggest that the relaxation of the elastic properties after a nonlinear dynamic excitation is the result of the coupled mechanisms of fast and slow hysteretic motions. Therefore, the instantaneous variations of the resonant frequency during the ring down of the sample are a consequence of the attained strain amplitude at every impact, as well as of the past history load (Scalerandi, Gliozzi, Bruno, \& Antonaci, 2010).

Fast motion hysteresis is thought to be driven by the recovery of asperities that are eventually broken during the strain field generated on resonance of the sample. On other hand, a different volume of asperities remains in metastable equilibrium once the dynamic excitation vanishes, and will return to the initial state because of thermal fluctuations (Lebedev \& Ostrovsky, 2014) and other mechanisms not yet established (P. A. Johnson, 2006) which takes place on a longer timescale (slow dynamics). Since the two mechanisms seem to coexist during a dynamic excitation (P. Johnson \& Sutin, 2005), the elastic softening $C_{E}$ can be written as the superposition of fast and slow contributions 


$$
C_{E}=C_{E, \text { fast }}+C_{E, \text { slow }}
$$

and analogously for $C_{D}$. If it is assumed that the fast hysteretic motion is mainly driven by the onset of the strain amplitude, the relaxation kernel owed to slow hysteretic motion $\left(C_{E, \text { slow }}\right)$ can be found by scaling the envelope of the strain amplitude -in the case when only one resonant mode dominates the dynamic response- and subtracting it from the total contribution as

$$
C_{E, \text { slow }}=C_{E}-\min \left\{C_{E}\right\} \cdot \frac{\Delta \varepsilon(t)}{\Delta \varepsilon_{\max }} .
$$

Therefore, it can be assumed that the fast dynamic effect $\left(C_{E, \text { fast }}\right)$ is proportional to the strain amplitude -as shown in Eq. 11-13 - while the deviation of the proportionality behavior of $C_{E}$ is gathered in the variable $C_{E, \text { slow. }}$ The value of $\alpha_{C E}$ after untangling the slow dynamic contribution for a single impact is $\alpha_{C E}=-710$ (Figure 11-6c), and consistently the same for every different hammer blow. Interestingly, these values are close to those obtained through the quantification of $\alpha_{C E}$ from the minimum offset obtained for five impacts (Eq. 11-15). Likewise for the analysis conducted on $C_{D}$ (Figures 11-6b and 11-6d). Therefore, after the slow dynamics of a single impact are untangled, the estimation of the parameter $\alpha$ approximates to the value obtained with a nonlinear resonant spectroscopy approach, wherein the effect of the slow dynamics is minimized (P. Johnson \& Sutin, 2005). The contribution of the slow dynamics becomes more evident when the signals are shown as a function of time. Figures 11-6e and 11-6f show the untangled fast and slow hysteretic effects on the relaxation kernels as a function of time. The fast counterpart is the scaled envelope of the strain signal $\left(C_{E \text {, fast }}=\min \left\{C_{E}\right\} . \Delta \varepsilon(t) / \Delta \varepsilon_{\max }\right)$, while the slow contribution $\left(C_{E, \text { slow }}\right)$ directs the global behavior of the relaxation kernels, $C_{E}$ and $C_{D}$, away from the scaled strain signal envelope. Remarkably, the slow dynamic contribution seems to be enhanced on $C_{E}$ compared with the relaxation of the attenuation properties $C_{D}$. This observation is not unique. Similar behavior was also observed in compressional mode DAET experiments conducted 
on rock (Renaud, Rivière, Haupert, et al., 2013). Although more research is needed in this respect, the fast hysteretic motion is most likely captured by the attenuation variation $\left(C_{D}\right)$ which recovers completely to the initial properties, $y_{0}$ (Figures 11-6f), at the time that the strain signal is completely damped, which suggests that the underlying mechanisms of slow dynamics differ in the recovery processes of the elastic and attenuation properties.
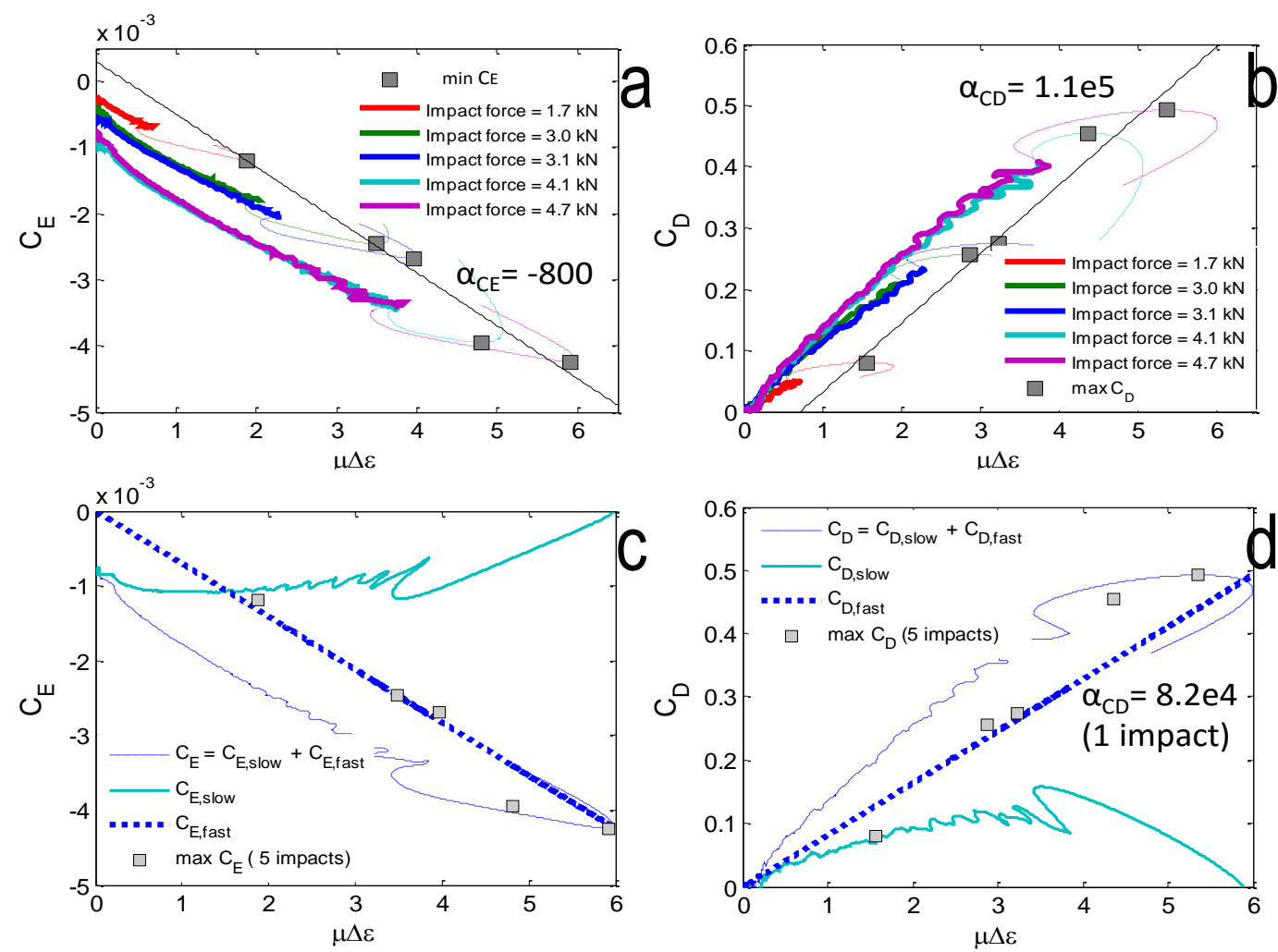

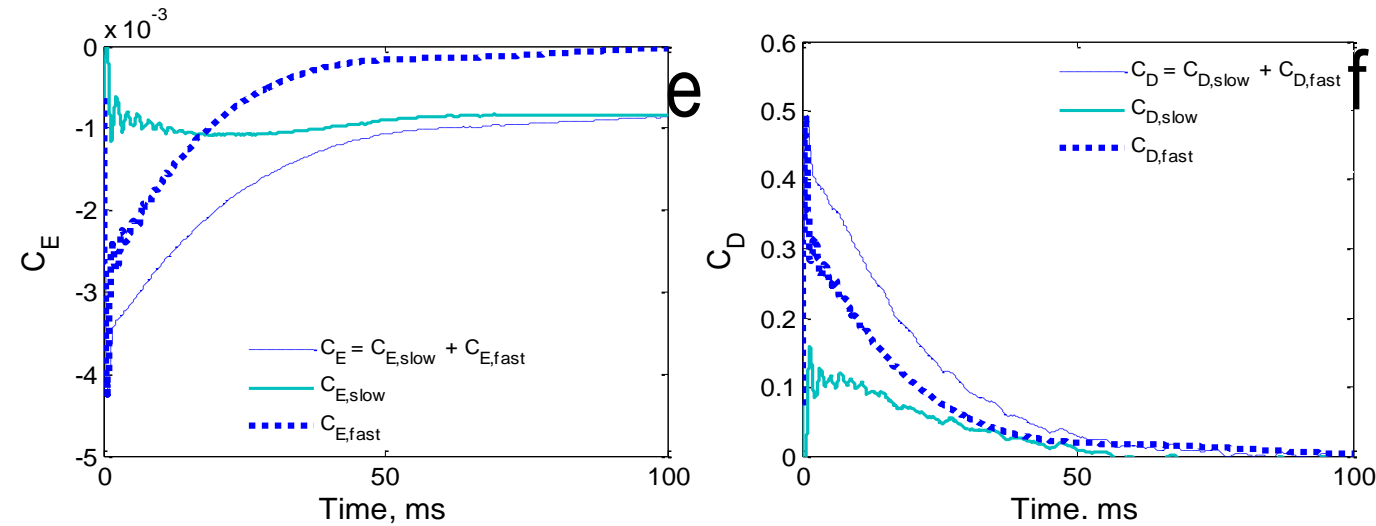

Figure 11-6 a) Relaxation kernel observed for the elastic properties for five different impact energies, b) untangled fast and slow dynamic contributions from $C_{E}$, as a function of strain amplitude and C) untangled fast and slow dynamic contributions from $C_{D}$, as a function of strain amplitude, e) untangled fast and slow dynamic contributions from $C_{E}$, as a function of time, and f) untangled fast and slow dynamic contributions from $C_{D}$, as a function of time.

\subsection{Conclusions}

This study shows the feasibility of extracting the full nonlinear behavior of materials by using transient solicitations to modulate a continuous high frequency probe. Unlike previous efforts that investigated impact-modulation of a continuous probe wave, the data analysis conducted herein allowed a more detailed description of the material nonlinearity. The approach was demonstrated in one undamaged concrete sample. The extracted dynamic features in this study are those expected for materials that present distributed contact-like defects such as concrete or rocks: 1 ) the relative variations of modulus with strain resembled a bow tie, 2) the modulus decreased and progressively was recovered with the onset of the strain amplitude, and 3) the modulus was not completely recovered at the time that the strain amplitude was completely damped. Despite only one concrete sample was tested herein, the extent of material nonlinearity is reasonable for undamaged concrete when compared with previous studies (Dahlén et al., 2015; Eiras et al., 2014; Payan et al., 2014). Prospective work will focus in assessing distributed microcracking damage and surface-breaking cracks 
in concrete samples. On other hand, the methodology proposed in this study can be transposed to various applications which involve non-steady-state vibration, such as the analysis of earth response during ground motion, in structure health monitoring applications by using ambient noise, as well as on-site assessment of infrastructure materials, where usually only one face is available for nondestructive inspection. Some of these applications were previously devised in other studies (Bui et al., 2013; Moradi-Marani et al., 2012). However, the approach and analysis conducted here allows a more detailed description of the material nonlinearity.

\section{References}

Bui, D., Kodjo, S. a., Rivard, P., \& Fournier, B. (2013). Evaluation of Concrete Distributed Cracks by Ultrasonic Travel Time Shift Under an External Mechanical Perturbation: Study of Indirect and Semi-direct Transmission Configurations. Journal of Nondestructive Evaluation, 32(1), 25-36.

Dahlén, U., Ryden, N., \& Jakobsson, A. (2015). Damage identification in concrete using impact non-linear reverberation spectroscopy. NDT and $E$ International, $75,15-25$.

Donskoy, D., Sutin, A., \& Ekimov, A. (2001). Nonlinear acoustic interaction on contact interfaces and its use for nondestructive testing. NDT \& E International, 34(4), 231238.

Eiras, J. N., Monzó, J., Payá, J., Kundu, T., \& Popovics, J. S. (2014). Non-classical nonlinear feature extraction from standard resonance vibration data for damage detection. The Journal of the Acoustical Society of America, 135(2), EL82-EL87.

Fröjd, P., \& Ulriksen, P. (2016). Amplitude and phase measurements of continuous diffuse fields for structural health monitoring of concrete structures. NDT \& E International, 77 , 35-41.

Gerandin, M., \& Rixen, D. J. (2014). Mechanical Vibrations, Theory and Applications. John Wiley \& Sons.

Hunt, F. V. (1960). Stress and Strain Limits on the Attainable Velocity in Mechanical 
Vibration. The Journal of the Acoustical Society of America, 32(7), 1123-1128.

Johnson, P. A. (2006). Nonequilibrium Nonlinear-Dynamics in Solids : State of the Art State of the Art in Nonequilibrium Dynamics. In P. P. Delsanto (Ed.), Universality of Nonclassical Nonlinearity (pp. 49-69). New York: Springer.

Johnson, P., \& Sutin, A. (2005). Slow dynamics and anomalous nonlinear fast dynamics in diverse solids. The Journal of the Acoustical Society of America, 117(1), 124.

Kolsky, H. (1963). Stress Waves in Solids. (Vol. 1098). Courier Corporation.

Larose, E., De Rosny, J., Margerin, L., Anache, D., Gouedard, P., Campillo, M., \& Van Tiggelen, B. (2006). Observation of multiple scattering of $\mathrm{kHz}$ vibrations in a concrete structure and application to monitoring weak changes. Physical Review E - Statistical, Nonlinear, and Soft Matter Physics, 73(016609), 1-7.

Lebedev, A. V., \& Ostrovsky, L. A. (2014). A unified model of hysteresis and long-time relaxation in heterogeneous materials. Acoustical Physics, 60(5), 555-561.

Moradi-Marani, F., Kodjo, S. A., Rivard, P., \& Lamarche, C. (2014). Nonlinear Acoustic Technique of Time Shift for Evaluation of Alkali-Silica Reaction Damage in Concrete Structures. ACl Materials, 111(January-December 2014), 1-12.

Moradi-Marani, F., Kodjo, S. a., Rivard, P., \& Lamarche, C. P. (2012). Application of the mechanical perturbation produced by traffic as a new approach of nonlinear acoustic technique for detecting microcracks in the concrete: A laboratory simulation. In AIP Conference Proceedings (Vol. 1430, pp. 1493-1499).

Naik, T. R., \& Popovics, J. S. (2004). The Ultrasonic Pulse Velocity Method. In V. M. Malhotra \& N. J. Carino (Eds.), Handbook on Nondestructive Testing of Concrete (2nd ed.). Boca Raton: CRC Press.

Paultre, P., Proulx, J., \& Talbot, M. (1995). Dynamic Testing Procedures for Highway Bridges Using Traffic Loads. Journal of Structural Engineering, 121(2), 362-376.

Payan, C., Ulrich, T. J., Le Bas, P. Y., Saleh, T., \& Guimaraes, M. (2014). Quantitative linear and nonlinear resonance inspection techniques and analysis for material characterization: Application to concrete thermal damage. The Journal of the 
Acoustical Society of America, 136, 537.

Quiviger, A. (2012). Ultrasons diffus pour la caractérisation d' une fissure dans le béton Approche linéaire et non linéaire. Aix-Marseille Université.

Quiviger, A., Payan, C., Chaix, J.-F., Garnier, V., \& Salin, J. (2012). Effect of the presence and size of a real macro-crack on diffuse ultrasound in concrete. NDT \& E International, 45(1), 128-132.

Renaud, G., Callé, S., Remenieras, J.-P., \& Defontaine, M. (2008). Exploration of trabecular bone nonlinear elasticity using time of flight modulation. IEEE Transactions on Ultrasonics, Ferroelectrics, and Frequency Control, 55(7), 1-10.

Renaud, G., Le Bas, P.-Y., \& Johnson, P. a. (2012). Revealing highly complex elastic nonlinear (anelastic) behavior of Earth materials applying a new probe: Dynamic acoustoelastic testing. Journal of Geophysical Research, 117(B6), B06202.

Renaud, G., Rivière, J., Haupert, S., \& Laugier, P. (2013). Anisotropy of dynamic acoustoelasticity in limestone, influence of conditioning, and comparison with nonlinear resonance spectroscopy. The Journal of the Acoustical Society of America, 133(6), 3706-18.

Renaud, G., Rivière, J., Le Bas, P.-Y., \& Johnson, P. A. (2013). Hysteretic nonlinear elasticity of Berea sandstone at low-vibrational strain revealed by dynamic acousto-elastic testing. Geophysical Research Letters, 40(4), 715-719.

Rivière, J., Renaud, G., Guyer, R. A., \& Johnson, P. A. (2013). Pump and probe waves in dynamic acousto-elasticity: Comprehensive description and comparison with nonlinear elastic theories. Journal of Applied Physics, 114(5), 054905.

Rivière, J., Shokouhi, P., Guyer, R. A., \& Johnson, P. A. (2015). A set of measures for the systematic classification of the nonlinear elastic behavior of disparate rocks. Journal of Geophysical Research : Solid Earth, 120,1-18.

Scalerandi, M., Gliozzi, A. S., Bruno, C. L. E., \& Antonaci, P. (2010). Nonequilibrium and hysteresis in solids: Disentangling conditioning from nonlinear elasticity. Physical Review B - Condensed Matter and Materials Physics, 81, 1-7. 
Trarieux, C., Callé, S., Moreschi, H., Renaud, G., \& Defontaine, M. (2014). Modeling nonlinear viscoelasticity in dynamic acoustoelasticity. Applied Physics Letters, 105(26), 264103.

Turgut, P., \& Kucuk, O. F. (2006). Comparative relationships of direct, indirect, and semidirect ultrasonic pulse velocity measurements in concrete. Russian Journal of Nondestructive Testing, 42(11), 745-751.

Van Damme, B., \& Van Den Abeele, K. (2014). The application of nonlinear reverberation spectroscopy for the detection of localized fatigue damage. Journal of Nondestructive Evaluation, 33(2), 263-268.

Van Den Abeele, K. E., Sutin, A., Carmeliet, J., \& Johnson, P. a. (2001). Micro-damage diagnostics using nonlinear elastic wave spectroscopy (NEWS). NDT \& E International, 34(4), 239-248.

Van Den Abeele, K. E.-A., Carmeliet, J., Ten Cate, J. A., \& Johnson, P. A. (2000). Nonlinear Elastic Wave Spectroscopy (NEWS) Techniques to Discern Material Damage, Part II: Single-Mode Nonlinear Resonance Acoustic Spectroscopy. Research in Nondestructive Evaluation, 12(1), 31-42.

Yang, Y.-B., Lin, C. W., \& Yau, J. D. (2004). Extracting bridge frequencies from the dynamic response of a passing vehicle. Journal of Sound and Vibration, 272(3-5), 471-493. 


\section{Chapter 12. Further discussion, conclusions, disparate tests and future work}



In this thesis, different vibration based NDT techniques have been investigated and used to assess the durability of cement based materials. Linear and nonlinear parameters have been extracted from vibration responses generated by impact. Based on the experimental program conducted in this thesis, it has been demonstrated that the investigation of material nonlinearity provides enhanced sensitivity for detecting damage features and subtle microstructure modification within the materials, especially at early stages wherein the standard (linear based) measurements may fail to discern it. From the stand view of damage detection, nonlinear parameters exhibited larger variations than linear parameters (resonant frequency and linear mode damping) upon increasing damage. These results are in good agreement with other studies that investigated different durability distresses in concrete, through different nonlinear based techniques (J. Chen, Jayapalan, Kim, Kurtis, \& Jacobs, 2009; Leśnicki, 2011; Payan, Garnier, Moysan, \& Johnson, 2007). In this thesis, three techniques have been investigated to assess the durability of cement based materials: i) Nonlinear Impact Resonant Acoustic Spectroscopy (NIRAS), ii) Nonlinear Single Impact Resonant Acoustic Spectroscopy (NSIRAS), and iii) Dynamic acousto-elastic test (DAET) using a continuous probe wave and an impact excitation.

NIRAS technique requires of multiple impact events to evaluate the amplitude dependent internal friction effects - that is, amplitude-dependent resonant frequency and attenuation - Thus, this technique can be easily implemented by varying the impact energy in the standard ASTM C215 test configuration. Then, the resulting downward resonant frequency shift can be obtained. Regrettably, the evaluation of the material nonlinearity underlies on the arbitrary units of the spectral amplitude. This concern impedes the comparison between different studies, since the resulting spectral amplitude is a weighted average of time-decaying amplitude —as it is typically generated by an impact-. In an effort of providing a quantitative measurement of the nonlinear hysteretic parameter, Yim and coworkers (Yim, Park, Kim, \& Kwak, 2014) related the frequency values as obtained through the FFT to the maximum acceleration peak attained in the time domain signal. Similar approach was used by Yan and coworkers (Yan, Jenkins, \& Pendleton, 2000). However, the

\section{$12-3$}


time domain signal must contain only one resonant mode, otherwise, the peak amplitude is overestimated. Moreover, the frequency value as obtained through the FFT of the entire signal may not precisely correspond to the amplitude value. Hence, NIRAS technique requires a reference baseline measurement for the undamaged case to deem the existence of damage, through the interpretation of the nonlinear parameters. The NIRAS configuration conducted herein -Chapters 2 to 6 - allowed investigation of the resonant frequency shifts owed to longitudinal and first bending modes of vibration - see Chapter 2-. Interestingly, the hysteretic parameters corresponding to the first bending mode $\left(\eta_{\text {flex }}\right)$ were consistently greater than those obtained for the longitudinal mode of vibration $\left(\eta_{\text {long }}\right)$. The precise cause of this difference is not clear at this time, but is likely to be in part caused by distinct strain fields within the sample associated with each mode (vibration mode shape), and how that strain field coincides with the relative orientation of the internal defects. Also, this effect was substantiated on glass fiber reinforced concrete (GRC) samples subjected to accelerated ageing conditions. It was observed that torsional modes and bending modes behave differently with increasing excitation amplitude, and their corresponding hysteretic parameters evolved in a different way upon ageing of the fibers. These results suggest that shear and compressive mode motions exhibit different hysteretic behavior. This contention was recently supported in a recent study that demonstrated that the hysteretic behavior owed to compressional and shear motions is intrinsically different for nonlinear mesoscopic elastic materials (Remillieux, Guyer, Payan, \& Ulrich, 2016). Still, more research is needed in this respect.

NSIRAS technique investigates the resonant frequency variation over the amplitude ring down signal, using the physical units of the signal. Unlike NIRAS approach, the investigation of the instantaneous variations of the signal parameters (amplitude, frequency and also attenuation) allows quantitative measurements of the material nonlinearity. And only one impact even is needed to investigate the material nonlinearity. Two different approaches for extracting and quantifying the material nonlinearity from a single impact were compared. In Chapter 8 was presented a Short Time Fourier Transform (STFT) approach. 
The signal analysis consisted of a sliding window that transforms the time segment within the window to the frequency domain at every window position. The results depend on window size and window type. On other hand, in Chapter 9 was described a signal analysis performed in the time domain. The signal analysis consisted in fitting the time domain signal to an exponential decaying sine function as -recall Eq. 9-2 from Chapter 9, and it is Eq. 121 -

$y(t)=\sum_{m=1}^{m=M} A_{m} \cdot \exp \left(\theta_{m}(t)\right) \cdot \sin \left(\phi_{m}(t)\right)$

Eq. $12-1$

where the functions $\theta_{m}(t)$ and $\phi_{m}(t)$ are polynomial functions that describe the time-varying phase and attenuation corresponding to a given mode of vibration $m$. In Chapter 9 an algorithm for fitting the experimental signals to the model in Eq. 12-1 was presented. Frequency domain and time domain methods were compared on a set of concrete samples subjected to a number of thermal shock cycles. At overall, the time domain analysis of the signal provided better estimation of the actual signal amplitude when compared to the frequency domain approach. However, the frequency domain approach is computationally faster and straightforward. The frequency domain approach may be also preferred when the signal contains several vibration modes and when very high polynomial orders are needed to describe the experimental signal. In these cases, the time domain fitting becomes less efficient. On other hand, different rheological models have been proposed to investigate the material nonlinearity in damaged concrete (Bentahar, El Aqra, El Guerjouma, Griffa, \& Scalerandi, 2006; Kodjo, Rivard, Cohen-Tenoudji, \& Gallias, 2011). In this sense, the particular arithmetic shape of the function $\phi_{m}(t)$ can be adapted to such rheological models. These models will be evaluated in ongoing research efforts.

From NSIRAS technique - either through time or frequency domain analysis-, it was observed a nonlinear frequency-amplitude dependence. This dependence differed from the NIRAS approach, whereby the resonant frequency is proportional to the impact energy. This

\section{$12-5$}


behavior was previously noticed in (Dahlén, Ryden, \& Jakobsson, 2015; Eiras, Monzó, Payá, Kundu, \& Popovics, 2014; Van Damme \& Van Den Abeele, 2014). It can be attributed to the slow dynamic effect, whereby the material temporarily memorizes the strain history attained at every impact event. Concrete presents asperities that may be eventually broken and recovered upon mechanical wave propagation. This process leads to a softening (fast dynamic effect) which is proportional to the attained strain amplitude in most materials ( $P$. Johnson \& Sutin, 2005). On other hand, a different volume of asperities remains in a metastable equilibrium, once the dynamic excitation vanishes, and will return to the initial state - before dynamic excitation - because of thermal fluctuations (Lebedev \& Ostrovsky, 2014) and other mechanisms not yet established (P. A. Johnson, 2006) which takes place on a longer timescale (slow dynamics). In NSIRAS measurements -this is also referred as nonlinear ringdown spectroscopy (Guyer \& Johnson, 2009)—, the memory effect complicates the quantification of the material nonlinearity, since different frequencyamplitude functions are obtained for different impact forces. In chapter 8 , wherein the experimental program used relatively similar impact energy, the material nonlinearity was quantified through the cumulative frequency recovery with time (IFT); it is defined as - recall Eq. 8-4 and it is Eq. 12-2-

$$
I F T=\int_{1}^{T} \frac{f_{t}-f_{t=1}}{f_{t=1}} \cdot d t
$$

where $f_{t=1}$ is the frequency at the first time window and $f_{t}$ those from the subsequent time windows up to a preset time $t=T$. In this way, the IFT value of a nearly linear material is zero, and it will increase as a measure that the material nonlinearity increases. However, it should be noted, that the IFT value depends on impact energy, and hence, any variability on impact energy will be reflected on the variability of the IFT. Likewise, this issue makes difficult the comparison of the nonlinear behavior across different studies. Yet, in Chapter 8, the IFT data provided a robust quantification of the material nonlinearity that is appropriate for comparison for samples collected from a standard test set-up. The results also demonstrated that the

\section{$12-6$}


IFT quantification exhibited enhanced sensitivity when compared to the standard resonant frequency and $Q$ measurements.

In Chapters 9 and 11 a straightforward method to untangle fast and slow contributions from a single vibration response was proposed. Figure 12-1 schematically describes this process. From a single impact event, the fast dynamic behavior, as that is obtained through multiple impact events, can be found, by simply relating the minimum downward shift of the resonant frequency to its correspondent maximum acceleration amplitude $\left(A_{\max }\right)$ as -recall Eq. 9-14 and it is Eq. 12-3-

$\eta=\frac{\min \left(\frac{f_{0}-f}{f_{0}}\right)}{A_{\max }}$.

In this way, the nonlinear parameter $\eta$ is measured in the reciprocal units of the excitation amplitude. Interestingly, it was found that the values of the hysteretic parameter $\eta$, approximately matched those values obtained by fitting the frequency data obtained from multiple impact events; that is NIRAS approach, and the hysteretic parameter is obtained as $\eta=\frac{\left(\frac{f_{0}-f_{i}}{f_{0}}\right)}{A_{i}}$.

In NIRAS tests, the slow dynamic effect contributes to the increase the variability on the estimation of the hysteretic parameter. This can be in part minimized by increasing the time lapse between consecutive impacts. In NSIRAS technique, the slow dynamic contribution is then found by subtracting the "fast dynamic" contribution - that strictly proportional to the amplitude of a given vibration mode (Eq. 12-3) — to the instantaneous frequency obtained over the ring down of the signal. The determination of the material nonlinearity from a single impact event reduces the operating time, and the number of impacts needed to investigate 
the material nonlinearity. Later on, it is shown that NIRAS technique can produce damage on the impact location; thus avoiding multiple impact may be interesting. Yet, several impacts are recommended to provide certain confidence on the reported values of the hysteretic parameter. The application of the NSIRAS analyses may have also relevance in industrial applications wherein the quality control of parts is conducted through a single resonant frequency measurement; this is however, beyond of the scope of this thesis. The consideration of the slow dynamic response on the investigation of the material nonlinearity from a single vibration response deserves further research, not only for enhancing the robustness on the measurement of the hysteretic parameter $\eta$, but also for providing additional valuable information about the mechanical integrity of the material. In this sense, further work will focus on determining whether different damage mechanisms (say sulfate attack, thermal damage or freezing thawing damage) produce dissimilar instantaneous frequency variations. On other hand, as in NIRAS test the results depend on the selection of the linear resonant frequency $\left(f_{0}\right)$. Then, because of the slow dynamic effect, the value of $f_{0}$ must preferably be determined a priori. Otherwise, the slow dynamic effect will be underestimated.
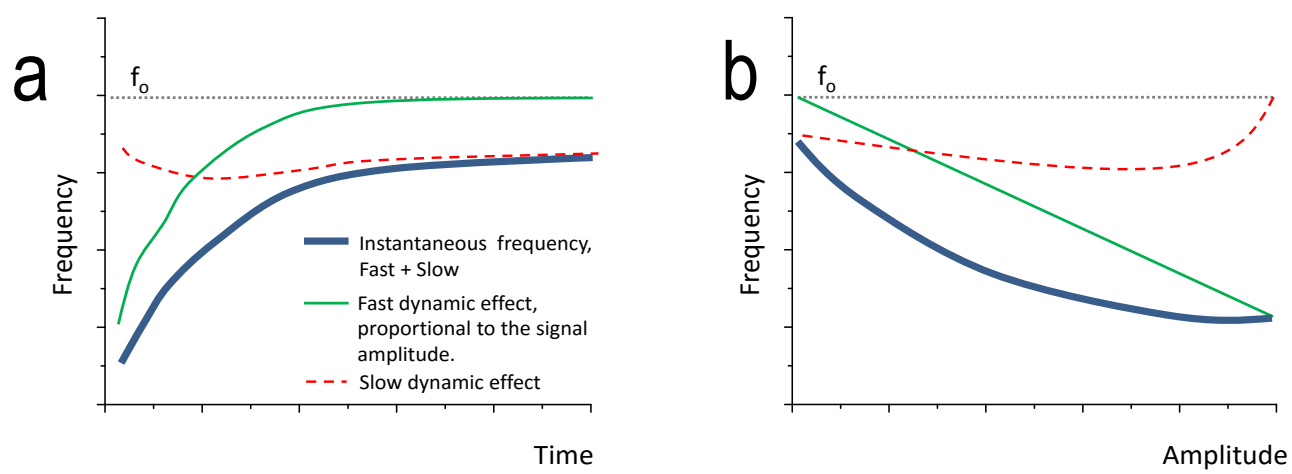

Figure 12-1 Resonant frequency and untangled fast and slow contributions obtained over a ring down signal, as a function of a) time, and b) as a function of the amplitude. 
The third technique investigated in this thesis consisted in a Dynamic Acousto-elastic Test. It consisted of a continuous wave as probe wave and a hammer blow as pump wave. The nonlinear resonant techniques (as NIRAS or NSIRAS) investigate the modulus variations over averaged strain values. Conversely, the main advantage of the DAET is that the variations of modulus can be related to the instantaneous values of strain, which allow investigation of these dependences. Unlike previous efforts that investigated impactmodulation of a continuous wave, the data analysis conducted herein allowed a more detailed description of the material nonlinearity. The extracted dynamic features in this study were those expected for materials that present distributed contact-like defects such as concrete or rocks, and previously observed in DAET: 1) the relative variations of modulus with strain resembled a bow tie, 2) the modulus decreased and progressively was recovered with the onset of the strain amplitude, and 3) the modulus was not completely recovered at the time that the strain amplitude was completely damped. Despite only one concrete sample was tested herein, the extent of material nonlinearity is reasonable for undamaged concrete when compared with previous studies (Dahlén et al., 2015; Eiras et al., 2014; Payan, Ulrich, Le Bas, Saleh, \& Guimaraes, 2014). Prospective work will focus in assessing distributed microcracking damage and surface-breaking cracks in concrete samples. On other hand, the methodology proposed in this study can be transposed to various applications which involve non-steady-state vibration, such as the analysis of earth response during ground motion, in structure health monitoring applications by using ambient noise, as well as on-site assessment of infrastructure materials, where usually only one face is available for nondestructive inspection. Some of these applications were previously devised in other studies (Bui, Kodjo, Rivard, \& Fournier, 2013; Moradi-Marani, Kodjo, Rivard, \& Lamarche, 2012). However, the approach and analysis conducted here allows a more detailed description of the material nonlinearity. 
The investigation of the material nonlinearity is subjected to different sources of variability. These were mentioned along this thesis, or addressed in separated chapters in case of the effects of the internal moisture content (Chapters 3 and 4). In the following, some of these issues are further discussed.

i) Signal processing and nonlinear parameter estimation. The signal processing and the method for extracting the nonlinear parameter, affect its variability. In general, the signal processing must provide a frequency resolution that allows describe the frequency variations produced upon varying excitation amplitude. For early damage detection purposes, it is crucial to provide high frequency step resolution. On other hand, the accuracy of the hysteretic parameter through nonlinear resonant tests depends, in part, on the determination of the linear resonant frequency value, $f_{0}$. The effects of the wrong selection of $f_{0}$ on Nonlinear Resonant Ultrasound Spectroscopy (NRUS) measurements were previously discussed by Johnson and coworkers (Paul A. Johnson, Zinszner, Rasolofosaon, Cohen-Tenoudji, \& Van Den Abeele, 2004). Since the resonant frequency values are normalized by $f_{o}$, any inaccuracy on the determination of this value will be reflected on the hysteretic parameter. These effects also concern the variability of the hysteretic parameter as derived through NIRAS tests. In NIRAS technique, $f_{0}$ is frequently assumed to be that obtained for the lowest impact energy event. Besides, the selection of $f_{0}$ from the lowest variability produced by a hammer blow cannot be comparable. Accurate and careful nonlinear resonant measurements, -for instance as those conducted by Pasqualini et al. (Pasqualini et al., 2007) - using NRUS technique do not seem to be achievable through impact based excitation techniques. Moreover, it is questionable if the value of $f_{0}$ was obtained in the linear strain regime. Since NIRAS technique it is intrinsically a qualitative evaluation - unless, only a short window at the beginning of the transient signal is analyzed, as in Chapter 9; scatter data shown in Figure 9-11-, the normalization of the resonant frequency by the resonant frequency obtained for the lowest impact energy $\left(f_{0}\right)$ is rather awkward. Perhaps, the quantification of the nonlinear hysteretic behavior through a linear 
regression that relates the frequency $(f)$ and amplitude $(A)$ is perhaps more appropriate; thus, it can be evaluated through the model

$f=f_{\text {int }}+\lambda \cdot A$,

wherein $f_{\text {int }}$ is the intercept and $\lambda$ is the slope of the relation between frequency $(f)$ and spectral amplitude $(A)$. Also, a normalization of the frequency values by the intercept in Eq. 12-4 -thus, $f_{0}=f_{\text {int }}-$ is more robust than assuming $f_{0}$ that obtained for the lowest impact energy event. The latter seem to be the approach conducted by (Yim et al., 2014), despite it was not specifically stated within the text. This was also the approach adopted in Chapter 9 for NIRAS measurements. On other hand, in order to provide quantitative measurements in nonlinear resonant frequency tests, the dynamic response (usually acceleration or velocity) is translated to strain. Despite these conversions are quite appealed, the equations to conduct such a transformation assume linear elastic behavior, and, they are derived from Euller-Bernoulli beam theory (in case of flexural vibrations) (Hunt, 1960). With increasing damage within the material, these conversions may deviate from those hypotheses. A comprehensive experimental study addressing this issue is still needed.

ii) Test configuration and sample geometry. The resonant frequency tests are normally performed in free boundary conditions. In free-free configurations, the sample is normally supported on a foam mat, or suspended on elastic wires or on rods at its nodal points (depending on the vibration mode). Alternatively, many studies have employed a cantilever configuration. However, non-ideal clamping conditions at the sample end may obscure the measurement of the material nonlinearity, since new sources of nonlinearity can be introduced in the system. In addition, Polimeno and Meo (Polimeno \& Meo, 2008) demonstrated that the torque applied onto the clamp affect the measurement of material nonlinearity. In such study, the nonlinear behavior of the material under inspection was reduced upon increasing torque onto the clamped end. Similar conclusions were drawn by Rivière and coworkers (Rivieøre et al., 2010). In general, resonant frequency tests aiming 
free boundary conditions are straightforward. For laboratory inspection of samples or material characterization, these effects can be avoided by the selection of a free-free test configuration, as is instructed in different standards (ASTM C215-14, 2014) for the determination of resonant frequencies. On other hand, the resonant frequency measurements have been performed on a wide range of sample size and geometries. In general, prismatic and cylindrical samples have been used for resonant tests. The sample geometry can affect the obtained results, since there seems to be an apparent strain rate dependence of the material nonlinearity (Nazarov \& Radostin, 2015). Therefore, for a given material, their intrinsic material nonlinearity would be enhanced for shorter samples as their resonant frequencies increase. To the author knowledge, size-effects on the investigation of the material nonlinearity have not been yet addressed.

iii) Effect of material conditioning. In Chapter 5, it was observed that the variability of the resonant frequency and $Q$ data, as obtained through the standard resonant frequency method, increased with damage. In particular, it was identified a serial correlation whereby frequency and $Q$ progressively decreased with the acquisition order. This effect was more prominent as a measure that microcracking damage increased. The literature reporting similar effects is rather scarce. Ryden (Ryden, 2011) observed similar behavior in asphalt concrete samples. In such study, the resonant frequency monotonically decreased with the test number. Bui and coworkers (Bui et al., 2013) also observed similar phenomena in damaged concrete through the time shift technique - this was briefly described within Chapter 1, subsection 1.2.4.2 Dynamic acousto-elastic test (DAET)—. More recently, this effect was leveraged by Somaratna (Somaratna, 2014) to assess distributed like damage in cement based materials. In such study, the resonant test protocol consisted in manually strike the samples every two seconds, on a set of Portland cement paste specimens which were subjected to different heat treatments. The material nonlinearity was quantified through the investigation of the drop in resonant frequency produced upon increasing number of acquisitions. Herein, to investigate this effect, further tests were performed by using an repetitive impact device on three concrete samples that underwent 100, 200, and 300 
freezing-thawing cycles, as instructed in ASTM C666 (ASTM-C666, 2012). Such a test aimed to repeatedly perform the standard resonant frequency test at a constant energy input; 300 signals were acquired. The impact rate was set to $1 \mathrm{~Hz}$ and two different energy levels were investigated, by tuning the input voltage of the amplifier that fed the impactor. Figure 12-2 shows a photo of the test configuration. The results shown in Figure 12-3a and 12-3b demonstrated that the variability of the resonant frequency depended on damage extent and on impact energy. Also, upon repetitive impact, the resonant frequency reached an equilibrium value. These tests were repeated after one-hour rest (results not shown), and the resonant frequency was partially recovered. Similar findings were reported by Somaratna (Somaratna, 2014). Moreover, these tests were repeated after immersing the samples in water during 72 hours. The results shown in Figure 12-3 shows the results obtained for the sample that underwent 300 freezing-thawing cycles. The results suggest that the origin of this behavior may be originated by friction like mechanisms while increasing moisture content allowed mitigation. These results taken together suggest that every measurement is affected by the previous reading. This effect may be related to the slow dynamic effect whereby the material temporarily memorizes the modulus reduction experienced at every impact event. These effects are disregarded in the standards - for instance, in ASTM C215 (ASTM C215-14 2014) - despite they affect the variability of the measurements. From previous effects, it can be also drawn that, slow dynamic effect also concerns the variability on the measurement of the hysteretic parameter as obtained through NIRAS tests. The impact of the slow dynamic effect on the measurement of the hysteretic parameters can be minimized by increasing the time lapse between consecutive impacts. Still, a comprehensive study aiming at evaluating the actual impact of the memory effect on the measurement of the hysteretic parameter would be desirable.

\section{$12-13$}




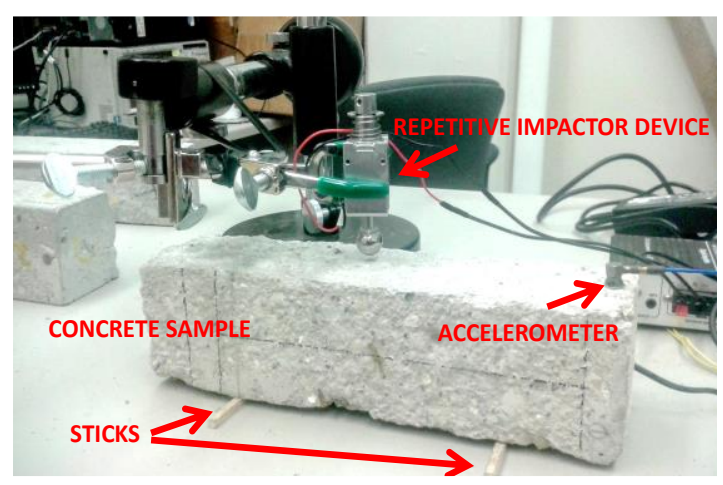

Figure 12-2 Photo of the test configuration, for repetitive resonant frequency measurements.

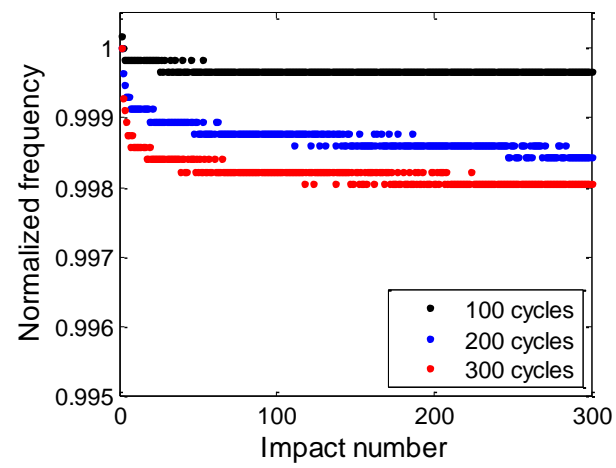

b
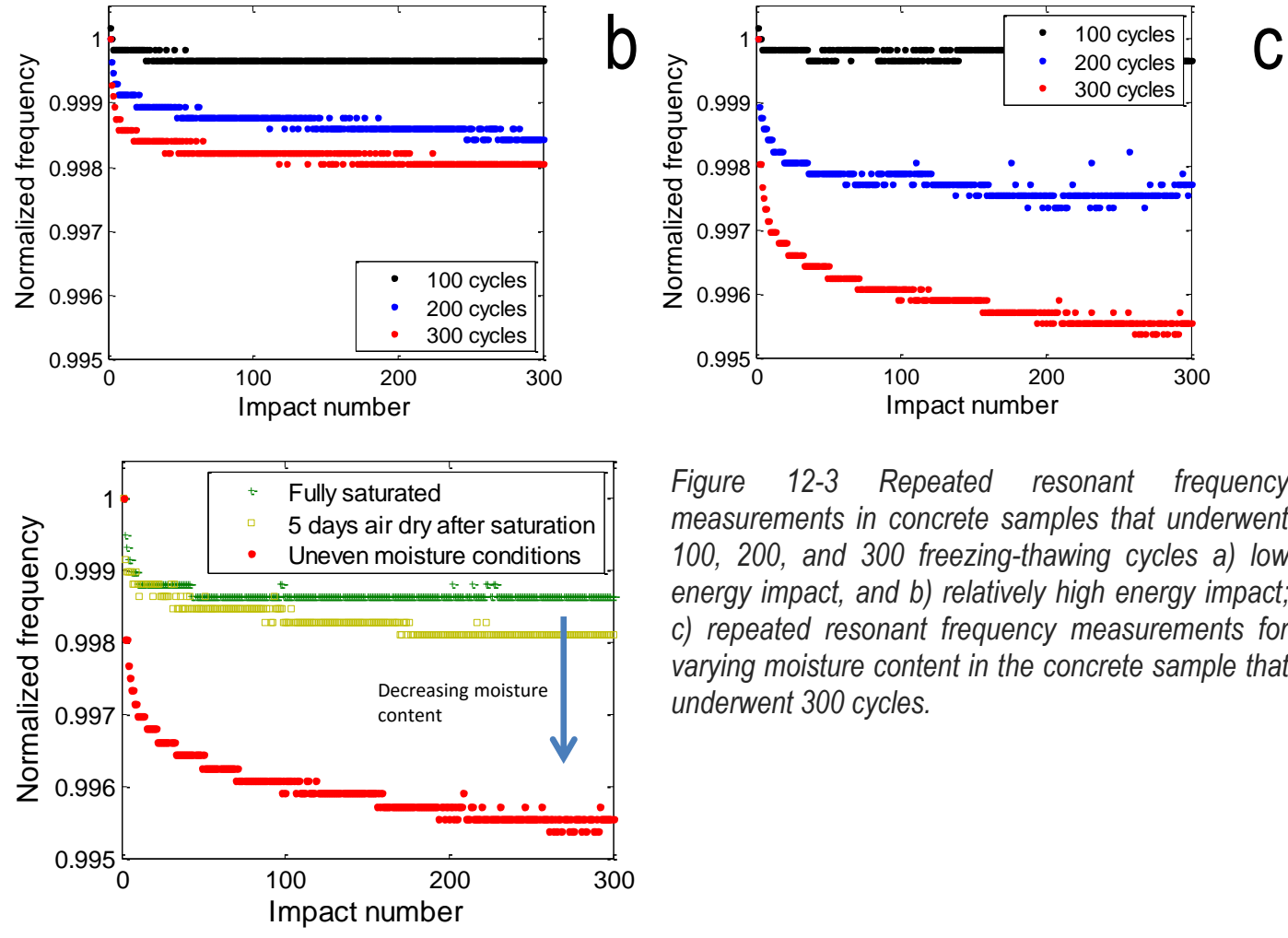

Figure 12-3 Repeated resonant frequency measurements in concrete samples that underwent 100, 200, and 300 freezing-thawing cycles a) low energy impact, and b) relatively high energy impact; c) repeated resonant frequency measurements for varying moisture content in the concrete sample that underwent 300 cycles.

iv) Impact calibration and cumulative damage on the impact spot. Regrettably, while the evolution of damage is monitored with time, there exists an accrued damage inherent to the impact excitation. This effect can bias the measurement of the material nonlinearity since the generation of microcracks would enhance the material nonlinearity.

\section{$12-14$}


Figure 12-4 shows a prismatic sample of $40 \times 40 \times 160 \mathrm{~mm}^{3}$ that was soaked in a solution with $15 \%$ of sodium sulfate, during more than 15 days. At the end of the tests, the expansive forces originated upon sulfate attack revealed cracking damage arising at the impact location. This observation call attention to the need of calibrating the maximum impact force applied onto the concrete samples. This disadvantage can be circumvented by using NSIRAS technique, which only requires a single impact event for obtaining the hysteretic parameter, and with the additional outcome of obtaining a quantification of the slow dynamic effect.
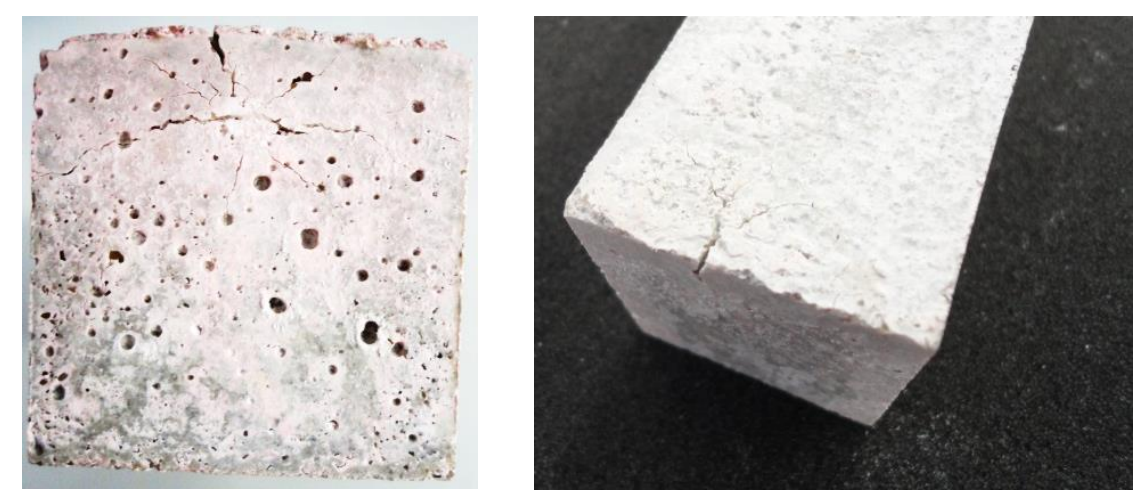

Figure 12-4 Two photos showing cracking damage at the impact location.

v) Double hump effect. Very frequently, the resonance spectra corresponding to the flexural mode of vibration of concrete samples exhibits a resonance mode close to main resonant peak (Jones, 1962). This effect is normally owed to a stiffness asymmetry within the sample under inspection, which in turn can be caused by variations of the properties across the sample (Amick \& Monteiro, 2006; Jones, 1962) or by the presence of localized defects, such a crack (ASTM E2001, 2013). The measurement of $Q$ in these cases must be disregarded. In addition, Lesnicki (Leśnicki, 2011) pointed out that a poor attachment of the accelerometer to the concrete samples may generate similar effect. Discarding the latter, 
this particular acoustic signature can be leveraged to detect deceptive samples or localized defects.

vi) Environmental factors: internal moisture content and temperature. In Chapter 3 and 4 , the effects of drying and internal moisture content were investigated. The results demonstrated that the linear $\left(E_{d}\right.$ and $\left.Q\right)$ and nonlinear $(\eta)$ constitutive properties of cementbased materials were affected by internal moisture content and by the oven drying temperature. $E_{d}$ values obtained in saturated states were found to be consistently higher than those at dry states. At saturated state, water acts confining the pore structure resulting in an increase of elastic modulus, and hence, subsequent removal of water yields a decrease of $E_{d}$. Further, the results show that drying treatments may lead to shrinkage microcracking. In addition, in Chapter 4, the rewetting periods were able to progressively alleviate the internal friction, and hence, to lower the values of $\eta$. These results call attention to the effect of internal moisture on obscuring the determination of internal damage in concrete. Careful environmental conditions are thus needed in laboratory experiments. On other hand, several studies have reported that the sample temperature affects the linear and nonlinear constitutive properties of concrete. These effects deserve further study.

With all, the present thesis investigated the feasibility of three different vibration based NDT techniques to quantify the material nonlinearity owed to distributed-like damage in concrete. NIRAS and NSIRAS show promise for enhanced assessment of different durability distresses of concrete, using a relatively inexpensive and well-vetted standard test configuration (ASTM C215-14). This idea is schematically illustrated in Figure 12-5. Other nonlinear based techniques, such as Nonlinear Wave Modulation Spectroscopy (NWMS) still remain difficult to perform, especially in concrete (X. J. Chen et al., 2008), and usually cumbersome equipment is required. Their applications are debatable when the scope of application needs timely assessment in laboratory of test specimens (Yim et al., 2014), or quality control inspection of pieces (Duffour, Morbidini, \& Cawley, 2006). The scope of use of the NIRAS and NSIRAS techniques is limited to durability tests wherein the evolution of

\section{$12-16$}


the concrete samples can be followed up upon increasing number of cycles or continued exposure in aggressive environments. Some examples include the assessment of reactive aggregates, freezing-thawing damage, and sulfate attack wherein the use of standard resonant vibration tests has been quite appealed (Malhotra \& Sivasundaram, 2004). In these cases, the easiness of the NIRAS technique may be preferred against other testing alternatives - for instance, NRUS technique which provides quantitative and more accurate measurements - at the expense of obtaining a qualitative measurement of the hysteretic nonlinearity. On other hand, the investigation of the instantaneous signal features may provide quantitative measurements. The determination of the material nonlinearity from a single impact event (NSIRAS) reduces the operating time, and the number of impacts needed to investigate the material nonlinearity, which can lead to local damage in the concrete samples. Yet, several impacts are recommended to provide certain confidence on the reported values of the hysteretic parameter for each damage stage. Finally, a DAET was conducted by modulating a continuous probe wave by a hammer blow. This technique allows a more detailed description of the material nonlinearity. Besides, this technique may have also be relevant for on-site inspection or passively monitoring of infrastructure materials.

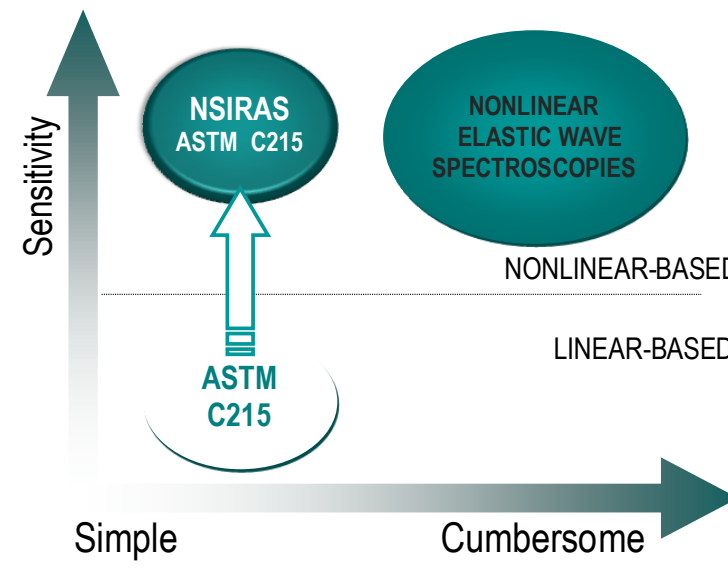

Figure 12-5 Schematic diagram that illustrates the advantages of extracting and quantifying the material nonlinearity from the standard ASTM C215 test configuration. 


\section{References}

Amick, H., \& Monteiro, P. J. M. (2006). Experimental Determination of Modal Damping in Concrete Beams. ACl Material Journal, 103(3), 153-160.

ASTM C215-14. (2014). Standard Test Method for Fundamental Transverse , Longitudinal , and Torsional Resonant Frequencies of Concrete.

ASTM E2001. (2013). Standard Guide for Resonant Ultrasound Spectroscopy for Defect Detection in Both Metallic and Non-metallic. West Conshohocken, PA (USA).

ASTM-C666. (2012). Standard Test Method for Resistance of Concrete to Rapid Freezing and Thawing.

Bentahar, M., El Aqra, H., El Guerjouma, R., Griffa, M., \& Scalerandi, M. (2006). Hysteretic elasticity in damaged concrete: Quantitative analysis of slow and fast dynamics. Physical Review B, 73(1), 014116.

Bui, D., Kodjo, S. a., Rivard, P., \& Fournier, B. (2013). Evaluation of Concrete Distributed Cracks by Ultrasonic Travel Time Shift Under an External Mechanical Perturbation: Study of Indirect and Semi-direct Transmission Configurations. Journal of Nondestructive Evaluation, 32(1), 25-36.

Chen, J., Jayapalan, A. R., Kim, J., Kurtis, K. E., \& Jacobs, L. J. (2009). Nonlinear Wave Modulation Spectroscopy Method for Ultra-Accelerated Alkali-Silica Reaction Assessment. ACI Material Journal, 106(4), 340-348.

Chen, X. J., Kim, J.-Y., Kurtis, K. E., Qu, J., Shen, C. W., \& Jacobs, L. J. (2008). Characterization of progressive microcracking in Portland cement mortar using nonlinear ultrasonics. NDT \& E International, 41(2), 112-118.

Dahlén, U., Ryden, N., \& Jakobsson, A. (2015). Damage identification in concrete using impact non-linear reverberation spectroscopy. NDT and E International, 75, 15-25.

Duffour, P., Morbidini, M., \& Cawley, P. (2006). Comparison between a type of vibro-acoustic modulation and damping measurement as NDT techniques. NDT and $E$ International, 39(2), 123-131.

Eiras, J. N., Monzó, J., Payá, J., Kundu, T., \& Popovics, J. S. (2014). Non-classical nonlinear feature extraction from standard resonance vibration data for damage detection. The Journal of the Acoustical Society of America, 135(2), EL82-EL87. 
Guyer, R. A., \& Johnson, P. A. (2009). Nonlinear Mesoscopic Elasticity. Wiley-VCH.

Hunt, F. V. (1960). Stress and Strain Limits on the Attainable Velocity in Mechanical Vibration. The Journal of the Acoustical Society of America, 32(7), 1123-1128.

Johnson, P. A. (2006). Nonequilibrium Nonlinear-Dynamics in Solids : State of the Art State of the Art in Nonequilibrium Dynamics. In P. P. Delsanto (Ed.), Universality of Nonclassical Nonlinearity (pp. 49-69). New York: Springer.

Johnson, P. A., Zinszner, B., Rasolofosaon, P. N. J., Cohen-Tenoudji, F., \& Van Den Abeele, K. (2004). Dynamic measurements of the nonlinear elastic parameter a in rock under varying conditions. Journal of Geophysical Research, 109(B2), B02202.

Johnson, P., \& Sutin, A. (2005). Slow dynamics and anomalous nonlinear fast dynamics in diverse solids. The Journal of the Acoustical Society of America, 117(1), 124.

Jones, R. (1962). Non Destructive Testing of Concrete. (J. Baker, Ed.). London: Cambridge University Press.

Kodjo, A. S., Rivard, P., Cohen-Tenoudji, F., \& Gallias, J.-L. (2011). Impact of the alkalisilica reaction products on slow dynamics behavior of concrete. Cement and Concrete Research, 41(4), 422-428.

Lebedev, A. V., \& Ostrovsky, L. A. (2014). A unified model of hysteresis and long-time relaxation in heterogeneous materials. Acoustical Physics, 60(5), 555-561.

Leśnicki, K. J. (2011). NONLINEAR RESONANCE METHODS FOR ASSESSING ASR SUSCEPTIBILITY DURING CONCRETE PRISM TESTING (CPT). Georgia Institute of Technology.

Malhotra, V. M., \& Sivasundaram, V. (2004). Resonant Frequency Methods. In Handbook on Nondestructive Testing of Concrete (pp. 167-188).

Moradi-Marani, F., Kodjo, S. a., Rivard, P., \& Lamarche, C. P. (2012). Application of the mechanical perturbation produced by traffic as a new approach of nonlinear acoustic technique for detecting microcracks in the concrete: A laboratory simulation. In AIP Conference Proceedings (Vol. 1430, pp. 1493-1499).

Nazarov, V. E., \& Radostin, A. V. (2015). Nonlinear Acoustic Waves in Microinhomogeneous Solids. Wiley.

Pasqualini, D., Heitmann, K., TenCate, J. a., Habib, S., Higdon, D., \& Johnson, P. a. (2007). Nonequilibrium and nonlinear dynamics in Berea and Fontainebleau sandstones: Low- 
strain regime. Journal of Geophysical Research, 112(B1), B01204.

Payan, C., Garnier, V., Moysan, J., \& Johnson, P. a. (2007). Applying nonlinear resonant ultrasound spectroscopy to improving thermal damage assessment in concrete. The Journal of the Acoustical Society of America, 121(4), EL125-L130.

Payan, C., Ulrich, T. J., Le Bas, P. Y., Saleh, T., \& Guimaraes, M. (2014). Quantitative linear and nonlinear resonance inspection techniques and analysis for material characterization: Application to concrete thermal damage. The Journal of the Acoustical Society of America, 136, 537.

Polimeno, U., \& Meo, M. (2008). Understanding the effect of boundary conditions on damage identification process when using non-linear elastic wave spectroscopy methods. International Journal of Non-Linear Mechanics, 43(3), 187-193.

Remillieux, M. C., Guyer, R. A., Payan, C., \& Ulrich, T. J. (2016). Decoupling Nonclassical Nonlinear Behavior of Elastic Wave Types. Physical Review Letters, 116(11), 115501.

RivieØre, J., Renaud, G., Haupert, S., Talmant, M., Laugier, P., \& Johnson, P. a. (2010) Nonlinear acoustic resonances to probe a threaded interface. Journal of Applied Physics, 107(12), 124901.

Ryden, N. (2011). Resonant frequency testing of cylindrical asphalt samples. European Journal of Environmental and Civil Engineering, 15(4), 587-600.

Somaratna, J. (2014, September 16). Evaluation of linear and nonlinear vibration methods to characterize induced microstructural damage in portland cement-based materials. University of Illinois at Urbana-Champaign.

Van Damme, B., \& Van Den Abeele, K. (2014). The application of nonlinear reverberation spectroscopy for the detection of localized fatigue damage. Journal of Nondestructive Evaluation, 33(2), 263-268.

Yan, L., Jenkins, C. H., \& Pendleton, R. L. (2000). Polyolefin fiber-reinforced concrete composites Part I . Damping and frequency characteristics. Cement and Concrete Research, 30, 391-401.

Yim, J., Park, S., Kim, J. H., \& Kwak, H. (2014). Nonlinear Ultrasonic Method to Evaluate Residual Mechanical Properties of Thermally Damaged Concrete. ACl Material Journal, 111(4), 399-410. 
